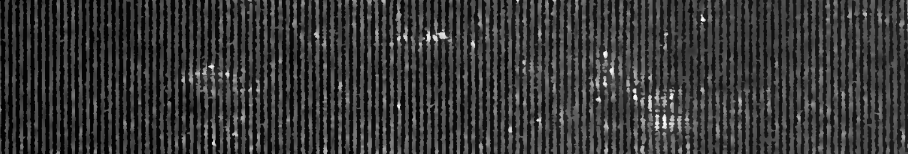

(3)

(3)

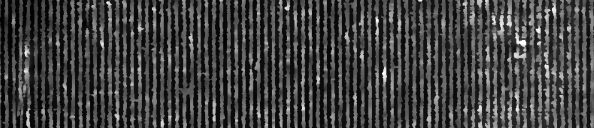

(I) |. m. (...  (m. m. m. - m. m. thomm. 


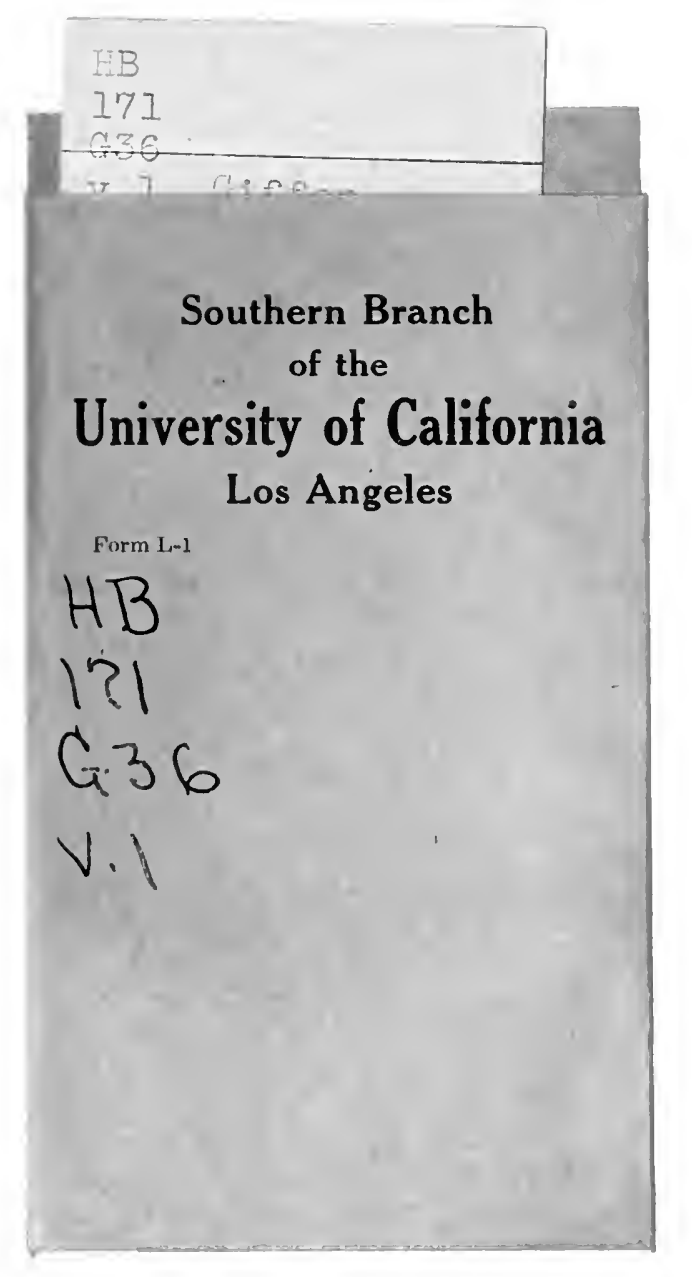


UNIVERSITY OF CALIFORNIA AT LOS ANGELES

THE UNIVERSITY LIBRARY

This book is DUE on the last date stamped below 

ECONOMIC INQUIRIES AND STUDIES 


\section{Digitized by the Internet Archive in 2008 with funding from Microsoft Corporation}




\title{
ECONOMIC INQUIRIES
}

AND

\section{STUDIES}

\author{
BY \\ SIR ROBERT GIFFEN, K.C.B.
}

VOL. I

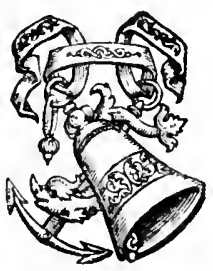

LONDON

GEORGE BELL AND SONS

I 904

33872 
CHISWICK PRESS: CHARLES WHITTINGHAM AND CO. TCOKS COURT, CHANCERY LANE, LONDON. 


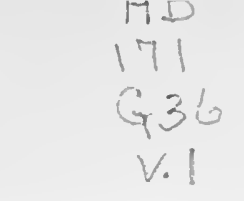

\section{PREFACE}

THE essays here selected for re-publication were 1 written at intervals during a period of more than thirty years. Accordingly they do not all speak from the same time, and that time the present. It is considered best, however, to print them substantially as they were written in the first instance, with the indications they contain of different circumstances, and a different atmosphere, from those now existing. They do not suffer, I trust, from a comparison between the ideas and anticipations they contain, and those which would now be expressed when new developments have taken place, and fuller information on some points is obtainable. Apart from other reasons for this course, it so happens that one or two of the essays belong to the history of the discussion of the subjects of which they treat. I would refer especially among such essays to those on the fall of prices in the first volume (Nos. II., IV. and V.); to the essay in the same volume on "The Use of Import and Export Statistics" (No. IX.), in which the subject of "invisible exports" was first discussed; and to the essay, also in the first volume, on "The Economic Value of Ireland to Great Britain" (No. XII.), which occasioned a considerable amount of controversy and contributed eventually to the appointment of Mr. Childers's Commission on Financial 
Relations. If such essays are to be reprinted at all, therefore, it will be convenient to the reader that he should have the original text before him. This may be the place to state that I have been frequently asked to reprint several of the essays, particularly the last of the series on the fall of prices (No. V. of the first volume- "Recent Changes in Prices and Incomes Compared"), and the above essay on "The Economic Value of Ireland to Great Britain."

Several of the essays, it will be observed, have already formed part of the two volumes of "Essays in Finance," which have been out of print for a good many years. The present issue, indeed, is in part owing to suggestions made to me that a new edition of these "Essays in Finance" is called for. The occasion of some of these older essays is, however, so long past that I hesitate to put them before a new generation, especially as they can be referred to by students, although out of print; while some of them are also superseded by later essays, where the argument is enlarged and completed. The bulk of the essays have not, however, been published before in a collected form. The concluding essay in Volume II., on "The Present Economic Conditions and Outlook for the United Kingdom," has not before been published.

In arranging the order of the essays I have been guided mainly, but not exclusively, by the chronology. In all cases care has been taken to indicate the year of publication or of writing at the beginning of the essay, and sometimes at the end as well. A conspicuous deviation from the chronological order is in the case of 
the essay on "Recent Changes of Prices and Incomes Compared," which was not written till I 888 , but is now reprinted in immediate succession to the essay on "The Fall of Prices" in 1873-79. This juxtaposition appeared obviously expedient to complete the series, and especially to bring together the anticipations of the earlier essays, the first of them, "The Depreciation of Gold since i 848 ," written in 1872 , before the fall of prices began, for comparison with the results ascertained by $\mathrm{i} 888$.

It would be out of place to go over in a preface the discussions contained in the essays themselves, however tempting it may be to do so in view of the fiscal controversy which has been so incessant during the last few months. It may be permissible, however, to notice that several of the essays have a bearing on this discussion, though it has always been my object to avoid controversy. The essays in particular on "Foreign Competition" (No. XI., Vol. I.); on "The Recent Rate of Material Progress in England" (No. XVI., Vol. II.); and the last essay of all, touch upon points that have been raised in recent controversies, though the subjects are treated non-controversially; while the essay on "The Use of Import and Export Statistics," though that was not its purpose, clearly touches on many points which our protectionist or fair-trade friends have put in issue. It is the same with the essay on "Protectionist Victories and Free Trade Successes" (No. $\mathrm{XX}$. in Vol. II.), and the essay "Are we living on Capital?" (No. XXVI. in Vol. II.). I have always avoided discussing the direct issue between free trade 
and protection, but not from any doubts on the subject. The argument for free trade generally, as expounded by the great authorities from Adam Smith downwards, appears to me complete both theoretically and experimentally, while our own experience under free trade is surely a demonstration that a state which says "Hands off" to its government in matters of business does better for itself than by letting government intermeddle. But every man to his own task, and in this matter the proper rôle for myself has hitherto been, I conceive, to explain the character of the statistical arguments which our fair-trade friends have adduced. Looking over the accompanying pages, as they go to press, I am interested to find how old are the complaints of foreign competition, dumping, excess of imports, and all the rest of the fair-trade stock of complaints. The essay on "Foreign Competition" was written in I877, and that on "The Use of Import and Export Statistics," dealing with excess of imports, in 1882 . So old are fairtrade heresies; and they are older still, I believe, for I find that I was writing anonymously as long ago as I 869 about "Revivers of British Industry." There were heretics of an older date still. The well-known author of " The Progress of the Nation," Mr. Porter, was afflicted by them long before, and when he was pressed by them about the ruination of the excess of imports, was wont to remark, I am told, that it was a very pleasant way of being ruined. The same may be said now. If we had believed the fair-traders, we should have gone back to protection thirty years ago and more. If we have been ruined through not following their advice, 
everybody must admit that so far the way of ruin has been a pleasant one indeed.

My thanks are due to the Editors of the "Economic Journal," the "Contemporary Review," and other editors, for permission to reprint essays which have appeared in their pages. My acknowledgements are specially due to Sir James Knowles for his permission to reprint from the "Nineteenth Century" the essays on "The Economic Value of Ireland to Great Britain," "The Standard of Strength for the Army," and "The Dream of a British Zollverein."

R. GIFFEN.

Chanctonbury,

Hayward's Heath,

January, I904. 



\section{CONTENTS}

\section{VOL. I}

PAGE

I. The Cost of the Franco-German War OF I $870-7 \mathrm{I}$.

I1. The Depreciation of Gold since i $848 \quad 75$ III. The Liquidations of $1873-76$. $\quad 98$ IV. On the Fall of Prices of Commodities

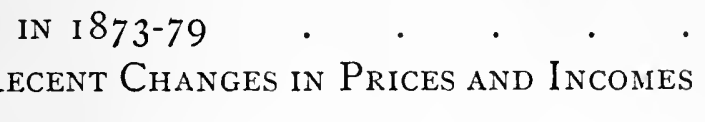

COMPARED . . . . . . ${ }^{1} 56$

VI. Mr. Gladstone's Work in Finance . 229

VII. TAXes on LAND . $\quad . \quad$. $\quad . \quad$. 253

ViII. The Taxation and Representation of

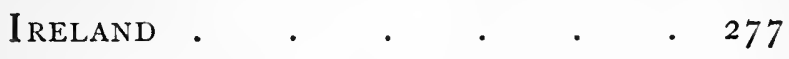

IX. The Use of Import and Export StatISTICS . . . . . 282

X. The Progress of the Working Classes in the LaSt halF CENTURY • . 382

XI. Foreign Competition • • . . 423 XII. The Economic Value of Ireland to Great Britain. . . . . $43 \mathrm{I}$

\section{VOL. II}

XiII. The Utility of Common Statistics . I XiV. On International Statistical ComPARISONS ini $\cdot \cdot \cdot$ 
XV. The Gross and the Net Gain of Rising WageS • . • • 79

XVI. The Recent Rate of Material Progress in England .

XVII. Protection for Manufactures in New Countries.

XVIII. Note on the Gresham Law . . 162 XIX. Fancy Monetary Standards . . I66

XX. Protectionist Victories and Free Trade Successes . $\quad . \quad 178$

XXI. Consols in a Great War . . I 89 XXII. Some Economic Aspects of the South African War . . . 204

XXiII. The Relative Growth of the component Parts of the Empire . 222 XXIV. The Standard of Strength for our Army: a Business Estimate 242 XXV. The Statistical Century • . 268 XXVi. Are we Living on Capital? . . 278 XXVII. A Financial Retrospect-I86IIgOI . . . . . . 306

XXVIII. The Importance of General StatISTICAL IDEAS

XXIX. The Wealth of The Empire, and HOW IT SHOULD BE USED • $\quad \cdot 363$

XXX. The Dream of a British ZollVEREIN .

XXXI. The Present Economic Conditions AND OUtlook FOR the UNITED KingDOM .

INDEX 


\section{ECONOMIC INQUIRIES AND STUDIES}

\section{I.}

THE COST OF THE FRANCO-GERMAN WAR OF I870-7I.

I $\mathrm{N}$ the following pages an attempt will be made to 1 answer various questions in relation to the cost of the Franco-German War.

The first question is the amount of the actual cost of the war, both direct and indirect. The object will be to reply to this question generally - that is, with as little reference as possible to the distribution of the burden. France and Germany have borne that burden most unequally, and neutral countries perhaps have not wholly escaped a share of the losses; but it will be interesting to ascertain first of all how much the world is really poorer. This will be the more necessary because it is considered that the question of the distribution of the burden raises new problems and requires separate discussion. The burden has not only been distributed unequally, but one country has been made to bear more than the whole cost of carrying on the war.

It is expedient, perhaps, to explain what is meant by the direct and the indirect cost. In the former will be included the outlay of the belligerent. Governments, the losses by the destruction of property in warlike operations, the requisitions levied in the invaded districts, and the like. The object, in short, will be to include whatever direct outlay the operations of the war have occasioned and the visible destruction they have caused. The indirect expenses will include every sort 
of material loss which is fairly traceable to the warthe loss of income to the communities whose pursuits are disturbed, the displacement of capital, the destruction of valuable lives, and the like.

The second question is the loss of capital to the world in consequence of the charge of the war. The first and second questions, it is conceived, are entirely distinct from each other. A war may easily cost a great deal more to the communities which engage in it than the permanent loss of capital which it involves. The expenditure may be defrayed as well by the temporary privation of the community as by abstracting capital from individual and national resources. In part the expense of a war is always so defrayed, and it is by not attending to the distinction that people are astonished at the recovery of nations from a war which has cost overwhelming amounts.

The third question is the distribution of the burden of the loss among the different communities affected by the war. It is conceived that the peculiar arrangements at the close of the late war, by which an enormous war indemnity was imposed on the diminished area and population of one of the belligerents, are worthy of separate treatment. How much has France been made to bear and what additional loss has been inflicted on the world by so great a burden being thrust on a single nation? How much has Germany gained by the receipt of a war indemnity far exceeding, it will be seen, the expense which it had incurred?

The fourth question will be the effect on the money markets of the world, and especially of England, of the financial arrangements made to meet these expenses and losses.

\section{I.-The Direct Expenses.}

It is too early yet to state any precise figures as to the actual amount even of the direct war expenditure by the respective Governments. According to the con- 
tinental plan of dealing with budgets, an effort is made in closing the accounts to throw upon each year every burden properly incurred in it, and include every receipt which belongs to it, according to the budgetary laws. The accounts are therefore kept open till the exact destination of each item is properly ascertained, and it is not for two or three years after that we have a closed account. There is likely to be an unusual delay in making up the accounts of the war years in France. The confusion of war creates accounts which it would be difficult in any circumstances to adjust, and the burning of the Hotel of the Ministry of Finance by the Communists will make the difficulty in the present case much greater than usual. The Budget Estimates, however, as revised to the latest date, are probably exact enough for the purposes of the present Memorandum, which need not go much into detail.

To deal with the case of France first. The first item in the direct expenditure is that of the Central Government. The amount under this head will probably be about $£ \mathrm{I} 00,000,000$, viz.:

Extra War Credits to Sept. 4, I870 ${ }^{1}$. . . . $£ 28,000,000$ $" \quad " \quad$ " from Sept. 4 , to Dec. $3 \mathrm{I}, \mathrm{I} 870^{1} \quad 38,520,000$

Estimated expense of maintaining German troops in France in ${ }_{1} \delta_{7}{ }^{2}$

$$
26,058,000
$$

$9,025,000$

$\frac{9,025,000}{f 101,603,000}$

In addition we should include the expense of maintaining the German troops in France subsequent to

' Speech of M. Thiers, June 20, I 87 I. Rapport sur l'ensemble de la Situation Financière de la France, par M. de la Bouillerie, au nom de la Commission au Budget. It appears that $E_{3}, 680,000$ of the credits opened in 1870 were carried over to $187 \mathrm{r}$, but the amount is apparently not included in the estimates set down for $187 \mathrm{I}$. In any case it will be safe to retain the original figure, to provide against under-estimates.

${ }^{2}$ Rectified Budget of ${ }_{1} 8_{7}$ I, p. xxv. The actual expense would not be so great as this, as the evacuation was accelerated, but how much 
I 87 I, viz., for two years and a quarter; the cost of rebuilding fortresses, re-equipping troops, and the like, which are all to be carried to a special account for liquidation of the cost of "repairing the misfortunes of the war." 1 M. Thiers estimated the probable amount of this liquidation in his Message of 7 th December last at $\mathcal{L}_{\mathrm{I}} 6,000,000$, but no proper details have yet been presented, and subsequent unofficial statements represent it as already $£ 20,000,000$. In any case, if we carry

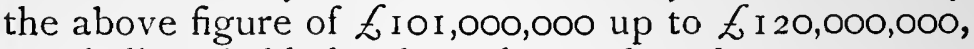
we shall probably be about the mark as far as concerns the direct cost of the war to the French Government.

Some doubt may be entertained as to whether the expense of rebuilding fortresses and re-supplying the army with war material should be included among the direct war expenses, but it is believed the proper course is to include these sums. A certain supply of fortresses and war material being considered necessary in peace to provide against the chances of war in general, any deduction from the stock in a particular war is a part of the direct cost of that war. And the value of this deduction is best represented by the cost of making up the deficiency. In the present case, the cost to France of the captured fortresses is probably greater than the expense to be incurred for providing makeshifts; but what France has lost Germany has gained, and we shall only have to deal with this point when we try to make an estimate of the burden on France alone.

It will be remarked, perhaps, that the deficits of France for 1870 and $187 \mathrm{I}$ and subsequent years are or will be greater than the above figures, taken in connection with the payments for the indemnity, would imply, but a part of these deficits arises from the failure of revenue, which must be dealt with in a different manner. The Germans, as we shall see, get some of it, and, otherwise, what the Government lost by the

less there is no means of computing. Any excess will be a set-off against under-estimates, which are almost certain to be very large.

M. Thiers' Message, December 7, i $S_{7}$ I. 
non-payment of taxes the French people, individually considered, gained. It is a set-off against the individual losses we shall afterwards have to reckon.

So much then for the direct cost of the war incurred by the Central Government. There remains to add the amount of requisitions levied by the invading army, the expenditure incurred locally, and generally the direct destruction of property in the war, so far as not provided for in the above items charged on the Central Government. These matters can only be roughly dealt with. The pages of the "Journal Officiel" for many months have been largely filled with Projets de Loi giving the Communes borrowing powers to cover their war expenditure. Years must elapse, probably, before the account on these heads can be complete.

Some facts, however, can be ascertained. In September last the Minister of the Interior, in a report to the President, stated the extent of the losses of the kind referred to, according to documents collected by cantonal commissions appointed ad hoc. It appears that the amount of the claims in the thirty-four departments invaded, excluding Paris, is $£ 32,844,000$, composed as follows :

War contributions.

Taxes levied by the Germans .

Requisitions

Destruction of property by fire and other causes .

Securities, articles of furniture, and other objects carried off without requisition .

$$
\begin{array}{r}
f_{1} 1,562,000 \\
1,965,000 \\
13,113,000 \\
5,640,000
\end{array}
$$

I0, 564,000

Total .

$E_{32}, 8_{44,000}$

To this total, however-assuming the items for the present to be correct-we must add the following items : (r.) One-tenth additional for the losses sustained by the inhabitants of Alsace and Lorraine. These provinces were the seat of war quite as much as the other occupied territory of France which was not annexed to Germany. They were not perhaps the seat of 
military operations for so long a period, since they were treated as virtually annexed after the fall of Metz, but they had to bear the brunt of much of the active part of the war, including the siege of Strasburg. No account of the individual losses appears to have been drawn up, such as the French Government has compiled for the territory which remained to it; but the German Government has been obliged to vote considerable amounts for indemnity to the inhabitants who have suffered, and doubtless much will remain which will never be compensated by the Government. As the population of the annexed territory is about $1,600,000$, and that of the remaining departments of France invaded about $\mathrm{I} S, 000,000$, it is plain that about one-tenth of the expenses incurred by the latter is not too small an amount to assign to the former.

(2.) We must add the war contribution levied in Paris at the conclusion of the armistice, and the war expenses and other losses which Paris had to endure. According to the report of M. Leon Say proposing the new loan for Paris last August, the municipality was altogether about $£$ I6,000,000 the worse for the siege and insurrection.

The war contribution was . . . . . . . $£ 8,000,000$

The loss of revenue was . . . . . . . . 4,000,000

The miscellaneous additional expenses were . . 4,000,000

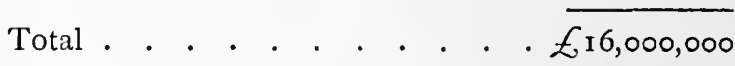

Deducting from the above amount the item of $\mathcal{E}_{4}, 000,000$ for loss of revenue which falls to be dealt with differently, like the loss of the State revenue, we obtain a total of $f_{1}$ 2,000,000 as the Paris losses by the events of the war, exclusive of its share in the direct national expenditure. According to M. Say's report the above

1 The revenue of Paris is about $£ 6,000,000$ a year, and the city was besieged or in insurrection about seven months, while for other two months communications were much interrupted. 
sum does not include the cost which must be incurred in rebuilding the Hottel de Ville, so that $\oint_{12}, 000,000$ is rather under than above the mark.

We have thus to add to the above total of $£$ I 20,000,000, which represents the direct expenditure of the French Government on the war and its consequences, a sum of about $£ 50,000,000$, viz.:

Requisitions and other losses in the 34 invaded departments, as above . . . . . $£_{32,844,000}$

Estimated losses of similar nature in Alsace and Lorraine . . . . . . . . . . . . . 3,284,000

War contributions on Paris, and other expenses . $\quad 12,000,000$

Total direct losses and expenditure by local authorities and individuals in France. . . Less amount voted by French Government on 6th September last and included in above estimates of national expenditure .

48, I 28,000

$4,040,000$

Net total .

$£ 44,088,000$

One or two remarks may be made in explanation of these items. One is, that the item of $£ 10,564,000$ for securities and articles carried away by the Germans "without requisition" is in all probability excessive. This is the sort of claim which is apt to be exaggerated greatly, because disproof will be very difficult, and the claimants will be tempted to make the most of the existing prejudice in France against the Germans. The value of the articles for which regular requisitionpapers were given by the German authorities is also, in all probability, exaggerated. It will be of little use, however, making any estimate of what the exaggeration amounts to, and deducting the sum from the total above set out. An error of this sort may fairly be set against the extreme probability of under-estimates in other directions which will not appear till the accounts are finally closed.

Another doubt which will be suggested relates to the apparent smallness of the items for the levies of 
the German armies during the war. Exclusive of the fine on Paris, it will be seen that the total amount received by the German armies from the occupied provinces was not more than between $£ 16,000,000$ and $£$ I $7,000,000$, viz.:

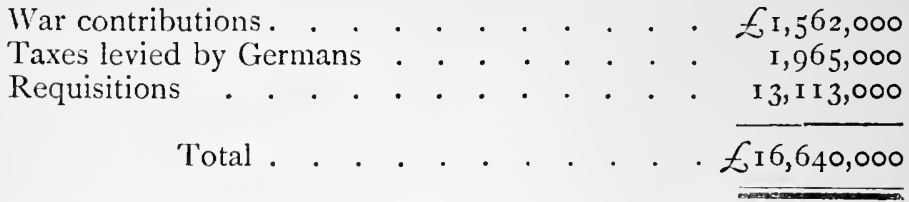

And it is not quite certain that the total is so large, for the value of the requisitions, as we have already explained, is doubtful. Even if we add something for the plunder on account of which the French have sent in claims to their Government for $£ \mathrm{I}, 0,000,000$, and allow also for the levies in Alsace and Lorraine, the money value to the German Government of the privilege of living on the enemy during the war would probably not be more than $£ 20,000,000$ or $£ 25,000,000$-only a fourth or a fifth of the war credits of the French Government itself. The expense of maintaining an invading army, according to this view, is not the most formidable item in the bill of war losses which a nation has to sustain. Nor is the fact to be wondered at, though contrary to the popular impression. After all, the invaders, unless they occupy large and wealthy cities-and this was not the case in France-can hardly impose on the country they invade more than the expense of their living. Clothing and munitions of war must all be secured beforehand or at home, and it is difficult to impose money fines which could be immediately useful when credit is suspended, however wealthy a country may be. The great bulk of the wealth is fixed in objects which cannot be carried away at all, or in objects which cannot be carried away quickly and sold, so as to be converted to the invader's use. He must take therefore, even for his own convenience, only what he can consume at once. A pro- 
longed occupation, with military operations suspended in the occupied districts, would enable the conqueror to impose heavier tributes, but such an occupation is only occasionally possible during a war.

Besides all this, there was a considerable local expenditure throughout France in departments not occupied by the enemy in mobilising the National Guard. But the amounts have been reimbursed by the State, and are included in the above war credits.

There are two heads of loss, however, about which, perhaps, there may be some doubt. The first of these is the damage caused to roads and bridges throughout the invaded departments. According to an official report made by a Commission of the Assembly, dated May 2 I, 187 I, these losses appear to have been:

\begin{tabular}{|c|c|c|}
\hline $\begin{array}{c}\text { Damage t } \\
, "\end{array}$ & $\begin{array}{l}\text { Communal roads } \\
\text { Departmental roads } \\
\text { Imperial roads . . }\end{array}$ & $\begin{array}{r}£ 400,000 \\
360,000 \\
366,000\end{array}$ \\
\hline & Total & $E_{1,1}=6,000$ \\
\hline
\end{tabular}

These losses, however, are probably included in the figures already submitted-the account for liquidating the cost of the war including large votes to the communes and departments, and the budgets including additional votes to the Ministry of Public Works for urgent repairs. The total amount is too small to make any material difference in the estimate of the total cost of the war.

The second doubtful item is the damage done to the railways, but it is not likely to have exceeded in amount the damage to the roads, the length of the railways endangered being much less than that of the roads. As a matter of fact, the railways were not much cut up, but were freely used by the Germans through the war. The rolling stock was injured or carried away by the Germans, but the rolling stock of all the railways in France can hardly be worth $£ 20,000,000$, and even if it was damaged 5 per cent.-a most liberal allowance 
- the loss would be under a million. The omission of any estimate for this head of loss, therefore, should it prove not to be included in the above figures, will not alter materially the totals with which we shall have to deal.

We may put the direct losses in France therefore at about $£$ i64,000,000, viz., $£$ I20,000,000 directly expended by the Government, and $£ 44,088$,000 expended or lost by destruction of property in the provinces. It remains to inquire what expense was incurred by Germany of a similar nature.

And first as to the Government expenditure. The amount, it is believed, cannot exceed between $£ 40,000,000$ and $£ 50,000,000$. We have been unable to obtain any exact figures, but a few considerations may satisfy us that $£ 50,000,000$ will be an approximately correct amount to take.

In the first place, this is about the amount of the sums which Germany had to borrow for the actual conduct of the war, and as the indemnity was not afterwards appropriated to defray the war expenditure, and there were no other extraordinary resources, the loans must be nearly the measure of the outlay of the German Governments. So far as can be ascertained, the new loans and additions to the floating debt were:

North Germany-

First issue of Treasury Bills . . . . . . . $£ 5,000,000$

First issue of Treasury Bonds . . . . . 7,500,000

Second ditto ditto . . . . . . 7, 7,500,000

Funded loan .

I $5,000,000$

$5,000,000$

$£ 45,000,000$

Prussian war treasure exhausted . . . . . 4,500,000

Total . . . . . . . . £ £49,500,000 
This was all the money which it was necessary for Germany to provide during the progress of the war. To err on the safe side, however, we may put the amount at $£ 60,000,000$, to allow for arrears left over. ${ }^{1}$

The direct expenditure for the war thus cost Germany, in the first instance, about $£ 60,000,000$, against $E_{1} 64,000,000$, which we have seen was the cost to France. Such is the difference made to a country, first, by being unprepared, and so having to spend more hastily; and second, by being the seat of war, when war is carried on in conformity with the rules which the Germans have followed. In any case, it is expensive to be the seat of war, but France was caught unprepared every way, and would have had to pay far more dearly than its opponent, even if there had been no indemnity to follow.

The other direct losses of Germany-viz., the losses of individuals - seem hardly worth considering. The only losses of the kind appear to have been the captures of German ships by French cruisers, but the captures were only eighty in number, and the total outlay thus occasioned, as well as for ships detained, appears to have been only $£ 450,000 .^{2}$ The amount is absolutely insignificant compared with the figures with which we are dealing. Claims have also been made by German shipowners on account of ships lying idle, but they belong to the department of indirect losses, with which we have yet to deal.

Another direct loss which would also be sustained by the Germans is the difference between the real value of articles requisitioned by the Government in mobilising the army and the price which the Government pays for them. But there are no data for es-

1 The actual outlay according to the latest German account is pu at rather more than $£ 90,000,000$, but this sum includes many indirect items, so that the above estimate is really near the mark. See "Preussischen Jahrbuch für I $875 . "$

${ }^{2}$ Berlin correspondent of "The Times," June 3 i 87 I. 
timating this loss, which could not however be large.

There is one other item which we must discuss before leaving this part of our subject. We may fairly include as part of the direct cost of the war the capital of the new pensions which the losses of the war occasion. They are part of the pay of the soldiers, and are directly caused by the war, although they are only paid in subsequent years. We must charge as part of the direct cost therefore a capital sum sufficient to provide the pensions. No very exact amount can be stated for two reasons: ( 1 ) the annual amount of the additional pensions will probably not be ascertainable for a year or two; and (2) there are hardly any data for calculating the capital value. Still the item is worth mentioning. In the French Budget for 1872 the additional military pensions charged amount to $£$ I 50,000, which at twenty years' purchase would represent a capital of $£ 3,000,000$, and it is not unlikely that before the accounts of the war are closed the amount will be about double, say $£ 5,000,000$ altogether. The cost to Germany will be at least as great, though no similar figure can be mentioned, as one of the uses of the French indemnity to the Germans has been the establishment for the first time of a military pension fund. It is impossible to say, then, what the cost of the pensions caused by the war will be. But as the war was not more murderous for Germany than France, but rather less murderous, and the scale of living has not been so high in Germany, we shall probably not be under the mark in estimating the cost of the war pensions to Germany at the same rate as the cost of the like pensions to France. We have thus an additional sum of $£ 10,000,000$ to add to the direct cost of the war$£ 5,000,000$ to each country.

The whole account up to this point will stand: 
Direct Cost to France.

War credits and expenses of re-equipment, etc. . . . . . . . . . $£ \mathrm{r} 20,000,000$

Fines, requisitions, and destruction of property (less $f_{4}, 000,000$ reckoned in war credits)

Capital value of war pensions

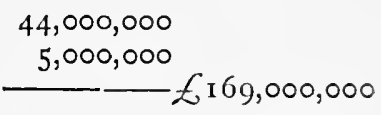

Direct Cost to Germany.

War credits, etc., less requisitions levied in France Capital value of war pensions

$$
\begin{array}{r}
£ 60,000,000 \\
5,000,000
\end{array}
$$

$65,000,000$

\section{'Total Direct Expenditure}

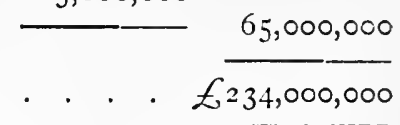

Such was the direct cost of the war to both Governments, so far as we can ascertain it. The two countries would have been "out" of this sum, and no more, had they been able to carry on their war operations without a stoppage of industry and production, and by hiring soldiers from distant countries with which they had no other relations. Looked at in this way, as the Finance Minister of a despotic country might be disposed to view it, war cannot be considered a very expensive game. For this sum of $£ 234,000,000$ the Governments of two great nations carried on unremitting hostilities against each other, employing altogether two-and-ahalf millions of men for a period of nearly eight months. That is, it cost them both nearly $£ 30,000,000$ a month. At this rate, war is cheap. The aggregate annual income of the people of the two countries is probably about $£ \mathrm{I}, 200,000,000$, so that the direct cost of war at this rate for a twelvemonth would have been a little over a third of the national income. Both countries therefore, so far as mere expenditure on warlike operations is concerned, and if the expense were divided equally, could have gone on fighting for an indefinitely longer period without exhausting their material resources. This is a somewhat different view from the popular one about the expense of modern warfare, but 
there is no doubt about the facts, and the conclusion is in agreement with what might be expected from the strength of modern industry. It is the natural result of the introduction of machinery and the great accumulation of wealth, that great communities should be capable of extravagance for lengthened periods without approaching exhaustion, a feat which was hardly possible before the age of mechanical invention. Of course they would impoverish themselves in time, but the margin before exhaustion comes, comparing modern societies with the old, appears to have been increased. ${ }^{1}$

\section{II.-The Indirect Expenses and Losses.}

IVe now come to more difficult ground. So far we have had tolerable data before us-the figures of budgets and official reports and the public borrowings of the belligerent Governments. But when we come to the indirect expense of a war we have no such guide. We know that it is quite as real a matter-that in any business the loss which a man has to undergo in withdrawing capital from some other undertaking to embark in it is fairly reckoned as part of the cost of the new business. If he is making ten per cent. elsewhere, and makes fifteen in the new business, his net gain by the change is five per cent. If his new business is wholly profitless, he loses ten per cent. Still worse, if he abandons the idea of profit altogether and expends his capital in extravagance, he is poorer not only by the loss of income for a time, but by the whole capital he wastes. This last is the case of a nation engaged in war to a greater or less extent-especially

1 The contributions to various charitable associations in relief of the wounded and other victims of the war are also a part of the direct cost; but compared with the other items here dealt with it would be of no moment to reckon them, even if exact data were procurable. But the relief societies were so numerous and scattered, and so large a part of the contributions was in kind, that there are practically no data for an estimate. 
in war as now conducted by European nations, who abstract from industrial pursuits enormous masses of the civil population. The community not only takes to spending, but part of its former income ceases. The expenditure and loss of income make up the bill which its extravagance really costs. But this loss of income in the case of great communities is difficult to ascertain. How far industry is suspended, and how far the war is the cause of it, are both very difficult questions to answer. And there are more serious difficulties behind. In the present conditions of modern industry, a nation whose pursuits are disturbed cannot fall back exactly into the old groove. When it settles down again it may have to engage to some extent in less productive industries than those which were formerly open to it. The difference between the old and the new profit is not only difficult to ascertain, but it is impossible of course to state the loss in capital which is equivalent to the loss of annual profit. On these points therefore, in relation to the present war, we shall only offer the roughest possible estimate.

To take the case of France first. The main point is the loss of national income, and one measure of the loss, it is conceived, will be the falling off of the national revenue. In proportion to the losses of the taxpayer, he would be able to pay fewer taxes, so that the national revenue would probably suffer in the same degree as the aggregate income of the nation. And as the national revenue and the falling off it sustained in the years of war are both ascertainable amounts, while the aggregate income of the nation is an approximately calculable amount, it will be possible to state in this manner what the deficiency on the aggregate income may come to. The figure to be thus obtained will obviously be a very rough one. Many parts of the French national revenue would not fluctuate with the prosperity or adversity of the people. The direct taxes on land, for instance, are in the nature of fixed charges, not varying with the income of 
those who pay them, but collected almost to the full amount, irrespective of individual profits or losses. A bad year will no doubt cause an unusual amount of "degrèvements" to relieve the very poor, but the bulk of the tax will be unaffected. Much of the same may be said of the other direct taxes, which are all fixed on arbitrary bases similar to the direct tax on land. On the other hand, other parts of the revenue might fall off to an amount much greater in proportion than the diminution of the aggregate income which was the cause of the failure. The attempt of individuals not to trench on their capital, but to square their expenditure with their diminished income, might cause such an economy of luxuries as very seriously to diminish the amounts raised from optional taxation-the taxation, that is, which people regulate for themselves by the consumption of taxable articles. The business of transfer may also be suspended to a much greater extent than the business of production, and so cause a disproportionate loss of revenue arising from charges on transactions. On the whole, however, when it is considered that as regards all moderate charges on articles of consumption a very slight reduction of the national revenue would imply very large economies on the part of the taxpayer, the tax being only a small part of the cost, and when it is also considered that the direct taxes which are not optional in their nature are only a fourth part of the State revenue of France, so that the fixed revenue, unaffected by the adverse fortune of the nation, is the least important-it may be assumed as most probable that the aggregate income of the people will have fallen off in excess of the proportion to which the national revenue has fallen off. To assume a loss of aggregate income in proportion only to the loss of national revenue will give us a minimum and not a maximum estimate.

Now what has been the loss of national revenue to France through the war? The French official estimates are as follows: 
Loss of revenue in 1870 . . . . . . $f_{\mathrm{I}} \mathrm{I}, 400,000$

Do. do. in $187 \mathrm{I}$. . . . . $13,480,000$

Total .

$£ 24,880,000$

Such is the calculated loss for a period of eighteen months, but two deductions must be made for our present purpose, as we are dealing only with the loss occasioned by the interruption of business through the war. We must deduct, in the first place, the loss occasioned by the Germans collecting the taxes instead of the French authorities, the amount so collected, as above stated, being $\ell_{1}, 960,000$. The taxes were in fact paid, though the French Government did not get them. And we must deduct in the same way the loss of revenue occasioned by the transfer of Alsace and Lorraine to Germany. This loss also was not caused by the deficiency of income of the French taxpayers. As the annual loss appears to be about $f_{2} 2,452,000$, ${ }^{1}$ the loss for eighteen months would be $£ 3,676,000$, which falls to be deducted along with the amount of the taxes actually levied by the Germans from the above total of $£ 24,880,000$. The net loss of revenue to France therefore due to the interruption of business, withdrawal of civilians from industrial pursuits, and the like, would be as follows:

${ }^{1}$ Annual loss of Revenue to France by transfer of Alsace and Lorraine to Germany [compiled from Budget of i 872 ].

Land tax

- $£ 219,000$

Personal and furniture tax

74,000

Door and window tax

Patent tax (estimate)

71,000

Mainmast tax .

Registration of stamp duties .

Customs and salt duties.

Miscellaneous indirect tax

Postal revenue

I I 4,000

18,000

619,000

296,000

$8+0,000$

120,000

So, 000

Produce of forest

Total

$\overline{f_{2,+52,000}}$

I. 
Total loss of revenue in eighteen months as above . $\quad £^{24,880,000}$ Deduct taxes levied by Germans . . $£ \mathrm{r}, 960,000$ " loss of revenue by transfer of Alsace and Lorraine to Germany. . . . . . 3,676,000

Net loss by interruption of business, etc. $\quad \frac{5,636,000}{£ 19,244,000}$

This is at the rate of $f_{12}, 800,000$ per annum, and as the annual revenue of France before the war, as fixed in the Budget for $187 \mathrm{I}$, was $£ 75,200,000$, the proportion of revenue lost by stoppage of industry is as nearly as possible 17 per cent.-the loss running for a period of eighteen months.

We have only, then, to apply this measure to the aggregate income of France for a similar period, to see what individual loss the war has occasioned. Various estimates have been given of that income, but taking the most moderate estimate of $£ 600,000,000$ yearly, the loss in eighteen months, at the rate of 17 per cent., would be $£$ I $53,000,000$.

To this ought perhaps to be added the probable loss of income in years subsequent to $187 \mathrm{I}$, before the routine of industry is fully re-established; but this would be too hypothetical an inquiry, and belongs rather to the question as to what has been the permanent loss of capital to France through the war.

Is there any way, however, of testing whether the French people on the average would only lose a fifth of their income for eighteen months, including a period of nearly eight months when both war and insurrection had been over, and much of the ordinary avocations of the people had been resumed? Let us consider for a moment in detail how far French industry would be affected.

It may be considered as certain, to begin with, that agricultural operations would not be very much interfered with. To a certain extent the season of the war was favourable to an agricultural country. The summer 
was far advanced when it began, and the autumn was well over before the levies whose absence would have seriously hindered agriculture were called out. Peace was finally concluded again before the end of February, in time to let the greater part of the levies return for the labours of the spring and summer. In this way the harvest of 1870 was gathered in somehow, notwithstanding the outbreak of war, and the harvest of I 87 I could not have been much diminished by the want of preliminary cultivation. Even in the occupied districts the harvest of i 870 would not be lost, nor would the preparations for the crops of ${ } 87 \mathrm{I}$ be much interfered with. As regards the harvest of 1870 , the change which was made by the invasion was that the German armies to a large extent reaped it instead of the French farmers, or it was destroyed by the operations of the war. But the losses of this sort have already been counted under the head of direct losses,' and ought not to be counted twice over. As regards the preparations for $187 \mathrm{I}$, the occupied districts stand in much the same position as the unoccupied, peace having been concluded in time to let the bulk of the labours of the season be proceeded with, and the occupation in no way preventing the return of the farmers to their work. There is no reason to believe that even in the occupied districts there was any material suspension of agricultural industry beyond what took place in other parts of France.

How much, then, would the suspension come to even on an extreme calculation-on the basis, that is, of all labour being stopped in proportion to the withdrawal of agricultural labourers for the numerous levies that were raised? Agriculture is unlike manufacturing in this respect, that its existence from day to day does not depend on the freedom of credit and perfect freedom of communication. These things are in the end important, but they can be borne for months without 
more than the most passing damage, if the farmer ultimately gets a market for what he does not consume himself, and the facilities of credit and free communication are again opened up. The loss, then, could hardly be greater than in proportion to the withdrawal of hands, and the withdrawal could hardly be more than about one-twelfth of the whole. The agricultural population of France is about three-fifths of the whole, or about $22,000,000$, of whom about $5,400,000$ would be adult males engaged in the actual work of production. Possibly we ought to include the estimate of a large amount for female labour and for the labour of grownup children, but our case is quite strong enough as to the small effect which the withdrawal of the levies would have on agricultural industry if we take the usual supply of labour at only 5,400,000 hands. The total new levies for the war being about 800,000 , the proportion from the agricultural districts would be 480,000 , which is almost exactly one-twelfth of the above total of 5,400,000 labourers. Assuming, therefore, that the diminution of agricultural labours for one year was one-twelfth-which is a strong assumption, as the labourers were only away for eight months, and that not for the best part of the season-we may estimate very quickly the loss of income that would be occasioned. The "net annual value" of the rural property of France is $£ \mathrm{I} 06,000,000,{ }^{1}$ which, according to the usual mode of reckoning, shows a production of three times that amount, or $£_{3}$ 18,000,000. One-twelfth

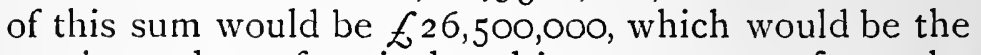
maximum loss of agricultural income-apart from the amounts paid in requisitions and fines-occasioned to France in the war of $1870-1871$. For the reasons above stated, however, the loss, it is believed, could not be so much. It is no doubt true that in exceptional districts, to which the services of the Peasant Farmers' Seed Fund were so useful, there was a great hindrance

${ }^{1}$ See Reports on Land Tenure in different countries in Europe, and Mr. Goschen's Report on Local Taxation. 
to production in the want of seed, owing to the thoroughness of the Prussian perquisitions; but in the absence of all reports as to large areas of land being left uncultivated, we may conclude that this cause exerted an almost inappreciable influence in comparison with the extent of French agriculture. Except in isolated cases, the war left the French agriculturists wealthy enough to resume their pursuits, and purchase seed and stock-the requisitions in the invaded districts, $f_{1} 3,000,000$, and the destruction of property, $£ 5,600$, ,oo, being, after all, barely 6 per cent. of the agricultural production of the whole of France for one year, and barely 12 per cent. of the production of the invaded districts.

We may set down, then, about $£ 26,500,000$ as the maximum loss of agricultural income. Reckoning in the same way the manufacturing loss, viz., in proportion to the withdrawal of labour, or about one-twelfth of the total production, we should have to add to this sum about $\mathcal{L}_{23} 3,500,000$, making the total loss of income by this mode of reckoning $£_{50,000,000.1}$ But the loss of manufacturing income would of course be greater, manufactures being so much more sensitive than agriculture to the disturbance of invasion. Without credit and without the means of communication, manufacturing establishments must be closed. Neither purchases nor sales except to a limited amount are made with ready money, and even if they could be made, war and invasion would prevent the conveyance of raw material and manufactured articles to and from distant spots which is essential to the life of any large trade. No doubt there are many industries which will go on as usual, the dealing from day to day in the necessaries of life going on nearly to as great an extent as before, and generally all retail commerce, as was the case in

${ }^{1}$ We estimate the manufacturing production at $\mathcal{E}_{2} \mathrm{~S} 2,000,000$, making up, with the above sum of $£_{3}$ I $8,000,000$ allowed for agricultural production, the total of $\delta 600,000,000$, which we have taken as the aggregate income of the French people. 
Paris during the siege, being more or less active. In the unoccupied districts, too, manufacturing enterprise would only be partially suspended, though it would, on the whole, be much less profitable than before; and the Germans, it is known, managed to prevent the complete suspension of business not only in Alsace, but in such advanced towns in their occupation as Rheims and Rouen. If we estimate that outside the invaded districts, including Paris, business was onefourth suspended for eight months of war, and that where the invasion extended it was three-fourths suspended for the same period, the estimate would hardly seem to be the least under the reality. But this would only make the loss of manufacturing income about $£ 93,000,000$, viz.:

One-fourth of manufacturing income in unoccupied districts $\left(£_{140,000,000 \text { annually }}{ }^{1}\right.$ ) for eight months . . . . . . . . . $£ 23333,000$

Three-fourths of manufacturing income in occupied districts $\left(\mathcal{I}_{\mathrm{I} 40,000,000 \text { annually }}{ }^{\mathrm{i}}\right.$ ) for eight months

$70,000,000$

Total .

Adding this sum to the above total of $£^{26,500,000}$ allowed for the loss of agricultural income, we obtain

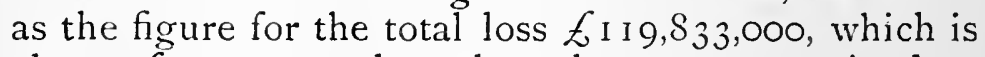
about $£ 30,000,000$ less than the sum we arrived at above by drawing what appears to us a legitimate inference from the diminution of national revenue. If we remember, however, that the suspension of manufacturing enterprise would continue for some months in I $87 \mathrm{I}$ after the war was over, and that in the present mode

1 Practically about one-half of France in population was occupied or besieged by the German troops, and the districts thus dealt with included Paris, Rouen, Rheims, Nancy, and other important towns, Paris itself being by far the most important manufacturing city in France. We assume, then, that half the manufacturing production was in the occupied and half in the unoccupied districts. 
of computation we have only been dealing with a period of eight months, whereas the former estimate applied to the whole of 1870 and $187 \mathrm{I}$, it will be recognized that the results of the two methods of computation very nearly correspond. So far as we can judge, $£$ I 50,000,000 would be about the mark.

There is one circumstance which may, perhaps, throw doubt on this conclusion, unless explained. The exports and imports of France have not diminished as we should expect them to do with the diminution of manufacturing production. The exports and imports of the last three years compare as follows:

\section{IMPORTS FOR CONSUMPTION.}

\begin{tabular}{|c|c|c|c|c|}
\hline Articles of food & & $\begin{array}{c}\mathrm{I} \delta_{7} \mathrm{I} . \\
\mathrm{I} 000 \text { frs. } \\
{ }_{9} \delta_{3}, 677\end{array}$ & $\begin{array}{c}\text { I } 870 . \\
\text { I } 000 \text { frs. } \\
720,844\end{array}$ & $\begin{array}{c}\text { I } 869 . \\
\text { I } 000 \text { frs. } \\
693,828\end{array}$ \\
\hline $\begin{array}{l}\text { Raw materials and } \\
\text { productions. }\end{array}$ & natural & $1,862,296$ & I, 679,988 & $2,030,6$ I 8 \\
\hline Manufactures & . & $3 \mathrm{I} 4,59 \mathrm{I}$ & 218,560 & 264,6 I 6 \\
\hline Other articles . & . & $232,68_{5}$ & I $6 \mathrm{I}, 9 \mathrm{I} 8$ & I 64,009 \\
\hline Total & . & $3,393,249$ & $2,78 \mathrm{I}, 3$ I 0 & $3,153,07 \mathrm{I}$ \\
\hline
\end{tabular}

Exports of French Productions.

Manufactures .

I,620,9 I I I $, 562,429$

I, 756,320

Articles of food, raw mate-

rials, and natural productions

Other articles

. . . .

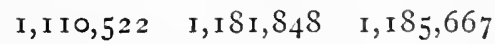

Total . . $\overline{2,865,613} \overline{2,860,127} \overline{3,074,941}$

These are not the figures of a trade which has diminished; it is rather an increasing trade. But the explanation is very simple. One is, that great internal losses would be likely to cause a large export for realization, while after the war was quite over the imports would at first increase largely, in order to replenish stores and warehouses and set many establishments 
going. Another explanation of the increased external trade is also to be found in the fact that two provinces between which and the rest of France there was formerly a most intimate home trade have, for the first time, become external; so that what was formerly home trade is now reckoned as foreign. In reality, the figures prove a falling-off of business, though the exact amount cannot be stated, and may not correspond exactly to the exact diminution of manufacturing production in France in the years of war.

So much for the loss of income sustained by Frenchmen during the war. But not only does the suspension of business by war and invasion cause a loss of present income to a community, it entails a permanent depreciation of producing power, that is, of the annual income which the community is capable of earningon which some estimate ought also to be placed. It is certain that some such depreciation cannot but occur. The connections of great establishments are destroyed, the staff is broken up, many labourers have been killed or injured, the business which is resumed after a war, at any rate after so prolonged an interruption of its usual course as French commerce sustained, is never precisely the same as it was before the war. Of course any estimate of the present capital value of an annual loss of income of this kind must be very wide indeed. Fortunately there is one French tax which appears to supply data for such an estimate. We refer to the Trade Licence Tax, which applies a varying scale to nearly every class of merchants and traders, according to the size of the towns in which they reside and the nature of business they pursue. Any great convulsion in business diminishing the amount of its profits must seriously affect the tax: many traders will be declassed; others will be driven from business altogether and occupy the place of labourers or assistants to larger capitalists; there will be a great deal of migration, during which capital will be locked up, or at least will be less productive. There will also be a great deal of 
emigration which will have the same effect, even if the emigrants, as will probably happen, should ultimately return. All the changes will cause the licence tax to be less productive, though perhaps the diminution may not go quite so far in proportion as the diminution in the earning power of the community. The scale of the tax remaining the same, and most people refusing to change their business even if they make less out of it than before, the result will be that the tax will yield nearly the same as before in proportion to the numbers affected, but those who pay it may all be somewhat poorer. Insufficient as the test is, however, it is the only one we have got, and it is perhaps better than none. The way to apply it will be to calculate what the annual loss of the business income of France will be if it suffers in the same proportion as the licence tax, and then multiply the sum so obtained by the number of years' purchase we may consider the income to be worth.

According to the Budget of 1872 , the loss on the "principal " of the licence tax due to the general effects of the war is between 3 and 4 per cent. The total deficiency, as compared with the estimate for I 87 I, which was made before the war, is $£ 168,800$, equal to 7 per cent. on a total yield of $f_{2}, 462,000$; but of this deficiency, about $£ 80,000$, or 3.3 per cent., is caused by the transfer of Alsace and Lorraine to Germany. There remains, therefore, only $£ 88$, ooo which can be ascribed to the general effects of the war, and the percentage of this loss is about $3 \cdot 7$, or say 4 per cent. If this test is fairly applicable, then we may assume that France has lost about one twenty-fifth part of its earning power in business in consequence of the warthat is, one twenty-fifth part of the above annual sum of $\mathcal{L}_{280,000,000}$ which we have reckoned as the income of the French people, independently of their agriculture, or an annual loss of $\delta_{\mathrm{I}} \mathrm{I}, 200,000$. How many years' purchase must we reckon to ascertain the equivalent capital value of this loss? This point must 
plainly be left a good deal to conjecture, but the equivalent, we should think, will be at the very least ten years' purchase, making the loss $£$ I I 2,000,000. The value of businesses reckoned by multiples of the annual income yielded varies indefinitely, and perhaps ten years' purchase would be too high an average in such a country as England, where profits are large in consequence of the large amounts which traders are able to borrow in addition to the capital they themselves embark; but in a country like France, where there is far less credit, and business capital, amount for amount, is consequently less profitable, ten years' purchase is probably rather too little than too much. At any rate, it does not appear extravagant to reckon that a war like last year, and the invasion which followed, besides the immediate loss of income and heavier taxes which they entailed, should have cost the business men of France the equivalent of $£$ I I 2,000,000, or $£$ I I, 200,000 per annum. There must have been a large loss of some kind on this head, and we do not see how it can be reckoned at less.

Probably the agricultural income of France may have permanently suffered in the same way, but it can hardly have suffered much, being almost independent of the credit and connections which make the life of business. A long-enduring war would have injured agriculture greatly, especially the culture of the grape, through the loss of markets and the displacement by competing vine districts, but a single winter's war could have no such effect.

We have still one more head of indirect loss to consider, viz.: the loss of life and the invaliding of wounded and sick. But we must pass these over very slightly, as losses on which no pecuniary value can properly be placed. We subjoin a calculation of what the capital value of the lives affected by death or invaliding in the French Army may come to: 
Estimate of money value of lives destroyed or injured in French Army:

$30,000^{1}$ killed

$30,000^{1}$ totally invalided . . . . . . .

$90,000,{ }^{1}$ about one-eighth invalided on the average

Complete lives destroyed (say)

Average earning power, $\mathcal{E}_{40}^{\circ}$ per annum

Total annual loss

30,000

30,000

I 0,000

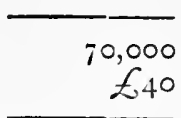

$£ 2,800,000$

Present value of annuity of $\mathcal{E}_{\mathrm{I}}$ on single life at age of 25 , and reckoning 5 per cent. (Carlisle Tables)

$E^{15}$

Estimated capital value of lives lost or invalided $\overline{£ 42,000,000}$

The total is $£ 42,000,000$, and we doubt if the loss or injury of life in an economic sense could be more. Still the calculation must only be taken for what it is worth, an imperfect way of representing in money the material loss which is certainly occasioned by the destruction of human life. In addition we should probably reckon that the loss and injury of life among civilians produced a similar loss. In Paris alone it is reckoned that the additional deaths due to the war were as follows in 1870 and $187 \mathrm{I}$ :

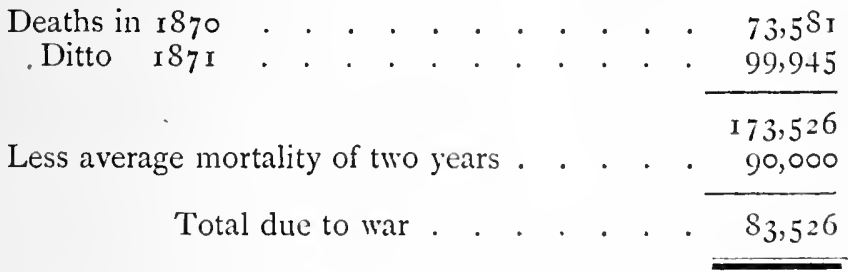

There must have been great injury to life beyond this where the additional mortality is solarge. Throughout

${ }^{2}$ According to these figures, our estimate of the total killed and wounded in the Frencl armies is 150,000 , but there are few official data, and we have been obliged to make the best estimate we can from scattered and contradictory notices in books on the campaign. The German losses, reckoned in the same way, were about roo,000. 
the country and in the numerous besieged places there would be a similar loss of civilian life by privations, but considering that Paris was exceptionally tried, and that the above total of $\delta_{3,000}$ would include the deaths of the soldiers in Paris, it would, perhaps, be unsafe to put the total deaths throughout France owing to the war at more than 200,000. And of these one-half would be aged, of hardly any economic value compared with the young, whose expectation of life is at its highest. ${ }^{1}$ Taking the loss of civilian life, therefore, as the basis of the preceding calculation at 100,000 units, the present capital value would be $£ 60,000,000$, which will fall to be added to the above $£ 42,000,000$ of Army loss-in all $£_{102,000,000}$. IVe repeat, however, that this calculation is only given pour memoire, and to render a little more definite the conception of the losses which are involved in war. It should be remembered, besides, that part of the losses on this account-so far at least as they affect the surviving community - must have been reckoned under the previous head, there being nothing to distinguish the failure of the licence tax through the death or invaliding of the licencees from the failure which is due to more general causes. In any general sum of the expenses of the war it would be improper to include both items to the full amount if they could be exactly ascertained.

The indirect losses of the French, therefore, in the war, omitting any direct estimate for the value of lives lost or injured, may be summarized as follows:

1. Loss of income in $\Omega_{70-71}$. . . . $\mathcal{E}_{150,000,000}$

2. Loss of permanent business, equal to . I I $2,000,000$

Total Indirect Loss (say)

$\mathcal{2}_{262,000,000}$

We come, then, to the German losses of a similar nature, which may be very shortly dealt with. The

Since this was written the fact of an unusual mortality having been occasioned directly and indirectly by the war, has been confirmed by the Census Returns of ${ }_{1} S_{7}$. 
principal causes of the great loss which France has sustained did not affect Germany. These causes, as we have seen, were not so much the abstraction of labourers from their employments, as the suspension of business through invasion. The loss of life in Germany was, moreover, confined to the Army, the privations of civilians, at least, being of the most insignificant kind compared with French privations. The indirect loss of Germany may therefore be summed up in the loss by abstraction of labourers, equal to estimated loss of France as above, or about $£ 50,000,000$; the loss by deaths and invaliding of soldiers, which we mention bour mémoire, would be about two-thirds of the estimated loss of France as above, or about $£ 30,000,000$.

We do not think it would be of any use reckoning anything beyond this for the suspension of business in Germany. Business, in fact, went on pretty much as usual. Though the German ports were blockaded, the ports of Belgium and Holland were open, and Germany retained all its land communications unimpaired. Loss, therefore, could hardly arise except to a quite inappreciable extent, for which it would not be worth while to make allowance. There is the more reason for this, too, because it is more than doubtful whether the loss by the abstraction of labour is not over-estimated, the labour having been abstracted, as we have already explained, at the season least injurious to agricultural pursuits. So far as any loss of the kind could be traced in its effect on German revenues, we have no data to go upon, the receipts of the various Governments having gone on increasing as if there had been no war. $^{1}$

We may end our inquiry into the indirect losses at

1 Something should perhaps be added for the indirect manufacturing losses of Alsace and Lorraine, but business there was not nearly so long disturbed as in the non-ceded districts of France, and the above allowance for German indirect losses is believed to be liberal enough in any case to cover those of the newly-acquired province. 
this point. No doubt other countries besides France and Germany were made to suffer-England especially; but the amount of the injury, even if not compensated by some indirect gains consequent on English manufactures temporarily or permanently displacing those of the belligerents, is lost in the enormous magnitude of the business over which the loss would be spread.

III.-General Summary of the Cost of the War.

Having thus gone through the various items of expense and loss consequent on the war, we may see what the whole amounts to. The totals are as follows:

France.

Credits for carrying on war, re-equipment, and the like . . . . . . E 1 20,000,000

Requisitions and fines levied by Germans and destruction of property in the war.

Capital value of war pensions

Indirect losses, omitting estimate for loss of life.

$262,000,000$

Total for France $\mathcal{E}_{431,000,000}$

Germiany.

Credits for carrying on war and for reequipment

E60,000,000

Capital value of war pensions . . . 5,000,000

Indirect losses, omitting estimate for loss of life . $50,000,000$

Total for Germany .

Grand total of cost of war I I $5,000,000$ $£ 546,000,000$

At this rate war is not so very cheap as it appeared when we looked only at the direct expenditure. It cost the two belligerents in seven or eight months about half their gross income, and such figures imply a very 
large exhaustion of stored-up capital. Even at this rate, however, it would no doubt have taken a long time to exhaust the material resources of France and Germany.

\section{IV.-The Permanent Loss of Capital.}

$\mathrm{Up}$ to this point we have been discussing the mere cost of the war, without any reference to the funds out of which it had to be defrayed. As we have already explained, the two questions are entirely distinct in theory. A very costly war may result in little or no permanent loss of capital, the belligerent nations paying the expense entirely out of their income, and likewise saving out of their income enough capital to compensate those indirect causes of subsequent annual loss which we have discussed at so much length. On the other hand, a very cheap war may prove burdensome from the mode of dealing with its finance. A nation may go on living as usual, and the capital burden will then prove very heavy. What usually happens, in fact, is the submission by the generation which carries on a war to the quasi-necessity of bearing a large part of the cost. The Governments, to secure credit for borrowing, if for no other purpose, must go as far as they prudently can in imposing taxes. Individuals who suffer loss of income have often no capital which they can trench upon, and will they nill they, must adjust their expenditure to their income. Those who have capital will try every possible expedient to keep it from diminishing. It is in this way that war, as a rule, is so quickly recovered from. A large part of the cost figures only as so much privation of those who carry it on.

Going over the items constituting the above total of $£ 546,000,000$ scriatim, we believe it will be found that a very large part indeed is not a permanent loss of capital, but is exclusively a loss endured at the time by 
the various victims of the war. Taking first the French expenditure, the principal item which became a permanent loss appears to be the direct expenditure by the Government, amounting to $£$ i $20,000,000$. No part of the extra war expenditure either of 1870 or I $87 \mathrm{I}$ was provided out of revenue. As regards 1870 , the case stands thus:

BUDGET OF 1870 .

Amount of peace expenditure. . . . . $\quad £_{72,440,000}$

" war expenditure . . . . 62,840,000

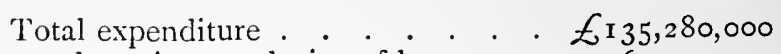

Estimated receipts, exclusive of loans . . $61,040,000$

Deficit .

The receipts were thus insufficient to meet the current peace expenditure, much less defray any portion of the war expenditure.

As regards $187 \mathrm{I}$, the account will stand:

Budget of 187 I.

Rectified amount of peace expenditure . $\quad £ 70,840,000$

Amount of war expenditure . . . . $35,082,000$

Estimated receipts, exclusive of loans

E105,922,000

$66,800,000$

Deficit .

$£ 39,122,000$

Here, again, the estimated receipts are insufficient for the current peace expenditure.

The whole war expenditure of the two years has thus been defrayed by borrowing, and constitutes a permanent burden on the country.

The second important item is the sum of $£ 44,000,000$ for fines and requisitions, but a large part of this amount, if not the whole, will probably be defrayed out of revenue. This would be the case with the French taxes levied by the Germans, and a large part of the 
requisitions, losses by fire and war, and the alleged plunder of the Germans, would be dealt with in a similar manner by the individuals concerned. They make claims for reimbursement against their Government, but in the meantime they have charged the expense to revenue, and not to capital. How much has gone to the one account and how much to the other it would be impossible to say, and to divide the amount equally between the two heads where there are absolutely no data will perhaps be the safest plan. On the other hand, the Parisian contributions of $£$ I $2,000,000$ have certainly been charged against capital. The whole item of $£ 44,000,000$ may therefore be distributed as follows :

Charged against Capital.

Parisian contributions . . $£_{12,000,000}$

One-half of remaining items ${ }_{15}, 064,000$

$E_{27}, 064,000$

Charged against Revenue.

Taxes levied by Germans . $£ \mathrm{I}, 960,000$

One-half of remaining items I $5,064,000$

$17,024,000$

Total as above

$\underbrace{}_{44,085,000}$

The direct expenditure of Germany, $£ 60,000,000$, was also defrayed entirely by loans, or by contributions of the French indemnity, which were entirely supplied out of special loans raised by the French Government.

The remaining item of $£ 10,000.000$ which we have mentioned as the capital value of the new war pensions is also a capital charge.

We come, then, to the indirect expenditure. The loss of income through the suspension of business was substantially a charge on the income of individuals. Many people, as we have explained, had no capital to fall back upon, and the unwillingness of owners of capital to trench upon it is also quite intelligible. In

I. 
fact, all accounts from France agree in the statement that nothing could exceed the desperate pinching of the people during the progress of the war. Some capital, however, must have been lost through this loss of income, in consequence of savings which would otherwise have taken place not having been made. All the usual savings would not be prevented, the pinching being most unequally distributed, but say two-thirds were prevented. We should then have a loss of capital due to this cause amounting to about $£ 60,000,000$, the annual savings of $F$ rance being at least $£ 60,000,000$, if not more, so that the usual savings for eighteen months would be $£, 90,000,000$.

On the other hand, while Frenchmen individually may have pinched to the extent of the $\oint_{1}$ 50,000,000 which we have estimated as their loss of income, they increased the burdens of the State by not paying taxes enough to meet the usual peace expenditure. The difference on this head in 1870 was $£$ I $1,000,000$, and in i 87 I, $£ 4,000,000-a$ total of $\ell_{1} 5,000,000$ falling to be added to the amount of savings prevented. We must also deal in the same way with $£ 4,000,000$ of Paris revenue lost, making the total charge to capital $£ 79,000,000$.

The second item of indirect loss, amounting to $f_{112,000,000}$, is also a charge on capital, representing a permanent deficiency of earning power.

As regards German indirect expenditure, it may be considered that in the circumstances it has nearly all been borne by income. $£ 50,000,000$ is not a very large deficiency, and would be easily covered by the privations of those concerned, while the saving of other classes in the actual circumstances of the war may have gone on as usual. We may divide the amount equally; however, between capital and revenue.

Summarizing the account just given, the whole war waste, exclusive of the value of destroyed or injured lives, will have been borne by capital and revenue as follows : 
France.

Direct war expenditure of France.$£$ 1 20,000,000

Requisitions, fines, etc. . . . . $27,062,000$

War pensions of France . . . . 5,000,000

French loss of present income . . 79,000,000 71,000,000

Capital value of depreciation of

French earning power. . . . I I 2,000,000

Revenue.

Er 7,022,000

\section{Germany.}

Direct war expenditure of Germany

German indire $\urcorner$ losses . . .

War pensions of Germany . .

$60,000,000$

$25,000,000$

$5,000,000$

Total for France and Germany

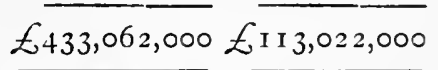

Four-fifths of a total expenditure of $£ 546,000,000$ which we consider to be the expenditure, exclusive of lives destroyed, may thus be considered a capital charge upon the resources of the communities concerned. It is probably equal to about five years' savings of France and Germany combined.

The distribution is, of course, very unequal, the capital loss to France being $£ 343,000,000$, and to Germany only $£ 90,000,000$; and the revenue loss to France being $£ 88,000,000$ against $£^{25}, 000,000$ primarily paid by Germany. But this and other inequalities in distributing the burden, we reserve for further discussion.

We need state very briefly the conclusions from these facts. Even a loss of capital of $£ 400,000,000$ cannot be considered a very serious drain on the resources of two such countries as France and Germany. Four years' saving will very soon be made up, say in two or three years, for one-fourth of the loss consists of savings prevented during the period of the war, viz.:

French savings prevented . . . . . $£_{79,000,000}$

(ierman ",

$25,000,000$

Total

E, $104,000,000$ 
so that there is only $£ 300,000,000$ of actually stored-up capital wasted, and requiring to be made good by subsequent thrift. In three years, then, the people of the two countries should be as well off as they were before the war, if no other circumstances had to be considered. The war would still have injured them and thrown them back. Although in three years' time they might have been as comfortable as they were before the war, they would not have been exactly as if the war had not happened, because the intermediate savings which now make good a past loss would wholly or in part have been added to the previous wealth. Probably at some early date they might have caught up their lost ground in the race by more energetic saving, so that there would have been little permanent loss of capital after all. Such saving would of course increase the amount of the losses of the war which would have been charged to the revenue of the existing generation, but the effect in diminishing the permanent loss of capital is all that we are now considering.

Nor could the loss of permanent capital be thought very severe if it had fallen on the two nations in the proportions originally defrayed by them. To Germany the loss would only have been $£ 90,000,000$, viz.:

$$
\begin{aligned}
& £ 60,000,000 \text { for direct expenses. } \\
& 5,000,000 \text { for war pensions. } \\
& 25,000,000 \text { for indirect expenses. } \\
& £ 90,000,000 \text { in all, }
\end{aligned}
$$

-which is no very great amount, probably about one and a half years' savings. To France the loss would have been four times as great, viz.:

$\mathcal{E}$ I 20,000,000 direct Government expenses.

$5,000,000$ war pensions.

$27,000,000$ requisitions, etc.

$79,000,000$ present income charged to capital.

I I 2,000, 000 depreciation of earning power.

$f_{3} 343,000,000$ 
-or about one-half more than if the amount had been equally divided, and equal perhaps to five years' savings instead of three. France therefore might have been expected to take two years more to recover than if that equal division had taken place. That is to say, it would have been five years after the war instead of three before the lost ground was recovered. No doubt the means of saving would be diminished by the interest which must be paid on the lost capital, but the former rate of savino, as we have already explained, will, for other causes, be increased rather than diminished.

We have still, however, to look at the subject from another point of view. The arrangements at the peace have complicated the question by shifting the burden, and perhaps more than the burden, on to the shoulders of only one of the belligerents. What changes have thus been made in the effects of the war losses, both as respects the total charge, and as respects the permanent loss of capital which each has to bear?

\section{V.-The Indemnity and Cession of Territory AND THEIR RESUlts.}

There are two ways in which the incidence of the burdens of the war was changed by the terms of the peace. One of these-the money indemnity - is very easily described. In addition to all their other burdens and losses, the French people were made to pay to Germany a sum of five milliards of francs, or two hundred millions sterling. Germany had so much less to pay, and France had so much more. And there are no qualifications or deductions to be made. The value of the Alsace and Lorraine Railways, amounting to $£$ I $3,000,000$, was indeed deducted, but only as between the Governments of France and Germany. As they belonged to a French company which had other lines in French territory, and had close connections with the French Government, Germany preferred to buy them, 
and instead of doing so by an actual payment in cash, deducted the value from the money indemnity it had to receive. But the French Government in turn had to come under obligations to the Railway Company for the amount. It bought the railways at a stipulated price, and transferred them to Germany at the price of \&I3,000,000, in place of paying Germany so much money. This was no real deduction from the total indemnity of $£ 200,000,000$ which was stipulated to be paid. Nor are any deductions, at least none worth speaking of, to be made on account of delay in the terms of payment. The stipulations of the Treaty are precise- $f_{40,000,000}$ to be paid within a year, and the remaining $f \mathrm{r} 60,000,000$ within three years after ratification, but of this latter amount $\mathcal{E}_{\mathrm{I}} 20,000,000$ is to bear interest at 5 per cent. from the date of the Treaty till payment. Any deductions, therefore, to be made for delay in payment apply only to a sum of $£, 80,000,000$, and of this sum $£ 40,000,000$ was in any case to be paid within a year, while the guarantees for paying the remainder were so stringent that the French Government in fact took care to pay the whole $£ 80,000,000$ by the beginning of March in the present year [1872]. The haste of payment caused the French to pay a good deal on account of commissions to bankers and loss by exchange, and these are a set-off against any advantage gained by having to pay no interest from the $x$ st of March, I87 I, to the time of payment. France has thus had to pay to Germany f200,000,000 net.

The other mode in which the incidence of the war losses and expenses was changed, and the burden shifted from one belligerent to the other, may require a little explanation. This was the cession of the greater part of Alsace and Lorraine to Germany, viz., the departments of Haut-Rhin, Bas-Rhin, Moselle, and parts of Meurthe and the Vosges. The territory in question was ceded without any deduction for the value of the public property it contained, or for the share of the 
French debt estimated to belong to it, or for its estimated value as a source of revenue. The effect of this arrangement necessarily was to increase the burden of the charges of the French State on the diminished territory and people. The diminished France was also less able to bear any increase of debt and taxes. It may be said, perhaps, that France was additionally burdened by no deduction being made for the debt, but nothing more, as the other expenses of government ought to be proportioned to the smaller area; but this is a narrow way of looking at the burdens of a great Power. A change of one or two millions in its people either way leaves it in pretty much the same position as it was before as regards its international duties and dangers. It is still practically the same unit, and most of its expenditure must be determined without any reference to the increase or loss of territory. The cession of territory, therefore, is a real loss, and its acquisition a real gain, without any drawback in either case so far as the material resources and taxpaying powers are concerned. France lost and Germany gained in a most distinct and measurable degree by the transfer of the two provinces from the one to the other.

The loss, measured by population, is about the oneand-twentieth part of France. According to the census of 1866 , the population then was $38,067,000$, and the cession would reduce the number by $1,597,000$. As the debt of France after the war is close upon $£ \mathrm{I}, 000,000,000$, it would follow that the diminished France has, in fact, been burdened with an additional debt of about $£ 50,000,000$ beyond what it would have to bear if the provinces had not been ceded. And the total addition to its burdens would be more than double that, as the interest of the debt is only about half the annual State expenditure which the French people have to meet.

There appears to be a more exact way of looking at the matter, however, and that is by comparing the revenue-yielding power of the ceded provinces with 
that of the rest of France. The comparison is not difficult to arrive at. The State revenue of France before the war was as nearly as possible $£ 75,000$,000, of which, as we have seen, the amount yielded by Alsace and Lorraine was $£ 2,400,000$. The ceded provinces, therefore, were hardly equal in economic vigour to the one-and-twentieth part of France, and their share may be more fitly stated at the thirtieth part. Still the deduction of a thirtieth would represent a very considerable sum, and the share of the increased debt alone would be upwards of $£ 33,000,000$. Double that amount, as above, would make the French loss of capital by the cession $£ 66,000,000$. Perhaps the following will be the most accurate way of arriving at an estimate. The revenue ceded at twenty years' purchase - which is not an excessive estimate for a country which has to borrow at 5 per cent. and upwardswould represent a capital of $£ 48,000,000$, but as France has had to increase its revenue one-third, we may consider that Alsace and Lorraine could have paid at least one-third more, or $£_{3}, 200,000$, making the equivalent capital at twenty years' purchase $£ 64,000,000$. We may consider, therefore, the loss of Alsace and Lorraine to France as equivalent to a loss of $£ 64,000,000$. In the case of any ordinary cession, half of this sum would at least have been allowed as the share of the debt, and the province was at least worth half as much again.

Some small allowance ought perhaps to have been made for the diminished expense of collecting the revenue and the diminution of one or two other charges, but suppose a tenth to be allowed-and this would far more than cover the saving in collecting the revenuethe capital loss to France on account of the cession would still remain about $£ 60,000,000$. Per contra, however, we ought to have added as part of the French loss the value of national property in the two provinces. The public buildings, fortresses, and similar property represent very large sums, and we cannot be far wrong 
therefore in retaining $£ 64,000,000$ as the figure for the total loss.

Such, then, has been the result of the arrangements for the peace. Germany gets $£ 264,000,000$ to set against her outlay and losses, and France has $f_{264,000,000}$ more to pay. To both countries the change makes an enormous difference in the final accounts of the war.

To begin with Germany, the curious fact will be that the war in a material sense has yielded a profit instead of a loss. Her losses, as we have seen, were only about $£$ I $45,000,000$ (viz., $£ 60,000,000$ direct outlay of Government, $£ 5,000,000$ for new pensions, $£, 50,000,000$ for loss of income and capital, and $£ 30$,000,000 for loss of life). The war having brought in $£^{264}, 000,000$, she is a gainer of the enormous amount of $\mathcal{L}$ I $19,000,000$. This is putting her loss in the most extreme form. Omitting, however, the very exceptional item for loss of life, the losses and outlay of the surviving com-

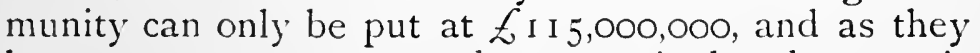

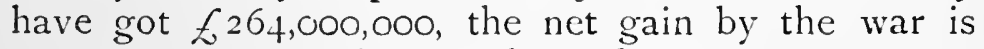

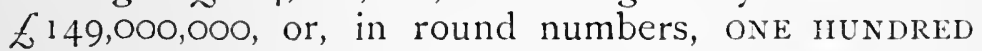
AND FIFTY MILLIONS STERLING.

The result is still more striking if we consider only the permanent loss of capital. Germany, as we have seen, lost permanently, that is spent out of capital instead of out of revenue, only about $£ 90,000,000$. The above $£ 264,000,000$, however, is all capital, so that Germany begins the world again after the war with $f \mathrm{I} 74,000,000$ to the good. Whatever justice or injustice there may have been in exacting an indemnity from France, there need be no disguising the fact that the indemnity not only makes good losses, but actually enriches Germany. It is about as much to the Germans as two years' arduous savings, if not more, and no such windfall, it may be safely said, ever fell to the lot of any community as the result of seven months' war. To be quite just, we must, of course, recognize that the gain by such a cession as Alsace and Lorraine is very apt to be lost to the nation, the Government taking 
care to spend the additional money it gets, and not remit the taxation of its subjects in proportion. Even the gain by the indemnity will be less than a similar accession of capital by industrial savings would be, because it will be received by the Government, and not by individuals. But after all deductions, no such money can come into any State without adding to the general means, and enriching every single member of the community. The prospect of such an indemnity more than justifies the eager expectation with which the Germans have discussed its payment.

What Germany has gained France has lost, and as regards France, the net result must be to swell its already gigantic losses to an enormous total. The whole cost primarily borne, excluding the doubtful estimate for the value of the lives lost or injured, was £43I,000,000, viz. :

Direct expenses of Government . . . $£_{120,000,000}$ Requisitions, fines, etc. . . .

War pensions

Loss of income, $1870-71$.

Depreciation of French earning power

Total .

$44,000,000$

$5,000,000$

I $50,000,000$

I $12,000,000$

$£ 431,000,000$

To which we must now add,-

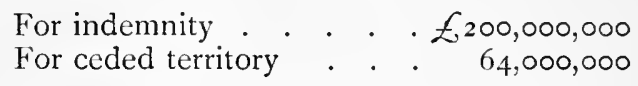

Total. . . . . . $\frac{£ 264,000,000}{£ 69,000,000}$

making in all the formidable sum of $£ 695,000,000$, or, in round numbers, SEVEN HUNDRED MILLIONS STERLING. This is of itself very nearly as much as the English National Debt, and very much more than the National Debt of France before the war. Excluding any direct estimate for lives lost and injured, this is the total loss strictly falling upon the surviving French community, and either borne by them out of their current income, 
or paid by capital on which they will have to suffer a loss of interest in future. The amount is truly enormous,-more than one year's aggregate income of the people, and six times as much as the entire annual revenue of the State, both for national and local purposes.

The permanent loss of capital is almost equally serious. The amount so lost, apart from the indemnity and cession of territory, was about $£ 340,000,000$, and the losses now being dealt with being entirely from capital, the total permanent loss of capital will amount to $£ 600,000,000$. While Germany therefore starts in the world about $£$ i 74,000,000 richer by the war, France is rather more than $£ 600,000,000$ poorer. In this case there is no doubt about the effect of the loss of territory. Whether the Germans gain by it individually or not, it is certain that every Frenchman loses. The three millions of revenue which the ceded provinces could have bcen macle to yield are missed in the French budgets, and their absence aggravates materially the difficulty of the search for new taxesin other words, compels the French Government to impose indefinitely more disagreeable burdens on the diminished population than would otherwise have been required.

We can now obtain a comprehensive view of what the war has really cost the French. Divided among a population of $36,500,000$, the total of $£ 695,000,000$ represents a sum of $£$ ig per head, or, taking the average French family as four persons, a sum of $£, 6$ per family. This was the entire cost of the war payable out of revenue and capital, but nearly an eighth was paid out of revenue, and the remainder, $£ 603,000,000$, which is the burden upon capital, represents a sum of £i 6 Ios. per head. The English National Debt at this moment is $£ 26$ per head, so that in one short war the French have lost three-fifths as much capital per head as the individual share of the English people in that debt which has hitherto been regarded as the most 
gigantic and oppressive burden upon the resources of a nation.

In comparison with the aggregate annual income of the French people, the loss is, roughly speaking, about one year's income, and estimating the annual savings at about $£ 60,000,000$, must be about ten times the amount of these savings. In ordinary circumstances, therefore, it would take nearly ten years for France to recover lost ground. Without the loss of territory and without an indemnity to pay, the French had lost as much as would probably have taken five years to recover, but the indemnity and the cession very nearly double the wound. For reasons already suggested, the period of recovery may, in fact, be lesswill probably be very much less - but the natural effect of the loss is to put France about eight years behind in its industrial career.

The greater part of the capital loss, it should be understood, falls upon France collectively, that is, upon the French State. Of the above total of $£ 603,000,000$, only two items will finally be borne by individuals, viz.:

Current loss of income borne by individuals $£ 60,000,000^{1}$

Other indirect losses . . . . . . . . I I 2,000,000

Total

$£_{172,000,000}$

leaving $£ 431,000,000$ to become a charge upon the State. This sum is made up as follows:

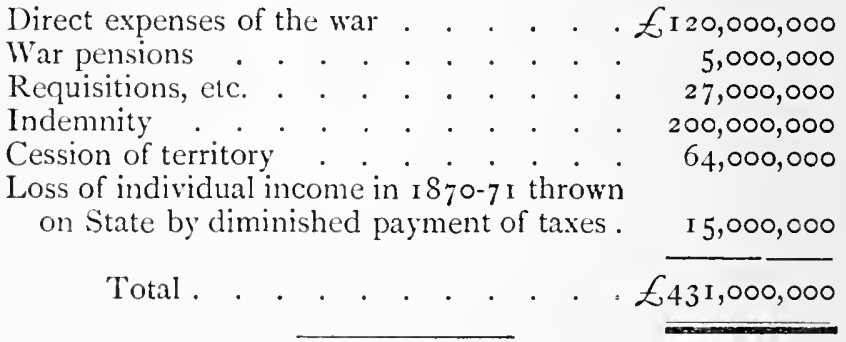

1' The aggregate loss of income was estimated above at $\mathcal{E}, 150,000,000$, and the amount charged to capital was $£ 79,000,000$, viz., $£ 60,000,000$ 
And the charge upon the State may be increased, and that upon individuals diminished, should the State finally repay not only as much of the requisitions as we have assumed to be charged to capital in private accounts, but the whole amount. That the charge is in no way exaggerated will be readily seen, if we compare the actual cash transactions of the French Exchequer during the last few months with the obligations which are still impending, and if we also inquire into the amount of the annual burden which will now fall upon the State. The accounts of the Exchequer will stand:

In the budget of 1870 the deficiency of receipts, exclusive of loans, was ... . $£_{74,240,000}$

In the budget of I 87 I it was . . . . 39, I 22,000

The indemnity paid in $187 \mathrm{I}$, deducting value of Alsace and Lorraine Railways, was . . 47,000,000

Total actually borrowed . . . $\overline{£ 160,362,000}$

To this we must add obligations outstanding at end of $1 \delta_{7} \mathrm{I}$, and the capital value of annual charges incurred without actual borrowing, viz. :

Indemnity remaining due after 1871 (three and a half milliards)

Value of Alsace and Lorraine Railways . I I, 1000,000

New war pensions . . . . . . . . . 5,000,000

Requisitions, etc. . . . . . . . $27,000,000$

Ceded territory . . . . . . . . . . 64,000,000

Amount of special budget for liquidating arrears of war.

$20,000,000$

Total .

$E_{429,362,000}$

At 5 per cent. the amount would involve an additional annual burden of about $£ 21,000,000$, and we find that, in fact, if the charge is less, it is due to a

of individual savings prevented, and i 9,000,000 charged to the State and to Paris by the payment of taxes being diminished, so that the revenue in $1870-7 \mathrm{I}$ was insufficient for the ordinary peace expenditure by $\AA_{15}, 000,000$. 
species of forced borrowing from the Bank of France at less than the market rate of interest. The French Government affirms that its agreement with the Bank is no injustice to the shareholders, the monopoly of an extended note-issue enabling the Bank to lend cheaper, but if the monopoly is worth much to the Bank, it would have been worth much to the State, and the transaction is, in fact, a sale by the Government of a certain privilege for the difference between the rate of interest which it does pay and what it would have to pay borrowing at the market rate. The additions to the annual charge of the debt traceable to the war as shown in the budget of 1872 are as follows:

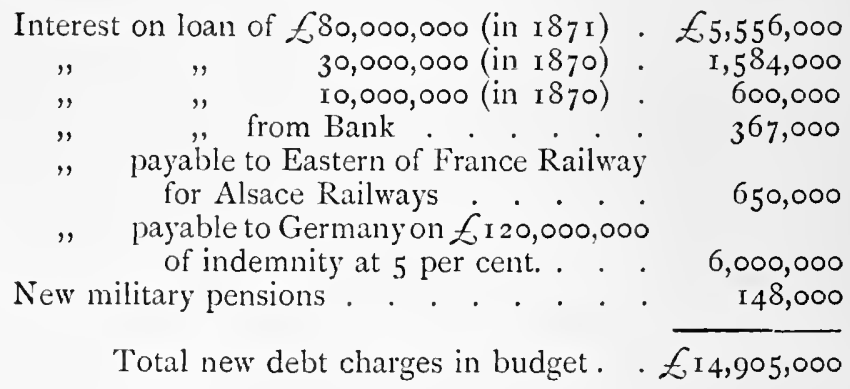
Add,

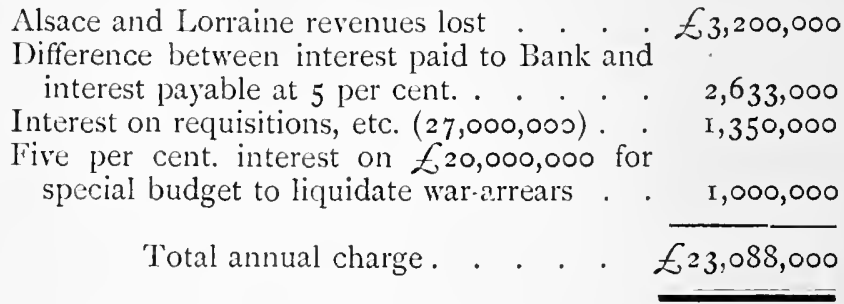

The whole charge before the war for "debt and dotations" was $£ 22,300,000$, so that it is no exaggeration to say the annual burden has been really doubled by the war and its consequences to France. The whole additional charge which yet appears in the budget is

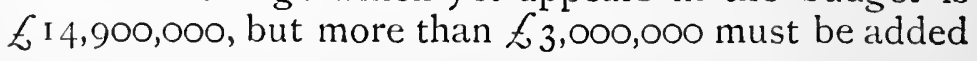


for loss of the revenues of Alsace and Lorraine, and even if we add nothing for the interest under-paid to the Bank, there are still two sums amounting together to over $£ 2,000,000$ in suspense, which the State must undertake to pay before it can fully discharge all the arrears of the war. If it does not pay the $£ 27,000,000$ for requisitions claimed-only a part of the total claim - the charge on individuals and local authorities will be increased, but it can in no way escape the burden of $£ 20,000,000$ for liquidating the arrears of the war.

The amount is of course an unprecedented addition to the annual burdens of a people by the events of one calamitous year. Taking it at $£ 22,000,000$, it amounts to I $2 s .3 d$. per head annually upon each inhabitant of France, or about $49 s$. per family. It is nearly equal to the annual charge for interest on the National Debt of England, for though the whole annual charge which appears in our budgets is $£ 27,000,000$, yet the interest at 3 per cent. on $£ 800,000,000$ - and we do not pay so much as 3 per cent. on the whole of it-is only

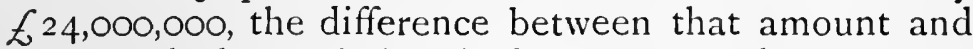
the actual charge being, in fact, an annual appropriation to repay the capital of the debt. In one year, then, France has added to her annual State burdens, besides the loss of individual capital, as much as the entire charge of our accumulated debt.

Whatever way we look at the matter, then, we cannot but be impressed by the enormous magnitude of the loss which France has sustained. The war itself was not so very costly if both nations had but divided equally the actual outlay of the Governments, and fought their battles on some debateable land without incurring the terrible losses of an invasion. But France was in fact invaded, had to bear the losses incidental to that state, had to pay, as the war went on, a large part of its invaders' costs, and in the end had to pay an indemnity and suffer a loss of territory which nearly doubled its losses. The loss of capital and the addition to the national debt are enormous, while several years 
must elapse before France, at the ordinary rate of progress, is even at the point of industrial prosperity which she had attained before the war.

A remark or two may be allowed on one or two points suggested by these facts. Will Germany, in fact, really gain much by the indemnity and additional territory in a material point of view? The capital is really a loss to France, and the Germans ought to gain, but will they really do so? If they do not, the transaction will be a net loss to the world, as well as a special loss to France. To some extent it must be so. The money is taken from individuals and goes into the hands of a Government, and this is a disadvantageous change. Even if the German Government uses the bulk of what it receives in paying off the national debts of Germany, so that the money comes back to individuals again, it will have been a long time in transitu-consequently, for a long time in a condition of impaired efficiency. The operation is, therefore, a net loss to the world, and Germany will be far from gaining all that France will lose. We need not add that if the German Government should devote the money to any extravagance - to some fancied Imperial necessity or caprice - the loss will be very serious indeed. The operation will have all the effect of a great loan for a pernicious purpose, and it will make no difference that the Government which borrows is not the Government which ultimately receives the money. So far as matters have yet gone, however, the indemnity appears to be fairly well used in an economic sense, though it is producing some effects which it is difficult to trace. The chief good uses are the establishment of a gold currency for Germany, the repayment of German debts, and as a result of these the reduction of German taxes. By all these operations the money which the German Government has got is being put to useful ends, though it cannot be said it is so useful as it would have been if it had never been transferred at all. Another purpose which the money has been made to serve is of a more doubtful 
kind. The German Government having large surplus funds in hand has become a lender on a great scale, and is the means of supplying German speculators and traders, and through them speculators and traders in England and throughout the world, with stores of cheap money. The money which Germany pours into the market competes with the ordinary loanable capital, and has prolonged the period of very cheap money which set in with $\mathrm{r} 867$. Is the effect of this diversion of capital in the end to be good or bad ? Probably it makes trade more prosperous for a time than it would otherwise be, so that one result of the French indemnity is to give a bonus to the trade of England, because England attracts the surplus money of the world, but it would be hazardous to say that an effect so artificially produced will in the end prove a benefit at all. Trade and speculation get to depend on the artificial stimulant, and the crash that may come on its withdrawal, of which there was a foretaste last autumn, may more than destroy all the unusual profits it has created.

The second point to be noticed is the probability of France recovering with unexpected speed. At its estimated past rate of saving we have been inclined to give it ten years to recover, and to save $£ 60,000,000$ effectually each year it must really save $£ 20,000,000$ more than it did before, for there is so much more taxation to pay. But all the chances are that the past rate of saving will be greatly increased. The anxiety of each individual in a nation which is habitually thrifty will assuredly be to make up for the storm which has passed over them by the most desperate inclustry and saving. They will seek in a year or two not only to recover lost ground, but to place themselves at the point of prosperity which they had looked forward to reach at a given period of their lives. It would not be at all surprising if the phenomenon to be witnessed in France for the next year or two were the multiplication of the national wealth by the doubling or trebling of the former savings of the people. A few years' savings of 
only $E_{100,000,000}$ would go a long way to fill up the chasm which has been made in the national resources; and a single bountiful harvest at such a time would be greedily made use of to repair the waste which is still fresh in every one's remembrance. France is very far indeed from being exhausted, though taxes are now difficult to find. A revenue which has augmented a million annually for many years is sure to have immense elasticity. The existing taxes must soon provide for all needs, if only the fatal habit of deficits in time of peace is scrupulously shunned.

\section{VI.-The Finance of the War and the}

Money Market.

Our fourth question was the effect of the war losses and expenses and the financial arrangements made to meet them on the money markets of the world. Hitherto we have been dealing only with the economic aspect of the war in its most general form-with the effect of losses and expenses which all belligerent communities are liable to feel, whether they possess the elaborate machinery of the modern money market or not. We have now to inquire how that machinery is affected or disturbed by war, and in what special way the last war operated and may still operate. Properly speaking this might have been a branch of the other parts of the inquiry, the losses or gains which arise to the world from war through its influence on the money market being an addition to or a set-off against all the other losses which are otherwise traceable to it, but it is conceived that it would have been inconvenient to deal with the subject in this manner. The losses or gains at the best would be quite incalculable, and the nature of war influences on "money" is in reality so intricate and important a topic as to justify separate treatment.

The common opinion-and in the usual case perhaps 
the true opinion-about the effect of war on money is very simple. War, it is understood, makes money dear. It creates a new and heavy demand on the circulating capital of the world, and must enhance the value of that capital. But this opinion carries us a very little way in studying the effects of the last war. The phenomena we meet are various. First came a spasm of dear money just at the outbreak of the war; then a long period of cheap money, lasting all through the war and for some months after it; then another spasm of rather dear money, and again a prolonged period of cheapness. At present it would be hazardous to say that it now tends in any way to make money perceptibly dearer. It $\mathrm{n}$ ay be said that after minor fluctuations economic theory will come right in the end, but the circumstances are perhaps enough to raise a doubt of the universal applicability of the theory. It is plain that in a war like the last it will be more practical to understand the laws of variation from the usual result than to rest contented with the knowledge of what the usual result may be.

To understand the matter thoroughly, it is submitted, the money market must be looked at in two different aspects. There is first of all its singular liability to momentary and superficial disturbance. The money markets of the world are now so much interconnected as to make practically but one market, with London for the centre, and the organization of this central market is of the most delicate sort. It is so contrived, by means of a hierarchy of banks and discount houses centring in the Bank of England, that in ordinary times the money it contains is made to go as far as possible, but when anything goes wrong the strain is very severe. The complete abstraction of any considerable amount, though it may be small in comparison with the aggregate transactions of the market, may disturb largely the current relations of supply and demand, and its effect will be multiplied tenfold by the sensitiveness of all concerned and the precautions they are induced to 
take. The natural structure of the market is such that this liability to disturbance must always be great; but, as if to intensify the evil, the natural means by which a sudden demand could be tided over and alarm allayed has been artificially destroyed. The expansion of the note-issues of great banks, when there is a sudden demand for money and the credit of the note is not shaken, is the obvious method of meeting a sudden strain, but Peel's Act forbids the exercise of any such power in London by the bank which has the monopoly of issue. Now that the inelasticity of the Act has become familiar, each sudden disturbance is liable to be increased in severity by the knowledge of all concerned that the natural remedy for it cannot lawfully be used. The second aspect of the market is the more general and important one of steady and periodic change, according as the supply of circulating capital exceeds or falls short of the demands of borrowers in the market. We must make a broad distinction between these two different aspects of the market in studying the effects upon it of war or of any other cause which produces large financial operations.

As respects the first aspect of the market, we do not think there can be any doubt as to the probable effect of a great war. It can hardly fail to cause the most serious spasmodic disturbance and a short period of dear money. Many of its demands are likely to be of extreme urgency, and the precautions which its outbreak and some of its incidents necessitate on the part of all who have money engagements to meet are also likely to be extreme. There is something formidable in the very name of war. But the dear money thus produced is only temporary and occasional, unless perhaps the temporary panic should be converted into a prolonged convulsion, a possibility which may be sometimes very threatening.

The effect of war on the money market, looked at in its second aspect, does not appear to be so clear. No doubt war absorbs capital, and the natural tendency of 
such an absorption, whether resulting from war or any other extravagance, should be scarcity of capital, for which accordingly higher rates would be charged. But when we examine the matter carefully we find that the effect of the absorption of capital is one of circumstances and degree. Much will depend on the amount of the war requirements, and great as these often are, we should not forget the magnitude of the market out of which the supplies have to come. Though the market may be so delicate as to quiver to a sudden demand of insignificant amount compared with its total business, its real resources are enormous, and if time is only given the most extravagant expenditures may be supplied without a shock. For such a purpose, it may be repeated, all the markets are one. Even if France and Germany had been unable to launch their loans in London, they would still have supplied themselves from the common resources of the European markets. French and German securities would have been sold abroad that Frenchmen and Germans might subscribe to their own loans, and as regards any effect on the money market, this is almost an equivalent process to having a loan subscribed in London. The question of circumstances is even more important. According as the war comes at a period when the current savings of the chief industrial communities are small or great, its effects will be serious or the reverse. If savings are abundant, the expenditure may be met out of surpluses which it might otherwise be difficult to employ. What is perhaps still more important, there is one secondary effect of war which in the actual circumstances of modern industrial societies will always help to counteract the tendency to dearer money which is the direct consequence of the war expenditure itself. This secondary effect is the diffused apprehensiveness and limitation of enterprise which war on a great scale between two leading members of the society of nations invariably produces. As thus viewed, war provides the capital for its own sustenance by checking the employ- 
ment of capital in other directions. It may be quite true, perhaps, that all the while the belligerent communities gradually get poorer, but this process appears to be really consistent after all with an easy money market. So long as capital is found for war by withdrawing it from other pursuits, the effect on the borrowing and lending markets will be nil. People will have less to borrow and lend, but the supply will be adjusted to the demand, and the rates will not be dearer. It would be the tendency of a prolonged war, of course, for the demand to outrun the process of diversion from other pursuits, but until that process is outrun, money will not grow dearer. The point is that war, to cause dear money, must not merely produce a great demand -it must produce a certain excess in the whole demand for capital, whatever causes may be operating at the time to increase the supply or to diminish other demands.

The phenomena of the war and its after-effects, up to the present date, suggest and confirm these views. And first, as to the influence of war in causing spasmodic disturbance. The first monetary spasm in the war, in July, I870, was clearly due to the precautions forced upon people who had money engagements to meet. War was declared upon the I $5^{\text {th }}$ of July. On the 2 Ist the Bank of England rate was raised from 3 to $3 \frac{\mathrm{I}}{2}$ per cent. ; on the $23 \mathrm{rd}$, to 4 ; on the $28 \mathrm{th}$, to 5 ; and on the 4th of August, to 6 -the rate having thus been doubled in little more than a fortnight. All happened long before the great spending and borrowing on account of the war began, and the cause was notorious and palpable. As the "Economist" ${ }^{1}$ at the time explained, we were "receiving securities from borrowers on the Continent, who think that money is more easily procured in London than elsewhere. These borrowers are mostly persons under heavy liabilities, and they send for cash in time of danger because they feel that at any

1 "Economist," July 23 rd, I $\&_{70}$. 
moment they may be asked for cash themselves." At the same time, foreign bankers having bills on London sent them in for payment, and did not take fresh bills, the same end of providing themselves being thereby secured. The demand for gold was also increased in London by the Bank of France exercising its option of paying in silver. In other words, the crisis in London was intensified by the precautions of the Bank of France, which undoubtedly would have taken another form had not this been open to it. We see, then, in a moment, how war produces a spasm of dearness without any of the expenditure which will ultimately act on the market having even begun. Of course, the demand, once begun was increased by the precautions of people at home, and so the effect was great and immediate. But a disturbance of this sort is very soon over. A week after the rate was at 6 , it was reduced to $5 \frac{\mathrm{T}}{2}$; a week later, viz., on August 18 th, it was reduced to $4 \frac{\mathrm{T}}{2}$; on August 25 th, to 4 ; on September Ist, to $3 \frac{1}{2}$; and finally; on September 15 th, to 3 per cent., the Bank all through having followed the open market somewhat tardily, but the whole period, nevertheless, commencing on July 2 Ist, and terminating on September $y_{5}$ th, having lasted less than two months. Taking it that the crisis was really over when the rate was reduced to $4 \frac{1}{4}$ on August i 8 th, the disturbance had, in fact, only lasted a month.

The second disturbance was in no way more prolonged, and though it arose in a somewhat different way, was distinctly traceable to a cause characteristic of the war. The Germans in the autumn of 187 I were receiving payment of a large part of their war indemnity. Besides the fine of $£ 8,000,000$ on Paris stipulated in the armistice, and the other fines and taxes levied in the occupied districts of France subsequent to the peace preliminaries on 26 th of February, I 87 I, estimated according to the table in the Appendix to amount to $£ 450,000-$ 
Viz. : Contributions

Direct taxes .

Indirect taxes

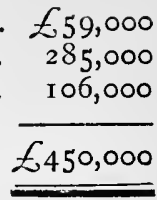

besides likewise the sums paid by the French Government for the expense of the German army of occupation, which must have amounted at least to five or six millions more-the Germans in 1871 received altogether from France and on account of the indemnity alone the large sum of $£ 47,000,000$ in cash or bills. This amount was paid, with the exception of a sum of $6,5,000,000$, between the 27 th of June, when the $£ \$ 0,000,000$ loan was subscribed and the first days of September, in the following form: ${ }^{1}$

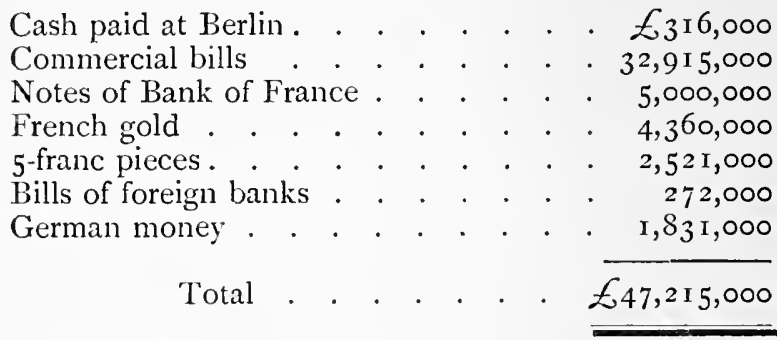

A large part of the bills fell due in London, and the amount representing them had been transferred to the credit of the German Government by September, while other bills were to come due in November following. Accordingly, the German Government, having previously received large sums in cash which it had locked up, was an unusually large creditor of Lombard Street at the most difficult period of the year, and wanting gold for the purposes of a new German coinage, suddenly exercised its power. The effect was almost instantaneous. The gold in the Bank and the Reserve rapidly fell off, and the rate was as quickly raised, as the following table shows:

${ }^{1}$ Budget of 1872 , Introduction, pp. xxviii.-xxix. 
BULLION.

RESERVE. RATE OF DISCOUNT.

September I4 . $£_{24,159,000}^{2} \mathcal{1}_{14,424,000}$

2 per cent.

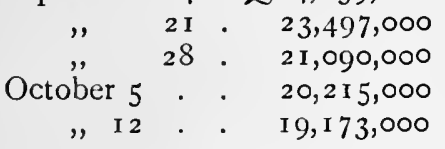

I 3,7 I I, 000

I I $, 077,000$

$8,920,000$

$8,064,900$

$\frac{3}{5^{1}} "$

The high rate in this case was maintained for five weeks - a longer period than in the crisis of July and August, I 870 , but the Bank had only followed more tardily than before the movement in the open market. The spasm was in reality equally superficial and almost equally soon over. In this case it did not, as in the former one, arise from the acts of individuals acting in view of the war, and it may be said that it would not have occurred if the German Government had been careful to avoid it, but it is one of the incidents of such large operations that the market is exposed to the caprice or mistake of the operating Governments. Precisely the same consequence might have followed upon the acts of a Government in suddenly calling up or discounting the instalments of a large loan.

While we speak of such disturbances as superficial, it would be a mistake to underrate their consequences and dangers. The chief sufferers in I870 and I87 I were bankers and the Stock Exchange, principally the latter, but no such disturbance can take place even on the Stock Exchange without much private loss and hardship to people who are not "speculators." It is easy to conceive besides, that crises thus beginning might have very wide effects, one crash leading to another all through the world of finance and trade, and there is no warrant that a future disturbance may not have such effects, though the conditions necessary for its development did not exist in 1870 or 1871 .

The present war, therefore, has acted as we may usually expect wars to do, in the production of spasmodic disturbance. As regards the other mode in which

The rate was really raised to 5 per cent. on October 7 , five days before the usual weekly court, when the rate is changed. 
war produces dear money-and that not temporarily, but for a long period--viz., by the absorption of capital -it will follow, from what we have said, that in the late war there have been counteracting circumstances. Speaking of the money markets of Europe generally, money has been cheap and not dear for a long period indeed, notwithstanding all the borrowing which the war has occasioned. In France, no doubt, the rate has been rather high, the Bank of France rate having risen to 6 per cent. at the commencement of the war, and been maintained at that figure till the 27 th of February last, a period of rather more than eighteen months. But France is the only part of Europe where money has been dear, and the rate there cannot be considered very high, when it is considered that the brunt of all the borrowing we have described had to be borne originally by one country alone. It is doubtful, moreover, whether so high a rate could have been maintained in France so long but for the artificial nature of its currency and banking system, which have impeded the free influx of money from the adjacent markets. Had France been more en rapport with the rest of Europe it would have been more quickly relieved from sources so numerous as hardly to have felt the drain. Even with this exception, then, we are entitled to say that money has been cheap in Europe, notwithstanding the war, and France is daily becoming less and less an exception.

We should say, then, that in fact there were several circumstances present to an unexampled degree during the late war, which counteracted the usual tendency of wars to produce a period of permanently dear money. The war broke out, in the first place, at a time of the most unprecedented prosperity-at the very flow of a most prosperous tide, and before the usual following of high prices and inflation had come to check the profits. The money markets of Europe were therefore well prepared to meet the unusual demand. Whether they could have met it without sensibly dearer money 
had everything else gone on as usual may be doubted, but the war, in fact, diffused a most unusual amount of apprehensiveness, and if it did not prevent the continuance and expansion of ordinary trade, at least it checked numberless new ventures of a speculative kind. There is no doubt, however, that in France ordinary trade was checked to a large extent, that being, as we have seen, one of the main causes of the French indirect losses. Great as the loss thus caused was, one result must have been that the French Government would have fewer competitors in the home loan market for means to carry on its struggle. A third cause of the abundance of capital was the extended issues of paper money in France. It is doubtful whether. the diminution of the demand for capital in France by the suspension of business would not have been counteracted by the new demand which would spring up in consequence of the old capital becoming of diminished effectiveness through the destruction of the machinery of credit; but if such a demand arose to any extent, it was in turn compensated by the large issues of paper. We shall not of course be understood to mean that capital was created by this process. What is true is that paper money economizes capital, and its issue has all the effect for the moment of an increase of capital, whatever bad results may afterwards ensue. In these four ways, then-the occurrence of the war at a prosperous period in Europe, the diffused apprehensiveness it produced, the suspension of trade in France, and the extension of the Bank of France note issue-the natural tendency of war to cause dear money by absorbing capital was counteracted, and perhaps more than counteracted. We have perhaps had cheaper money longer than we would otherwise have had, if there had been no war.

The effect in England has perhaps been greater than in the belligerent countries in this way, that besides all our own savings diverted from new enterprise by the diffused apprehensiveness of the time, the disposition 
has grown among foreign bankers and governments to accumulate spare money in London. London is the most convenient place for them to put their reserves, the war illustrated in a most powerful manner its special security, and one of the very steps by which the French Government made its borrowing easier-the issue of inconvertible paper-also tended to increase the exchange business of London, and consequently the foreign surpluses accumulated there. Paris had formerly been a rival of London as an exchange centre, but with inconvertible paper it could no longer compete. This has certainly been a cause of cheaper money. Had Paris and London continued to compete, more money would have been required by their aggregate business than is now required. The concentration of business in one centre only cannot but produce an economy of the instruments for carrying it on. The Paris money, moreover, is now used by a more efficient mechanism than it was used by in Paris, the agencies of the London money market being altogether superior. A certain amount of money has in this way been taken into a new channel where the same amount of money does more work than in the old channel. In every way, then, the foreign money goes farther than ever it did before.

Within the last three or four months there has been an additional counteracting circumstance. The German Government, instead of spending the money which is the usual destination of the proceeds of war loans, and instead of locking up the money as it did at one time, which had a still more disastrous effect than even extravagant expenditure, has taken to lending out a large part-how much is not known-of the funds which it has received. The aggregate loanable capital of the world is thus artificially increased by the finance arrangements in progress. Had the German Government employed all the surplus money to repay debt, the effect would have been less, because there is always a tendency for free circulating capital to become fixed. 
By the process of lending out, however, the money is kept more in hand, and competes with the ordinary supply of loanable capital in the world.

How powerful all these counteracting influences must have been is shown by the large amount of the French and German borrowings since July, i 870 . The Governments alone have borrowed:

\begin{tabular}{|c|c|}
\hline $\begin{array}{r}\text { Germany } \\
\text { less repaid }\end{array}$ & r $\begin{array}{r}f 50,000,000 \\
20,000,000\end{array}$ \\
\hline $\begin{array}{l}\text { France: } \\
\text { I870 Imperial loan } \\
\text { I } 870 \text { Morgan loan } \\
\text { I } 87 \text { I loan } \\
\text { From Bank of France }\end{array}$ & $\begin{array}{r}E 30,000,000 \\
10,000,000 \\
\text { - } 80,000,000 \\
60,000,000\end{array}$ \\
\hline City of Paris loan & $\begin{array}{r}180,000,000 \\
14,000,000\end{array}$ \\
\hline
\end{tabular}

Total borrowed . . . . .

Money has not been cheap, therefore, because war did not require much spending and borrowing. Large sums have, in fact, been taken out of the market, though plainly not larger than could easily have been met out of the current savings of France, Germany, and England, if only new enterprise was sensibly checked.

Something else has been taken out of the money market by the private borrowings of French merchants and manufacturers, but probably no large amount. Such demands would necessarily be limited by the deficient credit of the sufferers. The chief way, again, in which these losses would be replaced would be by the sale of securities, and it is noticeable that many French securities are now cheaper than just at the close of the war; but this may partly be due to the diminution in apparent value of the property represented by these securities. In any case, it is clear that the sale of securities has not checked to any material extent a 
general rise in the value of such property on all the exchanges of Europe. As that rise is due to the competition of accumulated savings for investment, it is clear that the private borrowings of Frenchmen have not sensibly aggravated-any more than the public borrowings - the general demand for capital.

The war of i 870-7 I, therefore, so far as it has gone, though it has illustrated the usual tendency of wars to cause disturbance in the money market, has hardly illustrated their tendency to cause permanently dearer money by the destruction of capital. It has illustrated, on the contrary, the strength of the counteracting influences which sometimes exist. There is nothing in the facts, however, to prove that these counteracting influences are always likely to exist. War will always cause diffused apprehensiveness, and invasion will suspend trade, and probably extended issues of paper will produce for a moment a new economy of capital, but the coincidence of a period of great prosperity throughout the world is not always to be looked for. Nor is it likely that the money borrowed will be often lent out in consequence of its being borrowed by one Government and ultimately received by another. Such a very favourable conjuncture for cheap money during and after a war is not certain to occur again. As we have already remarked, too, the war was not prolonged enough to test what the destruction of capital would lead to, or the tendency of war to outrun the process of diverting capital from other employments, and so make it in excessive demand. All that can be said is, that in certain given circumstances a great European war, which involved spending and borrowing to the amount of over $£ 200,000,000$ in about a twelvemonth, did not produce dear money. In the circumstances described, and with the means which the society of nations now possesses, this scale of expenditure was not large enough for such an effect to be produced.

But the account is not yet over; France has not yet borrowed all she wants; Germany has not received all 
she is to get; we do not yet see how Germany will dispose of what she does get. What effects may we yet expect from the financial operations to be completed?

On one point we think-viz., the possibility of spasmodic disturbance-there can be very little doubt. The German Government is still the holder of large sums at call or at short notice. In addition to the $£ 47,000,000$ indemnity money it got last year, besides smaller sums, it has just got $£ 26,000,000$ more, and so far as is known it has spent only a part of the money, not more than about twenty or twenty-five millions, in repaying debt, and not more than ten millions besides in miscellaneous purposes. We do not reckon what it keeps for the new gold coinage, for the coins will not be issued without a full equivalent being received, so that their issue will not lessen its power like a real expense. Germany has thus about $£ 40,000,000$ still at its disposition, which it may use for any object or any caprice it pleases. The absolute disposition of so enormous an amount, is almost a new power for any Government to possess, and increases, we fear, the liability of the money market to accidents. A Government which has the instalments of a loan to receive has great command over the market, but the German Government is in a superior position, having lent out the money on its own terms, retaining a large part of it at call or very short notice, and having in any case the power of rediscounting, by which it could convert the whole-or far more than enough to disturb the money market-into cash at a moment's notice.

The German Government has moreover $£$ 1 20,000,000 still to receive, and the French Government must not only borrow that, but considerable amounts besides. Experience justifies us in believing that there is a liability to accident in these operations, however anxious the Governments concerned may be to avoid them. What the state of matters will be when the German Government has got the command of the whole, in addition to all its previous command of the 
market, we forbear to speculate. Even after paying off all the debts of Germany, except the railway loans, which are profitable investments-with this exception not more than $£$ i50,000,000-the German Government will have a large surplus, and it is not certain that it will pay off all the debts. It may prefer rather to lend out the funds, and have control of them, and so avoid the necessity of ever borrowing again. Even if it does pay off the debts, it will have annual accruing surpluses, by which it will still possess control over large amounts. There is thus no visible end to the possibility of catastrophic action on the part of the German Government on the money markets of Europe. Nothing short of a great war or revolution can change this disagreeable condition, under which monetary business must now be carried on.

As regards the other class of effects, it appears at first sight not improbable that the course of the market may be pretty much what it has hitherto been. The larger part of the actual borrowing is over, and surprising as this fact may seem, considering what the French losses have been, and that the borrowing of France has only been $\ell_{1} 194,000,000$, it is not difficult of explanation. A great many of the losses, though real enough, do not affect the money market at all. The loss sustained, for instance, by the cession of Alsace and Lorraine requires no loan operation. It takes the shape of a new rent-charge upon the resources of France-for the retention of an old charge upon a diminished property has precisely the same kind of effect as the imposition of a new charge upon a property which is not diminished-but though the loss is a real one and will diminish in future the aggregate net income of Frenchmen, it has not the effect of the destruction of so much capital, which had to be taken out of the money markets where it was used. The same remark applies to the loss caused by the creation of new war pensions. The losses endured at the time and charged upon the annual income are also 
settled, and cannot now affect the money market. The individual loss of capital, and the loss represented by the depreciation of annual earning power, will also have a smaller effect than would be supposed from their apparent amount. So far as they consist of savings prevented, the world is poorer by a capital which would otherwise have existed; but the undertakings which the capital would have supported-that is, the demands upon the capital-have diminished too. The loss by depreciated earning-power would only be partially mitigated by loans, and it implies, moreover, the diminished credit of the borrowers, so that the effective demand on the aggregate capital of the world is far from being in proportion to the loss. The whole market is smaller, but the supply is adjusted to the demand. In this way, then, it happens that the larger part of the borrowing is over. The amount borrowed, even deducting what Germany has repaid, and not including private borrowings, has been $£ 224,000.000$, and, so far as can be seen, France will be clear, if it only borrows about $£$ i $20,000,000$ to pay off the indemnity, and $\mathcal{E}_{40,000,000}$ more to liquidate arrears. It is probable, too, that most of the private borrowings have already taken place, the earliest opportunity having been seized to restore establishments and resume business as completely as diminished means would permit.

It has also to be remembered that the greater part of the future borrowings will not be for purposes of expenditure, but only to transfer capital from one set of people to another. The money taken from the money market will be given to the German Government, and will not be spent, but used as capital. We have already shown that this will give the German Government very great power, but at present we have nothing to do with that point. It does not alter the fact that loans which are to be so used will not only not exhaust the resources of the money market, but by keeping in it funds which might otherwise have been sunk in some 
fixed form may even enlarge its resources. So far, then, there is some likelihood that the future finance operations of the war may help very little to cause dear money.

Another circumstance which points in the same direction is this. We shall continue in all probability to hold the private foreign money which comes to us in connection with our increased exchange business. France in any case could only get back its share in that business with difficulty, but the first condition of its even attempting to get it back-the restoration of a bullion basis for its currency-is not likely to be fulfilled for an indefinite time.

On the other hand, other circumstances which were very powerful during the last eighteen months have changed. There is now much less diffused apprehensiveness than there was. There is some apprehensiveness still, for foreign money partly comes to or remains in England for security, but the apprehensiveness is indefinitely less than when war was actually raging or only just concluded. The current savings of the world are also probably less than when the war of 1870 broke out or than they were during its continuance. We have now come to a period of high prices, and on all sides the complaint of manufacturers and traders is that their profits are very much less than they were. It may happen that even a smaller demand on account of the war than what has hitherto been so easily met may tell very much on the market. It may come into competition with other increasing demands, and hasten a period of dear money. The point is that the finance of the war is only one element out of many in determining the future of the money market, and while some of the special circumstances which have hitherto counteracted the natural tendency of war to turn the balance in favour of dear money are still in operation, some very important circumstances which acted in the same direction are changed.

On the whole, we should be inclined to say that the 
most important circumstances are changed. The most important single influence on money is undoubtedly the annual savings of England, and the savings have been diminished while the employment for new capital has increased. This change is the more likely to operate because the other special circumstances which have counteracted the tendency of war to make money dear - the increased supply of foreign money in London and the practice of the German Government to make loans-are likely to have been most powerful at first. The current demand gets adjusted to the new supply and other capital is displaced, and then the more permanent causes which govern the market return in nearly full force. The approach of a period of dear money may possibly have been retarded on the whole by the aggregate effects of the war, but the retarding influences are probably played out, and the future can hardly be the same as the past.

We must again repeat, however, that the possible action of the German Government is apparently the most important question for the future. Its power of spasmodic disturbance is obvious, and we may further point out that the more its practice of making loans has been discounted, so that the market has got to depend on this extraordinary supply, the greater its power will be. It may not only cause a spasmodic disturbance of unprecedented severity, but by withdrawing its supplies it may induce in a moment what may prove to be a prolonged change from cheap to dear money. It is not likely so to act, but its motives will be purely political, and no one can guess at all the circumstances and motives which from time to time may determine it to act. 


\section{VII.-Conclusions.}

The principal conclusions arrived at in the preceding pages are the following:

FIRST.-The direct expenditure in conducting the war amounted to TWO HUNDRED AND THIRTY-FOUR MILLIONS STERLING, of which the amount primarily spent by France was ONE HUNDRED AND SIXTY-NINE MILLIONS STERLING, and by Germany, SIXTY-FIVE MILLIONS STERLING. The items are:

Spent by France.

Extra war credits of French Government, including special budget of $£ 20,000,000$ for liquidating war arrears . . . . . . . . . $1120,000,000$

Fines and requisitions levied in occupied districts; destruction of property, etc., less $\ell_{4}, 000,000$ voted by Government included in war credits . . . . . . . . . . 44,000,000

Capital value of war pensions created. $\quad 5,000,000$ $\mathcal{E} 169,000,000$

\section{Spent by Germany.}

War credits, including maintenance of

French prisoners, etc. . . . . $£ 60,000,000$

Capital value of war pensions created . $5,000,000$

$65,000,000$

Total Direct Expenditure $\{234,000,000$

The above includes every cash outlay in actually conducting the war by the respective belligerent Governments, and the loss of property occasioned to the inhabitants of the invaded districts.

SECOND. - The indirect losses occasioned by the war to the communities of France and Germany respectively, amounted to THREE HUNDRED AND TWELVE MILLIONS STERLING-Viz., TWO HUNDRED AND SIXTY-TWO MILLIONS suffered by France, and FIFTY MILLIONs suffered by Germany. The items are: 
Suffered by France.

Estimated loss of income in $1870-7 \mathrm{I}$ by suspension of trade and abstraction

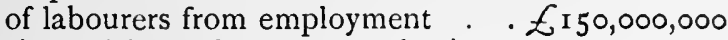

Estimated loss of permanent business or depreciation of annual earning power

Suffered hy Germany.

Estimated loss of income in i 870-7 I by suspension of trade and abstraction of labnirers from employment . . . . . . 50,000,000 Total . . $£ 3$ 12,000,000

This statement of indirect losses is of course an estimate. The basis as regards the loss of income is, in France, that the loss may be taken to have been in the same proportion to the aggregate income of the people as the loss of the State Revenue in I870-7 I was to the whole of that revenue; and in Germany, that the proportion of the annual income of the labourers withdrawn for war to the whole income of the people would be the maximum amount of the loss, as trade was very little interrupted. As regards the depreciation of annual earning power in France, the data for calculation are obtained by taking the per-centage of loss on the patent-licence tax the first year after the war, and reckoning that the annual loss of trade income would be in proportion. As the yield of taxes in Germany has not diminished, it is assumed that after-effects of the war of the kind which have been felt in France have not been felt in Germany.

THIRD.-The total cost and loss of the war thus reckoned is FIVE HUNDRED AND FORTY-SIX MILLIONS STERLING, the particulars being:

\begin{tabular}{|c|c|c|c|}
\hline $\begin{array}{l}\text { Direct } \\
\text { Indirect }\end{array}$ & $\begin{array}{c}\text { France. } \\
£ \text { I69,000,000 } \\
262,000,000\end{array}$ & $\begin{array}{l}\text { Germany. } \\
\delta_{65,000,000} \\
50,000,000\end{array}$ & $\begin{array}{c}\text { Total. } \\
£ 234, \infty 00, \infty 00 \\
3 \text { I } 2, \infty 00, \infty 00\end{array}$ \\
\hline Total & $f_{43} \mathrm{I}, 000,000$ & $f_{\text {I I } 5,000,000}$ & $£ 54^{6,000,000}$ \\
\hline
\end{tabular}


Fourth. - No estimate is made in the above calculation for the loss of life or injury thereto in the war. It is believed that no proper estimate can be made of such losses, and so far as they are felt by the surviving community, they would be shown among the other items of indirect loss. A calculation is given, however, for what it is worth, showing that the loss and injury to life in France might be represented by a sum of $£ 102,000,000$,

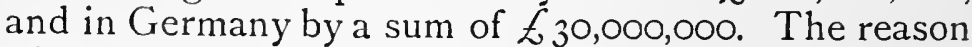
of the much larger figure for France compared with Germany is that Germany lost no civilian life, but in France, which suffered greatly by the siege of Paris and otherwise, this cause of loss accounts for sixty out of the above one hundred and two millions. The loss of soldiers' lives was also one-third greater on the French than on the German side, the total on that head alone being $£ 42,000$,oco against the German $£ 30,000,000$. These estimates, however, are only given en passant, and are not used in subsequent calculations respecting the war losses.

FIFTH. - The above losses have been principally defrayed out of capital-that is, have increased the indebtedness of the belligerent communities-but a considerable part has been dealt with at the time and paid out of revenue. The distribution of the items is as follows:

\section{FRANCE.}

Capital.

Direct war expenditure of France . $\mathcal{E}_{1} \mathbf{1} 20,000,000$

Requisitions, fines, etc. .

War pensions of France

French loss of present income

Capital value of depreciation of
$27,062,000$

$5,000,000$

$79,000,000$
I $2,000,000$
Charged on French earning power

Charged on Revenue.

$\mathcal{E I}_{7,022,000}$

$71,000,000$

Germany.

Direct war expenditure of Germany .

German indirect losses

$60,000,000$

$25,000,000$

War pensions of Germany . . . . $5,000,000$ $25,000,000$

Total for France and Germany $\cdot \mathcal{E}_{433}, 062,000$ 
Thus the amount charged to capital is FOUR HUNDRED AND THIRTY-THREE MILLIONS, and to revenue ONE HUNDRED AND THIRTEEN MILLIONS; the amount primarily charged to capital by France being $£ 343,000,000$, and to revenue $£ 88,000,000$, the corresponding charges primarily made by Germany being $£ 90,000,000$ and $£ 25,000,000$.

Sixth.-The above losses are not considered very serious, compared with the aggregate income of the communities concerned. Estimating that aggregate for each at about $£ 600,000,000$ annually, the direct outlay is only about one-fourth of that income, the total cost -omitting any estimate for loss of life-about onehalf, and the loss of permanent capital about one-third. Such losses should be easily recovered from, especially

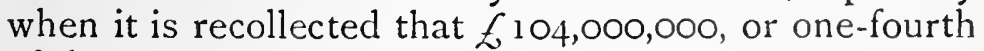
of the permanent loss of capital, does not represent any waste from accumulated stores, but merely an amount of annual savings prevented which would otherwise have been made. The waste from past accumulation is under three hundred and thirty millions sterling.

The cost, no doubt, had been unequally distributed even in the primary outlay - the primary loss of capital to France being $£_{343,000,000}$ against $£ 88$,000,000 lost to Germany. Still, even as thus unequally distributed, the loss might have been quickly recovered from. But-

Seventr.-The changes made at the peace have immensely increased the burdens of France, and even made Germany a gainer. France has had to pay to Germany an indemnity of $£ 200,000,000$ in money without any deduction, and the cession of Alsace and Lorraine is equivalent to a transfer of $£ 64,000,000$. The loss of France has therefore been increased by $£ 264,000,000$, while the loss of Germany, as the indemnity is so much in excess of all the war had cost it, is turned into a gain.

Omitting any estimate for loss of life, Germany's final account for the war will stand: 
Indemnity and territory received . . . . $£ 264,000,000$

Less total direct and indirect expenditure. I I 5,000,000 Net gain . . . . . . . . $£ \overline{\text { I } 499,000,000}$

Looking only at the permanent loss of capital, however, the gain of Germany is greater, because part of the war cost was charged to revenue, and the indemnity comes in as capital. The capital account will stand:

Indemnity and territory received . . . . $£ 264,000,000$

Spent out of capital . . . . . . . . 90,000,000

Net capital gain of Germany by the war. $\mathcal{L}_{\mathrm{i} 74,000,000}$

On the other hand, the final account of FRANCE will stand:

Total Cost of War.

Direct expenditure . . . . . . . $\mathcal{E}_{\mathrm{I} 69,000,000}$

Indirect ,

$262,000,000$

Indemnity and cession of territory . . . $\begin{array}{r}£ 43 \mathrm{I}, 000,000 \\ 264,000,000\end{array}$

Total cost to France . . . . $£ 695,000,000$

Capital Cost of War.

Amount of first outlay charged to capital . $£ 343,000,000$

Indemnity and cession of territory . . . $264,000,000$

Net capital loss to France by the war $£ 607,000,000$

The result is that while Germany gains ONE HUNDRED AND FIFTY MILLIONS on the whole, and ONE HUNDRED AND SEVENTY-FOUR MILLIONS in permanent capital, France loses nearly SEVEN HUNDRED MILLIONS on the whole, and rather more than SIX HUNDRED MILLIONS in permanent capital.

Eighti.- The magnitude of the loss to France is illustrated in various ways. The total of $£ 700,000,000$ represents the sum of $\mathscr{L} \mathrm{I} 9$ per head among a popula- 
tion of $36,500,000$, or about $£ 76$ per family. The capital loss of $£ 600,000,000$ is $£ 16$ IOs. per head, or $£ 66$ per family, the English National Debt being $£ 26$ per head: the French in a few months of war have lost three-fifths as much capital per head as the individual share of the English in their famous Debt. The total addition to the Debt of France is over $£ 400,000,000$, and the annual charge, allowing for the loss of Alsace and Lorraine revenues, and making a proper allowance for interest on the amount borrowed from the Bank of France, is virtually increased $£ 23,000,000$. This is about as much as the annual charge for interest on the English Debt.

Ninth.-The opinion is, however, expressed that France must recover quickly, though the new burden is equal to ten years' annual savings. The thrift of the people will be increased; an effort will be made individually to recover lost ground. A single bountiful harvest at such a time would go a long way to fill up the void created by these immense losses.

As regards Germany, a doubt is expressed whether the Germans will gain so much as France loses, the capital of the indemnity being transferred from individuals to the German Government, who cannot use it so profitably as individuals. It is doubted whether the practice of lending out large sums, though a preferable course to locking them up, will not in the end be injurious.

TENTH.-The financial operations incidental to these great losses and expenses seriously affect the money market. They have been a fruitful cause, in the first place, of spasmodic disturbance. The outbreak of war caused a monetary panic in July, I870, by the anxiety of people who had money engagements to meet to provide against the chances of war, and there was another monetary crash in September, 187 1, owing to the sudden withdrawal by the German Government of the money it had to receive. The war thus illustrates the tendency of wars in general to cause spasmodic disturbance in a 
market so delicately organized as that of London now is. And the liability to spasmodic disturbance continues, as the financial operations will not be complete

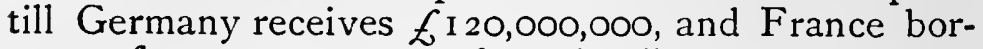
rows $£ 40,000,000$ more for miscellaneous purposes. The German Government has also complete control of the market, in consequence of the large amount of its loans.

A second tendency of war is to make money permanently dearer by destroying capital. But the effect of this cause has hitherto been counteracted, although the actual finance has been on a large scale, by the prosperity of the period when war broke out, the diffused apprehensiveness it generated, the partial suspension of trade in France, the accumulation of foreign money in London, which has risen to increased importance as an exchange centre, and the practice of the German Government latterly to lend out large sums from what it received. It is conceived, however, that as we are now entering on a less prosperous period, the war demands, although of smaller amount, may be more felt, and will help to accelerate a period of dearer money. Some of the counteracting circumstances have exhausted their first effects, and the market is left to the operation of the usual permanent influences. The fact that we are coming to a less prosperous period is in this view the most important, and ensures that the financial operations to be completed will have a maximum effect.-[March, I 872.] 
THE DEPRECIATION OF GOLD SINCE I 848 .

AVING made a somewhat extended inquiry into 1 the facts of the supply and distribution of gold since I $848,{ }^{1}$ we propose to comment directly on these facts in connection with the alleged depreciation of gold. Such an inquiry is probably not susceptible of any perfectly satisfactory conclusion. The common notion is that, as the supply of gold has enormously increased in the last quarter of a century, therefore there must have been a general rise in prices, and the sovereign will no longer go as far as formerly. And this easy belief has found a plausible confirmation in the conspicuous rise of prices, especially in a few conspicuous articles, which has just occurred. The very notion of a fall in the value of gold was likely to strike the imagination and produce belief; and the notion that a sovereign will not go as far as formerly is also one to which men are prone, although the real difficulty in a period when the scale of living is rising may be to make a sovereign go farther than it formerly did. But those who are acquainted with such inquiries will see at once that the common notion, though easily enough accounted for, is unconnected with any valid evidence. It is not a mere increase of supply which tends to cause a fall of value, but an increase of supply in excess of the demand. And supply and demand themselves are not mere accidents. In the long run supply is ultimately dependent on real causes operating on producers and merchants, and the effective demand

1 This paper was written in 1872 , as the sequel to a series of articles on the supply and distribution of gold from $1 \delta_{4} 8$ to date. 
changes with every change of price. The inquiry, therefore, if exhaustively carried out, would be resolved into an inquiry into the whole causes affecting the supply and demand for gold. It is obvious again that a mere rise of prices even of a large number of articles in a particular year or years proves nothing. Rises of price are known to have proceeded in past times from many other causes besides additions to the supply of money. Before it can be asserted that gold has depreciated in consequence of the gold discoveries, the other causes of a rise of price must be excluded, and a general rise, covering a mass of retail as well as of wholesale articles, and extending over a long period, must be established. But evidence on such points is nearly impossible. Invention is continually at work, diminishing the cost of production, and even producing wholly new articles, so that a group of articles representing fairly the general stock of goods in the world at one time would not so represent the general stock at an earlier or later time. A general change of prices, therefore, between two points of time would not be easily proved, and the work is ten times more complicated when the comparison is made over long periods. In making the inquiry, therefore, we are far from hoping to arrive at any complete results. Instead of rushing at the popular conclusion or its opposite, we should be quite satisfied if the facts yield some results, however incomplete, on which dependence can be placed.

There are two ways in which the fact of depreciation, or non-depreciation, may be approximately tested. The first is to compare the prices of as large groups of articles as possible, impartially selected, to ascertain whether there is an average rise, comparing one long period with others. If there is such a rise, the presumption will be that there has been a depreciation of gold - that its value in relation to other commodities has diminished, no matter what the cause may have been. But the comparison, for the reasons already stated, will be incomplete. In consequence of the in- 
creasing complexity of production, a group of articles which fairly represented the world's stock ten or twenty years ago, is now an unfair representation, and it will be necessary to inquire, if possible, on which side the inaccuracy of the mode of comparison would produce error. The second test, for which the facts we have collected will be most useful, will be to see whether the gold money of the nations using it has increased in greater proportions than their population and trade. Oth.ar things being the same, it follows from a general rise of prices that a greater quantity of metal must be employed in circulation to do the same work as before. If other commodities are unchanged, and population and business are the same, then if a sovereign is reduced to the value of half-a-sovereign, double the number of sovereigns will be required to make the same payments. And any similar reduction of value must be accompanied by a similar increase of quantity. No doubt the qualification that other things must be the same is very important, but it appears to be not altogether impossible to ascertain whether the requirements of a community for a gold circulation in proportion to the population have or have not changed, so that if they have not we should be able to affirm that a general rise in prices must have involved an addition to the circulation disproportionate to the increase of population and of trade. The existence or non-existence of such an addition in a given case, when other elements of difficulty can be excluded, would be determinative of a general rise of prices. Both methods of inquiry are necessarily incomplete, and it will be interesting to see how far they corroborate or confirm each other.

\section{I.}

We have to inquire, first, then as to the fact of a general rise of prices, selecting as large a group of articles as possible. This part of the inquiry is almost done to our hand. Mr. Jevons, in the inquiry which 
he made in 1863 , grouped together a large number of articles, whose prices he compared from year to year between 1851 and 1862 with the average of $1845-50$, the last industrial cycle of expansion and depression which occurred before the gold discoveries; and a similar comparison of prices has been carried out in the Annual Commercial History of the "Economist." In both cases the superficial result brought out is undoubtedly a general rise of price. Mr. Jevons, amongst other things, compared 39 articles, both separately and in the following groups: "I, silver; $2-7$, metals; I 3 , timber; 8-9, oils; I0-1 2, tallow; I6-18, cotton; I92I, wool, etc.; 23-28, corn; 29-3I, hay, etc.; 32-35, meat ; 36-39, sugar, etc. ; 14-15, dyes; 22, hemp omitted "; and the result of his inquiry was that the average ratio of prices each year, $1845-62$ to the average prices of $1845-50$, was as follows:

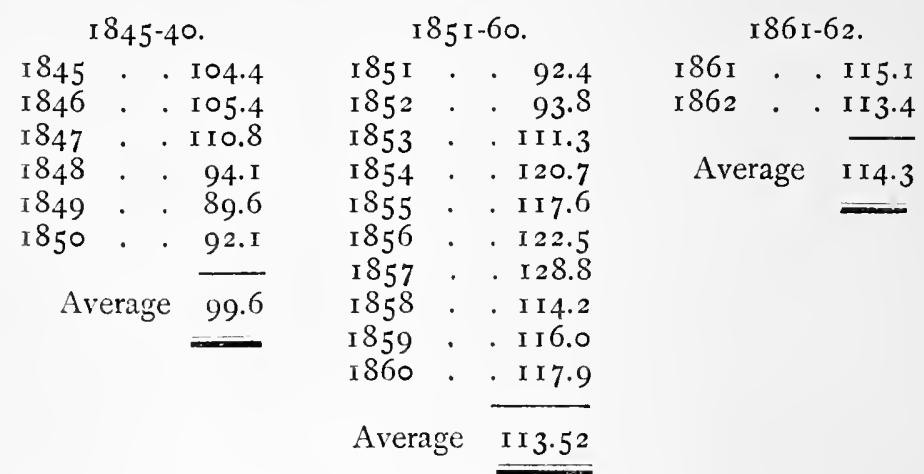

From these, and other figures of a like sort, Mr. Jevons drew the conclusion that the average prices of the first industrial cycle after I 850 were upwards of ro per cent. above the average before 1850 , each portion of the curve in the latter period being higher than the corresponding portion of the curve in the earlier period. Not only this, but the level of price in I 86 I and I 862 , when prices were at a minimum point of the new cycle then beginning, was I 4 per cent. above the average of I 84450. Hence the conclusion that there had been a general rise in prices, or, in other words, a depreciation of gold. 
The history since 1862 is given in the Commercial History of the "Economist," but although the articles referred to are nearly the same," the figures are not the average of each year, but the prices at the beginning of the year only. ${ }^{2}$ They confirm, however, Mr. Jevons's figures previous to $\mathrm{I} 862$, and show a great rise in price immediately afterwards, such as Mr. Jevons predicted. The rise is shown in the table we quote from, by an ind $x$ number, forming the aggregate of the ratios of the articles to the average price of $\mathrm{I} 844-50$; but besides the index number we subjoin the average ratio for all the articles in the form given by Mr. Jevons:

\begin{tabular}{|c|c|c|c|c|c|}
\hline & $\begin{array}{c}\text { Total } \\
\text { Index No. }\end{array}$ & $\begin{array}{c}\text { Average } \\
\text { Ratio to l'rices } \\
\text { of I } 844-50 .\end{array}$ & & & $\begin{array}{c}\text { Average } \\
\text { Ratio } \\
\text { of Periods. }\end{array}$ \\
\hline I $845-50$ & . 2200 & . 100 & . & . & 100 \\
\hline $185 \mathrm{I}-\mathrm{Jan} . \mathrm{I}$ & 2293 & $104.2)$ & & & \\
\hline I 853-July I & $236 I$ & 107.3 & & & I I $4.2^{3}$ \\
\hline $1857-"$ & . $\quad 2996$ & 136.2 & • & • & \\
\hline 1858 -Jan. I & . $26 \times 2$ & I I 8.7 & & & \\
\hline I86I- , , & . $\quad 2727$ & I 24.0 & & & \\
\hline $1862-$ & . $\quad 2878$ & 121.7 & & & \\
\hline $1863-$ & $349^{2}$ & I 58.7 & & & \\
\hline $1864-$ & 3787 & I 72.1 & & & \\
\hline $1865-$ & 3575 & 162.5 & & & \\
\hline $1866-$ & - 3564 & 162.0 & & & 140.1 \\
\hline $1867-$ & . 3024 & 137.4 & $\cdot$ & & 140.1 \\
\hline $1868-$ & 2682 & I 21.9 & & & \\
\hline $1869-$ & 2666 & I 2 I. I & & & \\
\hline $1870-$ & 2689 & I 22.2 & & & \\
\hline I87I- & 2590 & I 17.7 & & & \\
\hline ", & 2835 & 128.9 & & & \\
\hline
\end{tabular}

1 Viz.: Coffee, sugar, tea, tobacco, wheat, butcher's meat, cotton, raw silk, flax and hemp, sheep's wool, indigo, oils, timber, tallow, leather, copper, iron, lead, tin, cotton-wool; Pernambuco onlycotton-yarn, cotton-cloth.

${ }^{2}$ For the purpose of an inquiry like this, a set of prices at a given date in each year is practically almost as good as the average of the year. The object is to compare the average of one period of jears with that of another period, and it is most improbable that in each year prices at the given date would vary materially from the average of the year owing to some abnormal cause.

${ }^{3}$ This figure is the average of the whole period deduced from $\mathrm{Mr}$. Jevons's statistics. 
Making every allowance for the difference in the data, the fact of a much greater increase of prices between I86I-70 than between I85I-60, as shown by Mr. Jevons, is apparent. We may take it as certain that in the first decade after 1850 , prices generally rose upwards of io per cent. above the average of the preceding period, and that in the second decade there was a further rise, which cannot, however, be deduced from exactly the same data. The second set of figures gives apparently a higher series of ratios all through than the figures compiled on the method of Mr. Jevons, the excess being about Io per cent. Deducting this excess from the above average of 140 per cent. in the decade $1861-70$, we arrive at I 30 as the probable ratio of the wholesale prices of that period to the period before 1850 . According to this, the depreciation of gold had amounted, in two decades, to something like 30 per cent.

So far, therefore, a depreciation of gold is made out, but there are two important objections to the conclusions from the above figures. One relates to the extent of the depreciation which is due to the gold discoveries, and is, therefore, assumed to be more or less permanent. Textile fabrics, and the raw material of them, enter very largely into the table which is given in the Commercial History of the "Economist," the ratios for such articles comprising a third of the ratios included in the index number. But textile fabrics were the subject of a most exceptional rise of price in the years of the American War. Tobacco also rose in price from the same cause in the $1861-70$ decade. The great rise between 1861 and 1870 , therefore, was due largely to an exceptional cause, and the consequent depreciation of gold, on the average, was thus to some extent temporary.

The second objection to the figures is of a more general nature, and suggests an important qualification. The prices dealt with are wholesale prices, and mainly the prices of leading articles of raw material or of pro- 
visions. The prices of manufactured articles are almost wholly excluded, although the number and value of transactions in articles, after they leave the manufacturer's hands and are on their way to the consumer, probably far exceeds the number and value of similar transactions in the raw material. The distribution of a manufacture-say, woollen or silk fabrics-must, from the nature of the business, be a more complicated process than the growth and collection of the raw material for the purposes of manufacture. Omitting the prices of such articles, therefore, the tables omit the most important half of prices which require to be dealt with before a perfectly general rise can be ascertained. We admit, of course, that it would be quite impossible to compare the prices of an immense miscellany of manufactured articles, although a rough comparison can be made of the prices of a few raw materials, but the significance of the necessary omission ought not to be overlooked. As Mr. Jevons remarked in his volume, the whole tendency of industry since the gold discoveries has been towards the diminution of the cost of manufacturing and distribution-a circumstance which itself has increased the demand for the raw material. In omitting, therefore, the prices of manufactured articles, the effect has probably been to make the general rise of prices, which would argue a depreciation of gold, appear greater than it really has been, or even to exhibit the appearance of a general rise when no such rise had in fact occurred. That this is no mere quibble is shown very forcibly by some figures in the tables themselves. The Commercial History of the "Economist" happens to contain columns for the prices of cotton-cloth as well as for raw cotton, and the smaller rise of price in the manufacture compared with the rise of the raw material is very curious. We give the entire ratios: 


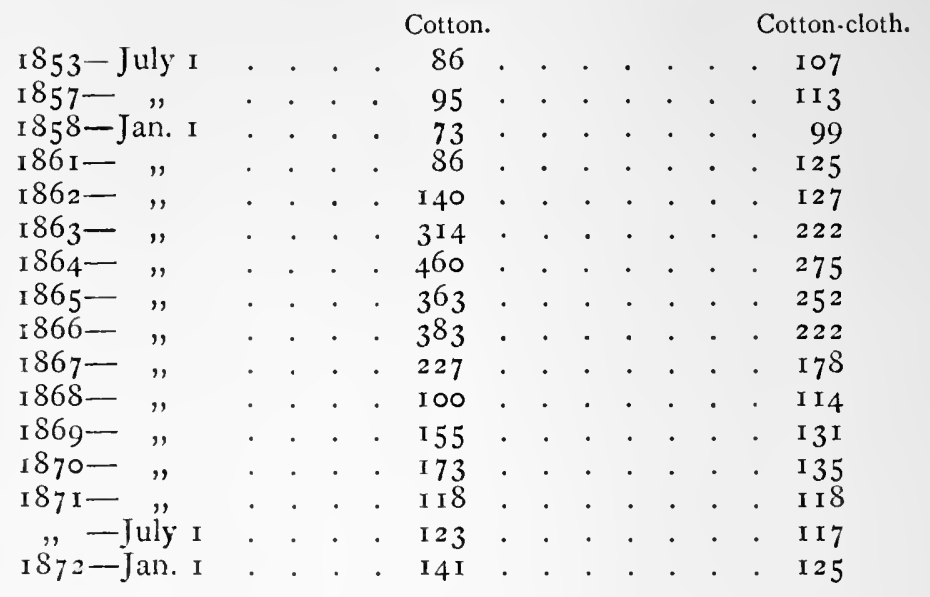

In some years, it will be observed, the rise in the raw material is indeed enormous, compared with the rise in the manufacture, and the difference goes to show that a table dealing mainly with raw materials would err on the side of showing a greater general rise than what had really occurred.

Another objection to the completeness of tables dealing with principal commodities only, and one indicating an error of the same sort, viz., an excess in the estimated rise of price, is supplied by Mr. Jevons's statements respecting " minor articles." To supplement his conclusions he made a table comprising, in addition to the 39 chief articles dealt with in his principal table, 79 minor articles, and worked out the rise of price in 1860-62 over the average of I 844-50. The result was that the 79 minor articles showed a much smaller per-centage of increase than the 39 chief articles. Mr. Jerons states:

"Doing this separately for the 39 chief and the 79 minor articles, I find that the prices of the former have, on an average, risen between $1845-50$ and $x 860-2$ in the ratio of 100 to 116.2 , which is equivalent to a depreciation of gold in the ratio of 100 to 86.0 , or by 14.0 per cent. 'The minor commodities, however, give a somewhat different result. In taking the mean, I have treated those which are bracketed together in the last column as having the importance only of a single 
commodity, so that only the mean of the ratios bracketed entered into the general average. We thus find there are 64 independent minor articles, of which the prices have, on the averages, risen between $1845-50$ and $1860-2$ in the ratio 100 to 106.76 , which would indicate a depreciation of gold in the ratio of 100 to 93.66 , or by 6.34 per cent., not half the change shown by the chief commodities."

The conclusion would therefore be, that the more miscellaneous the comparison can be made the smaller would be the general rise shown. Coupling this with the omission of manufactured articles, we obtain sufficient grounds for thinking that the general rise of price exhibited in the above figures is the maximum and not the minimum average. Taking into account such changes in price as have been caused by the invention of the Bessemer process for making steel, we should be inclined to doubt whether it could be proved that the general purchasing power of the sovereign has much diminished since 1850 . A table of the articles in which its power was likely most to be felt shows an average depreciation of about 30 per cent., but the real general depreciation, if any, must have been very much less.

It will have been noticed, perhaps, that we do not take into account at all the extraordinary rise of prices this year. That rise has been most sudden, and has undoubtedly raised almost every price except those of cotton and wool temporarily above the level of i $86 \mathrm{I}-70$. But we have yet to see, when this is absorbed in a group of years, what the average rise will prove to be. So far as can be judged, the present decade will not show any rise above the average level of i 86 I-70. It was a great point with $\mathrm{Mr}$. Jevons, when he wrote in I 863, that the level of price then established, at the minimum point of an industrial cycle, was considerably above the level at the corresponding point in $185 \mathrm{I}$. But it is evident from the above figures that prices in I 868-7 1 , when they were again at a minimum point, had fallen back to the level of $\mathrm{I} 86 \mathrm{I}-2$. The probability is then that the curve will not rise higher, and we may 
assume that there has been no further depreciation of gold since $\mathrm{I} 862 .^{1}$

\section{II.}

We have now to deal with the second test which we proposed to apply in considering the question of a depreciation of gold since 1848 . The direct test of prices, as we pointed out, is in various ways defective. Even after making the best comparison possible between two industrial cycles, the question will remain whether the groups of articles selected for comparison in respect of prices are fairly representative of the whole stock of commodities. In point of fact, as we have since shown, there is reason to believe that the group of articles selected for comparison being mainly wholesale articles was likely to cause error on the side of showing an excessive rise of price, although the selection was as impartial as possible. At the same time it would be difficult, if not impossible, to compare anything but the prices of wholesale articles, retail cornmodities being too various and changing to permit of any such comparison. The object of our second test, then, is to supplement and correct the first. It may be assumed, we say, that other things being equal - that is, no change occurring in the conditions which make coin be used-the circulation of coin in a country will vary in exact proportion to the growth of population and industry. If the population has grown in a certain proportion without being, man for man, more

1 This was the conclusion in $\delta_{72}$. Since that date the index numbers in the Commercial History of the "Economist," on the Ist of January in each year, have been:

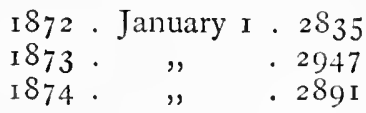

$$
\begin{array}{ccc}
\text { I } 875 . \text { January I } & 2778 \\
\text { I } 876 . & , & .27 \text { I } \\
\text { IS77. }, & .27 \text { I }
\end{array}
$$

When these are compared with the table on p. 79, the conclusion in the text is fully confirmed for the period subsequent to I 872 . 
industrious, the coinage remaining of the same value would increase in exactly that proportion. If the population had also become more industrious, so that, man for man, transactions and payments were increased, then, besides the increase of coinage in proportion to the population, there would be an increase in proportion to the accelerated activity of business, and hence too it would follow-this being the most important inf rence for our present purpose-that if the coinage depreciated in value it would increase in nominal amount in greater proportion than the increase of population and industry combined. The excess of such increase would be a measure of the depreciation which had occurred, and would corroborate or correct the inferences drawn directly from the rise of prices, which, for the reasons above given, must necessarily be incomplete.

The most important-perhaps the only importantcountry for which a comparison need be made is England. As the most developed country commercially at the time of the gold discoveries, English prices are more likely than almost any other to show the effect of a general depreciation of the measure of value. Is it possible, however, to make any real comparison of the growth of population, industry, and currency in England? The common notion is that it is not possible, the gradual perfection of the Clearing House arrangements having, it is supposed, economized currency in the interval since i 850 . But a little consideration, we think, will show that there are really some data to go upon. In England there are in fact two standard currencies-the sovereigns, which are in the pockets of the people and are used as small change, and the Bank of England notes, which are used for large payments. The economy of the Clearing House arrangements, it is conceived, applies only to the latter currency. So far as the use of sovereigns is concerned, the necessities and habits of the people are unchanged. Deposit banking was quite as much developed in I 850 , in proportion 
to the population, as it is now. What the Clearing House has accomplished is not anything which applies to the mass of the people in their use of sovereigns, but only something which applies to the arrangements among bankers themselves in which notes only are used. We may assume, then, that every increase of population and business since i 850 must have involved a proportionate expansion of the sovereign circulation, and that it is only an expansion beyond that proportion which can be considered as indicating a depreciation of gold.

What we have to compare, then, is the increase of population and industry in England since I 850 with the increase of the sovereign circulation. The increase of population is easily ascertained. As we showed in an article on the coinage, ${ }^{1}$ the population of the United Kingdom increased between 1848 and 187 I from $28,000,000$ to $32,000,000$, or 14.3 per cent. In such a comparison, however, we ought to look at the narrower England. Scotland and Ireland do not use a gold currency, and the increase of the circulation of sovereigns in the United Kingdom is, therefore, practically an increase of the circulation in England proper. And the increase of population in England and Wales since I 850 has been very much greater than the average increase in the United Kingdom.

In 187 I the population was. In 185 I it was

$22,704,000$

Increase in 20 years

I $7,927,000$

$4,777,000$

-which is at the rate of 26.6 per cent., or about 1.3 per cent. per annum.

Such has been the increase of population, and the increase of industry has been in much greater proportion. The annual income assessed to the income-tax increased in England between I 848 and I 868 as follows:

See "Economist," June 29, 1872. 
Amount in 1868

$\mathcal{E}_{365,366,000}$

Amount in 1848

$229,868,000$

Increase in 20 years.

EI $35,498,000$

-which is at the rate of about 60 per cent., or 3 per cent. per annum. And this is probably the minimum increase of business. As we showed in the article above referred to, our staple industries have increased enormously. The production of coal, between 1856 and I 869 only, rose 60 per cent., and of iron 53 per cent., while the development of the export trade, as respects the quantities of all our manufactures, was truly prodigious. We are within the mark, then, in assuming as the basis of comparison with the increase in the coinage, that population since 1850 has increased at the rate of I.3 per cent. per annum, and industry and wealth at the rate of about 3 percent. per annum. The population is one-fourth more numerous than before i 850 , and, man for man, their industry is nearly twice as productive as it was then. For these reasons their small change should have greatly increased, even without a depreciation of value; and if there has been depreciation, the increase should have been enormous.

But what has the increase been? Here we are best by new difficulties. The amount of the circulation at any given time can only be approximately stated. It is conceived, however, that if a minimum amount at an early date can be compared with a maximum amount at a later date, the full expansion of the circulation will be more than accounted for, the proportion of increase being made to appear greater than it really has been. This will be a safe figure to compare with the increase of population and industry, so far at least that any inference of a depreciation of gold will be quite as strongly, if not more strongly, supported than the facts would fairly warrant.

The gross addition to the circulation since 1850 has been about $£ 50,000,000$. As we showed in our article 
of August 3 Ist, the addition to the coinage since 1857 , deducting light coin withdrawn, and the exports of

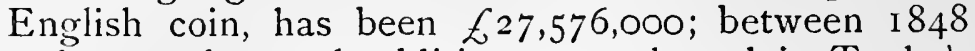
and 1857 the total addition, as reckoned in Tooke's "History of Prices," was $£ 22,000,000$ - the two sums making together almost exactly $£ 50,000,000$. But this is undoubtedly far in excess of the real addition. Mr. Jevons, in 1868 , in his Paper on the Gold Coinage read before the Statistical Society, pointed out that there was an excess in the statement of the gold coinage upon a mere computation of the addition in the above manner, amounting to about $£ \mathrm{I} 4,000,000$. And he gave other reasons for believing that there was a much larger melting of coined money than was commonly supposed. Deducting a million more for sovereigns melted since i 868, we arrive at the sum of $£$ i $5,000,000$ as a moderate deduction from the above addition of $£ 50,000,000$ to the coinage since 1848 , the real maximum addition to the minimum coinage before 1850 , whatever we may take it to be, being thus only $£ 35,000,000$.

Now the coinage before i 850 could hardly be less

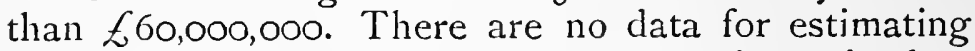
the amount exactly, but the figure may be arrived at indirectly. Mr. Newmarch, for instance, estimated that the gold coinage in circulation in I 844 was $£ 46,000,000$, and allowing only $£ 2,000,000$ for subsequent additions. which has been the average for many years, this would bring the total in I 850 to the sum named. The actual new coinage in the interval was $£ 27,000,000$. Another mode of verification yields the same conclusion. Mr. Jevons, in I 868 , ascertained that there were 44,000 sovereigns coined before i 850 out of every 100,000 then in circulation. This figure being then $£ 80,000,000$, the conclusion is that in I 868 there were still $£ 35$,000,000 of the coinage before 1850 in circulation. But meanwhile there had been withdrawn in light coin at least $f_{1} 0,000,000$, and there would also be some withdrawals for export, besides losses through melting, wear and tear, 
and the like which would easily sum up to $£_{1} 5,000,000$, the difference to be accounted for. There is a high probability, therefore, that the coinage at i 850 could not be much under $\mathcal{E}^{60}, 000,000$, if at all under that amount.

The increase in the coinage has therefore been:

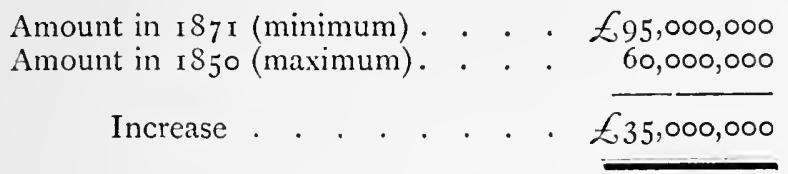

-which is at the rate of 58.3 per cent., or rather less than 3 per cent. per annum. Comparing this with the increase of population alone, which was 25 per cent. in 20 years, it would appear that there is an excess of 33 per cent. in the expansion of the circulation, which, according to this mode of verification, would be the limit of the depreciation of gold. As compared, however, with the increase of wealth and industry, there is no excess, the production of the staple raw materials of manufacture, coal and iron, having been at as great a rate between i 856 and 1869 alone, while the development of our export trade has been truly prodigious. We may safely say, then, that if there has been a great depreciation of gold since 1848 - that is to say, anything over 10 or 15 per cent.- there has been no such expansion of the small change circulation as we should have expected to follow that depreciation. As a corroboration of the direct evidence from prices formerly given, to the effect that the rise of prices has been little more than Io per cent., if any, the facts now brought out are clearly worth something, although it would be foolish to dogmatize on such points. The data are imperfect, but so far as they go they clearly point to a very limited depreciation of gold as the past consequence of the gold discoveries.

The question will arise on these facts whether the economists were right or wrong who predicted manifold economic changes as the result of the depreciation of 
gold following on the gold discoveries. The conclusion must be, we think, that so far as the facts have yet gone, the speculation indulged in was exaggerated. A depreciation of Io or I 5 per cent. in the measure of value spread over a quarter of a century is hardly of a kind to produce any social disruption. At the worst it is a Io per cent. income tax, and though a ro per cent. income tax would be all but intolerable when levied directly, experience has fully shown that a much heavier per-centage can be levied on communities indirectly without the victims being individually conscious of the process. This would be the modifying consideration in regard to fixed incomes, and, of course, as regards the other transactions of life, the change would be quite imperceptible. The fluctuations of prices in commerce are so large, that this gradual change diffused over a lengthened period would be wholly imperceptible, and would in no way alter the basis of contracts, or the effect of the continual adjustments of wages. In justice to the economists, however, it should be remembered -and the point is also important as a corrective of the popular ideas - that the condition of the expected depreciation has not been fulfilled. M. Chevalier's estimate of the probable annual production of gold was $£ 35,000,000$, and he thought it might be $£_{42}, 000,000$; Mr. MacCulloch's estimate was $£ 39,000,000$. As we have seen, however, the annual production has for many years been only about $£ 20$,000,000 per annum, which is very little in excess of $\mathrm{M}$. Chevalier's estimate of the total annual consumption, viz., $£ \mathrm{I} 7,850$,000. The material fact of production having thus differed so materially from the hypothesis on which the theory of a great depreciation, amounting to 50 per cent., was built, it is not surprising at all that the economists were out in their estimate of the depreciation. But there could be no better illustration of the error of the popular habit of assuming, with little proof, a permanent rise of prices, and then assigning the gold discoveries as the cause, with the assured conviction that 
this is all done in accordance with economic authority. The calculations which have helped the growth of this popular conviction were not positive but hypothetical, and the subsequent facts having contradicted the hypothesis, the calculations fall to the ground.

\section{III.}

The last question to be discussed in connection with the gold statistics we have lately collected, is the probable course of the future movement and its effect on prices. The past effect, as we have seen, is of a moderate description, not exceeding about to per cent. in the central wholesale markets of the world, where the effect of any change in the value of gold is most easily distinguished from other causes in the fluctuations of prices. It is urged, however, on one side that the causes of the depreciation of gold are only beginning to operate, that future supplies coming upon an overstocked market will have an immense influence; and on the other side that there are rather signs of a falling off in production, and that, considering the growing demands of the world, an appreciation of the standard is more likely than any further decline in value. What light is thrown on these opposing views by the facts which we have been investigating?

At the outset, we may say we have no intention of making any distinct prophecy. What the actual demand of the future will be, and what will be the actual supply, and in what way any tendency to fluctuations in value will be corrected by a check to production on one side or a diminished demand on the other, are all questions on which there are perhaps no sufficient data in existence for a sure opinion. The experience of the past twenty years should moreover counsel the utmost modesty of prediction. No one in I 850 would have predicted that of the immense new supply of gold then coming into the world one-fifth would be absorbed by India and the East, and nearly two-fifths more by at 
single European country-viz., France, which would practically substitute a gold currency for a silver one. No one would have predicted, moreover, that the United States would substitute paper for gold. Yet all these facts were more or less essential in 1850 in calculating the ratio of the demand to the then future supply of gold. Any prediction of the future is equally liable to be upset by unexpected incidents. All we shall do, therefore, is to point out the relation of the current supply to the current demand, and on what side the probable great changes that will affect the value of gold are likely to be.

According to the figures which we published in our general article on "The Production and Movement of Gold since I 848 ," " the current supply may be taken as $£ 20,000,000$. There may be some production besides in outlying countries, but this figure of $£ 20,000,000$ represents the amount which comes into the general bullion movement of the world. And this annual amount has also been a tolerably steady one for more than ten years. In the five years between 1852 and 1856 the annual production was as high as $£ 29,000,000$, and in the following five years the average was still as high as $\delta_{25}, 000,000$, but since i 862 the average has been $\mathcal{L}_{20,000,000 \text {, with } \delta 22,000,000}$ on one side and $£$ I $9,000,000$ on the other as the extremes of variation. The condition of production may, of course, change very quickly, but so steady a supply for a long period seems to argue that the industry is being carried on under stable conditions, and that about $£ 20,000,000$ may be relied on while the demand continues what it is.

The question of the current demand is a more intricate one. The whole history of the market in past times shows the powerful influence of extraordinary demands. But for the demand for India, and the demand for France, there would not have been sufficient 
outlets for all the new supplies of gold, aggravated as they were by the substitution of paper for gold in the United States. At the present moment, besides, the course of the market is likely to be governed as much as ever by extraordinary changes in the demand. Germany and Scandinavia are substituting a gold for a silver coinage on the one side, and France is substituting paper for gold, though its policy may change at any moment. The Indian demand, which was formerly so great. has also of late years fallen off, though $\because$ would be rash to assume that under no circumstances will it again revive. ${ }^{1}$ But omitting the question of these great movements for a little, there appears to be an ascertainable current demand of no small magnitude. (I.) England absorbs on the average about $£_{5}, 000,000$ a-year-about $£ 2,000,000$ for coinage, and the remainder for the arts and other purposes. (2.) There is a demand of about $£, 1,000,000$ per annum for South America. Our exports to Brazil and other South American States in the ten years ending 187 I were almost exactly $£ \mathrm{I} 0,000,000,{ }^{2}$ and this demand being for English sovereigns is apparently a steady demand. (3.) The annual consumption of Spain, Portugal, etc., appears to be about $f 800,000 .^{3}$ (4.) The annual absorption by India, though not so great as it was in I862-66, appears still to exceed $\mathscr{L}_{4}, 000,000$. In the five years ending 187 I the amount absorbed was $£ 21,458$, ooo, or over $\ell_{4}, 000,000$ annually, the extremes of variation being $\mathcal{E}_{2,28}, 000$ on the one side, and $\mathcal{E}_{5,592,000}$ on the other. Even before I 850 , it must be remembered, India was an absorbent of gold to the extent of about a million and a half annually, and it is not surprising that its great growth during the last twenty years should enable it to increase its demands. (5.) There is a steady Australian demand of uncertain amount; but probably nearly equal to the annual minimum

It has since revived to some extent.

"See Table XI, "Economist," p. 957, Vol Xxx. ${ }^{3}$ Ibid.

4 "Economist," Vol. XXX., p. 1430, Table II. 
coinage of the Sydney mint, or about $f \mathrm{r}, 200,000 \mathrm{a}-$ year. All these demands are comparatively stable, and have practically existed for ten years without any traceable permanent change in the level of prices, no further rise or fall, as we have seen, having occurred since 1862. They sum up as follows:

(г.) English consumption

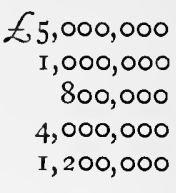

(2.) South American ditto

(3.) Portugal, Spain, etc., ditto.

(4.) Indian ditto

(5.) Australian ditto

Total current annual consumption $\overline{\mathcal{E}_{\mathrm{I} 2,000,000}}$

The figure is perhaps not quite complete, as there are no doubt many other miscellaneous demands not easily traceable; but increase such demands as we may, the conclusion is plain that a current annual demand of $\ell_{\text {I } 2,000,000}$ or thereabouts, would not take up a production of $£ 20,000,000$. If there were nothing else to be considered, the probability as regards gold movements of the next few years would be the accumulation of gold upon the commercial markets of the world, and a somewhat rapid inflation of prices, accompanied by a real and permanent change in the standard of value.

As we have seen, however, the extraordinary demands are most important in this question, and we have now to ask how far the annual excess of $£ 8,000,000$ in the current supply over the current demand will meet the extraordinary demands which seem in prospect. On this point we shall be inclined to say that there will not be enough for these extraordinary. demands without a great increase of production during the next few years. The first known demand is very" urgent and of great magnitude, viz., the demand for Germany. The Germans have decided to have a gold currency, and in round numbers this means that within the next few years Germany must obtain between 
$£ 60,000,000$ and $£ 80,000,000$ of gold. Germany is very much in the economical condition of France, and is now a good deal more populous, but France in twenty years took up about $£ 200,000,000$ of gold. To assume that Germany will use up half the amount in half the time is no extravagant supposition, especially as the German Government to begin with has extraordinary means at command, and being richer now than France was in 1850 , will require more at once than France then required. Last year, in fact, Germany, it is now known, coined about $£ 2 \mathrm{I}, 000,000$, and she proposes to coin $£ \mathrm{I} 8,000,000$ in the current year; and the scale of coinage is not above her needs, and will probably remain high for the next two or three years. In this single extraordinary demand, therefore, there is far more than enough to absorb the excess of current production over the ordinary current demand which we have above described. In addition, the known demands for the Scandinavian countries will absorb a good deal, though it is hardly worth reckoning them when so overwhelming a demand as that for Germany is impending.

The next great point as regards the future is the possibility of a resumption of specie payments by the two great "paper" countries-France and the United States--whose standard previous to inconvertible paper was practically gold. This resumption of specie payments will not cause so serious a demand as that for Germany, because gold in both instances has undoubtedly been hoarded, and will come out of its hidingplaces as soon as it is once more legal tender. But the United States at least has grown immensely since I 868, when inconvertible paper was introduced, and the presumption is, that the old hoards would not be sufficient for the new work they would have to do. To resume specie payments the United States must begin by a considerable coinage, and some additional coinage will probably also be required for a similar purpose in France. Here, then, we have the elements 
of another extraordinary demand besides that for Germany during the next few years; and we do not think the contingency should be disregarded. The inappreciable premium on gold in France is itself an indication that the evil of inconvertible paper is being kept within bounds, and always keeps the probability of a resumption of specie payments within sight. And the financial and political authorities of France will both be equally desirous that specie payments should be resumed at the earliest possible moment. In the United States, again, there is a growing opinion in favour of specie payments, and though the gold premium there is a serious matter, as it is not in France, the United States has ever shown a boldness and thoroughness in expedients which is foreign to the usages of the old world, and the fact of a high premium on gold is, therefore, a less barrier to the resumption of specie payments in the United States than it would be anywhere else. If the public mind in America is once made up to have specie payments, a somewhat revolutionary and decided action is quite as likely as not.

Our conclusion, therefore, is that the better probability of the next few years is an excessive demand for gold compared with the current supply. We have a regular annual demand for $£$ i 2,000,000 or upwards, leaving an excess of $£ \&, 000,000$ for any extraordinary demands; but one known demand of this sort seems likely to take far more than this excess for several years to come, and there are heavy contingent demands which it is needful to keep in mind. What the result will be it would be needless to speculate. Compensation will, perhaps, be found in a greater economy of existing stocks and a reduction of current demands, as well as in a pressure to produce more, which may have some result. But if the extraordinary demands continue, and if little can be made of the last expedients suggested, we should rather expect within the next decade that gold will rise in value, instead of continuing the fall which was arrested in 1862-in other words, that 
the general range of prices is rather more likely to fall during the next ten years than it is to rise. We must again repeat, however, that the point is one on which we have no pretension to dogmatize.-[December, I 872.$]$ 
THE LIQUIDATIONS OF $1873-76$.

WHAT are the characteristic marks of the great depression of trade during the last three or four years? It is now ascertained that such depressions are periodical. They recur at tolerably regular intervals, following in the wake of equally regular periods of great prosperity in trade, when everybody makes profits or seems to make them. The alternation has no doubt its roots in human nature, which lends itself to an ebb and flow, an action and reaction, in affairs. The depressions, like the periods of prosperity coming before them, have also many features in common. Just as the prosperity is shown by the prevalence of good credit, an active money market, and a high range of prices for both securities and commodities, so the depression is marked by a low range of prices, heavy failures, bad credit, and consequently a sluggish money market. But each depression has likewise its own special features and incidents. The crisis in which it begins, or which it produces, indicates some special development of trade at the time, or some special disease in it-the favourite business of a country changing from time to time, and a constant tendency existing to go to an extreme with the momentary fashion. We propose, then, to inquire what are these special features in the recent depression; this proceeding being likely, it is obvious, to be more instructive than a mere examination and record of those features which most depressions have in common. There is an additional reason for this course. An impression prevails that the present stagnation of trade $9^{8}$ 
is unprecedented in intensity and duration, and that it is likely to be permanent. A similar impression has often been found to prevail at such times, and it will be interesting to inquire whether it is now, for once, well founded, or whether in reality the depression is not much less than those to which trade has often been subject, and is not as likely as any other to terminate in a new period of prosperity.

\section{I.}

Endeavouring to answer the question we have put, what we are first struck with, in a general survey of the last three or four years, is the universality of the depression. Almost every civilized country has been affected. The beginning was in 1873 , with the great $V$ ienna panic and crash in May of that year-a crash which was accompanied by immense agitation throughout Germany and in England, and the occurrence of incidents on almost every European Bourse which only stopped short of panic. Next came a great panic and crash in the autumn of 1873 in the United States, perhaps the greatest event of the kind to which that country, though it has had many great panics, has ever been subject. This was accompanied by a renewal of agitation in England, as well as generally on the Continent, as the rates of discount in November, 1873 . significantly prove. At that date the minimum bank rate of discount was in London no less than nine per cent., the maximum being two and three per cent. higher; the minimum in Paris and Brussels was seven per cent.; in Berlin and Frankfort, five per cent.; Vienna, five per cent.; and Amsterdam six and a half per cent. The following year was comparatively quiet, but it was marked by great monetary disturbances in South America, and by a great fall in prices both at home, on the Continent, and in the United States. In 1875 came renewed disturbances in South America, a renewal of agitation in the United States and Germany, 
and then the Im Thurn, Aberdare, Collie, Sanderson, and other failures, constituting the commercial crisis of that year in England. This was in turn succeeded by a great collapse in foreign loans, which had been heralded and partly rehearsed in 1873 , on the occasion of the bankruptcy of Spain, and of which the conspicuous incident now was the non-payment of the Turkish debt interest. To all these events succeeded renewed depression and stagnation in trade at home, as well as on the Continent, the crisis in Russia in 1876 being very marked, and the whole continuing till it seemed to have a fresh cause in the apprehension and actual outbreak of the present war. Thus the depression has been widespread and general, Italy, Spain, and France perhaps escaping with little hurt, but Austria, Germany, Russia, the United States, and the South American countries having all been in deep distress.

This universality, on a comparison with former periods of crisis, may be in fact apparent only, arising from the greatly increased facilities of observation at the present day. There never was a time, probably, since commerce was sufficiently advanced in more countries than one to admit of crises, in which the commercial misfortunes of one country did not react on countries with which it did business. At such periods as $1825,1837-39,1857-58,1861-62$, and $1866-68$, it is undoubtedly the case that the crisis in England has been accompanied by more or less severe crises elsewhere-France, America, England, Holland, and the German towns on the Elbe, having shared each other's fortunes more or less during the whole period. Now the crisis is felt to be more extended, because we are immediately informed of the events in most distant places, because we see at once the association of failures at centres remote from each other, because we also see at once the effect in one place of the call upon it to render assistance at another disturbed centre of business. But it is also true that commercial relations are themselves far more extended than was the case before 
railways and telegraphs; that there are wide regionsin the United States, for instance-which could not have been the subject of crisis twenty or thirty years ago, because they were unpeopled; that such countries as Austria and Russia have lately shared more largely than before in industrial development; and that Germany has also advanced farther in the path which makes it possible for it to be the subject of a commercial crisis. There is consequently a real reason for the greater extension of the commercial depression of the last three years as compared with anything before witnessed, while it is equally true that steam and telegraphs, by facilitating communication, have destroyed the natural barriers between the different communities of the commercial world. The London money market appears to be the great equalizer of markets, because it receives the shock of every important business event throughout the world, and transmits the shock of what it feels to every other centre. But whatever the nature of the connection, it is certain that there is a connection between commercial crises in different parts of the world, and that the wider range of business increases the possible area of disaster when once disaster has set in.

\section{II.}

The next important characteristic of the depression, and, perhaps, the most important characteristic of all, appears to be that the conspicuous industry which has failed is that of the "exploitation" of new countries with little surplus capital, and whose business is mainly that of producing raw materials and food for export, by old countries which have large surplus capital, and are largely engaged in manufacturing; in other words, the investment in new countries by the capitalists of old countries. Much bad business is brought to light in every depression; but it is the peculiarity of the commercial cycle, as we have noticed, that there is a change from time to time in the favourite business, so 
that every period has its special trade development, and special trade disease. The favourite business for many years before 1873 had become that of foreign investment, and now the depression occurs where there was the greatest expansion. Direct evidence in such matters is difficult: it would hardly be possible to measure precisely the extent of the various descriptions of disaster which combine to make a crisis; but there are many facts and circumstances which can leave little doubt in the mind that the direct evidence, if it could be obtained, would wholly confirm the conclusion stated.

The order of events in the crisis affords of itself a very striking confirmation of the assumption. The difficulties commenced in the countries more or less farmed by the capital of England and other old coun tries; whose industries are nourished by public loans from England, and by the investment of private English capitalists within their territories, principally in the form of English iron and manufactures. The crisis in Austria, which was the first in the whole series, was a crisis in a country answering this description to some extent. To the United States, where the next great crash occurred, the description is still more applicable. The South American countries, whose prolonged suffering was the special feature of 1874 , are almost a domain of England; and Russia, too, is largely "developed " by English capital. Some of these countries, especially Austria and Russia, have not been exclusively dependent on English capital. They have also benefited by the accumulation of capital in Holland, Belgium, and France, which had been drawn largely to Germany before 1873 , through the French indemnity, and had overflowed thence into Austria and Russia; but the indemnity payments, though they helped to precipitate and aggravate the crisis in Austria, did not alter the power of that crisis to react on England. No doubt, in 1873 , as already noticed, the collapse of the foreign loan financing had been foreshadowed; but the anticipatory events of that year were in themselves 
comparatively unimportant, so that down to I 875 what chiefly happened was a succession of monetary and commercial crises in countries dependent on England, but from which England by comparison escaped. In I 875 these crises were succeeded by a crisis in England itself of very great intensity, naturally leading to a renewal of crises and distress elsewhere, though not of actual panic, and the whole culminating in the financial disorders of the foreign loan collapses, which will probably form, in after years, the most conspicuous feature of the whole series of liquidations. There appears to have been a natural order, therefore, in the successive crises to which the countries dependent on England have been subjected, leading to a crisis in England itself, and finally to a financial as well as a commercial collapse.

We have next to adduce in evidence the fact of the great expansion of the business of investment in foreign countries previous to the depression. The great multiplication of foreign loans in the period is now familiar. Not to speak of $\mathrm{T}$ urkish and other loans, which were so largely mere borrowings to pay interest, there was a loan of $£_{32,000,000}$ for Egypt, after there had been large loans in 1868 and 1870 ; Chili in the same time (1867-73) borrowed $£ 5,250,000$; Peru, $f_{24,000,000 ;}$ Brazil, $\mathscr{L}_{10,000,000 ;}$ Russia, $£ 77,000,000$; and Hun-

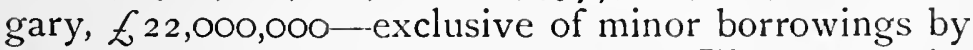
guaranteed companies and otherwise. These were the nominal amounts of the loans, and the real money or money's worth ever transmitted to those countries in respect of them must have been much less; but, making all deductions, they indicate an immense direct credit opened up in this country in favour of the States named. The minor borrowings we have referred to were equally important, if not more important, and, especially in the case of the United States, the aggregate of small loans for railways and other purposes was immense. All this direct borrowing likewise implied a great investment of capital privately in foreign countries. Merchants and 
traders were induced to set up establishments abroad to facilitate the business which the loans brought into existence, and accommodate the wants of emigrants to the new fields of industry. The result was a luxuriant industrial growth in the new countries by means of this vast direct and indirect credit which old countries were giving. Thus in the United States, immediately before I 873 , the length of the whole railway system had been doubled in seven years; in Russia almost the entire system of I 2,000 miles has been created since 1868 ; in Austria there had been an increase from 2,200 in 1865 , to over 6,000 miles in I873; and in South America, Brazil, the River Plate Republics, Chili, and Peru, had all been endowed with railways in a very few yearsthe loans for these countries above enumerated, and especially the above loan of $£ 24,000,000$ for Peru, being avowedly all for railways. And never was there a more rapid development of the foreign trade of the United Kingdom. The total import and export trade, which was $£ 500,986,000$ in i 867 , had risen in 1873 , or in six years only, to $£ 682,292,000$, or 36 per cent.; and the trade per head from $£ 16$ is. $3 d$. to $£ 2$ I $4 s .9 d$., or 32 per cent. The exports of British produce alone, to take the two extreme years, had risen from $£$ I 79,678 ,000 in 1868 to $£ 256,257,000$ in 1872 , or 42 per cent. in four years, the increase per head being in the same period from $£ 5$ i $7 s .4 d$. to $£ 8$ is $s$, or 37 per cent. All this had followed a rapid rise in previous years; for the panic of 1866 was chiefly the collapse of a home company mania, and had not brought with it discredit of foreign loans, or a collapse of the business of lending to foreign countries. And in one or two trades the increase of business was even greater than the general increase. Thus the quantity of our iron and steel exports rose from $2,042,000$ tons in 1868 to $3,383,000$ tons in 1872 , or 66 per cent. in four years; while there was simultaneously a rise of price which made the increase in values immense, not only in these, but in other articles where there was no such increase of quantity. 
It is sometimes said that the burst of trade which culminated in $1872-3$ was largely due to the extra demand for our manufactures created by the Franco-German War. This war checked manufacturing on the Continent for nearly a twelvemonth, besides causing a war demand for certain of our manufactures. But the comparison we have made is of a year when the war was long over, with a year quite before the war, while the most conspicuous instance of increase in our exports was in iron and steel, which was clearly in connection with increased railway construction abroad. The expansion of our foreign trade was thus manifestly in connection with the general expansion of our foreign investment business, and not the result of the accidental or temporary causes which have been assigned.

That there has been a most disproportionate stoppage of the foreign investment business, which would go far to account for the present depression, is also very obvious. I do not refer so much to the notorious stoppage of the issues of foreign loans, small and great: after every great crisis new issues of almost every kind come to a standstill, as frequent experience has shown. It was so after $\mathbf{1} 866$, and has been so after similar years of crisis, although I doubt if foreign issues, as distinguished from home enterprises, have ever been so completely stopped as they are now. Quite apart from this, we have unmistakable evidence of the decline in foreign investment business in the financial and industrial embarrassments in new countries, of which, as I write, the great railway strikes in the United States furnish a new illustration. There has also been a diminution of singular magnitude in our export trade. That trade has frequently fallen off in times of general depression, but never to such an extent as has lately been witnessed. The diminution altogether in the exports of home produce and manufactures has been from $£, 256,257,000$ in 1872 to $£ 200,639,000$ in 1876 , the change being partly due as usual, and perhaps rather more than usual, to a fall in 
price, but only partially to that cause. There has not since the free trade period been such a decline in our foreign trade, just as there had been no previous example of so great an expansion. The decline has also been mainly in the exports to such countries as the United States, which had been our great borrowersthe falling off to the United States alone being from $£ 40,737,000$ in 1872 to $f_{1} 16,834,000$ in 1876 , this latter figure being the lowest since i 864 . It has also been mainly in such articles as iron and steel; the exports of which diminished from $3,383,000$ tons and $£ 35,996,000$ in value in 1872 , to $2,224,000$ tons and $£ 20,737,000$ in value in 1876 ; while the exports to the United States alone fell from 975,000 tons in 1872 to only 160,000 tons in 1876 . The recent diminution in our export trade is therefore not only unusual, but it is a diminution of the exports to new countries, and a diminution of those articles which we send abroad for the purpose of new works in such countries. So great a change in one great branch of our business would go far to account for the general depression now prevailing, which is thus once more traced to the failure of our foreign investments.

The embarrassments in the new countries were also connected with the excessive development of their capabilities which had been attempted. A very considerable amount of the railway and other speculation during the last few years, has been proved to have been wholly in anticipation of the wants of the world, the evidence of this being an over-production of raw materials and food, the characteristic products of the new countries. Of this over-production the most significant sign was the low price of wheat in 1875 , notwithstanding the bad harvest of that year in several countries. There had previously been complaint of low prices in the United States-in 1873, for instanceand of inability to "keep back" crops. Similar complaints had also been received from Russia in 1874 . Even in 1876 the price of wheat was slow in rising in 
the autumn, notwithstanding a generally bad harvest, and the extreme war rise the following spring was only maintained a few days. In other words, the assumption as regards wheat that new countries might be settled indefinitely has proved to be erroneous. The result of what appears to be excessive cultivation is an unremunerative price, which leaves merely agricultural communities in distress, and disturbs their whole system of industry. It has been the same with other raw materials, such as cotton, although perhaps not to the same extent. But in general the business of producing raw materials and food had been overdone, and the crises in Austria and the United States in I $_{73}$, followed as they have since been by the similar crises in South America and Russia, were evidence that the power to support the financing of the previous two or three years, which was based on the business of investment in new countries, had ceased.

The uglier features of the collapse of foreign loans also furnish evidence of the characteristic mark of the crisis with which we have been dealing. In addition to the issue of loans, which involved the investment of capital in a fixed form to an extravagant extent, so that immediate loss and ruin could not but ensue, there had taken place in a few years before 1872 frequent issues of loans for foreign countries so called, which were only disguises to plunder the public. We refer to the loans for Honduras, Paraguay, San Domingo, and Costa Rica, which were investigated by the Foreign Loans Committee, and to a numerous class of which these were perhaps the most flagrant specimens. These were simply issues by knots of speculators, usually on the plea that they were for some public work-to which a small portion of the money raised was perhaps, in fact, devoted-but really with the design, as carried out by those concerned, to pay themselves large sums in commissions and otherwise, so long as the public could be got to believe in such things by the payment of interest out of the funds they had themselves ad- 
vanced. All this was very natural. The peculiarity of the time being the development of foreign countries by loans, it was only natural that the illegitimate financing of the time should also consist of so-called loans. As there had been bogus companies in the days of the company mania, so now there were bogus loans.

These are all circumstances tending to show how much the bad business brought to light in the recent depression was connected with the business of investment in new countries, and its accessories, which had previously just received so great an expansion. As we have already remarked, there was much bad business besides. In the set of failures connected with that of Messrs. Collie, what seemed to be shown especially was a peculiar disorder in the trade with India, the result, it is probable, of the undue investment of capital in that trade at a date as far back as the cotton mania in $\mathrm{I}_{86} 3$ and $\mathrm{I} 864$. But the bad business of foreign investment and financing has certainly been far the most prominent.

\section{III.}

A third distinguishing mark of the crisis appears to be the singular lightness of its effects on English industry and wages. As has been hinted already, such is not the common impression regarding it. On the contrary, the depression of trade is spoken of in common speech as something entirely unprecedented both in intensity and duration. But a careful examination must prove that, as far as matters have yet gone, the common impression is wrong, and the facts are entirely the other way:

The common impression appears to be due to a misinterpretation of two undoubted facts : first, the evident magnitude of the financial collapse in foreign loans, which has been productive of great social distress among the classes who have most ample opportunities of proclaiming their grievances; and next, the magni- 
tude of the decline of the foreign trade of the country, which is identified with a decline in its whole trade. But it is easy to see that there is a misinterpretation. The magnitude of the financial collapse is, of course, very serious. The novelty of the deception of the public by bogus loans has increased the evil as compared with the evil of a company mania, while the opportunities of fraud were really more favourable to the conspirators than in the manufacture of bubble companies. A State loan sounds more respectable than a company issue. On the whole, the securities of States for a long period had also answered better than the shares of companies, and although also in former years many State loans had proved the source of loss to English investorsseveral South American States, Greece, Spain, and one or two States of the American Union, having all proved defaulters-yet there had been no flagrant instances of loans which were merely cloaks to let promoters and financiers have commissions. The agents and institutions connected with States also controlled larger resources than had been controlled by the financiers of companies. The inability of investors, therefore, to form a good judgement on the investments submitted to them, their disposition to rely on market price, and other extraneous or irrelevant circumstances, was never experimented on so widely, or with more unfortunate results. Hence the magnitude of the bad business and the ensuing collapse. In the loans for Turkey, Egypt, and Peru alone, the depreciation of securities within a year after the Turkish collapse amounted to about $\delta_{1} 50,000,000$, while there is a total destruction or suspension of income from tainted securities exceeding $£ 20,000,000$ a-year. But, great as this collapse is, it has probably affected very little the accumulation or real wealth of the country. Many people feel themselves poorer than they were before, but the community as a whole is not really poorer by the pricking of all these bladders. A certain number of people are simply prevented from continuing any 
longer the process of living on their capital, for that was what they were doing when they were spending the so-called interest paid them, which was really only a return of what they had themselves advanced. But the whole of the so-called interest was not so spent, a great deal of it, as is the case with the interest of every description of investment, being reinvested, and in this way the collapse really changes nothing, except to let many people know that their accumulations were imaginary. The direct economic effect is consequently nil, although the social effects and individual disasters are of the most serious kind. The depression of trade attending a financial collapse ought not, therefore, to be measured by the seeming magnitude of the financial collapse itself, which last may be very great without the ordinary industry of a country being seriously checked.

As regards the second fact which is misinterpreted - viz., the decline of the foreign trade-the common impression only requires to be challenged to prove its unsoundness. We have probably a larger proportion of foreign trade than any other great nation. Our workmen and capitalists have gradually come to exchange a larger proportion of the products of their industry for foreign products than any other people. But even yet we are very far from exchanging more than a small part of what we produce. Our whole agriculture is for home consunıption; our coal and iron mining, our cotton and wool spinning and weaving, our manufactures generally, are also mainly for home consumers. A decline in our foreign trade, therefore, is only a decline in a branch of our whole trade, and should by no means be identified with a general depression in business. The recent decline in the foreign trade, moreover, is almost entirely a decline in "optional" business. It is a decline in our exports of such articles as we have been in the habit of exporting as a means of investing our capital abroad. When we stop such exports, certain branches of home industry, which have been fitted 
to this peculiar trade, suffer; but the capital which would otherwise have been sent abroad, and the means of producing that capital, are not destroyed. In the course of time, if the taste for foreign investment does not revive, the capital and labour employed in making articles for export will be turned to the production of articles for consumption and investment at home. Instead of merely looking at the foreign trade, then, we should look at our aggregate trade in such times of depression, and not suffer our opinions to be distorted by one or two conspicuous facts.

Coming to the subject in this way, we do not see how it can be doubted that the recent depression, although it is very protracted, is as yet singularly light in degree. Our imports of the chief articles of popular consumption, to begin with, have not diminished, but increased. Indeed, one of the favourite complaints about the depression of trade is the old cry of the excess of imports over exports, which is certainly greater than usual, because our investments in new countries have ceased for a time, but which is the permanent characteristic of English trade. It is quite certain, however, that no country sends us any goods on credit; it is England which always gives credit in the trade of the world. Whatever increase of imports there may be, then, is a sign of real ability to pay for them, and pro tanto of the undiminished prosperity of the country. To the same effect, we have the fact of an increase of railway traffic year after year during the depression. The increase in 1874 and 1876 , and again in 1877 , has been small; but in 1875 , the very year of the great commercial and financial collapse, it was considerable. Evidence in the same sense is also supplied by the nonincrease of pauperism all through the depression, and by the steady augmentation of the national revenue, until the present year, and by the increase of the savingsbank deposits. The non-increase of pauperism is no doubt partly due to our improved administration, but no improvement of administration could have prevented 
such an increase of paupers and decline of revenue as followed the panics of $\mathrm{I} 847$, I 857 , and I866, not to speak of the awful convulsions and distress which marked the depression of trade in still earlier periods. To any one who has even glanced at the economic history of England during the present century, the common talk now about the "unusual" depression of our trade appears simply ludicrous. The people who indulge in it have simply never thought of what depression of trade is. There has probably never been a great commercial crisis in England which caused so little suffering to the mass of the nation.

When we think of the matter a little, it seems reasonable enough also that the depression should be a mild one. Severe as the crisis has been, we were lucky enough to escape an actual panic, with the shock to credit and other lamentable incidents which a panic invariably produces. It is probable also that we were really befriended by the peculiar events in the money market in connection with the German coinage. The withdrawals of gold for Germany had the effect of anticipating the stringency in the money market which a period of great expansion ends in. The expansion was thus hindered from reaching the extreme it would otherwise have reached, and the reaction is less severe. Some good judges are of opinion that we have to thank yet another cause-the high normal wages of our workmen, and their independence of abundant harvests and cheap wheat, as compared with what was formerly the case, so that all our staple industries are steadier than they were. But I should doubt the effect of this cause without greater experience than we have yet had. Workmen will suffer, it is to be feared, in a way in which they have not lately suffered, if another time of expansion such as there was in 1872 should reach its full term, and industry be subjected to the strain of the inevitable reaction. But without this cause, the actual facts of the absence of a panic during all this depression, and of the successive stringencies in the money 
market which checked the exuberant growth of 1872 and 1873, appear quite sufficient to account for the comparative mildness of the effects of the depression we are witnessing.

\section{IV.}

The marks of the present depression which we have enumerated are thus its universality, its origin in the breaking down of the bad business of foreign investment, and its mildness in the United Kingdom as compared with former periods of depression. Is there anything in these peculiarities, or in any other circumstances of the depression, to lead us to anticipate that it will be unusually protracted or that its effects will be permanent? Is the depression, in other words, the beginning of anything unusual or unprecedented?

To put the questions thus explicitly is perhaps to answer them. Although there is much vague talk about existing depression-which is really based on an assumption that it is something utterly unheard of and must be lasting-it is not so easy to assert explicitly what is so confidently assumed. To suppose the permanence of almost any depression would, in fact, be to suppose a change in human nature itself. Universal dulness and poverty are, in fact, contradictions in terms, unless it is supposed that all people will voluntarily be idle when they have the strongest motives to work. Whatever awkwardness there may be in the distribution of labour and capital at certain times, the power to produce and the wish to consume ensure that with the means of production unimpaired-and there is no allegation that the means of production in the present case are impaired-production will go on and increase with the increase of population and with every species of chemical and mechanical improvement. It is thus morally certain that if at any time the industrial machine, as a whole, is partially disused and times are dull, a period of full employment and prosperity will return. And short of the depression being permanent, its I. 
effects will not, we think, be worse than usual, if indeed the worst is not already past. The disorder has been verygeneral throughout the world, because, industrially, the world is getting to be more and more one country; but there is manifestly nothing in the extent of a depression to alter its character or the power of the communities affected to recover. So far as England is concerned, moreover, all that has happened is that a particular part of our trade-our exports of domestic produce and manufactures-is momentarily weak, just as in former times the home trade dependent on railway contractors or bubble companies was weak. Our new investments in a particular direction have failed, but that is all. There is clearly no reason in this for any prolonged stoppage or diminished use of the industrial machine for all the miscellaneous purposes of life, although it will only be by degrees that new outlets for our surplus capital can be found. All the reasons assigned to account for the lightness of the depression until now-the absence of panic, the fact that the collapse is so much a merely financial one, and the circumstance that the expansion previous to the depression was arrested in its natural development-are also reasons why it should not be more protracted than usual. Some new mischief may of course arise, but there is nothing on the face of the facts, according to all former experience, to lead us to expect an aggravation of the present evils.

Nor do the special causes sometimes assigned for expecting an unusual degree and continuance of depression appear to be entitled to much weight. The British workman, it is said, drives business away by his misconduct and his demands for excessive wages. Foreign nations are increasing their manufactures of the very articles of which England, till lately, had a monopoly. Every import of a foreign manufacture into England, at a time like this, gives occasion for a new exclamation that English industry is threatened. The changes are constantly rung upon such facts as the in- 
creased capacity of the United States for the production and manufacture of iron; the importation of certain descriptions of American cotton manufactures into England; the appearance of Belgian and German manufactures in our markets at a cheaper price than the articles can be made by ourselves. But those who use this language appear to fail altogether in measuring the extent of the mischief they point out. A great deal of the apparent competition of foreign manufactures is due to the search for a market which occurs in every time of depression, and which furnishes no sure indication whatever of any real change in the currents of trade. All we know for certain is that on the other side the complaints abroad of the competition of English manufactures are loudest at such a time, and that facts as to foreign competition, similar to those now alleged, have been brought forward in every time of depression for the last half century, without any serious permanent result on English trade being traceable. That trade, on the contrary, as, for example, after the year i 869, when a great noise was made about similar facts, always makes a more rapid advance than ever after each depression. No one can dispute, indeed, that English workmen are often foolish for their own interest, or that some English trades have diminished, and others may yet diminish or may become stationary, while foreign trades of the same kind increase. Still the question here is of the general prosperity, and it is easy to recognize the strength of the influences which are likely, and, we believe, are certain to limit the evils feared, as, in fact, they always have limited them. Our workmen do, in fact, succeed in getting higher wages, as a rule, than foreign workmen; they do not migrate, and pauperism does not, on an average of years, increase-all signs that manufacturing, as a whole, whatever may happen to particular trades, increases in England. It is because there is so much more profitable manufacturing here than elsewhere that our workmen can enforce the higher wages. As 
we certainly cannot expect that foreign countries should manufacture nothing at all, but must rather desire their manufacturing to increase, there is really nothing in all that is said of foreign competition to concern us in an inquiry as to the permanence of the present depression.

The fallacy in the use of these alleged facts as to foreign competition consists, indeed, very largely in the forgetfulness of other facts which are equally material: that our foreign trade itself is not everything to us, but is, after all, only a fraction of our whole business; that long before competition can diminish that trade materially it must produce a fall of wages, while wages abroad will rise if foreign trade increases; and that although foreign countries increase their manufactures, we are not necessarily ruined-probably we are greatly gainers. To take what seems as formidable a case of possible competition with us as any that is threatened-viz., the increase of the American iron and coal industries under natural conditions. It seems probable enough that in course of time these industries will be very largely developed in the United States. The people have natural aptitude and skill, and other advantages, and they may produce iron manufactures cheaper than they can buy them abroad. In time they may export them to other countries. But how is England necessarily the poorer for that, and how much? We may come to export a smaller quantity of our iron manufactures to the United States than in the years before I 872 ; but at most we shall only lose the profit on so much trade, not the whole value of what we sold to the United States, which was, in comparison with our whole trade, by no means a large sum. Nor shall we even lose the whole profit. We can only lose the difference of profit between what was derived from that trade and the return on the less profitable trade, into which a portion of our capital and labour are diverted. Possibly, also, the growth of the world may be such that the expansion of the American industry will not be exclusive of, but will be coincident 
with a similar expansion of our own-there may be room for both of us. In that case there would be no reduction of the profits on our own trade at all, although America had become an exporter of iron manufactures. Ex hypothesi, the increase of the American iron trade would also mean that America becomes richer, and consequently a better customer to the world generally for other things-thus causing an increase of the general prosperity in which, with our extended and various trade, we could not but participate. Worse things may thus happen to us than a natural extension of the American iron trade; and if it is extended by protection only, it can of course do us still less harm. There is something essentially unsound, therefore, in the continual references to the increase of manufacturing abroad. Our concern should rather be to have that manufacturing increase. To anticipate that the world outsicle England is to be merely agricultural or mining, is to anticipate the maintenance throughout the world of the least productive forms of applying human industry, and of low purchasing power among other countries. What mankind require for the greater efficiency of their labour is that the proportion of people employed in agriculture and mining should diminish, and more and more attention should be given to other forms of industry. How England should grow poorer as this transformation is being effected, it is difficult to imagine. It appears to be as clear as any proposition, that the general increase of production, leading to still greater varietics and subdivisions of manufacturing than those which now obtain, must benefit most of all the countries like England, which have got the start of others, and possess all the best manufacturing appliances.

We should fully expect then, when the liquidations which have been in progress are over, to see once more a great revival of prosperity. Still more, according to all former experience, the prosperity to come must be even greater than anything yet seen. Ever since 
I 844 there has been an ascending scale in the rate of our industrial advance. The years after i 848-49 were more prosperous than any before, but the prosperity of $1863-65$ exceeded that of $1850-53$ just as the prosperity of $1870-73$ exceeded that of $1863-65$. In like manner the next period of prosperity will probably exhibit a fuller development than I870-73, and for a similar reason-viz., that the productive capacity of mankind in civilized nations, in proportion to their numbers, is annually increasiag-being capable of almost indefinite increase. More railways and more machinery, the improved knowledge of chemical and other arts, imply that one year with another, in proportion to their population, civilized communities can produce more real wealth than they did before. Depression comes at times, because mistakes have been made, and the wrong things are produced; but when the mistakes are corrected, or some new favourable influence operates, such as a good harvest, the tide flows again, industrial communities work up to their full power, and they are all richer than before. Possibly the workmen at a given place may take out their share of the increased production in the privilege of working fewer hours; but the prosperity is there, however it may be enjoyed. The great extension of railways throughout the world in anticipation of real wants, which was the mistake of the period of inflation, should, now that the mistake has been paid for, contribute to a more rapid advance of general prosperity than would take place if the world had fewer railways.

There has naturally been much talk during these liquidations of the commercial and financial dishonesty brought to light. At every such period there is an endless discussion of such matters, as if the worst evils of every crisis arose out of dishonest acts, and the practical questions were how such acts are to be prevented in future. But while recognizing the importance of such discussions in their own place, I doubt if they are as profitable and instructive as those who engage 
in them suppose. Improvement in morality is necessarily a slow process, and in so complex a world as that of modern business the efficacy of any external aids to prevent dishonest or quasi-dishonest practices, or an abuse of credit in some form or other, may be doubted. It would no doubt be important to discuss the immoralities disclosed during a period of crisis, provided a great deterioration of character had become manifest; but I should not look for a change of this sort in so short a time as that which elapses between different crises, and at any rate there was no such change manifest in the last crisis. There was nothing very novel in character after all in the Collie frauds, or in the financial swindling which has occurred. The Collie accommodation bills were no better and no worse than the accommodation bills in the leather trade discovered in 1857 , or the similar discoveries in other crises. At times, when trade becomes unprosperous, it is inevitable that bills will deteriorate in quality through the desperate efforts of people to carry on after they have become insolvent. The point where insolvency is passed must be difficult to discern for many houses which depend on borrowed money, and which engage incessantly in large speculations. Probably before the fact of irretrievable insolvency is fairly recognized by a house like Collie's, and desperate expedients to avert bankruptcy increase in number and frequency, enormous mischief has been done, and enormous losses to the people who have trusted them are unavoidable. The chief practical lesson to be learnt from such failures is really a detail of practice-the revelation to our great joint-stock banks of a defect in their system which should be easily curable, and the cure of which would mitigate the effects of catastrophes like that of Messrs. Collie. The financing of foreign loans was also no better and no worse than the financing of companies, or the construction of contractors' railways in past times. There are reasons in the nature of times of prosperity for the creation of pinchbeck secu- 
rities, and the details and particular form of security chosen are not of permanent interest. If the class of promoters is checked in one way, they will invent new methods and new fields of deception, still keeping within the wind of any laws that may be contrived. Since I 866 there have been few companies with large amounts of uncalled capital, the special evil of the preI 866 period; but the activity formerly witnessed in this field has been equally injurious, as we all see now, in the field of foreign loans. The exposures of the Foreign Loans committee in I875 have so effectually stopped these, that it has already become unnecessary to consider the particular recommendations they made. Probably promoters will now go into a totally different field, which I am disposed to think may be the creation of trusts or trust companies to "amalgamate" securities, and so distribute the risks. The principle seems fascinating: more than one of the numerous trusts now in existence have been fairly successful: we may accordingly expect an extension of the principle by which investors will be once more encouraged in the impossible experiment of making a high interest safely. But trust companies are really as dangerous as limited companies with much uncalled capital, or foreign loans, though in a different way. They amalgamate securities and distribute risks, it is true, but they add the great risk of a new set of intermediaries between the investor and his investment. In addition to his former risks, the latter, when he belongs to a trust, runs the risk of employing an adventurer or a thief to select and keep his securities. The danger is manifest. But if promoters do not go into trusts, or trusts do not " take," we may be certain they will try something else which will probably be found to answer, so great and so enduring is the infatuation of the public; and the mischief will be done before effectual warning can be given.- $[1877$. 
ON THE FALL OF PRICES OF COMMODITIES IN I $873-79 .^{\prime}$

7 HERE is a general agreement that during the 1 last few years there has been a heavy fall in prices. The fall in cotton and iron, and the various manufactures of cotton and iron, is notorious, and for the rest the losses in trade, in almost every description of business, have been such as to leave no doubt of a fall in price. It is usually a fall in price which cripples the weaker borrowers, and causes bad debts, and this makes a beginning of losses by which stronger borrowers are in turn crippled, farther falls in prices ensue, and more bad debts and losses are produced. When we see so many failures as are now declared, therefore, we may be quite sure that they are preceded and accompanied by a heavy fall in prices. But the question for statisticians in such a matter is not the fact of a general fall, but whether it can be measured and compared with other facts of a similar kind, and whether there is anything to show the fall to be of a more or less permanent character, and not merely a temporary fluctuation which will be corrected by an immediate rebound; in other words, whether the average of two or three years, including the present, will or will not exhibit a decline when a comparison is made with a date two or three years back. Looking at the matter in this more definite way, I have come to the conclusion that not only is there a decline of

1 Read before the Statistical Society, 2 ist January, i879. The tables referred to in the paper are not reprinted here, but will be found in the Statistical Society's "Journal " of Narch, 1879. 
prices at the present time from the high level established a few years ago, but that this decline is more serious than the downward fluctuation of prices usually exhibited in dull times, and that it may be partly of a permanent character unless some great change in the conditions of business should occur at an early date. I think this can be shown without difficulty with the help of some well-known figures which have been published lately, and which I propose to analyze and sum up, after which I shall proceed to discuss the causes of this apparently serious decline in prices, and some of the probable consequences.

\section{I.-The Extent of the Fall.}

To take the matters in the rough first : we may see what the general fall of prices has been by which the popular impression has been created. For this purpose I have made use of tables of prices of certain leading wholesale commodities which I prepared for a series of articles commencing in 1874 and continued for several years. From these tables I have extracted the prices on the Ist of January, in each year, carrying them back for the sake of comparison to the ist of January, 1873, which was the period, as we shall see, of maximum inflation during the late prosperous period, and bringing them down to the ist of January of the present year. The result is seen in the first table of the appendix to this paper, which certainly gives the impression of a tremendous fall, continued as regards almost every article from the time the table begins. Thus Scotch pig iron, which is the first on the list, falls from $127 \mathrm{~s}$. to 107s. $6 \mathrm{~d}$. the following year, and then to 8os., 64s. $3 d ., 57 s .6 d ., 5 \mathrm{I} s .6 d$. ., and 43 s., the fall in the end amounting to no less than 66 per cent. of the original price. In Straits tin the fall is from $£ \mathrm{I} 42$ per ton in January, 1873 , to $\delta_{120}$ the following January, and then to $£ 94, £ 82, £ 75$ los., $£^{66}$, and $\mathcal{E} 6 \mathrm{I}$, the fall in the end amounting to 57 per cent. of 
the original price. To pass from the metals to the raw materials of the textile manufactures, we find the fall in cotton to be from $10 d$. per lb. in January, 1873 , to $8 \frac{1}{8} d$. in the following January, and then to $7 \frac{1}{4} d$., $7 d$, $677_{8}^{7} d ., 6 \frac{1}{2} d$. , and $5 \frac{3}{8} d$., the fall in the end amounting to 46 per cent. of the original price. In wool the fall is from $£_{23}$ per pack in January, 1873 , to $\mathscr{L}_{19} \mathrm{I}_{5} \mathrm{~s}$. in January, i 874 , and then to $£$ I 85 s., $\ell_{1} 7$ ios., $£$ I 6 i 0 s., $£_{1} 5$ IOs., and $\ell_{1} 3$, the fall in the end amounting to 43 per cent. of the original price. The fall is not quite continuous in all cases. In wheat, for instance, although the fall in the end is from 55s. II $d$. to $39 s$. $7 d$. per quarter, or equal to 29 per cent. of the original price, we find the price in January, I 874, to have been higher than in January, 1873 , while in 1877 and 1878 the price was nearly as high as in 1873 . But in a good many instances at least there is a continuous and steady decline, and in some instances of intermediate reaction, as in the case of sugar, the recovery appears to have been for a short period only. As regards sugar itself, the price of $22 s$. in January, 1877 , stands out isolated among the years of low price on either side. Altogether there are sufficient instances of a continuous decline, and of other instances where the intermediate recovery was very brief, to justify us in speaking of the whole table as showing not only a heavy, but for the most part a continuous, fall in the prices of commodities, which commenced in January, 1874, and has lasted to the present time. Of course this must be on the assumption applicable to all such tables, that the articles are really representative of the wholesale markets. Short as the table is, however, I believe the articles are fairly selected, and they have at least this advantage, that they were selected in the beginning of 1874, with a view to recording current prices in a convenient and easily handled form, and have not been put together ex post facto for the purposes of the present paper.

To show how heavy the fall is, comparing simply 
January, I873, with January, I879, I have made up the following table:

Prices of Leading Wholesale Commodities in January 1873 and I 879 compared.

Scotch pig iron . . . per ton

Coals

Copper, Chili bars . . ",

Straits tin . . . . . ",

Wheat, Gazette average . per qr.

$\left." \quad \begin{array}{c}\text { Red spring, at } \\ \text { New York }\end{array}\right\}$ per bshl.

Flour, town made . per sack

, New York price per bshl.

Beef, inferior. . per 8 lbs.

$"$ prime, small .

Cotton, mid. upland . per lb.

Wool... . per pack

Sugar, Manilla Musca per cwt. Coffee, Ceylon, good ord.

Pepper, black, Malabar. per lb.

Saltpetre, foreign . per cwt.

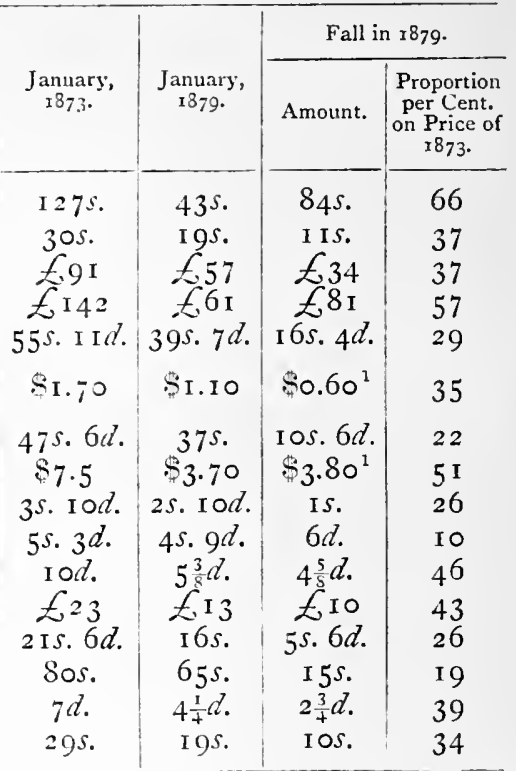

A table like this speaks for itself, and fully justifies the popular impression of a great and general decline in the prices of commodities. I think it even strengthens the impression. We should hardly have suspected beforehand that prices of wholesale articles not selected with a view to make out a case, but impartially chosen years ago as representative of the markets, would exhibit a fall in the last six years, ranging from 66 per cent. in the most extreme, to ro per cent. in the least extreme case, and ranging, with three exceptions only, between 26 and 66 per cent. So great a change would seem to make it probable both that unusual causes

2 The fall in the latter of these two cases appears to have been affected by the appreciation of the paper money in the United States. 
have been at work, and that unusual effects have been produced.

We come then to the question which we stated at the outset, viz., whether the prima facie impression is correct, and the fall is anything more than what has happened before, in the change from a period of inflation to a period of depression. To help in a solution of this question, I have availed myself of a table which was drawn up and is continued annually in a wellknown "Commercial History and Review," by a distinguished Member of this Society, whom it is not necessary for me to name. In this table (see Appendix Table II.) a certain value, IOO, is assigned to each group of a considerable number of articles in respect of the average prices of these articles in the years I $845-50$, the value of all of these together forming the index number 2200. The proportionate results in each year or period of years since the above date are then deduced, the sum of roo being added to when the price has risen and subtracted from when the price has fallen, and the results for each year being added giving a new index number. The net result now is the following series of index numbers, the one for January of the present year being my own addition, and being subject of course to the correction of the author of the table when he continues his work:

Date.

I 845-50 Average six years

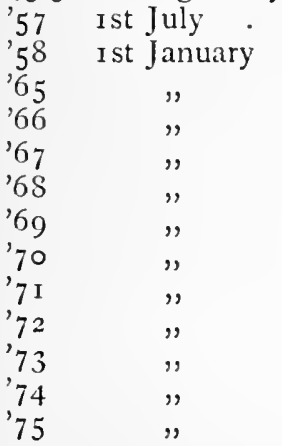

Index Number.

2200

2996

26 I 2

3575

3564

3024

2682

2666

2689

2590

${ }_{2} 835$

2947

2891

$277 \mathrm{~S}$ 
Date.

' 76

' 77

78

'79
Index Number.

27 I I

27 I 5

2554

$2227^{1}$

According to this, comparing January, I 873 , with the present time, we have a change in the index numbers from 2947 to 2227 , which is equal to a fall of 24 per cent. on the average. It appears, however, that between I 865 and I 87 I there was a still greater fall, the change in the index number between these dates being from 3575 to 2590 , or equal to 27 per cent. Great as the fall in recent years has been, therefore, it would appear that on striking an average it is more than paralleled by what happened in the immediately preceding period of depression. The explanation, I believe, is that in 1865 the index number was excessively raised by an exceptional circumstance, the great rise in cotton and cotton goods owing to the American War; but, apart from this exceptional circumstance throwing out the comparison of the former period, the recent decline is greater than that which followed 1865. Without any such exceptional occurrence to raise prices at first, there is finally on the average, according to this table, a decline of 24 per cent. I may add, perhaps, though I should be most unwilling to criticise the construction of the table, that it seems to me to give an excessive weight to cotton and wool, and too little to the metals, while coal is altogether omitted. The result is that changes in the price of textile articles affect the table much more than they would affect a similar table into which the metals entered more largely. On the other hand, considering how textile articles enter into general consumption, the table may be more perfectly representative of general prices than if the index number were differently composed.

The index number eventually published was 2202. 
But while this table does not show that the recent decline of prices is without a parallel, it indicates another fact of no small importance for the present inquiry. This is, that the closing index number approaches most nearly of all to that of the average of $1845-50$. That average is 2200 , but in all the years named, including 1857 and 1858 , and every year from 1865 inclusive, the lowest index number is higher than that for January, i 879. The lowest of the previous depressions following 1865 was 2590 , but the figure now touched is 2227 only. Even therefore if the fall from the highest point of the previous inflation is now less than it was after 1865 , we have still to consider that the inflation from which there is now a fall was not aggravated as that of 1865 was by a cotton famine, and that the descent is now to the lowest level of prices which appears to have been touched since i 850 . In other words, we seem to have been getting back in our years of depression to the average prices of the period just before the Australian and Californian gold discoveries began to tell on the markets of the world. This does not mean of course that prices are getting back to that average; we seem yet to be a certain way from that point; only that in our years of depression we touch a point much more nearly approaching that average than we did in the years 1868 and 1869.

Passing from these figures, I come to certain tables which were prepared last summer by my friend Mr. Arthur Ellis, one of the young Members of this Society, and who has already been a credit to us. As a supplement to the "Statist" of 9th June last, he published a long essay on the "Money Value of Food and Raw Materials," in which he compared the prices of I $S_{59}$, 1869,1873, I 876 , and the first quarter of 1878 , using for that purpose a new species of index number, based upon the relative amounts of articles imported, with certain additions for articles produced at home. The principal results of this procedure are exhibited in two tables, which are reprinted in the Appendix (sce Ap- 
pendix III.), and of which we have the net effect in the following short table in the body of the article:

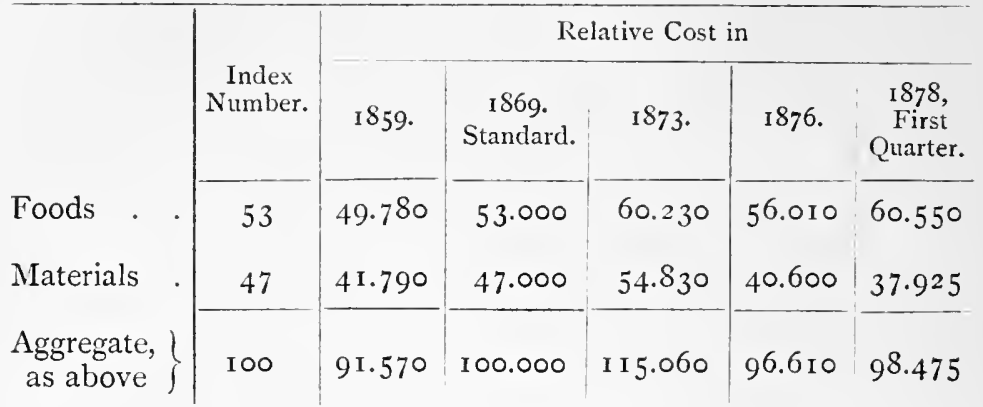

In other words, taking I 869 as the standard, we find that in 1873 the average prices of food and raw materials according to this mode of computation had risen about I 5 per cent., but in 1876 they had fallen rather more than 3 per cent. compared with 1869 , and in the beginning of 1878 were $1 \frac{1}{2}$ per cent. below the i 869 level. Considering the great fall of prices which has occurred since these tables were prepared, they may be considered to confirm fully what has been deduced from the above figures, that there has been a fall to a lower level during the present depression than what was established after the inflation of 1865 . Even at the beginning of last year prices were lower than they had been in I869, and there has been a great and general fall of prices since the beginning of last year.

A noteworthy point in this table is the circumstance that the fall is almost exclusively in raw materials. Since the table was prepared, however, there has been a great fall in articles of food, which are now at a low level of price like other things.

I have yet another set of figures, which you will perhaps allow me to refer to before I leave this question of the extent of the fall of prices in recent years. In a report which I have lately prepared for the Board of Trade, on the prices of our exports, copies of which are just being circulated, I have first of all shown in detail 
the prices of the various articles of our export trade, as deduced from the declared quantities and values in each year from I 86 I to 1877 , and I have then endeavoured to show the average rise or fall in price, taking $186 \mathrm{I}$ as the basis, by the above method of an index number, using the actual proportions of the value of the exports of each article to the whole value exported in calculating the average rise or fall of price. The result, I find, is that in the under-mentioned years, assuming 73. I as the index number, that being the proportion of the value of the enumerated articles of export to the whole export values, the following additions or deductions would fall to be made according to the average changes of prices as compared with $186 \mathrm{I}$ :

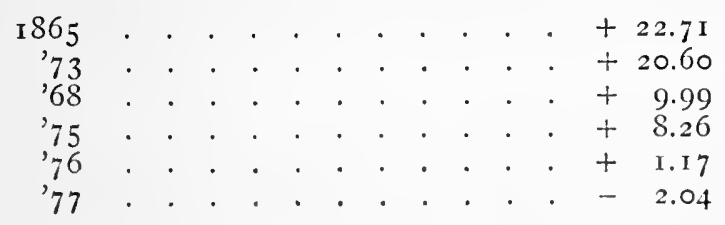

Here, again, without allowing for the great fall of prices in 1878 , we find an indication that prices are now at a much lower level than they were after the depression of 1865 . In 1868 the index number is still 9.99 above the level of 1861 , but in 1877 it is already 2.04 below that level, while in 1878 there has been a fall below 1877 . Curiously enough also it would again appear that in 1865 prices rose to a higher level in a time of inflation than they have since touched. The fall now is from a lower height than the fall after I 865 , though a much lower depth has been reached. Of course this tab!e only deals with exports, but in that respect it is supplementary and confirmatory of the above tables of Mr. Ellis's as to food and raw materials, which are mainly based upon the imports.

The general effect of all these figures may now be summed up. First, it has been shown by a general table of prices at the beginning of each year, from is 873 to 1879 inclusive, that there has been a general and 
remarkable fall in the prices of wholesale commodities in the period, this fall having also been to a large extent continuous, and amounting in the end, with three exceptions only, to between 26 and 66 per cent. Second, it would appear from a comparison of prices by means of the index number in the "Commercial History and Review," that the average fall between 1873 and I 879 is 24 per cent., and that the level of price now established is lower than any thing recorded since 1850 in the tables referred to, these tables comprising the years 1857 and I 858 , and each year since I 865 inclusive; further, that although the fall between $\mathrm{I} 865$ and $187 \mathrm{I}$ appears greater by this index number than between 1873 and the present time, yet there is a special explanation of this, and there is reason to believe the present fall to be unusually great. Third, it has been shown by certain tables of Mr. Ellis's that as regard food and raw materials, prices at the beginning of 1878 were lower than in 1869 , one of the years of depression following I 865, while prices are now considerably lower than at the beginning of $\mathrm{I}_{7} 8$. Fourth, it has been shown as regards the prices of exports, that the average in 1877 was considerably lower than in 1868 , while the fall to the present level was from a lower height in 1873 than the previous fall in $1868-70$ from the height of 1865 . Allowing for the further fall of prices in 1878 , we are confirmed in the belief that prices are now unusually low, and that the facts shown by the first index number cited rather understate than overstate the change. In other words, it is ascertained, by the concurrent testimony of all the facts examined, that prices of commodities are unusually low, though one of the sets of the figures would seem to throw doubt on the idea that the fall from the height of an inflated period to the present depth is unusually great. The preponderance of evidence seems, however, to be that there is an unusual fall, although it began from a lower level than what had been established in the previous inflated period. I have not attempted, however, to measure 
exactly what the extra depreciation is, though I should be inclined to put it at between 10 and 20 per cent. below the prices of $1868-7 \mathrm{I}$. In these matters great exactness is impossible; without waiting to aim at great exactness, I have thought it would be useful to bring the rough facts together, pending the more elaborate efforts which I trust some of our Members-perhaps $\mathrm{Mr}$. Jevons-may be induced to attempt.

\section{II.-The Causes of the Fall.}

To a certain extent there is no doubt or mystery about the causes of so general a fall of price. They are the same as the often recognized causes of similar downward movements. When trade is good a state of things is created in which a downward movement of prices is sooner or later inevitable. A great stimulus has been given to production in certain favourite industries; capital has been employed in creating new establishments, or in extending fixed works and plant; labourers have flocked into the trade, attracted by the high wages; at a point the demand is found to be below the supply, the prices of the manufactured article become unremunerative: and in time the raw material and labour employed in the trade are at a discount. The fall is precipitated moreover by the inability of speculative holders of stocks to hold on in face of falling markets. At each new stage of the decline new sales become necessary, till there is apparently no limit to the fall, just as before there seemed no limit to the rise. By sympathy almost all markets come to be affected, the low prices in one market attracting capital to it, and so weakening other markets, while speculators who are hit in one department of trade seek to cover their losses by sales of some commodity or stock which has not depreciated. This is the ordinary explanation of a general fall in prices; and the only feature in the late decline it would not explain would be the long continuation of that decline, and its renewal from time 
to time when many circumstances appeared to combine in favour of a new upward movement. This feature is, however, quite consistent with the usual course of a general fall of prices, though it has seldom, perhaps, been so prominently brought out as during the recent fall. In almost all markets there is constant action and reaction as well as the more general tidal movement which attracts attention when the course of prices for several years is looked at. It depends upon minor circumstances, we might almost say accidents, whether a given reaction will amount to a turn of the tide or not. If these minor circumstances are unfavourable for a time, the definite turn of prices upwards may be retarded, although the circumstances may be of a kind that when trade is stronger they would have little apparent effect. In this way it is quite possible, for instance, that the wars and rumours of wars during the last three years may have retarded the recovery in prices which is sure to come sooner or later, although trade is often brisk in time of war and amidst great political disquiet, as was the case for instance in $1870.7 \mathrm{I}$ during the Franco-German War. The great prolongation of the late decline, therefore, is not inconsistent with what we may expect at times when there is a general fall of prices.

We have something more to account for, however, than a general fall of prices, viz., the lower level which has been reached as compared with the last period of depression. This may be accounted for in part by the circumstance that the rise from which the present decline has taken place was not to so great a height as the rise which preceded the former decline; although a lower level has now been touched, the recent movement may be no greater; but even if we had not this explanation, or if it did not account for the entire descent which has taken place, there are not wanting special circumstances which go far to account for this great descent, as well as to account, if necessary, for that prolongation of the decline which has been referred 
to. Among these circumstances I would notice first the extremity of the discredit in recent years, and the piecemeal way in which the failures and disclosures causing the discredit have occurred. It is difficult in such matters to compare one time with another, and probably in every time of depression there is a feeling that things were never so bad before. I recollect perfectly well after the 1866 panic the languid and despairing feeling which pervaded the City for two or three years, when there was a prolonged reign of 2 per cent., and for a time discount houses were barely paying ros. per cent. for deposits. A famous article was written at that time in the "Edinburgh Review," on the strike of capital, and people blamed Lord Clarendon for having made matters worse than they were ever known to be before by the explanatory circular he sent to our representatives abroad with reference to the I 866 panic. The Overend failure had also been unprecedented, and so people were satisfied that the depression was the worst. But in spite of the gloominess of affairs after I 866 , it must be admitted, I think, that what came to light then was not so calculated to cause discredit as the revelations of the last three or four years. To that period belonged the Overend failure, the disclosures attending the break-up of a company mania of a not very extreme type, and some temporary difficulties of our great railway companies, whose debentures could not for a time be floated. Within the last four years, on the other hand, we have twice had commercial revelations of the most discreditable kind, viz., in I 875, when Messrs. Im Thurn and Co., Collie and Co., Sanderson and Co., and the Aberdare Iron Company all failed, besides many more, and next in the present year, ${ }^{1}$ when we have had such firms as Messrs. Smith, Fleming, and Co., Messrs. Heugh, Balfour, and Co., and Messrs. James Morton and Co., all collapsing. Next, there has been perhaps the greatest

I.e. 1878 , when the paper was written, although it was not read till January, $\mathbf{1} 879$. 
financial collapse ever known, viz., that of foreign loans, which has not, so far as known, inflicted incurable wounds in the banking world as the commercial revelations have done, but which has dried up the channels of investment, and reproduced the strike of capital so strikingly written about ten years ago. Last of all, we have had banking disasters quite on the scale of 1866 , including, perhaps, the most alarming, I might almost say bewildering, catastrophe ever known in banking annals, that of the City of Glasgow Bank. The spectacle of such colossal fraud, and of the danger run by investors in unlimited banks, seems calculated to create more distrust, and has, I believe, created more distrust, than the disaster of Overend's failure, great as that catastrophe was. Happily there has not been a panic during the last four or five years, although the City has more than once been on the verge of one; but, with this exception, the circumstances likely to cause discredit have altogether been stronger in the last few years than they were in and after 1866 . Allowing then for the illusion which present evils are apt to create, there appears to me something in the extreme discredit of recent years to account for the fall of prices to a lower level than after 1866 , although the real distress in trade may be no greater. The same result would have followed from the long continuance of discredit. If the disclosures which have been spread over three years had come all at once, say in 1875 , perhaps we should have had in that year a greater panic than that of I 866, and the distress which is now being felt would have followed sooner, but the reaction might have come quicker, through the more effectual clearing of the air. It is at any rate all but certain that in 1875 itself there was a reaction upwards, which was greatly checked by the revelations of that year, although another cause co-operated, viz., a succession of bad harvests, which I shall presently mention; and again, last year there was a general feeling that improvement had set in, when the disturbance in the money market 
in the autumn, culminating in the Glasgow Bank failure, at once threw matters back. The gradual character of the failures and revelations has thus had something to do with the greatness of the fall in prices. When just sufficient time has been given for speculators to take heart, suddenly some new evil breaks out, and prices tumble, as if from an inflated level, from the lower level at which they had been fixed in the first effort at improvement.

The second cause I would notice as probably contributing to the severity of the fall is the bad harvests of the three years 1875, I 876 , and 1877 . It has long been an axiom of economists that nothing so powerfully conduces to depression in trade, and a consequent fall in prices, as a succession of bad harvests. One bad harvest among several good ones may not have much visible influence, but a succession of them is recognized as a potent cause of mischief. The usual explanation has been that the bad harvest, leading to a high price of bread, causes direct distress among the masses of consumers, that their purchases of staple manufactures fall off, that the people in the trades so affected also become poor, and so by a quick round all trades become impoverished. If a second bad harvest follows the first, and a third the second, these evil effects are aggravated, and affairs at last come to be very bad. In addition, in a country like England, which has to import more largely from abroad when its own harvests are deficient, the bad harvests tend to make the exchanges adverse, raise the value of money, diminish new investments, and so injure trade. Whatever the modus operandi, the bad times following on bad harvests have been too notorious for the connection to be overlooked. Now, perhaps, we are only beginning to appreciate how bad the harvests were in this country for the three years before 1878 . The fact that the great rise in the price of wheat and bread which was formerly considered the worst effect of a bad harvest, and the most powerful cause of the succeeding depression, has not been observed in recent years, helped to blind business men to 
the actual deficiency. But the deficiency was most serious. The wheat harvest, to begin with, was undoubtedly most deficient. According to Mr. Caird, taking the average yield of the last thirty years to be I 00 , the yield of 1875 , I 876 , and i 877 was respectively:

$$
\begin{array}{llllllllllll}
1875 & . & . & . & . & . & . & . & . & . & \cdot & 78 \\
1876 & . & . & . & . & . & . & . & . & . & \cdot & 76 \\
1877 & . & . & . & . & . & . & . & . & . & . & 74
\end{array}
$$

In other words, our wheat harvest was deficient by one-fourth as compared with the average, and much more of course as compared with a good year for three years running. The usual rise in wheat and bread has not followed, owing to the very fact that the home yield is now less important than the aggregate foreign importations, but other effects of a deficient harvest must have ensued. Nor was there any compensation, as there often is in England, in the yield of grass and root crops, but the reverse. Here we cannot measure the yield in the same way, but the diminution of the stock of cattle and sheep in the three years ending 1877 was most marked. In Great Britain the reduction in cattle was:

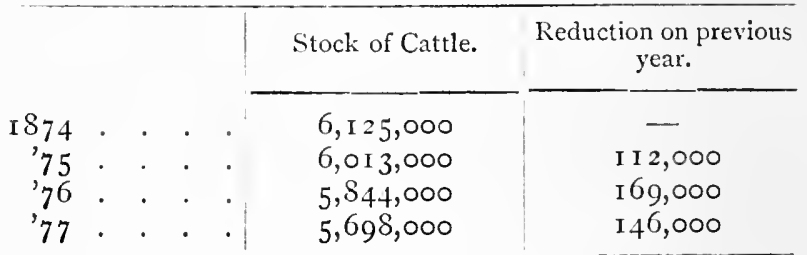

-making a total reduction of 427,000 in a stock of $6,125,000$, or about 7 per cent., in three years. In sheep the reduction was:

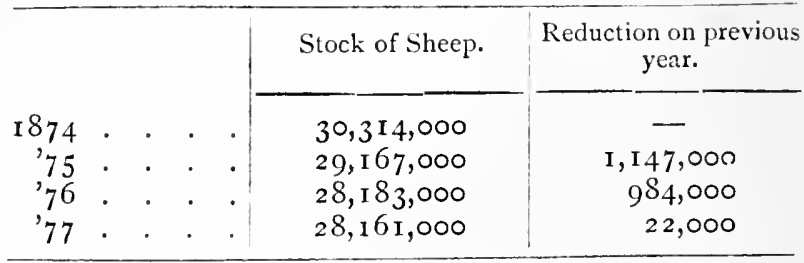


-making a total reduction of 2, I 53,000 on a stock of $30,3 \mathrm{I} 4,000$, or 7 per cent., in three years, the reduction in this instance having been almost wholly in the first two years. Such a reduction clearly implies, I think, some difficulty in the farming and landowning industry owing to the diminished productiveness of the industry, although it may be in part explained by the gradual substitution of superior for inferior stock - the diminution in numbers being accompanied by an improvement in weight and quality - and in part by the substitution of permanent pasture for other crops, the permanent pasture giving a larger net but a smaller gross produce. These explanations do not cover the entire ground, and something is left which can be placed to no other account than the unproductiveness of the industry.

Now although these bad harvests have not produced the effect of raising the price of bread, which used formerly to cause so much distress and depression in trade and a fall in general prices, with the exception of bread, business men and economists have both, perhaps, overlooked what the result must be of such a succession of mishaps to the greatest single industry in the country. Mr. Caird estimates the average annual value of our crops at 260 millions, and if the gross produce has fallen off Io per cent. for three years running, the cumulative effect on our home industry may have been very great. Instead of being able to save largely, farmers and the rural population may only have been able to save a little, and many, perhaps, have had to live on their capital, changes which would tend to weaken our whole internal trade, and diminish the fund for new investments. In actual fact, I believe it has been a characteristic of the money market since the spring of 1876 , at which date the effect of the bad harvest of $1 \$ 75$ would begin to be felt, that the banks connected with the agricultural districts have been poorer than they were. Some have been obliged from time to time to draw upon their spare money in London, and generally they have not been transmitting to 
London the usual large sums they have been able to send awaiting new investment. Another consequence of the bad harvest has undoubtedly been a less favourable foreign exchange, although it was only in 1878 that this unfavourable exchange culminated in anything like a serious stringency in the money market, and that stringency was much less than bad harvests had often led to in former times, owing mainly, I believe, to the plentifulness of floating capital throughout the world, which enabled us to attract with comparative ease what temporary money we required. Still there has been a stringency which would tend directly to check trade and lower prices a little, especially when trade was only barely convalescent, and which has indirectly checked trade a great deal by precipitating banking failures, and so causing much discredit.

It will be said, perhaps, that this unfavourable exchange was the result of the excess of imports and the wasting of our foreign capital, of which we have heard so much during the last few years. But so far as the excess of imports is due to a temporary deficiency of our harvest, I think it hardly proper language to describe the unfavourable exchange resulting as due to a waste of capital or to anything very mysterious, when it is the common and familiar, and also transitory effect of a common, familiar, and also transitory cause. Everybody allows that bad harvests make bad times, but unless bad harvests are to continue indefinitely, of which we have had no experience, this cause of mischief will soon be absent; undoubtedly it has helped to bring about the present extreme depression of prices.

A third cause which must be mentioned is the extraordinary demand for gold for the new coinage of Germany, and for the United States on its resumption of specie payments during the last few years. It is a little difficult to consider this point except in connection with the question of the supply of gold, and any variation 
in that supply which may have occurred, but what I desire to bring out is that apart from a permanent diminution of the supply, whether absolutely or in relation to the growing wants of the world, which would necessarily have a permanent effect on prices, extraordinary demands like those referred to would tend to produce a momentarily extreme fall. The reason is that a sudden pressure on the stock of the precious metals at a given period tends to disturb the money markets of the countries using them; makes money dear, or creates a steady apprehension that it may at any moment become dear; and so by weakening the speculation in commodities and making it really difficult for merchants and traders to hold the stocks they would otherwise hold, contracts business and assists a fall in prices. It is conceivable that after such a pressure the current supply of the metals may again be found sufficient to meet the current demands with prices raised to their former level; but while the pressure lasts prices are low.

Now the extraordinary clemands of the last few years -I think I may say eight years, the German lock-up having commenced in i 871 -have certainly been of a kind to produce some momentary effect, even on the assumption that the supply of gold, when the pressure is removed, remains sufficient for the wants of the world with prices at their former level. Altogether during the last six years Germany has coined 84 millions of gold, very little of this being re-coinage. The accumulation of gold in the United States, again, principally during the last two years, amounts to about 30 millions sterling, ${ }^{2}$ the stock of gold in the country above what it had for several years previous having been increased by that amount. These two sums amount to I 4 millions, and if we allow for other extraordinary demands, such as that for Holland, which has been substituting a gold for a silver money, and at the same

${ }^{1}$ The whole demand for the United States was ultimately much larger than this. 
time make deductions for what Germany may have recoined, we may say in round numbers that the extraordinary demands for gold during the last eight years have amounted to I 20 millions, or I 5 millions a-year. As the annual production of gold eight years ago was estimated at from 20 to 22 millions only, and has since rather fallen off, as we shall presently see, it is quite plain that these extraordinary demands can have left very little for the ordinary wants-the wear and tear of coinage, losses, use in fine arts, and new coinage to correspond with the wants of populations increasing in numbers and wealth. My own calculation in 1872 , in a series of articles which I then wrote, ${ }^{1}$ was that for many years previous the average requirements of the gold-using countries, excluding both Germany and the United States, which were not then in the list, had been I 2 millions annually But if you deduct 15 millions from 20 or 22 millions, you have much less than 12 millions left, and consequently the former state of things as regards prices could not have been maintained during these eight years. Now that the extraordinary demands are over, prices may recover, but the extraordinary demands must have contributed to the present adverse fluctuation.

These three causes then-the extreme and prolonged discredit, the bad harvests, and the extraordinary demands for gold-appear to me to have concurred in bringing prices of commodities to the lowest level which has been reached at any period for many years. That they would be sufficient to account for much of the effect which has been produced can hardly be disputed, and that they have existed is beyond all doubt.

The question is infallibly suggested, however, whether in addition there is not a subtler cause at work-an actual insufficiency of the current supply of gold for the current demands of gold-using countries. This is quite a separate question from the effect of the extra-

See above, p. 75-"The Depreciation of Gold since 1848." 
ordinary demands which have been described, and it seems to me most important that we should keep it separate. It is a subject infinitely more complex and difficult to treat, and one on which even the most skilled, I believe, would venture to give an opinion with far more diffidence than on the effect of the extraordinary demands themselves.

My own opinion is that some such cause nay have been at work, though whether its effects would have been at all marked as yet, in the absence of the extraordinary demands, may be doubted. The main presumptions to this effect are-first, the undoubted falling off of the gold supplies during the last twenty years. I have reprinted in the Appendix (Table IV.) that portion of the table put in by Sir Hector Hay in his examination before the silver committee which relates to the production of gold, as containing, I believe, the most generally accepted estimate of what the gold production has been. The following is a summary of that Table in quinquennial periods, with the annual average for each period:

Estimated Production of Gold in the Years 1852-73, in Quinquennial Periods, with annual Averages for each Period.

\begin{tabular}{|c|c|c|}
\hline Period. & Total Production. & Annual Average. \\
\hline I $852-56$ & $\underset{1}{E}$ & $\underset{29,933,000}{E}$ \\
\hline $57-61$ & $123,165,000$ & $24,633,000$ \\
\hline ' $62-66$ & I I $3, S 00, \infty 00$ & $22,760,000$ \\
\hline$' 67-71$ & $108,765,000$ & $21,753,000$ \\
\hline '7 I-75 (4 years) & $76,800,000$ & $19,200,000$ \\
\hline
\end{tabular}

The dwindling of the supply in this table is very marked, and naturally suggests that the effect on prices of the great gold discoveries may not have been continued much beyond IS6I, while lately the difference is so great that, even apart from extraordinary demands for gold, that effect may have been reversed. The difference of an annual yield of from 25 to 30 millions 
between I 852 and I $86 \mathrm{I}$, and an annual yield of less than 20 millions at the present time, is palpable. Of course the question is not settled by this consideration. One of the effects of the great gold discoveries was to create new markets for gold itself. Under its bimetallic régime France replaced an enormous stock of silver by gold, and, becoming a gold-using country, absorbed the new supplies to an enormous extent. India again absorbed an immense sum, especially during the years of the cotton famine, when her credit abroad was so suddenly and so enormously augmented. Until I 866 it may be said that the market for gold was so affected by extraordinary demands that there was hardly time for prices to settle down into a normal state, and the full effect of the new supplies on gold-using countries alone was never fully tested. But it is at least obvious that the diminished supply could not now meet the extraordinary demands which were met by the supply of the earlier years, even if the ordinary demands have continued the same.

I should add that not only do the figures show an actual falling off of supply, but there is a probability of the supply being obtained at a greatly increased cost of production. The nineteen millions now produced are obtained with more effort than the thirty millions twenty years ago. This means that if prices were to tend upwards a check might be put upon the movement by a still farther falling off of the gold supply. It might not pay to work mines which are now profitable if prices all round, necessarily including wages as well as commodities, were to rise.

We come then to the question whether ordinary demands have continued the same, to which the answer must, of course, be that coincident with the gradually declining supply of gold there must have been an enormous increase of current demands. The increase of population in the gold-using countries alone must have been nearly 50 per cent. In the United Kingdom alone, the annual rate of increase has been for long 
nearly I per cent. per annum, 0.83 per cent. between I $86 \mathrm{I}$ and $\mathrm{I} 87 \mathrm{I}$, which gives 28 per cent. in thirty years, while in the Australian colonies the rate of increase is, of course, much greater. Suppose the world's annual supply of gold before s 848 - say six millions sterlingwas quite sufficient to maintain equilibrium then, which I doubt, the natural increment of population, assuming it to be no more wealthy and to use no more coin per head than the population before ${ }_{4} 8$, would make the present usual requirement from the gold-using communities in existence before 1848 or their descendants about 9 millions. But the weal th per head has increased enormously. In the paper I read last year on Recent Accumulations of Capital in the United Kingdom, the rate of increase in the ten years ending 1875 was estimated at 27 per cent., and this rate of increase being deduced from the actual rate of increase in the assessments to the income tax, is not subject to the doubts which may be entertained respecting the totals of the accumulations themselves. Whatever the figures may be at the beginning and end of the period, such has been the rate of increase. Not only then must the requirements of gold-using people be increased by 50 per cent., to allow for the natural increment of population, but another 50 per cent. must be added for the greater wealth per head. This would further raise the usual requirements according to the previous i $S_{4} 8$ standard from the above sum of 9 millions, which allows for the increase of population only to $\mathrm{I}_{3} \frac{\mathrm{T}}{2}$ millions. The same conclusion is reinforced by a consideration of the quantities of goods dealt with in our principal industries. The production of coal in 1846 , as you will see by reference to Mr. Mundella's paper last year, was estimated in 1846 at $36,000,000$ tons; in 1876 it was $133,000,000$ tons; or about three times as much. Between I 854 and i 876 , or little more than twenty years, the production was rather more than doubled. The production of pig iron again has increased between I 840 and I 876 from I,396,000 to 6,556,000 tons, or 
about five times in less than forty years. The entries and clearances of ships in the foreign trade again have increased from I $3,307,000$ in 1848 to $5 \mathrm{I}, 53 \mathrm{I}$, 000 tons in 1877 , or nearly quadrupled. The imports of raw cotton again have increased from 6 million cwts. in I 848 to more than 12 million cwts. in 1877 , or 100 per cent.; and although this seems less striking than some of the previous figures, it is to be noticed on the other side that the exports of cotton-piece goods have risen from $\mathrm{I}, 096,75 \mathrm{I}$, 000 yards in $\mathrm{I} 848$ to 3,838 millions in 1877 , or nearly four times. But it would be needless to multiply instances. The peculiarity of the period has been the increase of mechanical invention and the constant augmentation of goods, so that the accumulation of capital above shown is even in less proportion than the increase of the movement in trade which the money in use has to move. It is a moderate calculation that if only the countries which used gold in 1848 , including their colonies, were now using it, the requirements to correspond with the increased population and wealth would be at least three times what they were, assuming prices to remain in equilibrium.

Nor is this all. The extension of the area of goldusing countries since 1848 , first, by the practical inclusion of France, and next, by the more recent inclusion of Germany and the United States, has no doubt added to the usual demands to an extent it is unnecessary to determine exactly, but at least by several millions. Thus while during the last thirty years the annual yield of gold has been falling away from its first superabundance, the current demands for the metal have certainly been growing with marvellous rapidity. If there was much need twenty years ago of new channels for the new gold supplies to prevent an enormous rise in prices, it is at least possible that more recently the increasing current demands have been sufficient to use up the diminishing annual supply. So far as we can judge, the point of junction of the two curves must have been at some date within the last ten years, 
though in such matters precision is of course impossible. In this view the fall of prices in the last ten years has been aggravated by a subtler cause than the extraordinary demands for gold which have existed. These demands have come upon a market which apparently had no surplus to spare. They have consequently been supplied very largely by a continued pressure upon existing stocks, till an adjustment has at length been made by a contraction of trade and a fall in values.

It may be said, perhaps, that the usual requirements of gold-using countries have been changed from what they were by the extension of the cheque and clearinghouse system, by the diminished use of gold in the arts, and by similar means. Perhaps there is some diminished use of gold in the arts, but, of course, the only really important question in this matter is the use of gold in coinage, and I should doubt if any great economy in the use of gold has been established in the last thirty years. Excluding Germany and the United States, which have just been added to the number, the principal gold-using countries besides the United Kingdom and its colonies are France, Portugal, Egypt, and the South American countries, but it would be difficult to show, I think, that the cheque system or any other system of economizing money has been greatly extended in those countries in the period. In the United Kingdom again all the recognized expedients for economizing money-especially the cheque and clearing-house system-seem to have been fully operative thirty years ago as they are now. The United Kingdom was very fully " banked" before i $8_{5} \mathrm{O}$, the growth of banks and banking business having since been no more than in proportion to the increasing wealth of the community. ${ }^{1}$ The circumstances are such, however, that a considerable allowance may be made

1 This is true substantially, notwithstanding the fact of a great increase of the number of bank branches in England in the last thirty or forty years.

I. 
for the introduction of economizing expedients, without altering the fact that the current gold requirements of the world have increased enormously since i 848 , while the annual supplies which threatened an incalculable rise of prices have been dwindling away.

Let me add, that whatever doubt may be entertained as to the actual meeting of the two curves of demand and supply of gold during the last few years-apart from extraordinary demands - all the facts and circumstances seem to indicate that the meeting point must come very soon unless the supply of gold is increased, or economizing expedients introduced and extended. At the recent rate of progress the current demands may be expected to increase at least 20 per cent. every ten years, so that if 20 millions annually are now just sufficient for all purposes, not less than 24 millions will be required ten years hence. In another ten years the annual requirement will be more nearly 30 millions. If we start from a lower total now, say from 16 millions, all the same the figure of 20 millions will soon be exceeded. And this without leaving any margin for extraordinary demands, which experience seems to show are never wanting, so that, as in a budget, allowance should be made for the unforeseen as in some sense more certain than all that is exactly forecast. If the scarcity of gold has as yet contributed very little to our money troubles or the fall in prices, it must at least be about to have that effect if no great change comes. Whether such a change is likely to come in the shape of an increased gold supply it will be for geologists and mineralogists to judge, but it is not reassuring to see how little comes practically of the recent gold discoveries in India, and the re-discovery in Midian. Whether on the other hand change may come in the shape of economizing expedients will be a point of no little interest for bankers and all other business men, and for legislators. Considering the slowness with which such expedients become effective when they are first introduced, and the perfection to which they have 
been brought in countries like England where they are introduced, I feel great doubts whether much relief can come in this way. On the whole, I see no other outlet from the situation than in the gradual adjustment of prices to the relatively smaller and smaller supply of gold, which must result from the increasing numbers and wealth of the populations of gold-using countries.

\section{III.-What the Fall Explains, and its Consequences.}

The fact of a fall of prices such as has been described explains a good many things, while the consequences of it, or, to speak more correctly, perhaps, of the more permanent of the causes which have contributed to it, must be far-reaching. There are one or two topics of importance in this connection on which I have a few brief remarks to offer.

First, we have a sufficient explanation in the fall of prices of much of the falling off in trade, especially our foreign trade, which is the occasion of so much alarmist writing. There is a constant assertion by some writers of two alleged facts, one, that our foreign trade is diminishing, the other, that foreign countries are gaining as we lose, from which the inference is that the decline of our trade is to be accounted for by the successful competition of foreigners. Indeed, it is sometimes said that the foreigner is taking the bread out of the mouths of our manufacturers and the men whom they employ. I have never seen this view supported by any careful examination of what the growth of the trade of foreign countries really is, or by a consideration of what goes on in our trade generally, and not merely in particular trades which may be affected here and there by the pressure of foreign competitors; but the question of the fall of prices appears to open up a new view. What if there is no falling off, or no material falling off, of our trade at all, so that all this writing about our decaying trade, and the gain of foreigners 
at our expense, is only so much writing in the air? It is clear that an average fall of 20 or 30 per cent. in prices must make all the difference in the world. We are not left to conjecture in the matter. The exports of British and Irish produce show a falling off in total value between 1873 and 1877 of about 22 per cent.

\begin{tabular}{|c|c|}
\hline The exports in 1873 were & $\begin{array}{r}£ 255,165,000 \\
198,893,000\end{array}$ \\
\hline & \\
\hline
\end{tabular}

which is almost exactly in the proportion stated. But we have already seen that while the index number of 73.I falls to be increased in 1873 , when a comparison is made with I $86 \mathrm{I}$ prices, by the sum of 20.60 , the index number falls to be decreased in 1877 by 2.04 , so that there has been an average fall of price between I 873 and 1877 of more than 20 per cent. ${ }^{1}$ There is nothing in the figures then to imply that the quantities of the articles exported in 1877 were less than in 1873 . To throw farther light on the point, I extract from the report to the Board of Trade already referred to, a table in which the prices of the articles of export enumerated in the statistical abstract, according to their declared values in 1873 , have been applied to the quantities exported in 1877 . The result is, that while the aggregate declared value of these enumerated articles in I 877 was $£ 147$, 801 , 000 , their aggregate value at the prices of 1873 would have been $£$ I $191,530,000$, which is within a million of the aggregate value of the exports of the same articles in i 873 . There are variations in the quantities of the articles, some increasing, and others diminishing between 1873 and 1877 , but the upshot is that if the prices of 1873 had been maintained all round in 1877 , the returns as far as the enumerated articles are concerned, and presumably as regards the remaining articles of trade where the entries

${ }^{1}$ And exclusive, of course, of the additional fall in 1878 . 
are mostly by value only, would have exhibited no decline at all.

It cannot be maintained of course that a fall of values only is immaterial. Profits depend on price, and this is an especially important consideration in the foreign export trade as regards articles exclusively or mainly of British origin, and where a large part of the value is not constituted by the cost of the raw material previously imported. Our trade may consequently be less profitable, though the quantity we turn out has not diminished. But other countries must suffer by the fall in price exactly as we do ourselves, and the question here is not of the profitableness of the trade at a given time, but of its extent; and as to this the impression that our foreign trade has diminished to any material extent during the last few years may be pronounced to be absolutely without foundation. Regarding profit, moreover, I may be allowed to say in passing, a good deal might be urged in favour of a time like this being really the most profitable in the end, notwithstanding all the complaints of depression. Much of the prosperity of years like 1873 is in reality hollow, and much of the dullness of dull times is due to the fact that people are forced to acknowledge themselves not so rich as they thought. But this is perhaps taking us away from the matter in hand, which is that of the volume of our trade only.

To be quite fair, it must be acknowledged that holding our own in such matters is not all that is necessary. If business is to be in a real equilibrium, there should be a steady increase in it pari passu with the increase of population. There has been some real check then to the growth of our foreign trade luring the last five or six years. But on the other hand, we must remember that previous to 1873 there was a marvellously rapid growth, much above the annual average. All things considered, it is yet too soon to complain of the check of the last five years as indicating the beginning of a permanent retrogression. 
The second point I shall advert to is the possible connection between the appreciation of gold and the depreciation of silver. It is an obvious enough suggestion that as silver in the markets of gold-using countries is only a commodity, it will probably sympathize with any general movement in the prices of commodities. Indeed, it has been urged by the Calcutta Government that it is not silver which has changed, but gold. Silver prices, they say, have not perceptibly risen in the Indian markets, although gold has risen. Without going into detail on this subject, which would take up a whole paper by itself, and which we may safely leave to Mr. Bourne when he comes to read his paper on the silver question, I may be allowed to remark that very likely gold and silver have both changed. One or two of the causes we have described as likely to produce a general fall in prices - the prolonged discredit and the bad harvests-have been as applicable to silver-using as to gold-using countries, and have surely been applicable to India and China, with their tremendous famines and much rottenness in their foreign trade. It was therefore possible that silver prices should have fallen like gold prices, and the relation between the two metals have been left unchanged; if silver prices have been stationary, or have not fallen so much as gold prices, then, as we cannot be sure how much the scarcity of gold has aggravated the fall of prices here, it is difficult to argue from the fall of silver in relation to gold that the difference between them arises from an appreciation of gold only. There may have been depreciation of silver as well, even if of a temporary kind only; the events of the last few years relating to silver-especially the sudden sales of the stocks of German silver, and the stoppage of silver coinage by the Latin union -being calculated to have that effect. The wonder, perhaps, rather is that silver has not depreciated still more. Possibly the stock in use in the silver countries is so large that great additions can be easily absorbed; but the change has yet to be tested, we must remember, 
by a period of good business and naturally rising prices in the silver-using countries. So far as it goes, however, the depreciation of silver in relation to gold, whatever changes may have occurred in silver itself in relation to other commodities, is not.inconsistent with the supposed change in gold in relation to such commodities.

A third point to notice is the connection between a great fall in the prices of commodities and a fall in wages. The two things are inseparably connected. First, in certain trades-and this connection has been specially shown of late years in the iron trade-the gross price of the articles produced is so much diminished, that if the cost of labour is unaltered the labourer will be receiving an enormously increased share of what is produced. Say an article formerly selling for $£ 20$, the cost for labour being one-fourth or $£_{5}$, falls in price to $£$ Io, then the $£ 5$ given to the labourer would be 50 per cent. of the selling price. It is incredible that so great a change could occur without the labourer being affected, and there have been even greater changes in the iron and coal trades. But, second, in almost all trades, especially those in which the cost of labour constitutes a large part of the cost of production, there is necessarily some connection, in the long run, between the money rate of wages and the prices of the usual articles of the labourer's consumption, according to his standard of living. It would take us out of our way to enter into a controversy here about the wages fund, but it is quite plain that the real wages paid by the capitalist to the labourer consist mostly of commodities; if money wages remain the same while commodities fall in price, there is an increase of real wages. In some way or other, then, an adjustment of money wages to reduced prices becomes inevitable. In miscellaneous industries this may be effected by the constant action of individual interests when changes of employment occur; by the steady substitution of superior for inferior workmen; by the transfers of busi- 
ness enabling wages of clerks and others to be revised; and by similar means. In more conspicuous trades, where large groups of men are employed, there are notices of reduction on a large scale as well as these minor instruments of effecting a reduction. But nominal reduction must come somehow, unless there is to be a real rise in wages. The visible opportunity of employers is of course the scarcity of employment and the disorganization of industry which attend a great fall of prices; but employers would obviously be unable to continue paying for any length of time really increased wages. There is no Fortunatus's purse which would not quickly be exhausted in such an attempt.

There is another subject of, perhaps, greater complexity which seems to be suggested. If a general downward movement of prices, due to a comparative scarcity of gold, has begun, are we not on the eve of a reversal of the changes which commenced with the Australian and Californian discoveries-changes so admirably described in Mr. Jevons's well-known book? These changes were substantially a gradual lightening of debts for the benefit of the debtor class, and to the immediate loss of annuitants and capitalists, however much the latter might be compensated in the end by an increase in the nominal income of their land, houses, and other securities. Now we may witness a gradual increase of the burden of debts to the loss of debtors, and for the immediate advantage of creditors, although, in the end, the latter may lose by the relatively diminished nominal income of their securities, following the adjustment of all prices to the new circumstances. There can be no doubt that some such general effect as this must follow, if it should, in fact, turn out that a serious appreciation of gold has set in, and the circumstances of its production and the use of economizing expedients do not change. In the end the effect in contracting trade is looked forward to with some apprehension by many of our best authorities.

I do not propose to dispute this conclusion here. It 
would land us in an almost endless controversy if we were to discuss whether a constant influx of new money, leading to a prolonged rise in prices, does more good or harm in the long run, than a constant failure of new supplies to meet current demands leading to a prolonged fall in prices. A great deal, I imagine, could be said on both sides ; the rebound from excessive inflation more than compensating perhaps all its alleged benefits, and the additional fall in prices due to a gradual scarcity of gold being as nothing when compared with the falls which take place from time to time owing to the simple failure of credit. But while avoiding this discussion, I may at least point out that the most serious effects of this incipient gold scarcity will probably be gradual, just as the effect of the discoveries in causing a rise of prices has been much more gradual and confined within narrower limits than economists were in the habit of anticipating. Particularly at the present moment the depression may have gone so far that the accumulating stocks of the precious metals will be sufficient for a good while to support a considerable expansion of trade-that it will only be later on, as prices tend to get back to the former level, that the real pressure of the scarcity will be felt. A year or two's ease in the money market following the events of last year will however be no proof at all that the causes above described have not been operative and will not again be operative.

\section{IV.-Concluding Observations.}

In bringing this long paper to a close, I have only, one or two practical observations to offer. The "moral" of much that has been said is clearly this - that if possible the scarcity of gold which has contributed to the present fall of prices, and may have farther serious effects in future, should, if possible, be mitigated, and should at any rate not be aggravated, by legislative action. I have expressed great scepticism as to whether, 
in fact, seeing how slow men's habits are to change, any mitigation is probable in the shape of expedients for economizing money. But it must be recognized that if bodies of men were amenable to reason in currency questions, and there was really a widely-felt belief of serious mischief impending from a gold scarcity, some economizing expedients could be tried. To give only one illustration: I suppose few things are more unlikely than that $£$ i notes, or notes for less than $£_{5}$, will again be reintroduced in England, but the introduction of such notes alone, with all suitable arrangements for their convertibility, would certainly go far to neutralize even such another extraordinary demand as that for the German coinage. The German demand for gold would itself have been much smaller than it was, but for the banking reform which accompanied the coinage, and part of which reform was the abolition of notes of small denominations. The United States' pressure for gold during the last few months would also have been far more serious than it has been, if the Government of that country had complicated its resumption arrangements by the abandonment of all greenbacks of from 5 to 25 dollars, and the prohibition of bank notes for such amounts. There seems a possibility of gaining something then by reintroducing $£$ I notes if the present gold scarcity should continue. I hope I shall not be understood as advocating such a change, or as being insensible to the weight of many practical objections which could be urged against it if it were immediately proposed. I am only mentioning it as a possible expedient for economizing money, and there are no doubt others. As regards small notes, however, it would seem that at least any change by countries which still retain them in the direction of their further abolition, leading to a greater demand for the precious metal, ought to be deprecated. Still more we ought to deprecate any change in silver-using countries in the direction of substituting gold for any part of the silver in use. It 
THE FALL OF PRICES OF COMMODITIES IN I 873-79 155 would be nothing short of calamitous to business if another demand for gold like the recent demands for Germany and the United States were now to spring up. Even a much less demand would prove rather a serious affair before a very long time elapsed. 
RECENT CHANGES IN PRICES AND INCOMES COMPARED. ${ }^{1}$

Contents : Preliminary-The Appreciation of Gold-The Degree and Character of the Appreciation-The Appreciation or Depreciation of Silver-Characters of Appreciation and Depreciation at different Periods-The Causes of Appreciation and Depreciation-The Redistribution of Wealth-The Future Course of Prices.

\section{Preliminary.}

A LMOST ten years ago I read a paper to the A Society on "The Fall of Prices of Commodities since I $873, " 2$ in which the suggestion was made that we were probably then in presence of, or about to be in the presence of, the phenomenon known to economists as appreciation of money, i.e., as our money is gold, appreciation of gold. The subject has since been widely discussed as a branch of the great bimetallic controversy, but I have not myself engaged in it except to reiterate the original suggestion in a paper on "Trade Depression and Low Prices" in I 885, and to discuss generally some aspects of the theory of the relation of the quantity of money to prices. It may now be permitted to me to return to the topic, and to explain more fully than I have hitherto thought of doing the extent and nature of the appreciation which was only a little more than apprehended when I wrote in 1879 , and some of the problems that arise for discussion in connection with it. In doing so I hope to be excused if the bearings or alleged bearings of the discussion on the bimetallic controversy are avoided.

' Read before the Royal Statistical Society, r 8 th December, 1888. For Appendices see Statistical Society's "Journal."

${ }^{2}$ See Statistical Society's "Journal," March, 1879, and preceding essay. 
Mr. Bagehot said in his "Lombard Street" that he proposed to keep clear in that book of the Bank Charter Act, because if he spoke on that subject nobody would heed what he said on any other. It would be much the same now with bimetallism: if that topic were to be touched upon, the main topic would be forgotten. It is of the utmost importance, however, that the question of the appreciation of money at the present time should be discussed for its own sake as a question of fact merely, and as a purely statistical rather than an economic question; a practical currency controversy interposed only confuses issues of the utmost consequence.

There is the more reason to keep clear of all controversy because it may be hoped that much of the discussion which has gone on will be shown to be verbal only, or to arise from mutual misunderstanding of terms. The leading facts are not really in dispute, and the only question is how to arrange and name them and use them in other discussions. When the phrase is properly limited and defined, the appreciation of gold of late years will be found to be in reality universally admitted, although in words opposed and controverted by many. Limitation and correct definition will enable us also to explain in what sense and to what degree, if any, silver has depreciated.

It will be convenient to begin with a few explanations and definitions.

First it is convenient to employ the phrases appreciation of money and depreciation of money in a strict study of the subject, and when the expressions are used scientifically, as the mere equivalents of the fall or rise of the prices of those articles or groups of articles with which money is compared. In other words, in this sense appreciation of gold would be only another phrase for a rise in the purchasing power of golddepreciation for a fall in that purchasing power.

The phrases have no doubt been used as bearing a different meaning, though a meaning, it is to be feared, not very clearly defined, and I should not pledge my- 
self that there is no passage in my own writings, though I trust I have generally been careful, which does not seem to read into the phrases a larger meaning than what is here expressed, but the convenience of strict definition, if it can be adhered to, is self evident. It agrees best, moreover, with the original literary use of the expression, purchasing power of money, and if the phrases did not exist in this sense, it would be absolutely necessary to invent phrases that could be so used.

It will be observed, moreover-and this is most important-that the phrases are themselves incomplete. To make them intelligible we must always understand or sub-understand some definite thing or things with which the money is compared. Instead of the general phrases, appreciation or depreciation of gold, appreciation or depreciation of silver, appreciation or depreciation of money of any kind, we ought to say in each case, appreciation or rise in the purchasing power of gold measured by wheat, or pig iron, or copper, or a certain group of articles arranged in a way so as to show a mean or average; and so on: whether we speak of gold or silver, or any other kind of money, always there must be something definite said or understood.

It may be convenient to assume afterwards that what is true of the measurement of gold or silver, or any sort of money, by one article or a group of articles, would be true if an average of all articles could be constructed; but always the scientific language which is exactly true is definite enough, and a clear line should be drawn between what is exactly known and what is inferred.

Confusion has arisen because a convenient shorthand phrase has come to be used dissociated from its primary uses, and its necessary limitations have been forgotten. The origin of inquiries as to changes in the purchasing power of money was largely historical. What a historian sometimes wants is to be able to say that a certain payment two or three centuries ago represents so much in the money of a different time, usually 
the present. But all that has ever been proposed, or is necessary, for such purposes, is to measure the money bycertain other articles, and give an approximate answer more or less complete. What the measure should be, for what purposes it can be used, and so on, are later questions, but the idea of an external measure of money of some kind is necessarily involved in any references to changes in its purchasing power. When we speak scientifically we must say the purchasing power of money over certain definite things, although popularly our idea may be the purchasing power of money over things in general, or the bulk of things.

The next preliminary point is that in dealing with the appreciation or depreciation of money, the nature of the economic movement in the country where the appreciation or depreciation takes place, or in two or more countries which may be compared, ought to be carefully considered. The signs of appreciation or depreciation are not the same in any two cases unless the economic movement is the same.

Thus in a stationary community, which goes on from year to year with the same population, producing and consuming the same things, and neither advancing nor going back, appreciation or depreciation of money, should it take place from any cause, would probably have uniform effects. The fall or rise of prices would extend to all commodities equally, and to wages and incomes also. A rise would entail a proportionate increase of wages and incomes; a fall a proportionate decrease. Nothing would be easier apparently than to ascertain appreciation or depreciation in such a community.

Of course, however, there is no such ideal community. In actual life the disturbance of money alone would probably disturb a great deal besides.

The case of an absolutely retrograding community, which is no doubt a very rare one, would supply somewhat different signs. It is quite conceivable that in such a community there might be a depreciation of 
money measured by commodities or large groups of them, and yet there would be no apparent increase of wages or incomes, because, the community retrograding, there is less of real things to divide, and there being in fact as much income expressed in money to go round as before, the loss to the community by its retrogression might be measured by the percentage rise of prices. Superficial observers would, however, be apt to say that because there is no rise of wages or incomes there is no depreciation of money, although there is unquestionably depreciation when commodities are the measure.

Retrogression is a rare case, but advance is not so rare, and we must consider carefully what may be the signs of appreciation or depreciation in an advancing community as distinguished from a stationary community.

Three kinds of appreciation and depreciation-six cases in all, if not seven-may apparently be distinguished plainly in such a community :

I. As regards appreciation there may be a case of falling prices of commodities coupled with stationary incomes and wages. In this case the fall of prices might be the measure of the increase of the return to the industry of the community, assuming that the labour employed in services improves generally as does the labour employed in the production of commodities. Still measured by commodities there may be an appreciation of money, although the diminution of wages and incomes which accompanies some forms of appreciation of money is absent.

2. There may be a case of less wages and incomes per head, in which case the fall of prices would be greater than in the first case, and the difference between it and the fall in wages and incomes might represent the advance in the return to the industry of the community. But the only distinction between the first and second instances is clearly the degree of appreciation. There can be no warrant for saying that in an 
advancing community appreciation as it has been here defined may not take place without an actual diminution of wages and incomes.

3 . There may be a case of not only less wages and incomes per head, but an absolute diminution of the aggregate of all individual incomes, notwithstanding an increase of population. In this last case the fall of prices and diminution of wages and incomes per head would be more severe than in the second case, where the diminution per head might not be so great as to prevent altogether the growth of the aggregate of individual incomes. Still this extreme form of the appreciation of money must not be looked for in every instance.

4. As regards depreciation again, there may be a case of stationary prices of commodities coupled with increasing wages and incomes per head. The increase in the latter case might correspond with the increase of the return to the industry of the community.

The important point to understand is that there may be a case of what may properly be described as depreciation of money where prices do not rise, just as there may be a case of appreciation where incomes and wages do not fall. Mleasured by incomes, though not by the prices of commodities, there may unquestionably in such a case be depreciation.

5. Depreciation may go so far that there is a rise of wages and incomes more than in proportion to the increase of the return to the industry of the community, in which case the improvement in the latter might be measured by the difference between the rise in the prices of commodities and the rise in wages and incomes.

6. Depreciation may go so far that there is absolute inflation in all prices along with a continued cheapening of production. In this last case along with the rise in commodities there would be an enormous rise in wages and incomes. But there may well be depreciation rightly called such without this extreme.

I. 
There is also as already hinted a seventh case, which may be described as intermediate between the mildest types of appreciation and depreciation above specified, a case namely in which, on the one hand, prices fall a little, showing appreciation measured by commodities, pro tanto, and on the other hand wages and incomes rise a little, showing depreciation measured by incomes pro tanto. Such a case may in fact occur in an advancing community, however it may be described.

It is expedient to put the cases thus generally, in order to understand in what class in each country respectively we are to put the appreciation of gold or depreciation of silver at the present time. There is nothing but confusion possible so long as people argue that because wages have not fallen lately there is no appreciation of gold, or because prices have not risen in silver countries, or have even fallen a little, therefore there is nothing which can properly be described as depreciation of silver in those countries. The economic movement of the country concerned, and the degree of the appreciation or depreciation of money, according to the measure of the money employed, are first to be understood. It will be found also, I believe, that one of the puzzles of the matter is strictly connected with this point. The figures of appreciation of gold, measured by commodities, in European countries, have not been balanced by signs of depreciation of silver in silver-using non-European countries. If the economic movement in India has been different from that in England, if an increase of the return to industry has been absent there, or has been at a different rate, may it not be somewhat difficult to state what are the proper signs of depreciation in India to be looked for?

A short preliminary explanation may be useful on yet another point.

A rise or fall between two dates in the purchasing power of money-an appreciation or depreciation of 
money-in itself implies a contraction or expansion of money. There is relative contraction or expansion, and this is true on any view of the relation of money to prices. Whether the quantity of money in use is the cause or the effect of a given state of prices, or partly the one and partly the other, a low range of prices means less employment for money than there would otherwise be, and a high range of prices means more employment. Consequently when prices change from high to low or from low to high, there must be in the former case contraction, and in the latter expansion of money. Absolutely there may or may not be less or more money at the latter date compared than at the starting, the absolute amounts being dependent on many causes, such as change in people's habits and the like, but relatively there must always be contraction or expansion.

In connection with this last point yet another explanation may be made. Whatever the thing used to measure the purchasing power of money may be, it must be treated while so used as an absolute measure, and when we do so, it becomes necessary to treat the rise or fall in gold as due to a change of demand for, or change of supply of gold, leaving out all consideration of changes in the measure itself. This is done every day when money is the measure; we neglect any changes in money itself, and treat only of demand and supply of the things measured. For those purposes where money in turn becomes the thing measured, and a commodity or group of commodities or the bulk of commodities becomes the measure, it is equally necessary to consider all the changes as arising from the demand or supply of the thing measured, i.c., money.

The question is largely one of language, and the two processes, viz., using money and commodities alternately as measures one of the other, are not inconsistent. The one variable is simply put against the other the better to understand the phenomena accord- 
ing to the special object in view. There is also a clear distinction between the cases where money is the measure, and those where another measure is sought. Money has become money because it changes least in short periods. For short periods therefore, and for comparing one commodity with another, in those periods, money is the common measure; any changes in it may practically be disregarded. But for longer periods, as already pointed out, the convenience of a different measure is felt. When we desire to know what the real wealth of a previous generation was compared with the present, some of the things which make wealth are found to be a better measure than money. Money then seems to change more from generation to generation than any other commodity almost compared with the average of the mass. But there would be no occasion for using a measure for money at all, unless the changes in the money were of such a kind that for the purpose in hand the changes in the measure used could be neglected.

\section{The Apprciation of Gold.}

Passing from these preliminary points, I begin by referring back to my former papers, and asking whether the suggestion there thrown out has since been confirmed by the facts, and in what sense there has been appreciation of gold in recent years.

Two things were stated with regard to the connection between the low prices of 1879 , and the contraction of gold which had taken place in the years following i 873 . The first was that the events in the money market consequent on the gold withdrawals for Germany, and for the resumption of specie payments in the United States, had contributed to the fall of prices by acting on the discount market, and assisting an oscillation from a credit to a discredit range of prices. This was an obvious and palpable fact of the time, but I laid no great stress on it. Oscillations in the money market 
and prices incidental to the ebb and flow of credit are familiar phenomena, and it could not be said in 1879 that the oscillation towards discredit was so very much more than usual, that apart from other circumstances the low prices should have been deemed remarkable. The second suggestion, however, was that although it was then early to speculate, there was reason to apprehend we were in the presence of, or about to be in the presence of, the phenomenon known to economists as appreciation of money. I did not define the terms, assuming them to be sufficiently understood by those interested, but the meaning, I believe, was clear enough. Appreciation or depreciation of money being phenomena only to be measured at long intervals, for it is only at such intervals that it becomes expedient to make commodities a measure, and so to measure money, what I had in my mind was to suggest that the course of prices in the immediately following years would probably deserve attention; that when time had passed for another cycle of credit and discredit, it would clearly be seen whether prices had fallen to a permanently lower level than in the period before 1873 , in which case there would be no question as to an "appreciation of money" having occurred. The reasons for that opinion, in which to a large extent there was only a repetition of what I had said so long ago as 1872 , appeared also to be overwhelmingly strong. There was visibly a strong "pull" upon gold, which was passing out of circulation in England instead of passing into it, as in the twenty years before 1873 . The production was obviously diminishing; there was also to all appearance an increase of the cost of producing gold, which pointed in the same direction of an increase of its purchasing power. All this was said with the least possible amount of theorizing. The quantity of money in supply and the demands upon it were certainly assumed to have some connection with prices, the theory of the connection having never before been disputed to my knowledge, but I did nothing more than point 
out that if the world was about to witness an appreciation of gold-a rise in its purchasing power measured by commodities, and ascertained after long intervals, so as to allow for minor oscillations and to permit of the use of the fact for the comparisons to which it is adapted-then there ivere sufficient facts in the supply of and demand for gold to account for the appreciation.

If the test of prophecy be the event, there was never surely a better forecast. The fall of prices in such a general way as to amount to what is known as a rise in the purchasing power of gold is generally, I might almost say universally, admitted. There is much assertion in some quarters that there is no appreciation of gold, but the assertion is made by those who attach a meaning, or think they attach a meaning, to the words which I confess I am unable to make out and express in my own language, and there can at any rate be no doubt that, as the phrase is here limited and defined, we have for some years been in the presence of the phenomenon known as appreciation of money. Measured by any commodity or group of commodities usually taken as the measure for such a purpose, gold is undoubtedly possessed of more purchasing power than was the case fifteen or twenty years ago, and this high purchasing power has been continued over a long enough period to allow for all minor oscillations.

It would be slaying the slain to recapitulate all the facts as to the fall of prices; but as the question was first distinctly raised at our meetings, and the record may be convenient, we may refer briefly to the evidence adduced in 1879 , and see how the tables look when continued to the present date, and what additional evidence has been worked up.

Let me first refer to the short table with which the paper in 1879 began, and which was made use of, it will be remembered, as an extraneous table which had been commenced several years before for another purpose, and which, though short, seems to me to contain a great deal : 
A.-Prices of Leading Wholesale Commodities in January, 1873,1879 , I $88_{3}$, and $\mathrm{I} 88_{5}$, and December, I 888, compared.

\begin{tabular}{|c|c|c|c|c|c|}
\hline & I873. & I 879. & I $8 S_{3}$ & $188_{5}$. & I 888. \\
\hline cotch pig iron. . . per ton & I $27 s$. & & & & $41 s$ \\
\hline oals . . . . " ", & & & I7s. $6 d$. & & \\
\hline Oopper, Chili bars . · & 691 & $£ 57$ & $£ 6$ & $E 4 S_{\frac{1}{2}}$ & $£$ \\
\hline traits tin $\cdot \cdot \cdot \cdot \cdot$, ", & EI42 & E6I & ¿93 & $\not 77 \frac{1}{2}$ & t $101 \frac{1}{2}$ \\
\hline $\begin{array}{l}\text { Wheat, Gazette average per qr. } \\
\text { New Yod spring, at } \\
\text { Nork per bshl. }\end{array}$ & $\begin{array}{c}55.11 d . \\
\$ 1.70\end{array}$ & $\begin{array}{l}39 s .7 d . \\
\text { SI.10 }\end{array}$ & $\begin{array}{l}40 s .4 d . \\
\text { \$I.1 } 8\end{array}$ & $\begin{array}{l}\text { 34s. II } d \text {. } \\
\quad 9 \text { I } c \text {. }\end{array}$ & 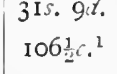 \\
\hline $\begin{array}{l}\text { Flour, town made } \text {. per sack. } \\
\text {,, New York price per brl. }\end{array}$ & $\begin{array}{l}47 s .6 d . \\
\$ 7.5\end{array}$ & $\begin{array}{l}37 s . \\
83.70\end{array}$ & $\begin{array}{l}38 s \\
84 \cdot 30\end{array}$ & $\begin{array}{l}32 s . \\
\$ 3.25\end{array}$ & \\
\hline Beef, inferior $\cdot{ }^{\cdot} \cdot$ per $8 \mathrm{lbs}$. & 3s. Iod. & 2s. $10 d$. & $4 s .4 d$. & $4 s$. & $2 s . S d$. \\
\hline 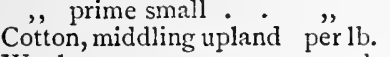 & $\begin{array}{l}5^{\text {s. }} 3^{d} \\
\text { Iod. }\end{array}$ & $\begin{array}{l}4 \text { s. } 9 d . \\
5 \frac{3}{8} d .\end{array}$ & $\begin{array}{c}6 s \\
5 \frac{1}{10} d\end{array}$ & $\begin{array}{l}5 s .4 d \text {. } \\
6 d .\end{array}$ & $\begin{array}{l}4 s .2 d \text {. } \\
5 x^{7} d .\end{array}$ \\
\hline $\begin{array}{l}\text { Wool } \text { Sugar, Manilla musca- per pack. }\end{array}$ & $£ 23$ & $£ 13$ & & $E_{\mathrm{II}}$ & \\
\hline $\begin{array}{l}\text { vado } \\
\text { Coffee, Ceylon, good red per cwt. }\end{array}$ & $\begin{array}{l}2 \text { Is. } 6 d . \\
\text { 8os. }\end{array}$ & $\begin{array}{l}16 s . \\
65 s\end{array}$ & $\begin{array}{l}\text { I6s. } 6 d \\
78 s .6 d\end{array}$ & $\begin{array}{l}\text { IOs. } \\
7 \mathrm{I} s .\end{array}$ & $\begin{array}{c}\mathrm{I} 3^{s} \cdot 3^{d{ }^{2}{ }^{2}} \\
91 s .^{3}\end{array}$ \\
\hline black Malabar per $1 \mathrm{~b}$. & $7 d$ & $4 \frac{1}{1} d$. & $5 \frac{3}{ \pm} d$ & & $75 d$ \\
\hline Saltpetre, foreign . per cwt. & $29 s$. & I9s. & I $9 s$. & $15^{s} \cdot 3^{d}$. & $16 s .6 d^{\circ}$ \\
\hline
\end{tabular}

The advantage of this table is that it leaves off at a point when trade is good, and there has been a good deal of inflation in different quarters, but although some prices are higher now than in $1 S_{5}$, they are still in very few cases higher than in ${ }_{1} \delta_{3}$, while they are far below the level of 1873 , and a good deal below the level of I 879; the latter, it must be remembered, being a year of depression, while the present is a year of expansion. The fact of continuously low prices for the bulk of staple articles is accordingly established by this short table, and this is what is meant by an appreciation of gold measured by commodities. There may be no appreciation, using the words in some sense not clearly defined; but that if we measure by the mean or average

${ }^{1}$ Corner.

"In I 888 this is the quotation of Brown West Indian. I have been unable to find a quotation for "Manilla Muscavado" in the usual price list; but the price of Brown West Indian in I 885 was nearly the same as that here given for Manilla Muscavado.

${ }^{3}$ This is Ceylon Plan. Mid., as I do not find the old quality quoted in the lists before me. The price taken in $\mathrm{I} S 85$ was rather higher than Ceylon Plan. Mid. at that time, but the difference was not material, and I have now taken the top price instead of the mean price. 
of the articles named there is a rise in the purchasing power of gold is self evident. The phrase is only a synonym for the fall of prices. There can be no dispute about the fact.

To the same effect are the conclusions from the index numbers, of which there has been so much talk of late years-the "Economist" index number, Mr. Sauerbeck's number, Dr. Soetbeer's number, and the Board of Trade index number, the latter based on the average prices of imports and exports. These numbers are so well known that I may simply copy a few extracts from the records and place them side by side, along with similar extracts for the price of silver, leaving them to tell their own tale. The table, of course, could be easily enlarged:

B.-Comparison of the Index Numbers of the "Economist," Mr. Sauerbeck, Board of Trade Import and Export Prices, Dr. Soetbeer, and an American Index Number.

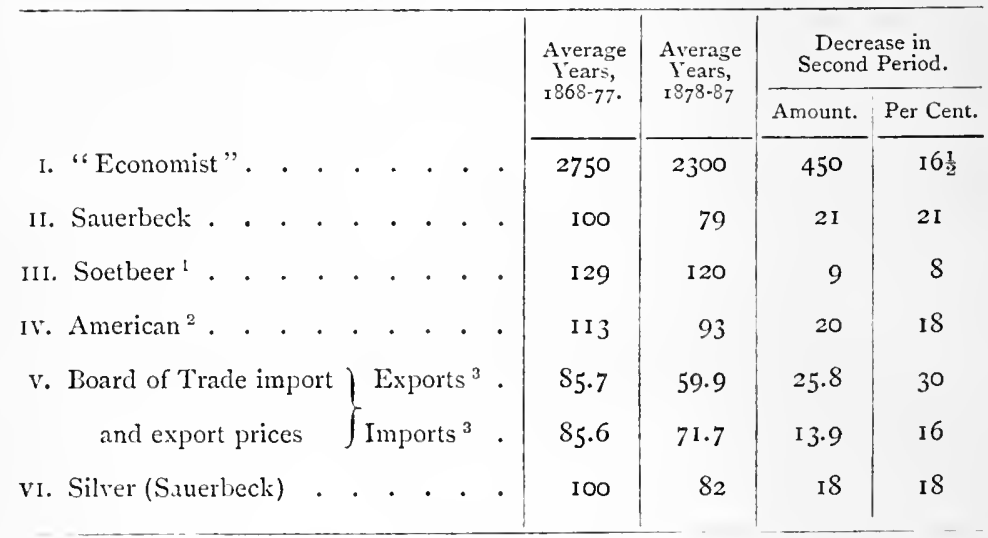

Thus, whichever of these measures be adopted, we

1 I 866-75 and $1876-85$.

2 I 866-70 and I876-80. The American figures are not later than I880. See Appendix III., appendix to first report of Royal Commission on Trade Depression.

${ }^{3}$ Figures of $\mathrm{I} 873$ and ${ }_{1} 88_{3}$. These figures not being calculated for every year, it is not possible to give an average of a ten-yearly period; but the results would be much the same comparing any other years at ten years' interval. 
are equally led to the conclusion that, measured by staple articles, no matter how we select them, gold is found to have increased its purchasing power; and the increase has lasted over a long enough period to allow for minor fluctuations, and to show a change which can be made use of for such comparisons as a rise or fall in the purchasing power of money is adapted to illustrate. In my evidence before the Royal Commission on Gold and Silver, I said a great deal about index numbers, and how they can be used, to which I may be permitted to refer here, as well as to the papers on the "Prices of Imports and Exports," laid before Parliament. Let me only say here, for the purpose of continuing the logical thread of the argument, that an index number, apart from the details of its construction, is a very simple matter. It is nothing more than a device to enable a mean or average to be struck of the prices of a great number of articles, the mean being the result of an addition of the prices of all the articles named divided by the number, and the average being arrived at after weighting the prices selected according to an estimate, on a subjective or objective basis, of their relative importance. The estimate in the case of the prices of imports and exports with which I have myself dealt, is on an objective basis, that of the relative importance of each import to the whole imports, and of each export to the whole exports. Formally the latter process gets rid of the only good theoretical objection ever made to the use of index numbers as a means of averaging a group of prices, the objection, viz., that all articles, important or unimportant, are treated alike; but I may state that practically, as the result of Mr. Edgeworth's mathematical investigations for the monetary committee of the British Association, of which several of us are members, the ordinary index numbers, which are exposed to the theoretical objections stated, yield much the same results as the formally more correct indexes. The reason is, that having been selected almost at random as it were 
fromamong staple articles which happened to be quoted in wholesale price lists, the articles in general have moved in sympathy, so that one selection yields much the same results as any other. This is what theory would lead us to expect, but in fact Mr. Edgeworth has tried and compared the different index numbers not only with each other, but with a new number based on a different objective basis, and for practical purposes there is not much to choose between them.

All this is important when we proceed to the next step, which is to infer from the appreciation of gold measured by the commodities or groups stated, the probable appreciation if we had for measure a still greater number of articles, or in fact all articles. This is a matter of inference; but when in fact the different groups include from 50 to 90 per cent. of the chief commodities in use or consumed, or good types of these commodities, it would require very strong suggestions as to an opposite movement in the smaller number of articles which cannot be brought to the test to overbalance the conclusion to which the index numbers point. There are facts which would lead us to presume that the fall of prices in the excluded articles has been even greater in proportion than in the case of the articles included; but without laying stress on this, the proportion excluded is so small that we may have confidence in the general conclusion from the actual measure. Thus it is a mere matter of arithmetical statement that, measured by any of the groups named, the purchasing power of gold has increased of late years; it is a matter of practical certainty, though there can be no arithmetical proof formally complete, that measured by things in general gold has appreciated-its purchasing power has risen.

There is also corroborative evidence of a very strong kind in favour of the same conclusion in various sets of facts as to values, which are referred to in the essay already referred to, published in 1885 . These are the facts as to the growth of import and export values 
compared with the growth of quantities, the facts as to income tax valuations, and the like. The facts on these heads are now notorious. The logic of the use of them is that they show effects in a mass, and thus get rid of any objections based on the possible peculiarities of some prices, though these are also got rid of, as we have seen, in a different way. Thus as regards imports and exports, if we are entitled to assume from the growth of quantities a certain growth of business, then if the growth of import and export values is at a different rate, the inference clearly is that the money expression of the individual things has changed. Hence only can it be that the mass of values is lower. The same with income tax valuations, as I pointed out in my paper at the British Association last year, ${ }^{1}$ and as I shall have occasion to point out again in a book on the "Accumulations of Capital in Recent Years," which will continue the paper read before the Society in January, 1878 , and which is all but ready for publication." If the produce of land commands a less money price than before, rent falls and the capital value falls; if houses are built of less costly materials, object for object, their capital value and rent are also lower than they would otherwise be. It is quite easy to calculate, given the increase of population, and assuming a certain growth in real wealth per head, what difference is made in the figures by the change in the money expression, which can only be ascribed to a fall in the money value of average things.

Now with regard to a comparison of the growth of imports and exports in quantities and values, the facts are very clear. To bring this out has been one of the objects of the various reports to the Board of Trade which I have made in the "Prices of Imports and Exports," and it was obviously a point of various tables which were laid before the Royal Commission on Trade Depression. It is unnecessary to go into an elaborate

1 See postea, "Recent Rate of Material Progress in England."

2 See "The Growth of Capital" (George Bell and Sons). 
comparison here. Let me only condense from the latter tables the following short table, comparing the growth of the money values of imports and exports per head with the growth of the entries of shipping per head:

C.-Average Imports per Head and Total Imports and Exports per Head of the Population of the United Kingdom in the Undermentioned Quinquennial Periods; with the Entries of Shipping per Head in the same Periods; also showing Percentage Increases or Decreases.

[Extracted from First Report of Trade Depression Commission, p. I27, etc., and continued.]

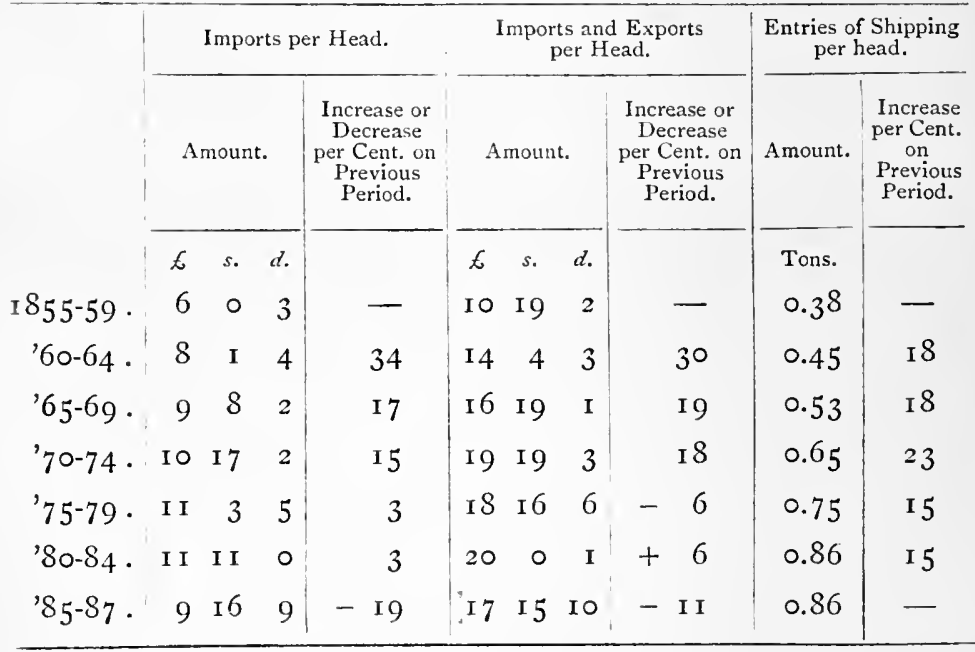

Thus while, in the earlier quinquennial periods, the increase in values is more than the increase of shipping, although the latter is very great, the increase in values practically stops short about i 874 , or amounts to very little after that; while the increase in shipping goes on at a very rapid rate, if not quite at so rapid a rate as formerly. There is much other evidence, if we go into details, of a rapid growth of our foreign trade, judging by quantities only, while values do not increase, for which those interested may be referred to the tables mentioned.

With regard to income tax and other property valuations, it will be enough to call attention to the failure of their growth as compared with the growth in the 
immediately preceding period, in the simplest manner. The following short table is extracted from the tables produced by Sir Algernon West to the Trade Depression Commission:

\section{D.-Wtatement of Gross Amount of Profits Assessed to Income Tax per Head in Undermentioned Quinquennial Periods.}

[Appendix to First Report of Trade Depression Commission, p. 212.]

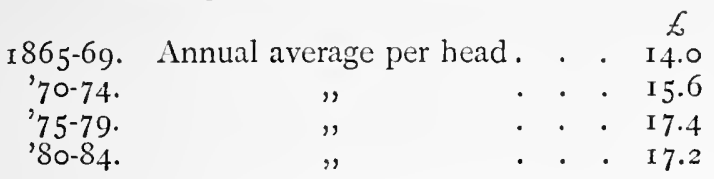

Allowing for the notorious increase in production per head shown by other statistics, such as the entries of shipping and the like, such a failure of money values to respond surely confirms the impression, derived from the above figures of fall of prices shown by index numbers and otherwise, as to the rise in the purchasing power of money being quite general. Whatever doubts may be raised as to the generality of the fall, when we look at prices merely, however grouped, there seems to be no room for them when we look at such mass observations as those of the growth of import and export values and valuations of property compared with the growth of things.

The evidence is not necessary for the purpose of proving the point, but the same divergence between the growth of quantities is noticeable in the statistics of import and export values, and statistics of property valuations, inforeigncountries. The tables put in by myself before the Royal Commission on Trade Depression fully show this; and reference may also be made to a statement on this head by Sir Louis Mallet, in a note of his to the Report of the Gold and Silver Commission.

It hardly seems necessary to mention the point specially, but so much has been said quite properly as to retail prices not following necessarily to the full extent wholesale prices, and as to the danger, therefore, of relying too exclusively on the latter, that it 
may be useful to point out the bearing of these mass figures on the question of how far wholesale prices are to be trusted as a measure of gold, because they may be assumed to be representative of prices of commodities in general. It seems to be plain that if retail prices did not follow wholesale prices more closely than would be thought likely at first sight, results like what is here shown in the mass would not appear. A little reflection will also show, I think, that retail prices can hardly fail to follow wholesale prices closely. So far as the difference between them and wholesale prices is made up by cost of distribution, there appears to be no small reason to believe, first, that the real cost of distribution, as well as the real cost of production, has lately diminished; and next that, at most, the mere cost of distribution is only a fraction, 20 or 30 per cent. at most, of the final cost of articles, so that, even if no economies are effected in distribution in a given period, the fall in wholesale prices must still drag with it substantially the fall of retail prices. Some retail prices may not fall nominally, as they embody largely labour expended on the wholesale article; but this phenomenon belongs in part to the phenomenon of a nondiminution of wages while prices fall, which may be the characteristic of some cases of appreciating money, and which is a characteristic of the present case, as we shall presently discuss. Thus the point of retail prices was a proper one to raise, and there is something in it, but there is nothing to prevent us forming the conclusion that the increase of the purchasing power of money of late years, indicated by the measure of wholesale commodities, is, in fact, quite general. We do not need to include all commodities, each properly weighted, to arrive at this conclusion.

\section{The Degree and Character of the Appreciation.}

The rise in the purchasing power of gold measured by commodities being established, it remains for con- 
sideration to which of the types described in our preliminary remarks this appreciation belongs? Is it an appreciation in which the income per head of the community, and the earnings per head of the wage-earners, diminish? Is it an appreciation in which the aggregate income of the whole community diminishes? Or is it a case where incomes remain stationary although commodities fall?

I assume the community to be itself one of the advancing type, as in fact all the communities which are gold-using undoubtedly are. Tried by the test of things produced, all these communities have lately been advancing in population and wealth, however difficult it may be to measure what the percentage of advance is. Appreciation of money in their case must accordingly conform to one of the three types stated: (I) a fall of prices along with stationary incomes; (2) a fall along with diminishing incomes per head; (3) a fall along with a diminution of the aggregate money income of the community. To which category does the appreciation belong?

The facts here are most difficult of measurement, owing to the want of records of wages in a tolerably complete statistical form. Records of wages for a purpose like the present ought to show the aggregate earnings of the wage-earning part of the community, from which, with a knowledge of the population, the amount per head can be deduced. With such records at short intervals, the result we now wish to arrive at would appear at once, not as a matter of inference, but as a statement of fact. But no such records are in existence. Instead there are only records of isolated rates of wages, not "weighted" in any way, with apparent changes in opposite directions from time to time, so that it becomes most difficult to deduce what the general movement is. Fortunately for us, however, there is in England at any rate a record of a large part of the income of the nation which may be considered tolerably complete, and which may help, along with 
careful study of such wages records as exist, to show what the conclusion on the point before us must be.

The records referred to are those of the income tax, which have already been quoted for another purpose, but which may again be used with greater detail for the somewhat novel question now raised. Here there is an account of a large part of the gross income of the nation from time to time, largely, though not exclusively, the earnings or profits of capital. Assuming the recipients of this income not to change greatly from year to year in proportion to the general population, though we cannot count their numbers, then we may infer that the income per head diminishes or increases as we find that the annual amount divided by the numbers of the general population diminishes or increases. We can also see directly whether in the aggregate this portion of the national income diminishes or increases.

Looking at the income tax income then we find that the figures for the last twenty years, ending I SS6, and beyond this we need not go, are as follows:

Income Tax Income in the undermentioned Years.

[In millions.]

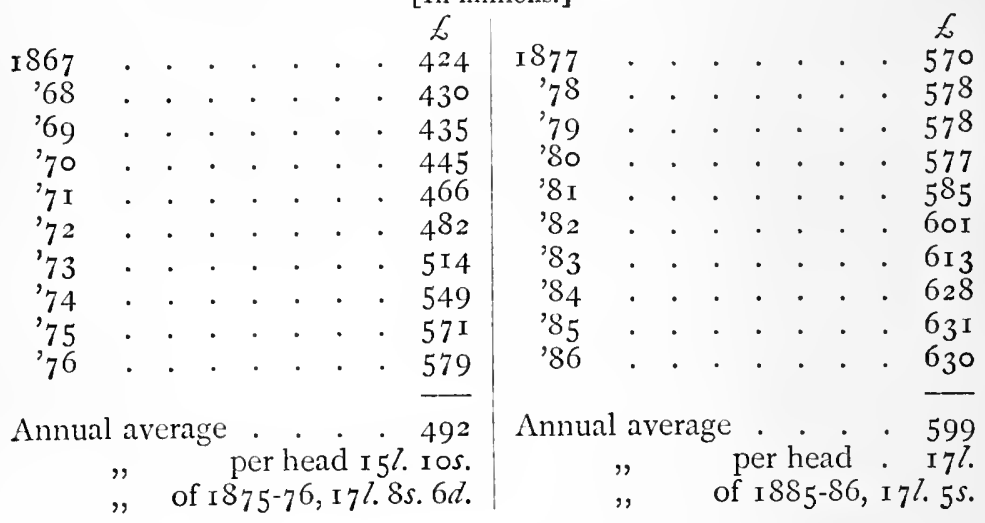

This shows a material increase even in the amount per head comparing ten years' period with a ten years' period. It will not fail to be observed, however, that 
while in the first ten years' period, the increase from the beginning to the end of the period is very great, the reverse is the case in the second ten years' period, the income having increased little all through. The average in the first ten years' period is thus the average of years of rapid growth; the second of an almost stationary period. Comparing the two last years of each period only the income per head is found to have even slightly diminished.

Unless therefore there has been something different in the progress of non-income tax incomes from what has taken place in income tax incomes, the inference would be that the appreciation of gold measured by commodities of late years is an appreciation which has not extended, or has yet extended very little, to the diminution of incomes per head, much less to a diminution of the aggregate of individual incomes; in other words it must be an appreciation of a comparatively mild type.

So far as I can judge, also, what we do know of wages points in the same direction. I shall mention the facts and circumstances which seem to point in this direction, and refer to and explain any opposing facts which seem to point in the opposite direction.

First then there is a general impression that wages have not declined at all, or at least have declined very little. Popular impressions count for very little as a rule when they can be brought to the test of figures; but if there had been at all a general and heavy fall of wages, a fall at all approaching the fall in the prices of commodities, it is an event which must have made a great deal of noise. I remember Mr. Jevons, who was present when I read my paper in $\mathrm{I} 879$, remarking to me as we left the meeting that he looked forward with some foreboding to an appreciation of money, anticipating, as we all did then, that wages would follow suit to the fall of prices, and not adverting to the possibility of a considerable fall of prices without incomes per head declining. That there have not been strikes 
and lock-outs on an extensive scale, such as Mr. Jevons anticipated, is evidence pro tanto that the general and severe fall in wages he rather looked forward to, and many more of us also looked forward to, has not in fact occurred.

As a farther proof of there being no great fall in wages, I may perhaps remind you of Mr. Goschen's puzzle on this very head when he delivered his address on appreciation of gold at the Bankers' Institute in I 883. He could not then account for wages and incomes keeping up and prices declining. Since $188_{3}$ certainly there has been no material decline of wages, and the puzzle would remain unless upon the hypothesis now put forward of an increase of real wealth, which is represented by the same money income as before, but to which the fall of prices ensures that the same income will go farther than it did.

I have still more important evidence to adduce, however, as to the generality of the impression that there has been no general fall in wages of late years corresponding to the fall of commodities. Looking over the bulky volumes of the Trade Depression Commission, we find that one of the questions put to chambers of commerce and other mercantile bodies, and to workmen's associations, bore on this very point. They were asked to say in 1885 whether wages were then less on the average than they had been in the previous twenty years. This was not precisely the question we should have liked to put for the present purpose, but allowing for the fact that the average would include the inflated years of $1872-76$, the answer that wages were not then under the average of the previous twenty, or very little under the average, if at all general, would seem to show that there can have been no material fall in money wages of late from the average of the ten years I $867-76$, which is the starting point of the comparison of the fall of prices. The answers however are most conclusive on the point. I have extracted them one and all, except one or two detailed tables which I deal 
with specially; and I have placed these answers in the appendix. They speak for themselves. They seem to be absolute proof that there could have been no great and general fall in wages of late years.

There is moreover statistical evidence of the general maintenance of wages in the leading industries of the country. In the last report on Trades Unions, by $\mathrm{Mr}$. Burnett, the labour correspondent of the Board of Trade, there will be found a series of tables, including among other particulars the standard rates of wages for a long period of years in various trades there mentioned. ${ }^{1}$ From this I extract the following particulars:

\section{E.-Comparison of Wages Rates published in the Second Report of the} Labour Correspondent of the Board of Trade on Trades Unions.

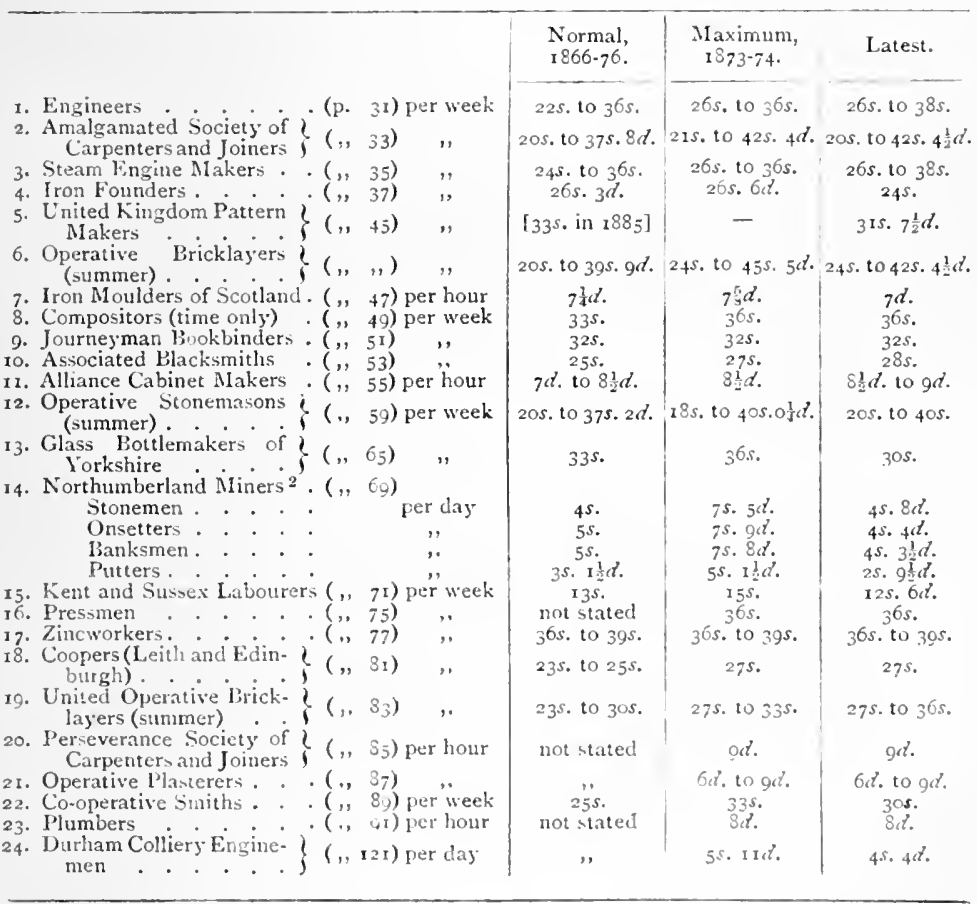

1 "Report on Trades Unions, C-5505, Sess. I 888 ," pp. I 34 et seq. A great number of rates are given. I select a few only as specimens. 
E.-Comparison of Wages Rates, etc.-continued.

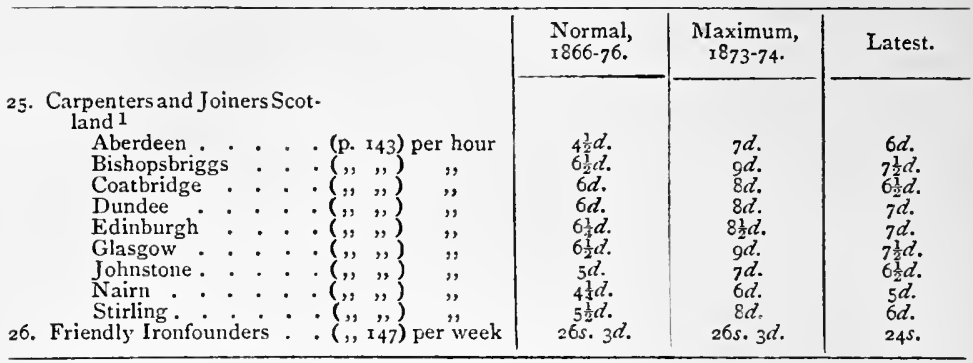

It would be most desirable to have more details of this sort, but the indication is certainly not that of greatly declining wages of late years when period is compared with period. There are some cases of decline, but on the whole the normal wages of ten or fifteen years ago are maintained. The cases where the decline takes place are mainly in the coal and iron trades, where there was special inflation in $1872-76$, and also agricultural labour, where there was also some inflation about the same date; but even in these cases the decline below the average wage as it stood before the inflated years, or even below an average for a long period, including the inflated years, is not very marked. Of course a few exceptions would not alter the general conclusion. Incessant changes are going on in the conditions of different trades and their relations to others. The average wage may be maintained throughout the labouring community, notwithstanding these special declines.

To the same effect are various tables which can be extracted from the bulky volumes of the Trade Depression Commission. I begin with two or three tables put in by Mr. Lord, the President of the Manchester Chamber of Commerce, the last being a summary of longer tables whose construction does not appear logically correct, but which contain data, as far as I can judge, pointing to the conclusion arrived at, although

${ }^{1}$ About 86 piaces given. About one place in ten picked out. 
RECENT CHANGES IN PRICES AND INCOMES COMPARED I 8 I the process by which it is actually arrived at may not appear strictly and logically correct. These tables are as follows:

\section{F.-Wages in Lancashire Mills given by Mr. Lord, President of the Manchester Chamber of Commerce.}

[Appendix, Part I., to and Report of Royal Commission on Trade Depression (p. 377).]

\section{M.-Cotton Spinning and Weaving.}

\begin{tabular}{|c|c|c|c|c|c|c|c|c|c|c|c|c|c|}
\hline \multirow{2}{*}{$\begin{array}{l}\text { Num- } \\
\text { bers Em } \\
\text { ployed. }\end{array}$} & \multirow{2}{*}{\multicolumn{2}{|c|}{ Description. }} & \multicolumn{11}{|c|}{ Average Weekly Earnings. } \\
\hline & & & & 1850. & & I 860. & & I 870. & & I 877 . & & I 88 & \\
\hline IO & $\begin{array}{l}\text { Strippers and } \\
\text { grinders . }\end{array}$ & & o & $\begin{array}{l}s . \\
\text { I I }\end{array}$ & 00 & I4 & & $\in s$. & 0.1 & $\begin{array}{lll}\mathcal{L} & s . \\
& \end{array}$ & & Es. & $\circ$ \\
\hline I 6 & Rovers . . & & o & 7 & 60 & I I & 0,0 & I I & 6 & 019 & 60 & I 8 & $\circ$ \\
\hline $5^{2}$ & Minders . & . & $\circ$ & I $S$ & 00 & I 8 & o 1 & 2 & 0.1 & I IO & O I & 9 & $\circ$ \\
\hline 60 & Winders . & ${ }^{\circ}$ & $\circ$ & 8 & 60 & 9 & 00 & II & 6. & $\circ \mathrm{I}_{4}$ & 00 & $0 \quad 12$ & 6 \\
\hline $33^{\circ}$ & IVeavers. & & o & 8 & 20 & I4 & 90 & I 5 & 60 & $\circ 16$ & 00 & 0 I 5 & $\circ$ \\
\hline 2 & Mechanics . & & I & I & 0 I & 4 & $0 \mathrm{r}$ & 6 & 01 & I IO & O' I & I 10 & 0 \\
\hline Io & $\begin{array}{l}\text { Overlookers } \\
\text { and tacklers }\end{array}$ & & t & I & 01 & 5 & O I & Io & $0: 1$ & I I 4 & $O I$ & I 13 & 0 \\
\hline
\end{tabular}

At the above rates the weekly wages of operatives working a mill of $\mathrm{t}, 000$ looms with requisite spinning, viz.:

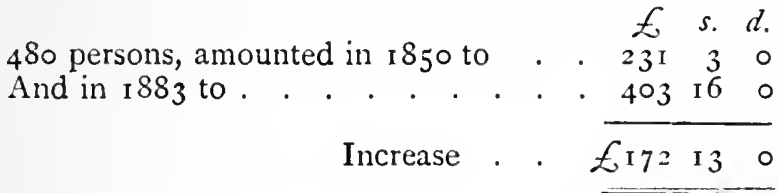

$$
=74.69 \text { per cent. }
$$

Increase in $188_{3}$ over $18_{5}$. 
In $185^{\circ}$ the great majority of weavers had only two looms each; now they average about three looms each.

N.-Cotton Spinning and Weaving, Medium Quality.

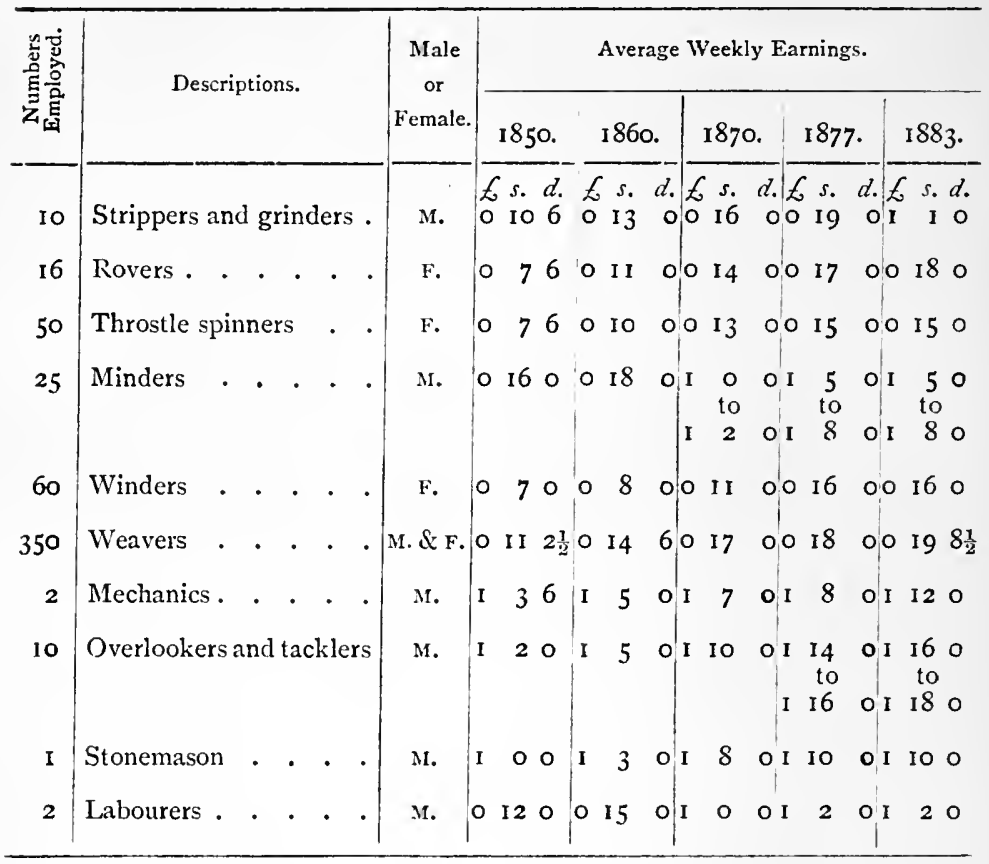

At the above rates the weekly wages of operatives working a mill of $\mathrm{r}, 000$ looms with requisite spinning, viz.:

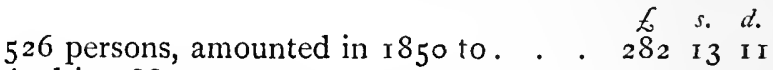

And in 1883 to......... . $51316 \quad 5$

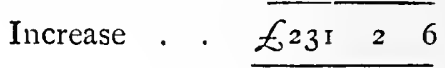

$=8 \mathrm{I} .75$ per cent.

Increase in $r 883$ over $185^{\circ}$.

In 1850 each weaver tented on the average 2.74 looms.

" 83 " " 
G.-Summary of Tables showing Increase of Wages given in several Trades in Lancashire, given in by Mr. Lord, President of the Manchester Chamber of Commerce.

[Appendix to First Report of Royal Commission on Trade Depression, p. 99.]

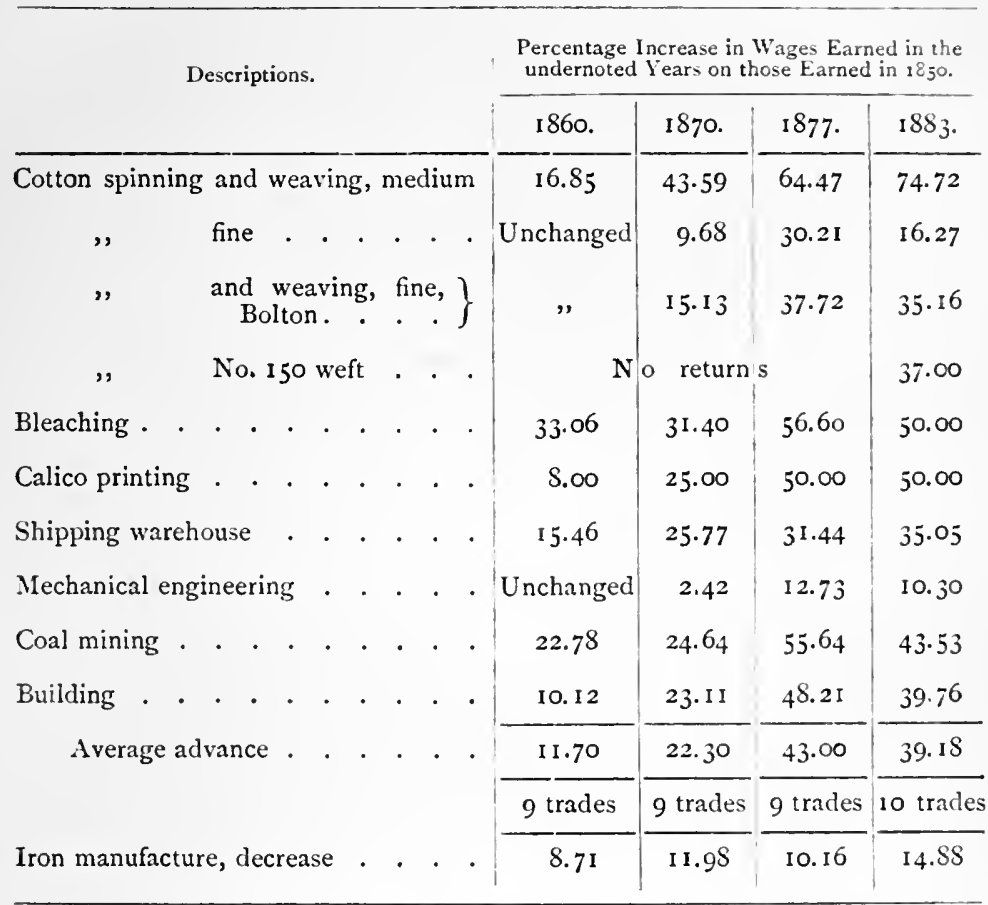

(Signed)

GEORGE LORD,

President.

Manchester Chamber of Commerce, May, $188_{3}$.

Thus it seems to be demonstrated that in the leading industries of Lancashire, comparing a date two or three years ago-since which there has been no fall in wages - with a middle period in the wages course between 1865 and 1875 , there is not only not a fall in wages, but even a rise. The details in $\mathrm{M}$ and $\mathrm{N}$ fully show this, and give the necessary strength to the above summary of more detailed tables, which it would occupy too much space to quote. 
To the same effect is a record of wages paid at Newcastle in the chemical trade, laid by Mr. Allhusen before the Commission, and which happens to be in a very convenient form for showing the facts.

\section{H.-Record of Wages Paid at the Newcastle Chemical Works from I 840 to end of 1885 .}

[Statement of Mr. Allhusen. Appendix to Third Report of Royal Commission on Trade Depression, p. 307.]

Record of Wages Paid at the Newcastle Chemical Works from 1840 to end of 1885 .

\begin{tabular}{|c|c|c|c|c|c|c|c|c|c|}
\hline Years. & \multirow{2}{*}{\multicolumn{2}{|c|}{$\frac{\text { Blacksmiths. }}{\text { Per week. }}$}} & \multirow{2}{*}{\multicolumn{2}{|c|}{$\frac{\text { Millwrights. }}{\text { Per week. }}$}} & \multirow{2}{*}{\multicolumn{2}{|c|}{$\frac{\text { Bricklayers. }}{\text { Per week. }}$}} & \multicolumn{2}{|c|}{ Joiners. } & Labourers. \\
\hline & & & & & & & Per $w$ & ek. & Per week. \\
\hline & & & & & & & $s$ & & \\
\hline I 840 & 20 & 0 & $2 \mathrm{I}$ & 0 & 20 & 0 & I 8 & ० & I $2 s$. to $13 s$. \\
\hline '50 & 22 & 0 & 23 & ० & 22 & 0 & 20 & 0 & I $4 S$. \\
\hline '55 & 24 & ० & 25 & ० & 24 & 0 & 22 & 0 & I $4 s$. to I $5 s$. \\
\hline '6o & 26 & 0 & 27 & 0 & 29 & 0 & 24 & 0 & I $6 s .$, I $8 s$. \\
\hline 72 & 28 & 0 & 30 & o & 22 & $0^{1}$ & 28 & o & $20 s$ \\
\hline$' 73$ & 32 & o & $3^{2}$ & o & $3^{2}$ & 0 & $3^{2}$ & 0 & $20 s$. to $22 s$. \\
\hline '74 & 32 & o & $3^{2}$ & 0 & $3^{2}$ & ० & $3^{2}$ & 0 & 22s. ", $24 s$. \\
\hline '75 & 32 & o & $3^{2}$ & o & $3^{6}$ & $\circ$ & $3^{6}$ & $\circ$ & 2OS. ," $22 s$. \\
\hline${ }^{\prime} 76$ & $3^{2}$ & o & $3^{2}$ & o & $3^{6}$ & 0 & $3^{6}$ & 0 & $22 s ., 24 s$. \\
\hline$' 77$ & 30 & 6 & 30 & 6 & 34 & o & 34 & $\circ$ & $20 s$. to $22 s .6 d$. \\
\hline${ }^{\prime} 78$ & 28 & $\circ$ & 28 & $\circ$ & 30 & $\circ$ & 30 & $\circ$ & I $8 s$. \\
\hline '79 & 26 & 0 & 26 & $\circ$ & 28 & ० & 28 & $\circ$ & I $7 s$ \\
\hline 'so & 27 & 6 & 27 & 6 & 29 & 6 & 27 & 6 & I $8 s$. \\
\hline '8 I & 30 & $\circ$ & 30 & $\circ$ & 29 & 6 & 29 & 6 & I $8 s$ \\
\hline '82 & 30 & $\circ$ & 30 & $\circ$ & 29 & 6 & 29 & 6 & I $8 s$ \\
\hline${ }^{\prime} 8_{3}$ & $3^{I}$ & 6 & $3 I$ & 6 & 29 & 6 & 29 & 6 & $\mathrm{I} 8 \mathrm{~s}$ \\
\hline '84 & $3 I$ & 6 & $3 I$ & 6 & 29 & 6 & 29 & 6 & I $8 s$ \\
\hline '85 & 27 & 6 & 28 & 6 & 28 & o & 28 & $\circ$ & I $8 s$. \\
\hline
\end{tabular}

Note.-Up to year I 87 I a week's work consisted of 6i hours; from that period, 54 hours.

${ }^{1}$ Sic in original; but ought not the figure perhaps to be $325 . ?$ 
To the same effect is a similar table put in by Sir I. Lowthian Bell as to coal mining, though here the short period of inflation in $1873-74$ is very distinctly marked, and the normal rates of wages before and after that date are in this case not distinctly marked:

\section{1.-Earnings of Coal Hewers in Durham.}

[Statement of Sir I. Lowthian Bell. Appendix, Part I. to II. Report of Royal Commission on Trade Depression, p. 34I.]

\begin{tabular}{|c|c|c|c|c|c|}
\hline Year. & $\begin{array}{l}\text { Weight of Coal } \\
\text { Worked. }\end{array}$ & Daily Earnings. & Year. & $\begin{array}{l}\text { Weight of Coal } \\
\text { Worked. }\end{array}$ & Daily Earnings. \\
\hline & cwts. & s. $\quad d$. & & cwts. & s. $\quad d$. \\
\hline 1871 & 83.87 & $4 \quad 5.67$ & I 878 & 90.00 & $\begin{array}{ll}5 & 0.55\end{array}$ \\
\hline '72 & 76.03 & $5 \quad 7.40$ & '79 & 74.63 & $4 \cdot 4^{2}$ \\
\hline 73 & $71.9^{6}$ & $8 \quad 3.54$ & 'so & 91.96 & 3.73 \\
\hline '74 & 70.80 & $\begin{array}{ll}6 & 10.65\end{array}$ & 'S I & 94.79 & $4 \quad 10.20$ \\
\hline '75 & 70.14 & $5 \quad 9.13$ & '8z & 107.74 & $\begin{array}{ll}5 & 2.57\end{array}$ \\
\hline 76 & 78.64 & 510.16 & ${ }^{\prime} s_{3}$ & 107.21 & 3.53 \\
\hline$' 77$ & $86.9^{6}$ & $5 \quad 3.9$ & '84 & 106.96 & 1.27 \\
\hline
\end{tabular}

Putting all the evidence together, there seems little doubt that in staple trades wages have been maintained, or nearly so, as compared with the average of i 867-77. There are exceptions, but not sufficient to obscure what the general movement has been.

To be quite fair it may be useful to conclude this review with a table of agricultural labourers' wages, in which, as already referred to in connection with the figures from the Trades Union Report, there is apparently a decline, at any rate from the high level of I 872-76. The table in question was put in before the Royal Commission on Trade Depression by Mr. Druce, who had been one of the Assistant Commissioners of the Royal Commission on Agriculture some years before, and is as follows: 
Rate of Money Wages of Ordinary Agricultural Labourers, $1870-7 \mathrm{I}$ and I 880-81. Statement of Mr. S. B. L. Druce.

[Appendix to 3rd Report of Royal Commission on Trade Depression, p. 296.]

APPENDIX A.-II.

K.-Statement put in by Mr. S. B. L. Druce. (See Question 9, I 53.)

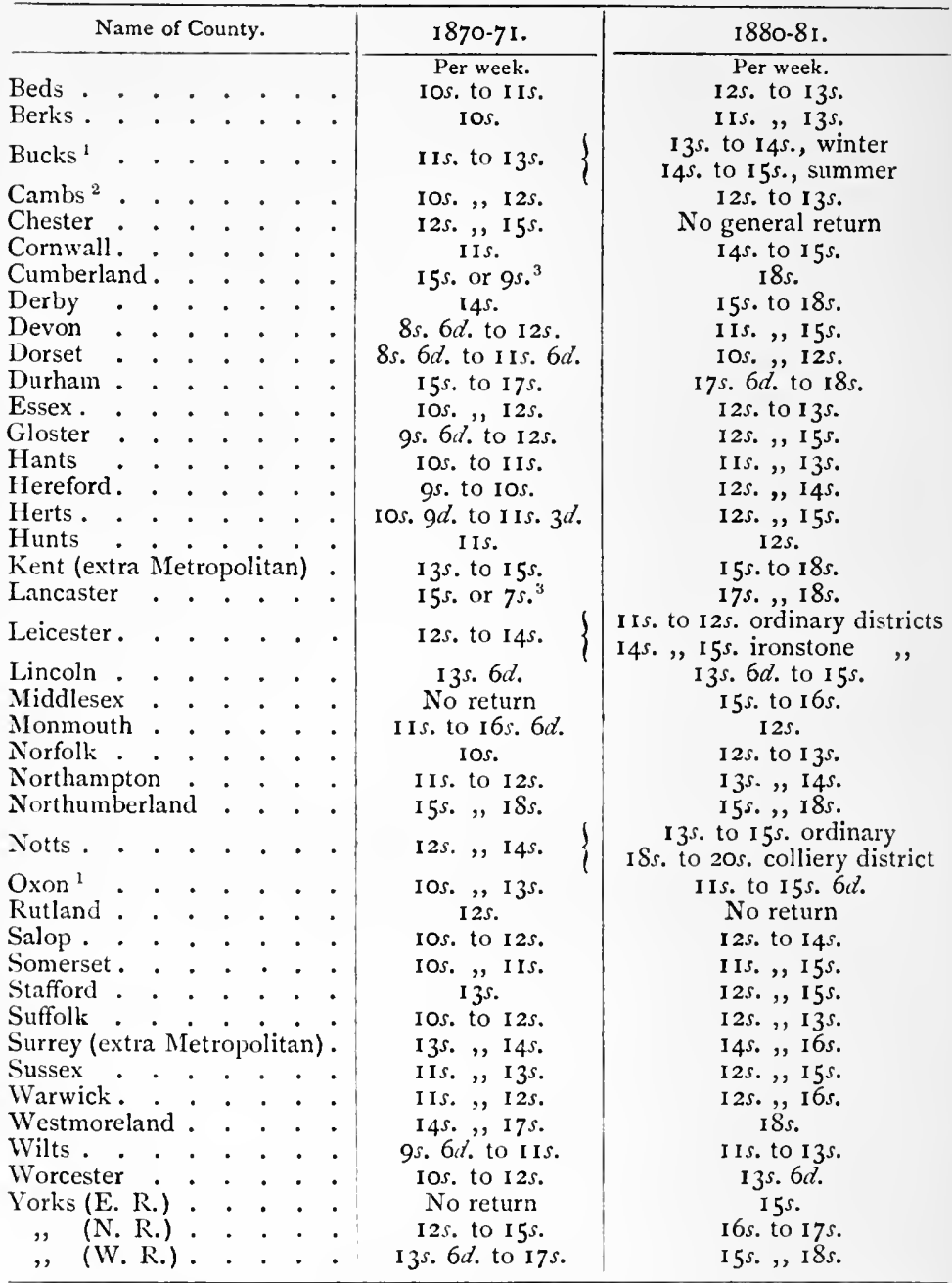

${ }^{1}$ Extracted from the Report of the Commissioners on the Employment of Women and Children in Agriculture, r867-68.

${ }^{2}$ For quarter ended Michaelmas, 1869 (harvest money not included).

3 The latter with board and lodging. 
From this it is evident that the fall in agricultural wages recently which has undoubtedly taken place, can hardly have been very great from the normal average of i $867-77$, as marked by the wages of $1870-$ $7 \mathrm{I}$ included in the above table, but must have been from the high level of I880-8I, to which they had risen in the interval. This is evidently the case, in fact, if we look at the figures for agricultural labour in the above Trades' Union Table E. Even agricultural labour cannot be said to have sustained a material fall from the high average of $1867-77$, though there is a distinct decline from the maximum of those years.

While revising the proofs of this paper, I have had the advantage of receiving a copy of Major Craigie's most valuable paper on the Agricultural Labour Bill read at the Farmer's Club on the roth instant. Major Craigie's conclusion is that at the present time, as compared with ten years ago, the drop in that part of the labourer's wage paid in money is from i 8 to 20 per cent. in the east, and in the rest of England about 12 per cent. He adds that as the numbers of labourers are about ${ }_{7}^{5}$ ths of the whole in the latter districts, perhaps a drop of i 4 per cent. will represent the loss of wages over the farmed surface of England. But this is comparing the present time with the high level ten years ago, and the average drop would of course be less comparing ten years' period with ten years' period. Major Craigie at the same time gives most interesting tables showing the real improvement in the labourer's position notwithstanding the fall in money wages, which confirms in the strongest way the present argument that the appreciation is a case of appreciation measured by commodities in an advancing community, so that money incomes, though just maintained, or not quite maintained, go further than they did before.

It would be needless to multiply figures. The common impression as to wages having been maintained, while the prices of commodities have fallen, is not only confirmed by the proof above given as to 
income tax incomes having been maintained, and by the statements of numerous observers with special means of knowing, but by actual tables of wages statistics derived from a variety of sources, and all telling the same tale. The appreciation of money, therefore, as far as England is concerned, is an appreciation unaccompanied by any serious general decline in average incomes and wages per head, much less by any decline in the aggregate national income.

It should be added, however, that the maintenance of individual incomes at the former average level has at most been barely accomplished, and no more. The appreciation has very nearly, if not quite, been one of the second type, viz.: where not only prices of commodities fall, but where average incomes expressed in money decline.

It is not necessary for confirmation's sake to go abroad, but it may be useful to do so, while the facts cannot but throw light on the further question, which is a most interesting one, as to the area of the appreciation.

As regards Germany, I have only to refer to Dr. Soetbeer's "Materialien," from which I extract and place in the Appendix certain particulars as to wages and incomes. Dr. Soetbeer uses these very particulars to disprove the assertion that gold has appreciated, but this is with reference to the peculiar meaning or no meaning of the word which has been productive of so much confusion in all these discussions. We are at liberty to use the same particulars to demonstrate the character and degree of the appreciation as we have limited and defined the phrase.

With regard to Belgium the figures are contained in a blue book issued last session, ${ }^{1}$ compiled from an inquiry into the wages and condition of the working classes, which has just been made by the Belgian Government. From this blue book I have compiled 
and put in the Appendix one or two short tables. The figures certainly show a fall in the iron and coal trades, but not a general fall at the present time as compared with the average of $1867-77$. I desire to refer especially to the table in which the wages are directly compared with the quantities purchaseable at the average prices of the years in question. This is the most direct way of course of putting the rise in real wages. Whatever the intermediate changes in money have been, and although they are no higher at the end than the beginning, their purchasing power has been immensely increased.

Similar particulars for France yield the same conclusion, the difficulty here being to show any general decline. I do not make any extracts, however, and may content myself with a reference to the elaborate particulars at p. 132 et seq., Appendix, Part II., Second Report of the Royal Commission on Trade Depression.

Similar particulars for Italy are to be found in the Report of the Royal Commission on Trade Depression. To corroborate them I extract and put in the Appendix an extract from a report by Mr. Kennedy, lately Secretary of Legation at Rome, which appears to be conclusive on the point.

Thus the phenomenon of falling prices of commodities and stationary or, at least, not greatly declining incomes and wages, appears to be very general in gold-using countries. It does not follow that the result should be the same in every country. We cannot assume the rate of advance in material progress to be the same in each, or that the margin between the average prices of commodities and the average income should widen in the same way. But although the same result precisely is not to be looked for, if we could measure with the necessary degree of fineness, we cannot but assume that the communities of all the countries named are progressing to some extent, and that consequently, if commodities fall and incomes remain 
stationary in one, the same results should appear in the other with only minor divergencies. When we find, therefore, that everywhere in Europe at least, wages and incomes remain stationary, or at least fall much less than the average prices of commodities, we cannot but conclude that the type of appreciation is everywhere the same, and that we are in the presence of a phenomenon which extends over a wide areathat phenomenon being an undoubted rise in the purchasing power of money measured by commodities, but this rise being unaccompanied by any corresponding diminution of wages and incomes which would not unnaturally be looked for, but which reflection shows need not take place in advancing communities when prices fall.

\section{The Appreciation or Depreciation of Silver.}

The appreciation of gold measured by average commodities being thus established, and the appreciation being of a type in which, as the communities affected are advancing at the same time in material wealth, there is no diminution, or at any rate no great diminution, of average incomes, the question arises, what are the similar facts respecting silver?

Of course, as regards the relation of silver to commodities, there can be no question. In each case, whatever fall in the gold prices of commodities is shown, would either be less or more than the fall in the gold price of silver by an exact percentage. There is no room for theorizing. It is a case of exact measurement, with this difference only, that silver and gold can be measured against each other with more exactness than any other commodity against one or the other.

It would seem to follow also that on the whole, if we avoid extreme years, the average fall in commodities measured by gold rather exceeds the average fall in silver measured by gold. In other words, instead of speaking of the depreciation of silver, though that is a 
correct enough phrase when we measure it by gold, we should be quite justified in speaking of the appreciation of silver when we measure it by the average of commodities in the way above described.

This is true when we measure silver in gold-using countries, but what is true there, a little reflection will show, must also be true in silver-using countries. In these days of quick communication it must be assumed that every improvement is for the benefit of consumers generally in the long run, though there may be important exceptions for a time when a backward country is first brought into contact with the rest of the world, and all its produce obtains an enhancement of value. Still the latter cases are exceptions, and it may be taken for granted that a rise or fall in prices in one locality, if at all general, is accompanied by a similar rise or fall throughout the world. I assume then that silver has appreciated a little, measured by commodities, in those countries at least which, like India, are in close and intimate intercourse with the civilized world. If necessary the exact correspondence between Indian and European prices could be shown, but it does not seem worth while to labour the point.

But to what type does the appreciation of silver conform in India? Clearly, if the community of India had been advancing as European communities, and especially the community of the United Kingdom, have been advancing, there would be a material difference in the growth of incomes in India and England respectively. Silver prices having fallen very little compared with gold prices, then, in an advancing community using silver, money wages and incomes ought to have risen in order that wages and incomes may maintain the same relation to commodities that they do in advancing gold countries, where, as we have seen, wages and incomes remain stationary while prices fall. The one change would be the exact counterpart of the other. But, so far as I have been able to learn, no such increase in Indian wages and incomes has, in fact, taken 
place. On this head I can only accept the statements of Indian authorities, and Mr. Barbour, who is in the best position to be an authority, is quite explicit on the point. In his evidence before the Royal Commission on Gold and Silver, he was asked by the Chairman (Question I, 162) whether, with respect to labour, the value of silver had decreased in India, and he replied:

"I think that the wages of labour have risen in large towns, and along the railways, and in places where large manufactures have been started, and especially the wages of skilled labour. As regards the great mass of the people, I do not think there has been much change; and very often the labourer is paid in kind [paid by produce], so that one could not say that the money wages had risen or fallen. I have made some inquiries as to the cost of carrying the mails by runners. I applied to the head of the post office, who obtained from the auditor of the post office accounts a statement of the wages paid to what are called postal runners, and I found very little change in the rates. I will put in a paper giving those rates: it goes back for a considerable number of years. There is a rise in the rates up to, I think, about I 870 or so, and since that there has been very little change-a slight tendency to rise."

"First Report of Gold and Silver Commission," Question I, I 62, p. 60.

Nothing more need be said, but I may add that I am led to believe from conversation with residents in Inclia who are shrewd observers, that the authorities are right. There has been no general or material rise in wages and incomes in India in the last ten or fifteen years. What I believe has occurred is a rise of wages in the large cities of India and in some districts near the gold mines, not sufficient to affect greatly the general average. The conclusion consequently is not that the facts as to appreciation of gold in Europe measured by commodities, and as to a less appreciation of silver in India measured by commodities, implying a depreciation of silver measured by gold, are out of harmony, but that 
India, as a community, has not of late been advancing as European communities have advanced. Hence the absence in India of many of the usual phenomena of depreciation of money, though some of them must have accompanied an increase of wages and incomes in India, such as would undoubtedly have taken place of late if India had been an advancing community, although the silver prices of commodities had fallen a little.

I make these observations with some diffidence, and in the absence of fuller information, which is much to be desired, as to prices and wages in India. It would be most interesting to know, on its own merits, how much the people of India have been gaining in material wealth of late years. It appears somewhat remote to bring in the relations between gold and silver prices and gold and silver wages as having a bearing on this point, but with good statistics the topic should be in no way remote.

Similar statements, it may be noticed, are made by consuls of the United Kingdom in silver-using countries, in reply to the wages query of the Royal Commission on Trade Depression contained in the circular sent to H.M.'s representatives abroad by that body. From Mexico, from China, from Japan, or at least from many places in these countries, and from other countries also, the report is that there has been no noticeable rise of wages for twenty years, or since 1870 . From Russia and Austria, which are paper countries, but with little discount on the paper compared with silver, there is much the same reply.

The inference as to the slow growth of silver-using communities as compared with that of gold-using communities is a specially important one, as we shall afterwards see. It bears upon the question of the future demand for gold compared with that of silver. For the present purpose, however, I am using it merely to show the nature and extent of the depreciation of silver. It can hardly be spoken of anywhere as a depreciation at all, even when the measure is the income per head 
of a community, and there is obviously no depreciation, but appreciation only, when the measure is that of the average of commodities.

At this point we may notice what was adverted to in the opening remarks with reference to the puzzle caused by there being no phenomena of depreciation of silver in India answering exactly to its depreciation measured by gold in Europe. Clearly the correspondence cannot be exact, because the economic movement in India and in Europe is not the same. The difference accounts, especially, I think, for that most curious puzzle of all, which seems so insoluble, viz., the slowness with which wages adjust themselves in England and India to the changed ratio between gold and silver, so that the Indian producer who has no more wages to pay, while his produce commands relatively more silver than the produce of the English producer commands of gold, in comparison with what was formerly the case, appears to have a permanent advantage over the English competitor. Clearly if real wages are rising in England generally more than they are in India, wages here may not apparently be adjusted to this specific change, because along with the apparent adjustment required another change has to be adjusted, viz., the increase in real wages. Thus the English producer appears to be more and more handicapped by his Indian competitors, because he cannot get money wages down. If, however, there had been no fall of prices and no fall in silver, this difficulty would have been the same, only it would have taken the form of rising wages here with prices stationary, instead of the form of stationary wages and falling prices. Always the real changes must have been the same. The change, however, implies no insuperable difficulty in the English competition maintaining itself. Real wages increase because the work done is better generally, and though there may be momentary difficulties in special trades, always this improvement in work will tell.

The facts as thus described also appear to account 
for the extent of the recent flow of silver to the East, on which there appears to be some misconception, and on which I may be allowed to say something, as the name of a revered authority, Mr. Bagehot, whom I am specially bound to defend, has been brought into question. Mr. Bagehot, it is said, when the depreciation of silver measured by gold began, discouraged a panic feeling by predicting a great export of silver to the East, and a continual demand for silver as it fell in value, so that unlimited depreciation was not in prospect. The event, it is said, has belied his prediction, and shows that his appeals against panic were not well founded.

I remember no conversation with Mr. Bagehot having the purport stated, and I was in close communication with him till he died. What he was always speaking of was a sudden depreciation of silver such as took place in 1876 , when the market fell away suddenly to $3 s$. I I $d$., and of this he predicted that it would speedily right itself by stimulating exports of goods from India, and so creating a demand for silver for export to India. In this Mr. Bagehot was undoubtedly right. Indian trade was stimulated, and there was a large export of silver from Europe to India immediately after Mr. Bagehot made his statement as to what was going to happen, while the price of silver recovered to over $4 s .6 d$., and only fell very gradually after that for a good many years until, in I 886, another fall occurred such as Mr. Bagehot wrote of in 1876 . Mr. Bagehot by no means predicted that silver would go back to its ancient level, nor was any such idea in his mind. He was the last man in the world to discount the future or to take very long views.

Since Mr. Bagehot died, however, the circumstances relating to both silver and gold have very greatly changed, and I am tolerably confident that he never said anything to imply a belief that the stimulus to Indian trade, which he anticipated from a momentary great drop in silver, would be permanent and continuous 
in totally different circumstances. The new circumstances are what economists would recognize as rather an appreciation than depreciation of silver, and this aspect of the fall in silver was certainly not so visible before 1877 , when Mr. Bagehot died, as it has since become.

I have further to point out that the flow of silver to India of late years has in fact been on a considerable scale. Since 1877 the influx into India in tens of rupees has been:

\section{Net Imports of Silver into India by Sea in the undermentioned Years.}

[In thousands of tens of rupees.]

\begin{tabular}{|c|c|c|c|}
\hline $\begin{array}{c}\text { Year ended } 3 \text { Ist } \\
\text { March. }\end{array}$ & Imports. & Exports. & Net Imports. \\
\hline $\begin{array}{r}\text { I } 874 \\
\prime 75 \\
, 76 \\
\prime 77 \\
, 78 \\
, 79 \\
, 80 \\
' 81 \\
' 82 \\
' 83 \\
' 84 \\
' 85 \\
' 86 \\
' 87 \\
' 88\end{array}$ & $\begin{array}{r}4,143 \\
6,052 \\
3,464 \\
9,992 \\
15,776 \\
5,594 \\
9,605 \\
5,316 \\
6,466 \\
8,358 \\
7,408 \\
9,110 \\
12,386 \\
8,220 \\
-\end{array}$ & $\begin{array}{c}\mathrm{I}, 648 \\
\mathrm{I}, 4 \mathrm{IO} \\
\mathrm{I}, 909 \\
2,793 \\
\mathrm{I}, \mathrm{I} 00 \\
\mathrm{I}, 623 \\
\mathrm{I}, 735 \\
\mathrm{I}, 423 \\
\mathrm{I}, 087 \\
878 \\
\mathrm{I}, 003 \\
\mathrm{I}, 864 \\
780 \\
\mathrm{I}, 064 \\
-\end{array}$ & $\begin{array}{r}2,495 \\
4,642 \\
1,555 \\
7,199 \\
14,676 \\
3,97 \mathrm{I} \\
7,870 \\
3,893 \\
5,379 \\
7,480 \\
6,405 \\
7,246 \\
1 \mathrm{I}, 606 \\
7, \mathrm{r} 56 \\
9,2 \mathrm{I} 9\end{array}$ \\
\hline
\end{tabular}

And I maintain these are large figures. They would hardly have taken place unless there had been some increase of wages and incomes in India, though, as we have seen, there is no large general increase of such wages and incomes. India remains a consumer of silver on a large scale. No doubt for many years, owing to the great advance in prices and wages which took place in India between I 850 and I 870 , India was a consumer 
on a still larger scale, just as England was a large consumer of gold for monetary purposes in the same years; but while in the last fifteen years England has ceased to be a consumer of gold, India remains a large consumer of silver. The difference arises in part, I believe, from the fact that, while gold has appreciated greatly, measured by commodities, and gold incomes have not increased, silver has appreciated only a little, measured by commodities, and silver incomes, though silverusing communities have not advanced as gold-using communities have done, have nevertheless advanced a little.

I have to apologize for this digression as to the flow of silver to the East, but my excuse must be the expediency of showing that all the facts, when rightly understood, are in harmony. The flow of silver to India should be in strict relation with the degree and nature of depreciation in its money and the economic progress of its inhabitants.

\section{Chavacters of Appreciation and Depreciation at Different Periods.}

Making the broad distinction we have made between the course of prices and incomes, it may be useful to look at what happened in previous periods of appreciation or depreciation, and see how they may be characterized with reference to this distinction. A good deal of light seems to be thrown on the subject by so doing. Much doubt is removed as to when there has been appreciation or depreciation.

We may take first the period following the Australian and Californian gold discoveries. Mr. Jevons showed for this period an appreciation of money, measured by staple commodities in England, amounting to about 15 per cent. As you are aware, however, the statement was not universally accepted as representing the change in prices of commodities generally; and still retaining the confused idea as to appreciation 
being something absolute and independent, which is so difficult to get rid of, economists argued that Mr. Jevons had not made out his case. I have been told myself that because I agreed that the limit of the depreciation measured by commodities in the twenty years after I 850 was a very narrow one, I must admit that the subject is extremely difficult, and we may equally conclude now that appreciation is not established with any certainty! When we bring in the question of incomes, however, the character of the period which Mr. Jevons described is placed beyond all question. If the margin of the rise in the prices of commodities was a narrow one, the rise in incromes and wages was immense. As to income tax incomes, the facts are notorious. The income tax income per head of the people of the United Kingdom, which was about $\delta_{11}$ just before 1850 , amounted about 1875 to over $\delta_{17}$. There is reason to believe moreover that the growth of working class incomes corresponded, on which head I may be allowed to refer to the papers on the "Progress of the Working Classes" which I read to the Society in 1883 and $1885^{\circ}$ The case between 1850 and 1870 therefore was one in which there was a moderate depreciation of gold measured by commodities, but as the community was advancing in real wealth at the same time the improvement in its condition was indicated by the larger growth in incomes than in the prices of commodities. Scientifically stated then, there was unquestionably depreciation between 1850 and 1870 ; the depreciation being that characteristic of an advancing community, when prices of commodities rise a little, and incomes rise a great deal.

Looking at the matter broadly the difference between that period and the later period since 1873 may simply be described as being that while the increase in real wealth in the two periods was much the same, the community received the benefit in the former period in the form of a great rise in money incomes accompanied by

\footnotetext{
Sicf: Statistical Socicty's "Journal," 1883 and 1885 , and for the first of these essays postea.
} 
a much less rise in commodities, and in the latter they have received the benefit in the form of stationary and almost slightly declining incomes, accompanied by a great fall in the prices of commodities. The facts are all in harmony. The substantial result to the community, apart from the redistribution of wealth involved, is the same in both periods, but the money expressions and the changes in these money expressions are different.

Going back a little further, again, it is easy to see that the period between the early part of the century and the eve of the gold discoveries of $1848-50$ was one of great likeness to the present period since 1873 . In both there was the same steady fall of general prices, a fall which has long been recognized, in spite of the unwillingness of many economists, such as Tooke, to speak of it as a rise in the purchasing power of money. Now we must add that there is a farther likeness in the circumstance that between the early part of the century and i 845 average money incomes increased very little. Nothing is more remarkable than the small advance of income tax incomes between the date when the income tax was left off in $I_{15}$ and its renewal in $1 S_{43}$, there being in fact no advance, or barely any advance, allowing for the increase of population. It is equally on record, though there are no exact statistics, that money wages during the same period were with difficulty maintained. Hence the general likeness between the period I I 5-45 and the present time. Appreciation of money shows itself in both periods in much the same way, and is of much the same type, though I am inclined to think that the advance in real wealth before I 845 was not so great as it has since been.

Going back still further, it will be found that towards the close of last century, and during the early part of the present century, there was a remarkable rise of prices, and an equally remarkable, if not more remarkable, rise of incomes, indicating that, on the whole, the community was then advancing. In thus speaking, I 
leave out, of course, that part of the rise of prices and incomes which answered to the depreciation of paper. Apart from this element, there was a great rise in prices and incomes in the last quarter of last century and the beginning of the present century, though rather more in incomes than in prices. The data are too scattered to enable us to speak with much exactness, and it would take us too far at present to go into historical investigations; but that there was at the time spoken of depreciation of money, measured by commodities, such as we had between 1850 and 1870 , is undoubted, and there was at least sufficient advance of incomes to raise a question whether the whole change was not of the same type, though the degree of advance in real wealth was not nearly so marked as in the period $1850-70$.

It is not proposed to go back any farther at present; but enough has perhaps been said to show how fruitful such investigations may be made when the relations between prices and incomes are kept steadily in view, and how necessary it is to allow for the economic movement in a community in studying the signs of appreciation or depreciation of money. The apparent inconsistencies between a fall of prices and no fall of wages, or no corresponding fall, and vice versâ, are all to be reconciled. When this is done there can be no sort of doubt as to the changes in the purchasing power of money at different times in the last hundred years.

Equally when we turn to another field the utility of the comparison is shown. In India, as we have seen, since about 1873 , there is notably no depreciation of silver measured by commodities; there is perhaps a slight appreciation. There appears also to be a slight increase of incomes, though not much. Just before I 870 , however, there was unquestionably depreciation of silver in India, marked by a rise of both prices and incomes, and a little more in incomes than in prices. In India the real progress in both periods has been less than in Western Europe, but the facts again are all in conformity. As the community advances, though some- 
what slowly, depreciation of money measured by commodities is accompanied by a greater increase in money incomes than in the prices of commodities. On the other hand a stationary value or slight appreciation of money measured by commodities is accompanied by stationary or only slightly rising incomes.

This characterization of the various sorts of appreciation and depreciation may be used generally in comparing different countries at different times. The fact of appreciation or depreciation of money is one which must be frequently kept in view in economic comparisons, and the nature and degree of appreciation or depreciation must equally be considered. A study of the economic movement in the chief countries of the world, and in different provinces of the same countries for the last century, if not longer, comparing prices and incomes all through, could not but be most instructive.

A useful explanation with regard to the employment of certain phrases in economic discussions appears likewise to be suggested. We often hear of certain things, such as war, causing high prices, and other things, such as abundant harvests, causing low prices; and the high prices are spoken of as "dearness," and the low prices as "cheapness." But when the expressions are analyzed it will be found that the "dearness" and "cheapness" can have really nothing to do with money prices; that real "dearness," that is a high price in relation to income, and real "cheapness," that is a low price in relation to income, are intended; while it is farther obvious from what has been said here that "dearness" and "cheapness" in this sense may co-exist or come about with any conceivable range of money prices or any conceivable change in that range. Things may become cheap in this sense when money prices rise and dear when money prices fall-not perhaps in a short period, and especially as regards a particular article, money then being the most stable measure, but certainly as regards an average of articles in those long 
periods when it is found convenient to invent measures for money itself. Much confusion has arisen from the neglect of this distinction. The common notion that war prices are high money prices, which is so inveterate, although it is absolutely disproved by experience as well as by theory, is an instance. Perhaps-to give an illustration from present controversies-the question whether abundance of commodities or scarcity of money causes a given appreciation of money, which we shall presently have to notice, would never have become a question at all, if it had been clearly recognized from the first that the effect of abundance of commodities properly belongs to a question of real cheapness, where the ratio of the commodities to incomes is involved, and that the effect of scarcity of money properly belongs to a question as to the range of money prices only where the ratio of commodities to money is involved, so that there is no antagonism between the two causes as they are not related to the same class of effects.

\section{The Causes of Appreciation and Depreciation.}

What are the causes of the changes in money with which we have been dealing? I approach this topic with great diffidence. The changes have been rung, as you are aware, on the antagonism, or supposed antagonism, which has just been mentioned, between the influence of abundant commodities and the influence of scarce money on prices. It has become extremely difficult for a modest student like myself to strike in with a few appeasing words, and show that there is a great deal to be said on the subject which does not touch on the conflict at all, and that the conflict itself is more about words than things.

I would begin by saying that there is, necessarily, ambiguity in asking generally what are the causes of the appreciation of gold or depreciation of silver? There is liability to misunderstanding, as we have seen, in the fact that there may be appreciations and deprecia- 
tions of quite different types, and what is true of one may not be true of another; but in addition causes are hardly to be treated in this general way when we are dealing with economic phenomena, or indeed with any scientific phenomena. We should hardly ask what are the causes of the sun rising in the east, without limiting the question in some way so as to show what facts are assumed, and where the point as to the rising in the east comes in. In the same way we must limit and define the inquiry as to the causes of appreciation and depreciation of money at one time as compared with another.

I have to begin then by drawing attention to what is stated in the preliminary remarks, to the effect that there must be a sense in which the ascription of every case of appreciation of money to a contraction of money, and every case of depreciation to an expansion, must be true. There must be relative contraction and expansion whatever the absolute changes may be; and as there is an incessant action and reaction in all economic phenomena, this means that contraction of money may always be taken as the cause of an increase of the purchasing power of money, in the sense that such an increase necessarily implics contraction as compared with what would otherwise be. We may infer the one fact from the other, which is the inportant point for us, without troubling our heads very much about metaphysical ideas of cause.

Using the words contraction and expansion in this sense, however, a very different view would be taken of the causes and order of the phenomena from what would be taken by anyone attaching a totally different meaning to contraction and expansion, and overlooking the relative nature of the expressions as thus used. Both disputants might be right, but then they would not be talking of the same things.

According to this view, then, as already explained, it becomes convenient, to say the least of it, to treat all the changes, whether in the demand for or supply 
of money or the demand for or supply of commodities as changes in the circumstances of money, although in discussions where money itself is treated as the measure the same circumstances may be spoken of as changes in the circumstances of the things which money measures. Everything turns on the point of view. Thus, a general and continued fall of prices being proved, and commodities being taken as the measure of money, the circumstances imply a contraction of money as compared with the time just before. Whatever the real changes may have been, and whatever may be the ultimate causes of one thing exchanging at a particular ratio for another, for the purpose of the special inquiry, where money is being measured, the changes must be spoken of as changes in money, and as the purchasing power of money is increased, there is contraction of money.

It would only vary the language a little to substitute for the phrase contraction of money increased cost of production, just as it would be to substitute in the opposite case lowered cost of production, in both cases relatively to commodities. Relative contraction and expansion of money may either be conceived of as causes or effects of changes in the ratio of exchange with commodities; if we conceive of them as effects we should speak of the relative change of cost of production as the cause; but the result is the same so far. It is the circumstances of money we must view as having changed.

It appears to be possible, however, to go farther, and to point out that by comparison, if we attend carefully to the terms of the comparison, we can say positively that the recent change from a high to a low level of prices is due to a change in money, of the nature or in the direction of absolute contraction.

If we look at the matter dynamically, what we find is that over a long period of years the circumstances affecting the two factors in the ratio between money and commodities, viz., money on one side and com- 
modities on the other side, so varied from moment to moment at one time that the ratio remained steady, and so varied at another time that the ratio changed. If at the moment of transition from the steady to the changing ratio it is found that the circumstances of the one factor have not altered dynamically, but that the progress remains what it was before, then it is a proper conclusion that the circumstances of the other factor have altered dynamically, and that the change in the ratio is to be ascribed to the change in that other factor.

This description applies exactly to what went on between commodities on the one side and money on the other from 1850 to 1873 , and the change which occurred about the latter year. Before i $\delta 73$ for rather more than twenty years the circumstances of commodities and of money, supply on one side and demand on the other, were undoubtedly in a state of constant flux, but the movement was such in both cases, the changes so kept pace with each other, that the ratio remained unchanged, or if anything gold fell and commodities rose. A bout 1873 there was an alteration, but according to the best observation the movement in commodities continued what it had been, the quantity increasing at as great a rate as in the period just before, but not at a greater rate. The inference seems conclusive therefore that after 1873 the alteration in the economic movement was in money, and to this must be ascribed the change of prices which has occurred.

It is only an additional confirmation of this view that actual changes in the movement in money in a direction likely to lead to a fall of prices can be referred to. The argument, on the assumption that the movement in commodities has been correctly described, would be complete, even if we knew less about the changes in money than we do. Whatever may be the qualities or conditions which make money exchange at a particular ratio for a group of commodities, then the changes in those conditions from day to day which made money 
remain steady in price towards commodities or to fall a little before 1873 , must have undergone an alteration in their course about 1873 . The effect being different, and the course of commodities being the same after 1873 as before that date, it must have been the course of money that changed.

The actual facts that we find as regard changes in the movement of money before and after 1873 are most striking.

In the fourteen years ending I87I, which was the last year before me when I wrote the paper in 1872 already referred to, the net imports of gold into England, the excess of the imports over the exports amounted to no less a sum than $£ 67,776,000$, viz.:

\section{Excess of Imports of Gold into the United Kingdom over Exports.}

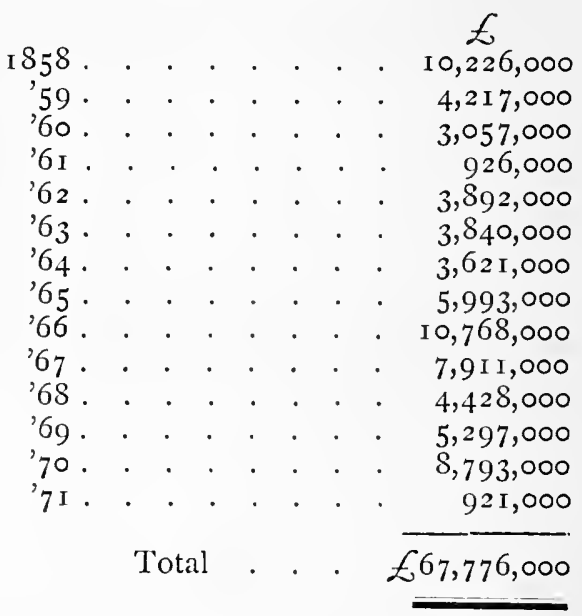

This is an average of about $£ 5,000,000$ per annum or nearly so. In the following sixteen years, however, there has been hardly any excess, as the following statement shows: 


\section{Excess of Imports of Gold into the United Kingdom} over Exports, I 872-87.

\begin{tabular}{|c|c|c|c|c|c|}
\hline & & & & Excess of Imports. & Excess of Exports. \\
\hline & & & & $E$ & $\underset{1,280,000}{\mathcal{E}}$ \\
\hline 1872 & - & . & & - & $x, 280,000$ \\
\hline$' 73$ & . & . & - & $I, 540,000$ & - \\
\hline '74 & . & . & . & $7,439,000$ & - \\
\hline 75 & . & . & - . & $4,493,000$ & - \\
\hline$' 76$ & . & . & . . & $6,960,000$ & - \\
\hline$' 77$ & . & . & - & - & $4,93^{2,000}$ \\
\hline '78 & . & . & . & $5,902,000$ & - \\
\hline 79 & . & . & . $\cdot$ & 一 & $4,210,000$ \\
\hline '80 & . & . & . . & - & $2,374,000$ \\
\hline '8 I & . & . & . . & - & $5,536,000$ \\
\hline$' 82$ & . & . & . . & $2,353,000$ & - \\
\hline '83 & . & . & . . & 665,000 & - \\
\hline '84 & . . & . & . . & - & $\mathrm{I}, 269,000$ \\
\hline '85 & . . & . & . . & $1,446,000$ & - \\
\hline '86 & . & . & . & - & 391,000 \\
\hline \multirow[t]{2}{*}{ '87 } & . & - & . & 632,000 & - \\
\hline & Total. & . & . . & $3 \mathrm{I}, 43^{\circ}, 000$ & I $9,99^{2,000}$ \\
\hline $\begin{array}{r}\text { Dedu } \\
\text { por }\end{array}$ & $\begin{array}{l}t \text { excess } \\
\text { s . . }\end{array}$ & of & $\left.\begin{array}{l}e x- \\
\cdot\end{array}\right\}$ & I 9,992,000 & - \\
\hline Net $\mathrm{T}$ & otal & . & . . & I I $, 438,000$ & - \\
\hline
\end{tabular}

Allowing for the increase of population, the excess of imports in the second period, to correspond to the excess in the first period, should have been very nearly $£ 80,000,000$; actually it has only been $£_{11}, 438$,000.

Whatever evidence there may be about the quantities of gold in the world and in the banks or Government treasuries of other countries, the difference in the amount available or required for the United Kingdom is enormous. As the United Kingdom, it may be added, is and has been practically the only free market, working on the same basis all through, the figures are worth all the others. In the one period then we get nearly $£ 70,000,000$. In the other period, when in 
the same proportion we might have expected nearly $£ 80,000,000$, we got about $\mathcal{L}_{\mathrm{I} I, 000,000}$ only. It is clearly impossible to contend there has been no change in the movement of gold, comparing the one period with the other.

If we looked at coinage or other details, the result would be the same. The stock of gold in England available for money has not been added to of late years as it was in the period just before. The stock with the additions has had to do more work, and it has only been able to do so because prices have fallen, and incomes have not risen, whereas from 1850 to 1873 , when gold was going so largely into England, not only did prices rise a little but incomes a great deal. ${ }^{1}$

Of course, however, the special point of view has always to be considered. The comparison is of movements in two periods, and the change in ratio is ascribed to an arrest of the movement in one of the factors which is apparently established beyond all question.

To put the matter into more popular language, we might perhaps say that the stationary or rather rising prices of commodities between I 850 and I 873 , although commodities were increasing as much as they have done since 1873 , were maintained by continual additions to the stock and efficiency of money. Since 1873 the movement of additions to the stock which was a very pronounced one has been arrested, if there has not been an actual withdrawal from or diminution of stock uncompensated by an increase in the efficiency of money. Consequently the fall of prices since 1873 is explained by the check to the previous movement, when the matter is looked at dynamically and the periods are compared.

The utility of this mode of comparison is also obvious, and it was simply by using it that it was possible to anticipate fifteen and then ten years ago the actual

1 The comparison would be still more striking, I believe, if we could compare the excess of imports of gold from $185^{\circ}$ downwards. But there are no official statistics of gold imports before 1858 . 
course which prices have since followed. In my paper in 1872 on "The Depreciation of Gold since 1848 ," 1 this was exactly the method followed. The real progress of the community at a certain rate was assumed, and then as it appeared probable that the amount of new gold available for an increase of business could not be the same as before, but was likely rather to diminish, the conclusion was that the course of prices would be different from what it had been. The common opinion then was different. It was freely said that as there was so much gold about, there was enough for every purpose, and prices would rise farther. But the method of dynamic comparison, as the event has proved, made a true forecast possible. Again in 1879 it was always the dynamic comparison that was in view. Two passages may be extracted from the paper of 1879 which put the view plainly. First, speaking of the past, I said:

"The peculiarity of the period has been the increase of mechanical invention and the constant augmentation of goods, so that the accumulation of capital above shown is even in less proportion than the increase of the movement in trade which the money in use has to move. It is a moderate calculation that if only the countries which used gold in 1848 , including their colonies, were now using it, the requirements to correspond with the increased population and wealth would be at least three times what they were, assuming prices to remain in equilibrium." ${ }^{2}$

Next as regards the future:

"Let me add that whatever doubt may be entertained as to the actual meeting of the two curves of demand and supply of gold cluring the last few years apart from extraordinary demands-all the facts and circumstances seem to indicate that the meeting point must come very soon unless the supply of gold is increased or economizing expedients introduced and extended.

${ }^{1}$ See supra, pp. 75-97. 
Whether such a change is likely to come in the shape of an increased gold supply it will be for geologists and mineralogists to judge, but it is not reassuring to see how little comes practically of the recent gold discoveries in India and the re-discovery in Midian. Whether on the other hand change may come in the shape of economizing expedients will be a point of no little interest for bankers and all other business men, and for legislators. Considering the slowness with which such expedients become effective when they are first introduced, and the perfection to which they have been brought in countries like England where they are introduced, I feel great doubts whether much relief can come in this way. On the whole, I see no other outlet from the situation than in the gradual adjustment of prices to the relatively smaller and smaller supply of gold, which must result from the increasing numbers and wealth of the population of gold-using countries."

I spoke to much the same effect in a few words following on Mr. Goschen's address to the Bankers' Institute in I883. "If it is found," I said, "that the annual supply of gold, now that the transition period may be considered over, is not sufficient to maintain things in what we may call an equilibrium, that there is a constant increase in population and in the resources of mankind from time to time going on, and the supply of new money is not quite equal to keep things at an equilibrium, then we may have a long-continued fall of prices from generation to generation, and this will probably have very great effects as time goes on. We may perhaps have what may be called a permanent transition period, as far as I can see."

Thus the idea of a dynamic equilibrium has always been in my mind as the basis of any comparison between period and period, and I must maintain it, especially after the event, to be a useful method of comparison. In any case you must define your idea of an equi- 
librium at starting, or you can have no clear notion of the facts at all.

It would perhaps be possible to leave the discussion at this point. If the dynamic comparison here made is useful, partly for forecasting the future course of prices, and partly for explaining generally the relations of money, commodities, and incomes to each other when prices change, then it is a comparison which ought to be made, whatever else is done or omitted. It carries us a long way in the investigation. So much is said, however, about other comparisons, especially about the abundance of commodities causing the fall of prices and not the contraction of money, that at the risk of burdening myself with controversy I propose to add a short criticism on this discussion.

Clearly the suggestion already made that the two causes are not on the same plane-abundance of commodities properly belonging to a question of real cheapness, while scarcity of money belongs to a question of money prices only-covers the whole ground. But the point need not be pressed. The argument from the abundance of commodities may be demonstrated to be faulty in other ways.

The question immediately arises, looking at the whole course of the discussion, whether those who insist so much on the increasing abundance of commodities as excluding any idea of the contraction of gold are not really attempting the impossible, viz., to measure two variables, one against the other, without a third common measure by which to try them. We know, however, so little of the ultimate facts which regulate the ratio of exchange between particular commodities, that it would be useless to determine, except in a comparative and limited manner, what are the facts which change at a given time, and how one commodity may exchange for less than before, although it may be produced in smaller quantity; another for more than before, although it may be produced in greater abundance; and although it may be true gener- 
ally in theory that increase of supply means a lower rate of exchange for the article supplied, and a less supply a higher rate of exchange. The concrete facts are in truth infinitely difficult to follow out, and no one should attempt to do so without limiting his quest in some way.

When, therefore, abundance of commodities is pitted against scarcity of money in the way that is sometimes done, I confess my inability to follow the discussion at all. I seek in vain for the exact terms of the comparison -the definition of the equilibrium which is the starting point of the comparison, and a description of the changes as from this equilibrium. The whole discussion is bewildering to a degree.

I would say, however, though it is not quite safe to speak in the absence of all clear definitions by the disputants themselves, that the contention that the recent change in prices or in the purchasing power of gold is to be ascribed rather to the increasing abundance of commodities than to any contraction of money, is obviously, as far as it has any reason at all, based upon an attempt at a totally different comparison from the one which we have now made. For the purpose of this comparison the quantities of commodities and money, or the conditions of their production, or whatever determines the ratio between them, are assumed to be in a state of rest just before the change in prices occurs -a statical and not a dynamical equilibrium is assumed; - and as it is found that commodities go on increasing, and there is no actual diminution of money from that point or very little, the subsequent change in prices is ascribed to the change in commodities. But whatever may be thought of the validity and usefulness of such a comparison, what I have to submit is that it is obviously, and by the terms of it, a totally different comparison from what is attempted when the two periods are looked at dynamically and a dynamic comparison attempted.

The difference between the two comparisons can be 
illustrated very simply by diagrams, which show at a glance that those who argue for abundance of commodities as causing the recent fall of prices, start from an assumed equilibrium of rest at the date when the fall began, while the comparison which asserts a change in money is really a dynamic comparison. (See p. 214.)

The first diagram, it will be seen, shows commodities and money both increasing from i 850 to 1873 , and the ratio between them remaining steady; there was in truth a moderate rise of prices, but it would complicate the diagram to show this; after i 873 commodities went on increasing as before, but there was a check to the increase of money, and hence the fall of prices is ascribed to this check to the increase of money. This was the change that took place in 1873 or thereabouts. The recent fall of prices, therefore, in a dynamic comparison, is clearly due to a change in money.

The second diagram, on the other hand, starts from I 873 only, assumes a state of rest as at that date, and thence as commodities increase, while money does not, the fall in prices after that date is ascribed to the increase of commodities. It is the increase of commodities which causes a change from the assumed state of rest. But this second diagram is only a copy of the second half of the first, and deals with the same facts, only presenting them in a different way, and without comparison with the previous period, which is the essential point of the comparison in the first diagram.

The two comparisons, it is plain, are fundamentally different, and to argue as if they were the same must cause endless confusion.

My own opinion is that a statical comparison, besides being much more difficult than those who attempt it imagine, is not of much use when you do make it. The economic world is in incessant movement, and the comparison required for any purpose is almost always dynamic. You have to compare movement with movement if you want to find out what is changing, not state with state. In any case also the movement is much 


\section{DIAGRAMS}

ILLUSTRATING DIFFERENT COMPARISONS AS TO THE CAUSES OF THE RECENT FALL IN PRICES.

FIRST DIAGRAM.

CHANGE IN MONEY VIEWED AS CAUSE OF CHANGE. DYNAMIC COMPARISON.

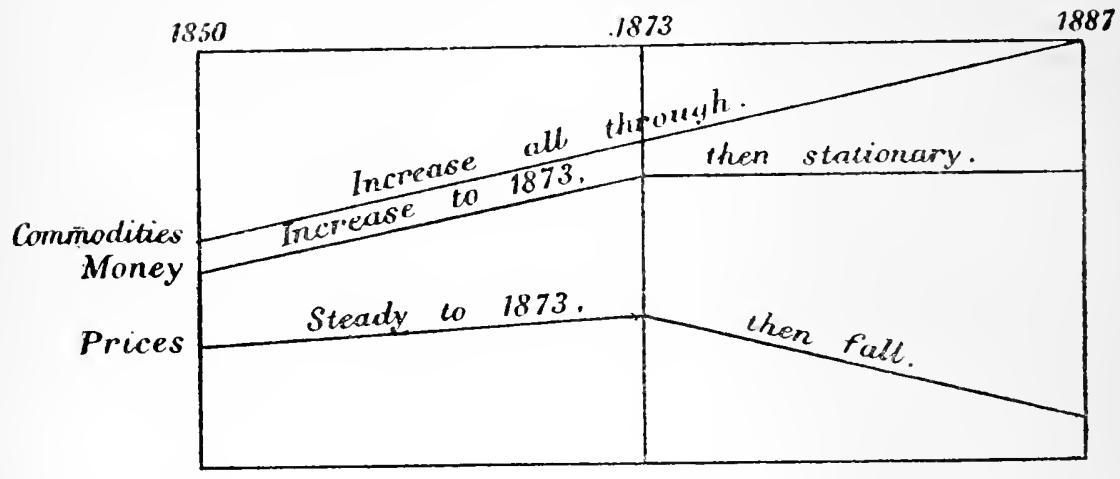

SECOND DIAGRAM.

CHANGE IN COMMODITIES VIEWED AS CAUSE OF CHANGE. STATIC COMPARISON.

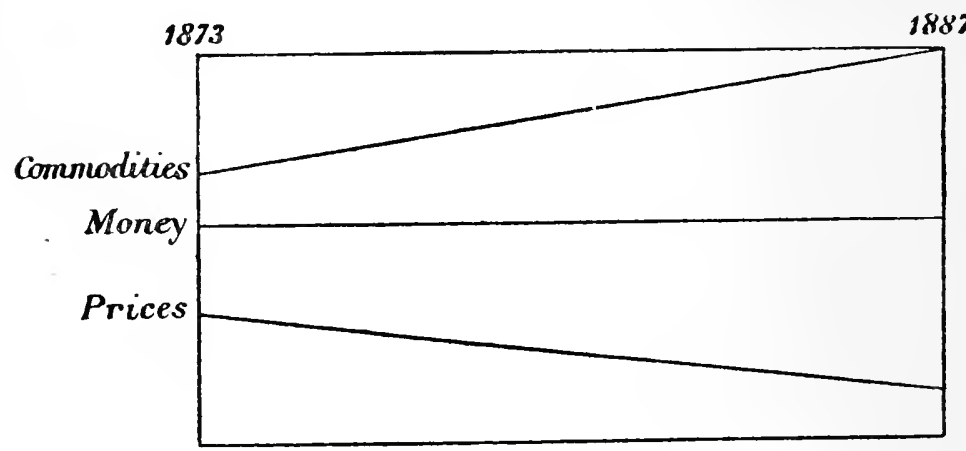


more easily compared. You may not be able to tell all the causes of a given economic condition so as to compare it with another economic condition and its causes; but if you can take two economic conditions succeeding each other, and point out a difference in the movement of one of two factors which must have contributed to the conditions, you have something definite and palpable to rely on.

Those who divell on the abundance of commodities rely on the great authority of Tooke, and much of their writing is in fact a reminiscence of Tooke. I may be allowed a word therefore regarding Tooke's place in the literature of these discussions. To my mind he is completely superseded by Jevons. With all his industry and knowledge of business - and there is no more acute or fruitful author to study-Tooke never seems to have got into his mind the notion that the causes of changes in prices which he dealt with were not all on the same plane, and that most of what he said about good crops and the rest of it causing a fall in prices could be admitted without bringing into question the notion that looking at the whole history from another point of view the average changes from generation to generation could be described as changes in the value of money. He had no good idea besides of the logical or scientific value of an index number, such as his successor, $\mathrm{Mr}$. Newmarch, found himself compelled to adopt in his continuation of the "History of Prices." Mr. Jevons has changed all that. By demonstrating how an index number can be used on an extensive scale, he has in fact demonstrated that in point of fact changes in average prices from generation to generation can be traced, i.e., changes in the average purchasing power of money; and most of Tooke therefore, as far as questions like the present are concerned, goes by the board. In theory, however, Tooke never denied that there might be changes in the supply and demand for money adequate to cause great changes in prices. Where he failed was in recognizing the special character 
of the problem, and the inapplicability of most of the points he raised--as to good harvests and the like accounting for changes in particular commodities-in a discussion in which from the necessity of the case the average of commodities is itself the measure, and the question is not of real cheapness or dearness, but of money prices only. After Jevons, Tooke is really out of date, and nothing is more curious than to see how in the recent discussions disputant after disputant seems unable to follow Jevons, and prefers to go back to an order of ideas which is entirely superseded.

As showing farther the difficulty of the method of a statical comparison in this very matter, I may refer to the excellent mathematical work of Dr. Kral, with a preface by Dr. von Neumann-Spallart, in which an attempt is made to prove that the change from a high to a low level of prices is due to a change in commodities and not in money. It is evident from this book that if a solution could be found for this question, starting from a statical equilibrium, the most difficult mathematics would be necessary, whereas when a dynamic comparison is attempted, the result stands out with striking distinctness, and there is no difficulty.

I have only to add that for the purpose of forecasting the future it is absolutely necessary we should look at the matter dynamically. We cannot trace out all the causes which produce a given ratio between prices and commodities. We can see, however, that the movement in one or two important factors of that ratio is in a certain direction, by which an equilibrium of a certain kind is established. It is easy to predict that a continuance of the movement in the leading factors must lead to one kind of result, and an alteration in that movement to a different result.

\section{The Redistribution of Wealth.}

The consequences of an appreciation of money would demand a chapter to themselves, but though unable to 
treat the subject fully in the present paper, I am unwilling to pass over it altogether, as it must be referred to when we come to draw conclusions as to the future prospect.

These consequences are usually dealt with in two divisions: 1 . The effect of appreciation in checking industry and so retarding the increase of wealth; and 2. The social and other effects of appreciation in redistributing wealth. The former of these branches need not, however, detain us. I do not consider it really important. Industry goes on with any sort of currency provided it does not change in short periods. It is hard to say whether abundant money causing inflation is better or worse in the end in its effect on production than a contraction of money which causes appreciation. What I have to say on these points moreover is said elsewhere. I shall only deal then with the effects of appreciation, and of course in this connection appreciation of the special character above described, in redistributing wealth.

It is obvious beyond all question that these effects may be important. Measured by a certain standard, the average of commodities, the weight of all permanent burdens is increased as compared with what would have been the case if there had been no appreciation. People in paying annuities or old debts have to give sovereigns which each represent a greater quantity of commodities, a greater quantity of the results of human energy, than it would have represented if there had been no appreciation. It may be quite true that on the average the individual in paying a clebt, as his average income is not less, only uses the same proportion of that income or the capital represented by it to discharge the debt, and in this sense there is superficially no increase of the burden on the average in the case supposed; but it is hardly to be assumed, I think, that the increase of production is an increase without additional effort-it is the effort rather of a human unit who is always becoming on the average a stronger producer-and in 
admitting consequently that the same proportion of a larger production is required to pay larger debts, it remains true that there is an increase of burden, although it happens to be borne by stronger producers. It is at any rate quite clear that the benefit of an increase of production is distributed differently when money appreciates measured by commodities than when it does not appreciate. The debtors pay more than they would otherwise pay, and the creditors receive more.

The matter is thus not unimportant to the two large classes of people who make up the community. Appreciation is a most serious matter to those who have debts to pay. It prevents them gaining by the development of industry as they would otherwise gain. There may be compensations in different directions, as by the lowering of the rate of interest which seems to take place as the result of appreciation, but on the whole the balance is against the debtor, as compared with what it would be if there were no appreciation.

On a large scale this applies to transactions between nations. A creditor nation is able to draw more from its tributaries, who have to pay it in the appreciating money, than it would otherwise be able to draw. To pay the same debt they must send to their creditors 30, 50, perhaps I00 per cent. more produce than they would otherwise have to send. There is no doubt that in this sense the weight of the gold debt of a debtorcountry like India or the United States has enormously increased of late years. The resources in both cases may have grown even more largely than the burden, but there is nevertheless an increase of the burden itself.

All this is treating the question with regard to the average effect. It is still more important to remember, however, that the average may be made up of a great variety of cases, and in fact there is no doubt the redistribution described spells ruin to individuals and classes. Although average production is increased, there are large masses of property where there is no increase, or little increase, where the fall of prices there- 
fore means a diminution of the gross money return, and where, consequently, the property being mortgaged, the margin of the mortgagor is swept away. This has now become a familiar matter to most people in connection with the depression in land-owning, but the landlord only exemplifies an extreme case of a general mischief. He owns very often only the margin of a margin. The rent itself is the margin of profit remaining after the expenses of cultivation and the farmer's profit have been deducted from the gross produce, these expenses not being reducible, at any rate at once, with the fall in prices. Of this margin again the nominal owner only gets a remainder, and he would often be a loser, even if the rent represented the same proportion of the gross produce as before, because being less in money the whole of it is swept away by the charges and debenture interest so that there is no remainder. In this way landowners who seemed to have so safe a position have been ruined by the score. But this case is the case mutatis mutandis of every ordinary shareholder in a company who has debenture holders and holders of preference shares in front of him. Margins are everywhere endangered. On the other hand the owners of the preferences so long as they are safe are paid much more than they would have been paid if there had been no appreciation. They belong to the creditor class, and gain where the others lose.

All this, let me repeat, is involved in the appreciation of money measured by commodities, even though incomes as a rule do not diminish. The mischiefs are no doubt less than if there was a still greater fall of prices, accompanied by a serious diminution of incomes on the average. But they are mischiefs as far as they go. No doubt one reason they have been less felt than would otherwise have been the case is that many people are both debtors and creditors. They not only own land, perhaps, but they own Government and the like stocks, where they are preferred creditors, and where they gain consequently by the appreciation of money. But there 
are sufficient cases of marginal owners whose margins have been swept away to make the social effects of the redistribution of wealth involved in the appreciation of money measured by commodities very widely felt.

At the same time, it should be recognized that in some cases the appreciation, though it means apparently a redistribution of wealth, does not really involve that mischief; it only anticipates what would otherwise happen. For instance, in giving more to a wage receiver or salaried servant, whose nominal income is unchanged, it may still only place him in the position in which a gradual rise in the scale of living would have placed him. If real wealth had been increasing without a corresponding fall of prices, or rise in the purchasing power of money, then wages and salaries must infallibly have risen. In these cases, although redistribution of wealth seems involved in the appreciation, there is no real redistribution involved; there is a general increase, in which all incomes participate on the average.

The appreciation in any case is not one to be regarded with a panic feeling except in special cases. Especially as regards national debts, which are not themselves increasing in a mount, the increase of burden need not be very formidable, for two reasons: I. The reason already mentioned, that the income per head in the case supposed does not diminish, so that the charge per head cannot be more than it was before; and 2 . The fact that population in an advancing community is always increasing, so that if the debt does increase, the burden on each individual taxpayer must diminish from period to period by the increase of their numbers. The taxpayer does not gain as he would gain if there were no appreciation of money; but the case must not be spoken of as that of a debt growing and swamping the debtor. There is a third reason, viz., the reduction of interest which seems to be a consequence of the appreciation of money; but as this involves disputable matter, I do not insist upon it, although in the 
case of our own national debt the reduction of interest by conversion, as we all know, has been most serious. It is obvious practically that there are many national debts where the appreciation of money, for the reasons stated, and also because the debt is so small, does not lead to such an increase of burden as to be serious. It does not follow, of course, that all communities and all national debts are in the same case. Where debts increase fast, and where, in addition, as in the case of France, there is no rapid increase of population, the problems involved in the appreciation of money may at any time become serious. I should look for troublous times, for instance, both for some of our Australasian colonies and for a country like the Argentine Republic, even if the appreciation does not grow more serious than it has been. That the pile of debts has to be paid, principal and interest, in appreciating money, even if individual money incomes do not diminish, is a most serious consideration. The increase of the wealth of such borrowers ought to be enormous to enable them to bear safely the debts they are incurring.

\section{The Future Course of Prices.}

What is to be the movement of prices in the future? Of course no one would attempt prophecy in such a matter. We can only assume the continuance of certain conditions which seem more or less probable, and infer from past experience what the result will be. In I $\delta_{72}$ this method of proceeding enabled me to anticipate as highly probable the fall of prices which has since in fact occurred. What are the data now for an anticipation regarding the future?

On this head then I am bound to say all the evidence seems to me to point to a continuance of the appreciation. So far as can be judged, there is no end to the progress of invention or improvement in industrial qualities among gold-using communities. The increase of the numbers of such communities, especially 
English-speaking communities, also goes on at a very rapid rate. The conditions therefore are generally so far the same as they were in 1872 . There are no special demands for gold ahead such as were then in view, first of all for Germany, and more recently for the United States; but, per contra, the area of ordinary use has been enormously enlarged. France and England before 1872 were almost the only gold-using countries, the United States at that moment, though gold was its principal metallic money in use, being on a paper basis; but since 1872 Germany, the United States, and Italy, among the leading countries of the world, have all become gold-using. The increase of population among some of these new additions to the gold-using area has also been remarkable, while the increase in England goes on at as great a rate as before, and the increase among the minor gold-using countries, such as the Australian colonies, the Cape, and Brazil has also been remarkable. It has to be considered again that the transition from a silver to a gold standard among wealthy nations is a secular phenomenon, and that we may fairly expect the gold-using area to increase as one nation after another becomes richer. First England about two centuries ago went over to gold; more recently, rather more than fifty years ago, the United States went over to gold with the help of a bimetallic law, but really with the deliberate intention to get gold; still more recently, France took to gold, refusing to part with it after having once got it, and suspending the coinage of silver when silver threatened to become the principal money in use, and therefore the standard, just as England, for similar reasons, suspended the coinage of silver in I798; still more recently Germany, and then Italy, not to speak of minor countries, have become gold-using. It is impossible to suppose that this favour to gold is accidental, or that the movement to adopt it will not extend to other countries as they grow richer. We who are gold-using may think it highly desirable that other 
nations should favour silver more than they do, but the tendency to go over to gold must be recognized as a fact. At this very moment two of the countries to whom a silver money might be thought most useful when they resume specie payments, viz., Russia and Austria, do in fact keep large bullion reserves in gold, this being especially noticeable in the case of Russia; while the intention to have a basis in gold is further marked in the case of Austria by the fact that silver is at a discount compared with the paper, and gold only at a premium. I should anticipate, therefore, as most likely an extension, and not a contraction, of the goldusing area in the coming years. There is also a natural reason of great weight for the preference. As peoples become richer the mere weight of silver makes it inconvenient for all concerned to handle it to the necessary amounts if it is used at all in the daily transactions of life. Gold becomes a quasi necessity and not merely a luxury, and this necessity increases rather than diminishes not only among communities which are not gold-using, but even among those which are already on a gold basis. With regard again to the use of gold in the arts, we cannot but expect the demand of the richer nations as they grow richer to increase. It is now very considerable, amounting at a low computation to two-thirds of the annual production, and is most likely to increase.

All these facts point to a continued pressure upon gold, against which the only compensation would be a more extended use of economizing expedients. Such economizing expedients will in fact, as I believe, mitigate and modify the demand for gold, but the question is to what extent? and just as I believed in $1 S_{72}$ that they would not do so to the extent of preventing a fall of prices, should the supply of gold not increase, so I do not believe now that they will have a mitigating effect to any serious extent. The question then becomes, what is to be the supply of gold? A great deal is said about the Transvaal and other sources of supply, 
and if there should be an enormous development of gold mining the tendency towards a rise in the purchasing power of gold would no doubt be checked or reversed. But it would take a very large development indeed to produce any result of the kind, perhaps an addition of 10 or 20 millions to the annual supply, while the demand itself will of course increase with a diminished cost of producing gold as compared with other things. The better probability seems therefore to be that the increase of the purchasing power of gold will continue from the present time. If it does not increase, there must be a very large increase of the supply.

Will silver participate in the fall along with other commodities? Here the better probability seems also to be that the tendencies rather are towards an increase of the divergence between gold and silver which has been going on for centuries, in consequence, as I believe, of the growing wealth of nations making them turn to gold one after another as they find or make opportunity. The silver-using nations are nations with much smaller individual incomes than gold-using nations; they are not so progressive; while if they do progress they are apt to resort to gold more and more, partly as a supplement to, and partly as a substitute for, silver as they come to have a variety of dealings and transactions in which gold is more useful than silver. At the same time nothing is more remarkable than the continued increase of the supply of silver, which is produced geologically as yet under different conditions from gold, and is more susceptible of almost unlimited development. The difference between gold and silver geologically was well expressed by M. Leon Faucher forty years ago, when people were excited by the gold discoveries, and his remarks have since been confirmed by the subsequent great development of silver mining. M. Faucher says:

"It is not without some show of reason that mythology, transporting the analogy of the physical into 
the moral world, made the age of silver succeed that of gold. Historically, in fact, the discovery of and the working of gold preceded that of silver. Gold is almost always found either pure or mixed with silver. In searching the beds of rivers and streams it has been obtained by the mere process of washing. This work is within the reach of the rudest state of society. It appears like a treasure spread over the surface of the earth, under the very feet of the first occupier of the soil. Silver, on the contrary, is embedded in rocks of primitive formation, and is seldom found near the surface of the earth; its extraction requires a combination of science, machinery, and capital. It is the work of a state of civilization already far advanced, and firmly established. . . . Not only did the value of money and of the precious metals increase in the long dark night of the middle ages, but the relative value between silver and gold which had been established by the progress of industry again changed. Gold preserved its value the longest; its supply was fed by the washings of the golden sands, a fit occupation for the knowledge and tastes of an ignorant people. The working of the silver mines, on the other hand, being a work befitting a civilized and scientific people, was naturally interrupted, and languished during a period of spoliation and endless warfare. Hence, as we may suppose, even the scarcity, both relative and absolute, of silver; the comparison with gold remained at I I and I 2 to I from the ninth to the middle of the sixteenth century. It required the excessive and sudden abundance springing from the working of the mines of Potosi and Peru, and of Zacatecas in Mexico, to reduce the proportion to 14 and 15 , the average rate at which it remained in Europe until the end of last century. ${ }^{1}$

There is a strong drift of things therefore towards appreciation of gold, and relative depreciation of silver, though not as yet an actual depreciation of silver mea-

${ }^{1}$ Leon Faucher, "Remarks on the Production of the Precious Metals." Translated by Thomson Hankey, jun. London, I 852 . 
sured by commodities. If this drift goes on, the divergence between the two metals will increase and not diminish. This impression will be confirmed, I think, when the ratio between the two metals is looked at historically. I extract the following short table from Soetbeer, adding the figures subsequent to 1680 as of common knowledge :

Ratio of Silver to Gold from 1500 to the present time.

\begin{tabular}{|c|c|c|c|}
\hline Years. & RatioSilver to Gold. & Years. & Ratio Silver to Gold. \\
\hline I $50 \mathrm{I}-20$ & $10.75: 1$ & I 64 I-6o & I $4.50: I$ \\
\hline '2 I-40 & I I.25: I & '6I-80 & I $5.00: 1$ \\
\hline '4I-6o & I I.3O: I & & \\
\hline '6I-80 & I I.50: I & 1800 & I $5 \frac{1}{2}$ \\
\hline '8I-I600 & I $1.80: 1$ & I $800-50$ & I $5 \frac{3}{4}:$ I \\
\hline $1601-20$ & I $2.25: \mathrm{I}$ & '50-70 & I $5.40:$ I \\
\hline $2 \mathrm{I}-40$ & $14.00: 1$ & Present time & $22.00: I$ \\
\hline
\end{tabular}

The steady dwindling of the ratio of silver to gold over the whole period is manifest, and perhaps it may be lawful to mention, without incurring the charge of bringing in the bimetallic controversy, that the great nations of the world, with the single exception of England after i680, before which a considerable part of the fall took place, were bimetallic almost the whole time. The movement has thus been steadily towards a decline of silver in reference to gold. Of course the change in the last few years has been most unusually sudden and severe, but there was, it will be observed, a very serious change, indeed, in the early part of the seventeenth century; and it may be suggested that the whole economic movement in modern times is quicker than it was formerly, while the run upon gold has been fostered by the unusual supply which came on the market from I 850 on wards, and the increase of supply in the case of silver, from the sheer weight of it, produces no such effect, if it does not produce the opposite effect. 
I regard all this movement and have described it as a natural movement. This would hardly be the place to discuss the bimetallic theory if we were inclined to do so, but certainly it may be allowed, even by bimetallists, I think, that the tendencies to divergence between gold and silver are strong enough to require a very powerful controlling influence to keep a constant ratio between them, if they are to be controlled at all, which I do not believe to be possible. In fact, but for the accidental gold discoveries of $1848-50$, and the previous discoveries in Russia, the increasing divergence between gold and silver which was manifested before that time would have long previously produced a fall of silver in relation to gold like that we now witness. Such a fall was in fact anticipated by economic experts before I 850 . The events of $1848-50$ suspended the economic development. To all appearance it is again in full course. The probabilities appear to point to a further heavy fall of silver in the next ten or twenty years, the reason at bottom being the run upon gold and the short supply of it, though the steady increase of the production of silver, and the comparatively limited natural area of its use, also count. ${ }^{\mathrm{I}}$

Is there anything to be done by Governments to mitigate the appreciation of gold or provide against its effects, is a question which will naturally arise. The anticipation I ventured to indulge in in 1879 to the effect that we should infallibly have such topics as the issue of $\mathscr{E} \mathrm{x}$ notes brought up for discussion has certainly been more than fulfilled. To find a Royal Commission recommending the issue, not merely of $£ \mathrm{I}$ notes but of Ios. notes, and these based on silver, is certainly a sign of increased readiness to discuss currency innovations. But the only suggestion I would make is of a statistical kind. All these difficulties seem to me to suggest the expediency of further

${ }^{1}$ This has been fully confirmed by the actual course of silver prices since 1888 . [1903.] 
scientific study by those interested of the theory and practice of index numbers, which supply a means for providing for deferred payments by substituting a different currency for money, as is done by the corn averages for tithe and by corn rents generally. If we cannot invent a money that will itself be stable over generations, may it not be possible to devise a substitute by which the deferred payments will themselves change with the changing value measured by some other standard, and in that way the redistribution of wealth will in some degree be lessened?

This last suggestion can hardly be expected to be a very popular one at present, while as yet index numbers are hardly known to the public. It is remote enough from any practical issues. But in any case, it may be hoped, studies like what we have been engaged in to-night will not be in vain apart from practical issues. Knowledge is always useful, and a clear insight into what is going on and what is fairly to be anticipated may both prevent panic and enable business people to make sensible arrangements in their provisions for the future which otherwise they would not think of. In documents charging estates, for instance, lawyers might have been able to save their clients much embarrassment by charging a percentage of net rental only, or a sum to be varied by another measure, as the tithe is varied, instead of a fixed and unchangeable sum in money. Generally in a time of appreciating money business men must consider carefully the effect of engagements to pay money at distant dates. Many mischiefs might have been avoided if all concerned had realized ten or fifteen years ago what was likely to happen in money, and good will now be done if possibilities are kept steadily in view.

Note (1903).--The anticipations as to the likelihood of a farther appreciation of gold were not realized in consequence of the South African, Westralian, and North American gold discoveries, but enormous as these discoveries have been, there is as yet little sign of another great depreciation of goll. 


\section{VI.}

MR. GLADSTONE'S WORK IN FINANCE. 1

THERE is a universal agreement of opinion that 1 Mr. Gladstone's strength is finance. Those who dispute his capacity in other respects allow that figures steady him, and his achievements in this field have been the principal boast of his admirers. Until lately, indeed, it might be said, there was little else to boast of; Mr. Gladstone's career had been otherwise mainly interesting as a psychological study, exhibiting the process by which a peculiar mind, starting with a false appreciation of the tendencies of the time, and imbued with notions of a theological cast, has gradually harmonized itself with these tendencies, and discarded theological conceptions in the domain of politics. Because, then, Mr. Gladstone is so prominent, and his repute is so largely due to success in one department of politics, an inquiry into what his work here has been, without embracing his whole career, may be more than justified. This would be the case altogether apart from his recent accession to the premiership. No doubt the past history of any premier, the predilections he has manifested, and his success, or supposed success, in a particular department, are likely to throw light on his future policy. But it is enough to know that Mr. Gladstone, as a prominent party leader, is mainly praised for his finance-has his achievements here put forward as a main reason for supporting him. This fact alone proves that the work is considered of a vitally important character, intimately concerned with the business of politicians in the present time. By studying Mr. Glad-

1 Written in 1868 . 
stone's finance we are likely to get light on some of the most important problems which our public men have to solve-unless it should prove, what we find is not the case, that great achievements in finance, of the kind so much praised, are no longer possible. It will be said, perhaps, that the subject is familiar enoughMr. Gladstone and his financial deeds have been in all the papers these many years. But common as is the talk of Mr. Gladstone's finance, it may be doubted how far it is really known. A generation has grown up which knows not Mr. Gladstone directly, or the work that he has done-to whom his great budgets are matters of history quite as much as the Reform Bill of 1832 , or the dreary politics which preceded it from is 85 downwards. There are plenty of men among us who have lived through the whole period, but the last events are almost as unknown as the first to those who were at school during the Crimean War, or have graduated since 1860 , but who will henceforth have their share in the politics of the future. On this account it may be useful to resume questions and arguments which may to some be stale and commonplace, and mark out the outlines of a period from which the present has been developed. Perhaps those who are older may not wholly lose by looking broadly at the past. A deliberate retrospect may remove or modify the partial impressions of the hour-may show what was essential and permanent, what are probably, therefore, the strongest influences in the times which are beginning.

The talk is of finance, but the fact which meets us at the threshold is the secondary place of what passes by that name in the financial record of this country during recent years-that is to say, since i 842 . The ordinary understanding of a financier's duty-and usually the correct understanding-is, that he is to find ways and means for expenditure, and maintain the credit of his Government. With the expenditure itself it is not supposed he has much to do, except that having to furnish the means he is expected to criticise it closely, 
and reduce the bill if he can. What he must know is the way to borrow cheaply, or to raise a revenue with the minimum of resistance. The unpardonable sin is not the infliction or maintenance of bad taxes, but the failure to find the money. The history of States, as a rule, has shown Governments spending up to the limit of their means, the limit of what could be screwed out of their subjects; and books on taxation bear curious witness to the anxiety of the problem-how to find a new instrument of raising the wind. There is nothing, says Adam Smith, which governments have been so ready to borrow of each other as a new tax. The most important financial exploits on record have likewise been those of financiers, such as the younger Pitt, in the conduct of a great war. To keep the stream of expenditure flowing, without totally exhausting the nation, and to devise a new expedient with every fresh strain on the national resources, were the tasks that had procured most renown. But the problems of recent years have been of a different order-a different exercise of ingenuity has been required. The conditions have wholly changed. The experiment of free trade, so much recommended as it was in order to improve the revenue. had other relations as important, or more important, to the general welfare of the country. Whether the experiment was worth trying for the good of the country, and how to find the means of trying it, became the financier's questions. But the necessity of looking so much more to the general welfare of the country is not the only change. What must besides be taken into account is the marvellous and unprecedented increase of the national wealth in the course of a very few years -an increase which apparently has not yet approached a permanent check. The aggregate income of the nation has probably been doubled within the last thirty years; the taxable income of the country must have increased in much greater proportion. To maintain in such circumstances an equilibrium between State income and expenditure became so easy a task that, if 
that were all, a financier might fold his hands. But the overflow of means beyond all former precedent, as soon as it began to be felt, could not but impose new duties. Among these a financier of the old school would hardly have thought of aught else but the wholesale reduction of taxation, and the improvement of the national credit by the diminution of debt, or the accumulation of a "reserve"- the steps which are suggested at the close of a great war, when the diminution of the demands on the Exchequer produces a similar abundance. But much else was to be thought of. The signal growth of wealth, if it had preceded, instead of succeeding, the commencement of free-trade legislation, should itself have suggested the revisal of a scheme of taxation handed down from other times. Happening as it did, it furnished another reason for carrying on the work begun, for making the revision complete, and thus enlarging the cause which had assisted so much in producing this very effect. All the reasons for continuing the experiment were reinforced by the initial success. Whether at the time the idea of that success was not much exaggerated is not now in question. In other circumstances commerce and industry might not have flourished as they actually did after free-trade measures; there might have been an advance to prosperity, although not the same brilliant prosperity, without any such measures at all. Still the proofs are abundant that this new legislation had been a large part of the battle. Before 1842 the condition of the country was alarming, in a way we cannot easily imagine. Successive deficits in the revenue were but a feeble index to the complaints of suffering which arose from every quarter. The country was standing still, with a vast gulf between the rich and the poor, and political discontent assuming the most threatening forms. The visible beginning of a change was the free-trade experiment-the abolition of the burdens which those concerned at the time felt to be hindering their business. If other forces, such as railways and steamships, came into play, and intensified 
the apparent effect, it is still true that there was an effect to be intensified, and that politicians had some excuse if they ascribed, perhaps, more than its fair share of the cause to what their own hands had wrought. It could not be a question, at least, that the work should be carried on which had assisted so beneficial an endone of the effects being the supply of more means with which to carry it on. What remained for financiers to consider was the order of the subsequent steps, and how far the process should be carried.

The change suggested another problem of equal importance-the assistance to be given by finance in ameliorating the condition of the masses of the community. The whole tendency of the time is to bring this problem directly before statesmen and Parliaments; but the new increase of wealth, by raising the masses a little, by putting them on a better vantage-ground, by opening out for them new and unexpected vistas, has perhaps been more effectual than any other single cause. The conception of a vast manufacturing community, well fed, and housed, and clothed, living in comfort-what would even have been thought affluence only a century ago - was hardly thought possible till people witnessed the growth of such a community almost before their eyes. But once made a possible, almost an actual, fact, the expediency of consulting this people's welfare, of giving them more chances, of making life richer and more enjoyable for them, became much less problematical than it had seemed even to very good men. Statesmen came under new obligations, and the idea forced on financiers, almost unconsciously, was that, instead of benefiting the masses merely by undoing still further an antique legislation, they could also add to their means by reducing the taxes which pressed on them. To distribute the accumulated wealth of the country more evenly, to cause it to be shared more and more largely by the massespecially those who are just struggling out of the borders of pauperism-are objects of paramount im- 
portance, which might be worth, if need were, the weighting of the balance of taxation in favour of the poor. Whether their condition could not yet more be improved by the appropriation of the new wealth to the development for the general interest of the " monopolies of civilization"-whether financiers should not be prepared to find means for this sort of expenditure -is equally a question which presses. To urge this earnestly may appear to some to be devotion to a not very high aim, but not to those who know what "wealth" for the poor means. Command of the means of enjoyment is, in truth, the beginning of civilization. The roughest navvies may gain little by the sudden possession of high wages, but the second generation of a highly-paid labouring class develops new tastes and gifts. Recent history has furnished too many illustrations of the fact to make it any longer doubtful. The increase of wealth in the possession of the mass of the community is therefore an aim of first importance. If a financier can accomplish it by reducing taxation, or by other means in his power, all his energies should be bent to the task.

What share, then, had Mr. Gladstone in the financial tasks of the period? in what direction will his future influence be bent? are the questions we have to answer. Glancing backwards, it is not difficult to see that all the problems stated have been solved, or many steps made towards solving them; and, whatever the criticism of detail, the respective merits of the financiers of the time can almost be measured by the bulk of their contributions to the work. Tried in this manner, Mr. Gladstone's contributions are confessedly the largest of the whole twenty-six years since i 842. All that is characteristic in the last sixteen is exclusively his. There have been other Chancellors of the ExchequerSir George Lewis, Mr. Disraeli, and Mr. Ward Hunt -but, as fortune or management would have it, they have contributed almost nothing among them to the work of the period. Mr. Disraeli's insignificant con- 
tribution in the budget of I 867 is literally almost the only thing which Mr. Gladstone cannot claim. It is obvious, too, that a very large share of the work has been got into these sixteen years. Of the four great stages into which the whole period may be divided, two at least are included in the later time. To Sir Robert Peel belongs the first step in 1842 , and the second step in I 845 ; but the stages of 1853 and I 860 were marked with equal distinctness, and were hardly of less importance. To take the test of the amount of taxation reduced, it appears that, in the years $1842-52$, the balance of remission was $£ 7,000,000$, while in $1853-66$ the balance is $\mathcal{L}_{\mathrm{I}} 3,000,000$. This, too, was in spite of the fact that the expenditure in the former period was only between $\mathcal{L}_{50,000,000}$ and $\mathcal{E}_{52}, 000,000$; whereas in the latter period it has been between $£ 65$,000,000 and $£ 70,000,000$. The proportionate merit of Mr. Gladstone is not so great as the figures show, because all our figures are now bigger, and the taxes reduced would not have been so productive, when they came to be reduced, but for Sir Robert Peel. They are proof, nevertheless, that a great deal was done; and when the details are looked at, the conclusion is not less unfavourable. To the first period necessarily belongs the redress of the worst evils in the old system-the abolition of export duties, of import duties on the raw material of manufacture, and of certain oppressive excise duties, such as that on glass; above all, the destruction of the corn laws, with the reduction of duties on other articles of food. Still, how incomplete the work would have been without Mr.Gladstone's contribution. There were no export duties left for him to touch, but every other feature of Sir Robert Peel's work is found in his. The abolition of the excise on soap and on paper released two home industries of the first magnitude, and were quite as important measures in that kind as the repeal of the duty on glass. Mr. Gladstone, again, first reduced yet further the customs duties on articles of food, and finally abolished every duty of that kind, with the single 
exception of the shilling duty on corn. Sir Robert Peel, besides, only began the total abolition of duties, his main steps being merely to make reductions. Mr. Gladstone has swept the tariff clear, leaving only certain charges on great articles of consumption, with supporting duties on a few articles besides.

This is a fair account, so far, of the difference between the two periods - without any design, it may be added, to disparage the work of the first period for the sake of eulogizing Mr. Gladstone. The measures of 1842 and I 845 have the merit of novelty, which, in a matter of this kind, far outweighs every other. They broke the spell of the old system, and gave the country, as it were, life from the dead: any fresh additions to that life are hardly to be compared. Still it is also just to see how large the additions were. Their full effect is hardly perceived, because they came in the midst of abounding prosperity; yet without them the new era would show fewer signs of an economic revolution. The occasional fits of languor would probably have been far more severe. Mr. Gladstone's share, however, appears the more important, if we consider that the later problems were almost exclusively his. They were all raised, more or less, in the earlier period. Even then the success of free trade had suggested the continuance of the work; Mr. Gladstone was only one of many on whom the experiment made a deep impression. Even then the idea of relieving the burden of taxation so as to ameliorate directly the lot of the masses by taking less out of their pockets, as well as by lightening the springs of industry, had come into view. But the main work in that period before I 853 still was the relief of industry-the continuance of the free-trade experiment through its earlier stages. Mr. Gladstone, on the contrary, had to pursue the task through all the later and less obvious stages; while, as he completed the task, the relief of the tax-paying masses came directly in his path. His work, on the whole, was one of greater complexity; and where the indications were less sure, the personal 
merit of success was proportionately greater. Mistake in development was more easy than at the first start, when things were so bad that you could hardly shake off anything without doing infinite good. By the necessity of the case, too, he has had rather less popular support. He has not had the popular clamour to carry him through, which made some of the steps so easy to Sir Robert Peel after the first had been taken.- He has been compelled to create an artificial intelligence, an artificial agitation, to supply the place of feelings his predecessor had at command. Add only one more difference. The one lever with which Sir Robert Peel wrought was the income tax, to replace the revenue sacrificed until the natural process of recovery. Mr. Gladstone has devised more than one subsidiary aid, like the extension of the succession duty to real and settled property, and the increase of the spirit duties-processes which leave in his favour, as we have stated, the balance of remitted taxes, but which made a good deal easier the various steps in his progress. Of the same order of work, in a financial view, is the vigorous warfare he has waged from the beginning to the end of his career against the growth of expenditure-a warfare not required in the same degree before the Crimean time.

Little more need be said, perhaps, to show the extent of Mr. Gladstone's share in the finance of the period. But the fact that his period required so much management may need some explanation. It may not be plain at first sight that the questions were very difficult. There is a popular impression that the progressive increase in the revenue is the whole secret-when financiers have surpluses to give away, it is thought they cannot go far wrong. To remove the impression, let us watch what the history has been, how little would have turned the scale.

In 1853 it was far from certain whether the mere work of relieving industry would be carried any further. The country already was feeling itself more prosperous, and although various taxes, such as the advertisement 
duty, were the subject of agitation, although the general sentiment was in this direction, yet there was no such strong body of opinion as would have forced things in the direction which $\mathrm{Mr}$. Gladstone selected. On the other hand, there were various powerful circumstances tending to an opposite course. Thanks to its own demerits, and perhaps also to the ingenuity with which public men, not excepting Mr. Gladstone, had committed themselves to its condemnation, the income tax was almost as good as doomed. The work bargained for when it was imposed had long since been performed, and the first thing desired was to be free of the burden. Proposals to renew it were unpopular; and just before, a committee which had been appointed to consider its reconstruction had been unable to agree, while collecting a mass of evidence to prove its inequalities. At the same time, all the interests which had been deprived of protection were clamorous. The agricultural interest especially was eagerly demanding the transfer of local charges to the Consolidated Fund, and would have welcomed, abore all things, a reduction of the malt tax as a concession to its claims. A popular proposal talked of was a re-adjustment of the house tax, which had been substituted for the window duty, so as to make it fall on a lower class of houses. Thus it was quite possible in the circumstances of that time that, but for good guidance, these interests would have been heard above everything-that the income tax would have been sacrificed gradually, without securing any more relief to trade (excepting the trade in malt), and that in a house duty the lower middle classes and the working classes would have had imposed on them a drawback on the reduction of the tea duty, which was the only boon suggested for their benefit. All the while, too, though this could not be foreseen, the national expenditure was destined to rise to an unwonted height, partly in a great war, partly in the military excitement which that war nursed into new life all over Europe. Had no decisive remissions been made in $18_{53}$, had not the 
way to do so been discovered notwithstanding every obstacle, it is altogether doubtful when they would have been made-what agitations and controversies would have been necessary to effect them when the country, in the actual course of events, was pushing on to new conquests.

That the remissions took place-to the extent in money of more than $£ 5$, 000,000-may be held in these circumstances to show that the financier who had the management of them had a true insight into the situation. The impression is more than confirmed by an examination of the budget of i 853. The budget was a surprise to the Chancellor's contemporaries ; but looked at closely, it rests upon the firm discernment of two points which ought to have been as clear to every one as they were to him, but were not, in fact, so clear. The first is the great value of the work of having set trade free. In their very prosperity people had forgotten it, so that the willingness to pay the price of the income tax had died out. Mr. Gladstone only urged that what was good in I 842 and 1845 must be good in I 853 , though the sharpness of the stimulus in the earlier years no longer existed. Such a position suggested as a natural corollary the continuance of the income tax for the sake of further remissions-the great point at which Mr. Gladstone aimed. Although expenditure had not increased in the ten years as it afterwards did, it had still increased so far that the abolition of the income tax was not so easily manageable as it was calculated it would have been. Its reduction could only take place gradually; and it was easy to argue that as the tax must at any rate remain, they might as well keep it at a higher amount than was absolutely necessary, and associate it with further remissions. 'This was the vital point of the budget, and made the subsidiary points more easy to handle, though, looking upon the whole as a piece of persuasion, hardly anything was unimportant. The controversy about the inequalities of the income tax was especially placed in an entirely 
new light. These inequalities were to be no worse than they had been, and as the practical difficulties in the way of its reconstruction were endless, and it was still to be only temporary and to do for the country the old work, there were good practical reasons for enduring it somewhat longer. It was, perhaps, more effective to remind people that, after all, those who were most hardly dealt with by the tax, who would have cause to grumble most, had really been direct gainers in money by the new legislation, as well as by the general improvement of the national industry. This was the Minister's justification for extending the tax to incomes under $f$ i 50 , by which its amount and effectiveness would be increased. The argument was special and narrow, but it reminded people in the most telling way of the nature of the new régime, and taught them not to calculate too nicely the price they were called on to pay. The idea of calling in new aids to help in the work-mainly, the extension of the succession duty to real and settled property-was even more exclusively Mr. Gladstone's. A like proposal had not been made since the days of Mr. Pitt. Though it has not realized what was expected at the time, it has gradually become profitable, and has yielded assistance in the task of remission which is not to be despised. It was like the discovery of a national estate, which had been appropriated to their own use by the individuals of a favoured class, and it secured to the country for all purposes a source of revenue peculiarly unobjectionable. By directing attention to new sources of income, Mr. Gladstone undoubtedly solved the problem of meeting the high expenditure of the years that were to come, without stopping the work of reform. Without such aids we should, perhaps, have been paying to this day a shilling income tax, without the remissions which were contained in the latest budgets of the series.

The features of personal effort in the next great stage, that of $1860-66$, are perhaps more difficult to make out. The start would seem to have been macle amid the 
loud din of party wrangling about comparatively small points-objections to proceeding in the way of free trade by means of treaties; clamour about Coventry distress; and the woes of paper-makers subjected to foreign competition, while foreign nations were allowed to maintain their export duties on rags, so denying them perfectly free access to the raw material. It may well seem, in the midst of such wrangling, that there was no real controversy, and no real difficulty-that only some minor points of procedure had to be adjusted, so that no one financier could claim any particular credit. The perplexities of 1853 , it is plain, had likewise come to an end. The agricultural and other interests were less clamorous, having survived the deluge, and found themselves more prosperous than before. The inequalities of the income tax were less talked about, either because of the circumstance so well known to economists, that taxes, the longer they continue, tend to adjust themselves; or because, being richer, people felt less the pinching of the tax. But the situation, when looked at, discloses great difficulties, which made the selection of the right path hardly a bit more easy than it had been in 1853 . The danger caused by public indifference to the work of reform was now very marked. They were disposed to approve and acclaim another characteristic budget, but their hearts were not so set upon it as to compel Ministers to introduce such budgets, or make an Opposition forbearing and careful. Perhaps they thought themselves, in their prosperity, almost sure of such work. But the great danger of all, which threatened an indefinite postponement of the whole work, was undoubtedly the growth of expenditure. Between 1853 and 1860 the annual charge for the supply services had actually increased by the sum of $£$ I 4,000,000-had increased, as Mr. Gladstone explained, at the rate of $j 8$ per cent., while the wealth of the country had only increased at the rate of $16 \frac{1}{2}$ per cent. And there was no repugnance in the public mind towards almost any expenditure: that the country 
was rich, and could afford what it really wanted, was the new formula coming into vogue.

With such a condition of things, then, in 1860 , the budgets of finance ministers were not likely, as a matter of course, to be progressive. The temptation must have been strong, with Palmerston in power, to let things slide. People would have been quite satisfied with a little effort to reduce the income tax and the war duties on tea and sugar, which had not yet been repealed, and there end. Here, then, was Mr. Gladstone's personal mark upon the time. He would not have it that the work should stop; but in spite of high expenditure, and the indifference of popular feeling, proposed changes of the very greatest magnitude-in fact, proposed almost at once to finish the work of the period. To carry out the French Treaty was itself a large work, involving the sacrifice of a considerable revenue by the lowering of the wine duties, but to add on to it the repeal of the paper duty, and of all duties on articles of food, except the shilling duty on corn, and the clearing away from the tariff of all the small burdens, was to show a new sense of the importance of the task. Mr. Gladstone, in short, was not satisfied with a small effort, but desired a remission which people would perceive, which would tell on commerce and industry. That he was right in his aim will surely not be doubted after the event; nor should it be doubted that by thus presenting the question, by showing the possibility of a great achievement, he created a new interest in the work which would not have been felt in piecemeal reductions. Grood judges say that the French Treaty was enough; that the inauguration of free trade on the Continent was sufficient to mark a single great budget; and there was probably ample work, in passing it, in explaining how the treaty might yet be a free-trade one, although in form more suited to the days of protection-a topic, by the way, with which Mr. Gladstone had long before been familiarized when Sir Robert Peel's Governmentwas vainly negotiating a very similar treaty. 
But, judging by the event, it is difficult not to feel that the larger the work, the more beneficial it was likely to be in proportion, and that the excitement of interest required the very strongest stimulants. Perhaps in no other way could the income tax have been maintained at a high figure, or a vantage-ground obtained for fighting expenditure, which last is perhaps the cardinal feature of Mr. Gladstone's latest policy. As it happened, his failure in this warfare made it very convenient, financially, that his repeal of the paper duty was checked for a year by the action of the House of Lords; but any further failure would have been disastrous, and the following series of budgets would have been utterly impossible. The figures have lately been discussed ad nauseam, but it is not possible to go outside the fact, that but for the reduction of expenditure from $£ 69,502,000$ in 1860 , and $£ 72,792,000$ in $\mathrm{I} 86 \mathrm{I}$, to $£ 65,914,000$ in 1866 , the whole process of that time -the gradual diminution of the income tax and tea duties, and smaller reliefs to industry, the clearing off of the remnants of the great work-must have come to an end. In the latter years, it seems plain, Mr. Gladstone was preparing another great coup: the income tax was left at the manageable rate of $4 d$. in the pound, while the revenue for the year i 866-67 showed a surplus of about $\ell^{2,700,000}$ on an expenditure of $£ 66,780,000$. Had the same management continued, the year 1867 might well have been the era of another great budget, in which the alternative would have been, more distinctly than at any period since $\mathrm{I} 842$, the laying of the income tax on the shelf--but this time a light income tax--or the continuance, if there was room for it, of the work of invigorating the industry of the country, and ameliorating the lot of its masses. This was the fruit of keeping expenditure down, whatever clamage, in the shape of insecurity or inefficient services, may have been the consequence. In a financial view the success was complete enough, and it was got by following a path which was far from patent. 
Mr. Gladstone, in another way, has shown in this later period his discernment of what is required by proposing to tax the charities - a measure which, in addition to its other merits, would have added to the fund by which the general work of remission might be carried on. He failed to carry it as he had carried the succession duty on real property in I 853 . The attempt, nevertheless, proved how strenuously he was fighting for the sake of those measures of finance by which the country has prospered so much.

It hardly comes within my plan to criticise in detail Mr. Gladstone's qualities as a financier; but before glancing at the work of the future, and the probable direction of his influence, it may be useful to look at him personally, and point out in one or two important particulars his strength and his weakness. What is the main secret of his splendid success? As far as reputation goes, I believe the impression is that even in finance, what has made him successful and popular is his oratorical power. People look to his budget speeches, remember their startling effects, have been moved by stirring speeches and comparisons to take an interest in subjects which, as usually treated, are repugnant. But for his oratorical art, it is hardly to be questioned, he would not have created that artificial intelligence which was essential to success. Looking back on the whole series of his speeches, however, it is not this power which strikes the reader most. One is sure to find, indeed, not a few faults in taste, and very often a defective exposition. In his last budget speech, for instance, an impressive statement as to the danger of a load of debt, and our duty to discharge it before the exhaustion of the coal-fields, is merely the preface to a scheme on the paltriest scale by which this duty was to be discharged. Defects of this kind are apt to spoil the appreciation of harangues which can hardly be understood without a feeling of the whole circumstances, not afterwards easy to supply. But what begins to be clear is something not so obvious to those who listened to 
the speeches at the time-who had almost forgotten one before they heard another. This is the continuity of the orator's own mind, his firm grasp of certain leading ideas of which every new speech is only an application. We see this conspicuously in his notion about checking expenditure. There is hardly one of his great financial efforts in which he does not recur to the theme-his whole financial theory being plainly coloured with a passion against the waste of money, with which experience has taught him to identify almost any Government expenditure. The cry, he has lately said, is always for more efficiency; but he had found that when any money was granted, the cry was as loud as ever. Perhaps more conspicuous still is his impression of the power of free trade. The salient fact he got hold of from the first was the multiplication of the means of employment by taling off artificial restrictions. Long before his first great budget, while he was at the Board of Trade under Sir Robert Peel's Government, we find him making numerous proposals, of which this was the theme; as, for instance, in a remarkable speech on abolishing the prohibition of the export of machinery. Even in defending the corn laws he assumes that the prospect of increased employment for the people is an irrefragable reason for their abolition-only they must beware of giving too great a shock to old arrangements, and suddenly throwing people out of work. The changes are rung on these phrases almost to the last. The invigoration of trade and commerce, the lightening of the springs of industry, are much in his mind even when proposing the reduction of tea duties, by which money would be put directly into the pockets of the poor. If Mr. Gladstone has changed his financial opinions at all, it is on such a matter as the income tax. It has been a gradual or cyclical change. As the experiment proceeded, he has come to appreciate more and more its merits as an engine of fiscal reform, though, perhaps, also, the circumstances have changed-the increased expenditure upsetting all the calculations by which the 
tax would have been temporary, and yet every existing benefit secured. Change of this kind is plainly not inconsistent with the utmost firmness and continuity which characterize a sure-judging mind. To this quality I would attribute in the highest degree Mr. Gladstone's success. The power to persuade others was a valuable gift, but in scientific questions-and finance is scientific, or it is nothing-it is essential to be right in fact. Mr. Gladstone understood at a very early period, and in all its thoroughness, the meaning of the work to be done, and hence the steadiness of his aim.

At the same time, in other matters besides the income tax, he has not been insensible to the teaching of events. He did not anticipate the overflow of prosperity which has marked the time. Free-trade measures, it should not be forgotten, were rather promoted at first to keep England from decaying altogether. But as the prosperity advanced, he has continued to enlarge on the duty and necessity of ameliorating the lot of the masses-of keeping this, likewise, as an aim constantly to be cherished. That this sure-judging mind is commonplace and average in its sympathies, always looking at the things as they can be presented to a popular audience, such as Parliament really is, narrows its range of action very much, but that is only saying that the defect is inherent in the very qualities by which the success has been gained.

Were this the only great quality in Mr. Gladstone as a financier, there would be some cause to wonder at the excuse he has given for applying to his finance the epithets, adventurous and crotchety. It is a remarkable alliance with love of subtlety and detail, and with abounding activity and energy, which has introduced into Gladstonian budgets those brilliant devices from which common people are apt to revolt. But Mr. Gladstone, with all his foundation of commonplaceness and steady popular judgment, would yet have been very little in finance without his love of detail and wonderful knowledge of expedients. To a very large 
extent this only means that he has the enthusiasm of his occupation. People succeed in nothing unless they give their days and nights to it, and Mr. Gladstone has given to finance the sweat and toil of many years of his life. By dint of much study he has acquired a genuine love of the niceties of the malt tax credits, the alcoholic test in the wine duties, the effect of an extra Sunday in a year diminishing, and an extra day in leap year increasing, the amount of revenue, and the infinitely complex problems which are bound up with sugar. He had a real intellectual pleasure in inventing and explaining that intricate operation $\mathrm{B}$ in the Terminable Annuities Bill of three years ago. The singularity is, that people rather like in him an exposition of minute detail which hardly another financier could make tolerable. The net result is, that he is what may be termed rusé in finance-never without resource at any crisis. The abundance of expedients, and his audacity, have damaged him in the past, but would hardly have done so if full justice had been done to the solid qualities in which, after all, they had their root.

Mr. Gladstone, nevertheless, has committed many financial sins. Trying so many ingenious schemes, he could not but fail in some; as he failed with the plan for converting the debt, and so reducing the interest, in his budget of 1853 , and as he failed on a smaller scale with the stamp on shipping forms, which he expected to parallel his successful penny stamp on receipts. Perhaps, too, he owes to the want of pliancy in his nature a certain capacity of provoking and stimulating opposition. The proposal to tax the charities in $\mathrm{I}_{86} 3$ was pushed on with too much haste and vehemence; not even Mr. Gladstone could bring all the world to see at once the force of that logic by which the conclusion in his own mind was slowly built up. On one occasion, too-in I860-his haste and vehemence led him to make arrangements which would have landed him in a huge deficit, and possibly damaged irretrievably his financial repute. The primary duty of finan- 
ciers, though it has been dwarfed by other considerations, cannot wholly sink into abeyance, and a great gulf between expenditure and income would not have been forgiven. In fairness, however, it must be allowed, Mr. Gladstone was at least conscious of the risk, and was only more passionately bent than others on the remissions he was effecting. As we could hardly have had the work done at all without him, the error is comparatively venial. It is, perhaps, a graver fault that on the question of expenditure his teaching and preaching have been too one-sided. He has taken a somewhat narrow view, with the obstinacy of his nature, and harped upon that-very effectively, no doubt, but not with the effect a fuller exposition would have had. It is not the whole truth about expenditure that it is to be discussed as a natural evil, which financiers must league themselves with such allies as they can get to keep under. Nor can any certain measure of expenditure be found in a comparison between one period and another. In addition to what he has done, beyond pointing out the importance of a nation setting a scale for itself, and comparing always the price it pays in taxation with what it gets in money spent, Mr. Gladstone would have done well to, examine directly the services to which the money is applied. The exposure of inefficiency and waste, of the multitude of useless objects which are sought after, would have been worth a great many speeches in the air, which left behind a vague doubt whether there was not something right on the other side-whether, with all its inconveniences, the high expenditure had not some excuse. Direct teaching by the highest financial authorities on the principles of military and naval expenditure is really a good deal required; and $\mathrm{Mr}$. Gladstone, if some critics are right, might only too easily have shown how all the efficiency talked of, or even more real efficiency, might have been gained at less cost.

Imperfect as this survey has been, it may not be impossible to derive from it some clue to the future. 
The general features of the situation, it will be evident, are substantially the same. If we have no longer to do with the extension of a free-trade policy, our revenue being derived from no protective duties, and our tariff being so contrived as to yield a large revenue with the least possible injury to trade, and the least trouble to the taxpayer, we have still the main condition of allthe rapid increase in the national wealth and the elasticity of the revenue. The present temporary arrest of our progress - if, indeed, there has been any real arrestdoes not alter the general set of the current, which begins once more to flow in the old direction. We may fairly count on the revival of prosperity for an indefinite period to come, just because labour grows daily more intelligent and effective, and mechanical agencies are continually multiplied. A financier may safely count on a return to nearly the old average of $£ 1,750,000$ increase in the year. Such a fact must furnish ever-new opportunities of great budgets, and would have furnished an opportunity two years since had there been any one to seize it, or had the country not been occupied with other matters. The opportunity may at once be made by reducing expenditure to the level at which it stood when that opportunity arose, and trusting to the immediate revival of the revenue. But without any such effort-by merely keeping things as they are, or reducing a very little-any Government may easily have the chance of continuing the work. Is it worth continuing? or are there any counter-schemes to make the finance of the new period altogether novel?

Looking at the past, there is hardly a doubt as to what the action of financiers should be, or as to the line of action Mr. Gladstone would recommend. There is still much in a financier's power towards ameliorating the lot of the masses. The duty on corn, the taxes on locomotion, not a few of the stamp duties, the fire insurance tax, the tea and sugar duties, are all burdens whose abolition would benefit the country, and for the most part put money directly into the 
pockets of the poor. ${ }^{1}$ So long as taxes of this kind remain, and the wealth of the country grows as it has done, it will be the business of financiers to give people the benefit of the facts. That taxation may rapidly be made much less burdensome than it is should be the guide of their action. The objection may be urged that people would really gain more by a more judicious expenditure-as on education and other things which are now starved. But sudden expenditure on a large scale, even for the best of objects, is not likely to be productive-is not likely in this country to be tried; so that finance ministers may remain at ease notwithstanding this contingency. They need not apprehend any expense to swamp their budgets if there is any decent management, procuring for the country all the real benefit it can gain. The most extravagant could hardly pretend that the new things wanted will cost the country an increasing amount of nearly $£ 2,000,000$ a year, which would be necessary to keep pace with the increasing growth of revenue. Others, however, will say that attention should exclusively be given, for a long time to come, to the diminution of the debt. But this purpose ought surely to be compatible with very large remissions of taxation, as it was, in point of fact, during Mr. Gladstone's last period. To divide the work would be a very fair arrangement, applying equal sums to the remission of taxation and the reduction of debt-an arrangement which has this advantage, that every diminution of the debt lessens the annual charge, and so increases the surpluses that future Chancellors of the Exchequer may expect to give away. How much may be done in this direction is perhaps not well understood. But two facts may set it in a proper light. One is that

1 The taxes here referred to were almost all abolished a few years after 1869 , tea being the principal exception. The reimposition of the corn and sugar duties in late years and the repeal of the corn duty after existing for one year only need not be more than mentioned in this place. 
during the last fifty years the capital of the debt has

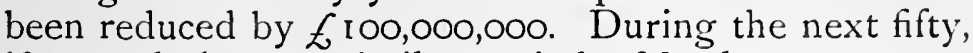
if we only have a similar period of broken peace, we should, if we do as well as the last two generations, reduce the debt by $£ 300,000,000$. Our taxable income is three times greater than it was in $18 I_{5}$, and we should be capable of thrice the effort. The other fact is, what might have been during the last sixteen years if the growth of expenditure had been checked with firmer hand. Long before this the free breakfast-table, which Mr. Bright has imagined, might have been enjoyed, and the capital of the debt still farther reduced. If we choose to stand still, and devote all our surpluses with accumulations to paying off debt, we might accomplish as much in the next ten as we have done in the last fifty years. Of course, all this must be written barring accidents, but it proves the measure of the nation's ability; and, much as may be allowed beforehand for accidents, it is hardly wise to forget a high aim altogether, merely because an undefined worst may happen. The facts show, however, that even a great disaster-a war on the largest scale-might occur without arresting for a long time the work of financial reform. It is surely, then, the more allowable to look forward to a better future for our masses, for better conditions of existence so far as the State can make them better, than these now enjoy. Not only might there be a free breakfast-table, but, better still, it should be possible in a very near future to make England a free port, except for spirits and tobacco, without entertaining any grand scheme of direct taxation. Of course so much will not be done without raising the question of equalizing taxation upon the various classes of the community - a question which the working classes will not lose by having raised; but if it is possible to do so much, the worst difficulties of the question may be evaded. With the income $\operatorname{tax}$ at a vanishing point, if not quite abolished, the richest classes could hardly complain of others gain- 
ing rather more than they do by the wholesale remissions of taxation which common prosperity has made possible.

Of course the financial work of the next few years will include much more than this. The succession duty may be further extended, the charities taxed, and many more expedients tried. There are points without number for financial ingenuity, and in a Government of his own, Mr. Gladstone may be expected to aid with all the suggestions his experience and study have furnished. Above all is the question of extending the principle which has been called in to sanction the purchase of the telegraphs. Here, too, much might be said to show how well disposed Mr. Gladstone will be to venture farther in this direction-to acquire the railway monopoly, and work it for the benefit of the whole community. ${ }^{1}$ This will be the introduction of some novelty in finance, as the State may lose or gain, financially, by the experiment, though the community can only gain; but it does not seriously affect the prospect of direct financial benefit through the continuance of the work of reform in its recent groove.-[i 869.]

How far the country has ever been from any measure like the purchase of the railways by the State, which was at one time so popular, need not now be pointed out. I should not myself be so decidedly in favour of such a scheme as I once was, but the present state of the railway question is as unsatisfactory as it ever was, and either purchase or an analogous measure must be held to be still on the cards. I leave the sentence in the text as I wrote it as an indication of opinion at the time. Of course no reference is made to Mr. Gladstone's work as Chancellor of the Exchequer at later periods when he was also Prime Minister, long after the date when this essay was written. But there was nothing special in the later finance, in comparison with what was accomplished in the earlier period. 


\section{VII. \\ TAXES ON LAND. ${ }^{1}$}

A CURIOUS and instructive collision has just A occurred between a bold and comprehensive project in the application of political economy, and one of those traditional cries in English politics which originate in some class interest, or in circumstances quite different from those which now exist, and yet colour strangely the discussion of practical reforms. I refer to the proposals of the Land Tenure Reform Association on the one side, and the agitation against local rates, or rather against the burdens on land, on the other. There could not be a wider divergence of ideas and aims than what is here discovered. The Association addresses itself directly to one of the gravest questions which can come before an old and crowded community - the question, namely, how the ownership and occupation of its narrow area should be regulated. It challenges the complete applicability here of the rule of absolute ownership which is found expedient as regards other property, and proposes, among other restrictions, that individuals who are allowed to have exclusive possession of any part of the national soil should be specially taxed. In this way, it is argued, the whole community may benefit in some degree from the competition which is inevitable when a large population is crowded into narrow room. The proposal has at least the merit of coming down from philosophy to practice, and raises in a suitable manner a question of the first importance in a democratic society, where the political power is in

1 Written in ${ }_{1} \delta_{7} \mathrm{I}$. 
the hands of masses who are not the possessors of the soil. The opposing cry-that the possessors of land, or that land itself, are already unjustly burdened-is of a very different kind. It has long occupied a principal place in the party politics of England, though perhaps it was never louder or more persistent than it is now. But it is based upon no great principle. Apparently it began when all taxation was heavy, and when the possessors of land, from their political influence, had a peculiar power of making themselves heard; and it has descended to our own day, partly from habit and partly from keen self-interest, the promised gain to a class from any material change being, as we shall see, very great. But whatever its history, it springs evidently from the lowest practical side of politics-the exact opposite of the rival agitation. In discussing, as I now propose to do, the question on which this collision of opinion occurs, it will probably be useful to keep in mind the contrast which is here presented. Some good may be done by bringing scientific principles to bear on the traditional cry against rates, and by confronting the philosophical principles of Mr. Mill, and of the Association whose programme he expounds, with the practical facts and difficulties of English finance.

I.

It will be convenient to examine, first, the traditional cry. While a good deal has been said and written on the economic theory by which the proposals of the Association are supported, the means of reducing it to practice have only been discussed in the most general terms. If we begin with a question in the practice of English taxation in this matter, we shall obtain a near view of the field to which the theory must be applied. On the other hand, the indigenous discussion, as it may be termed, is most confused; and progress will be difficult till the confusion is cleared up.

The confusion is at the very beginning. It is difficult 
to get an exact statement of the grievance of which so much is made. The common mode of speech is something like this:- that land, or real property, has to bear more burdens, in proportion to its value, than any other kind of property. Lord Salisbury, Sir Massey Lopes, and a hundred others, have rung the changes on this theme during the last few months; and I have read not a few laborious estimates of the personal property in the country, and the burdens upon it, got up for comparison with the more accurately ascertained facts as to real property and its burdens. But what is meant by real property bearing burdens is found on examination to be far from clear. The case is sometimes argued as if the burdens were in the nature of an income tax upon the owners of property, and the rate of the tax is contrasted with the rate which falls on incomes from personal property, or on incomes which are not from property at all; but at other times there is evidently some vague notion that property, as such, should be equally taxed, and that the rule is broken in the case of land. Confused as the statement is, we must take it as it comes, and inquire into the principles it assumes.

Whichever alternative we take, it must strike every student of finance that the principle laid down does not make out the case, even if the facts are as supposed. In either case it is a misapplication of the real doctrine of equality in taxation which political economy lays down. Taking the first alternative, that it is the owners of real property who pay a larger income tax than others, it is no doubt true that each taxpayer should contribute according to his ability; but it would not follow that a special income tax on a certain class would offend against the maxim. If this were so our present income tax would be grossly unjust, for the masses of incomes are exempt. 'Theoretically, however, it is obviously quite possible that to produce the final result it may be necessary to tax some sort of incomes exclusively, or more than any other sort. Say, for instance, 
in a country where a large part of the taxation is raised by duties on articles of general consumption, and is therefore borne by the masses of the people, and another large part by an income tax which in conjunction with the other taxes falls with peculiar weight on the lower middle class-clearly, in such a community there might be some reason for a third set of taxes designed to fall on the classes more or less exempt from the other two branches of taxation. And if these classes possessed almost exclusively some special kind of property, a tax on that property, supposing it could be made to fall on its owners, would be the very thing to redress an existing inequality. I am only supposing a hypothetical case; but it is enough to show that inequality of burdens on different kinds of property is no part of the theory of taxation.

If we take the other alternative, which makes no assumption that taxes upon a particular sort of property fall upon the incomes of the owners, the theory of the grievance will even appear absurd. How can it be supposed that there is any principle of political economy, when one sort of property is taxed, requiring all property to be taxed alike? Ex hypothesi, the ultimate incidence of the tax is not upon the owners of it, and before deciding to tax all property equally it would be necessary for a legislator both to weigh the immediate effects of his measures and the object he wishes to arrive at. In point of fact, the considerations which induce a legislator to impose or retain special taxes on property will induce him to tax some kinds and let others be exempt. As with taxes on the profits of a particular trade, with which a tax on property may be classed, his object will either be to impose some charge on the general consumer, in which case the tax will fall to be dealt with as one of the many taxes on consumption, or he will select some trade in which the limitation of the area of profit-the tax not being charged to the consumer-will produce the minimum of inconvenience to the whole community. The particular tax 
will not be unjust per se, but its injustice will be determined by the nature of its ultimate incidence, and the extent of its hindrance to business as compared with other taxes. Such considerations have hardly been touched on by those who complain of unequal taxes on property, but they are essential to the question when the so-called burdens on property are not of the nature of an income tax upon its owners.

What has been said may be enough to prove the great imperfections in the statement of the grievance under discussion. It may be useful to note, however, that in the actual circumstances of England, on the principles suggested, there is a violent presumption in favour of existing taxes on property or profits. They are not likely to be objectionable on any of the grounds suggested. The reason is that they are the last of a heavy burden of a similar kind, and the fact that they are the last is so far a proof that they have been distributed-that if the persons who pay them suffered at one time, they have long since been compensated. Any long-continuing tax on profits tends to adjust itself, but in the case of England during the last thirty years the adjustment has been favoured by the remarkable growth of the country under the stimulus of the removal of other taxes. The limitation of the profit area caused by the tax has been more than made up by the general progress. Unless, then, there is some overwhelming objection, or some greater good to the whole community would result, such as comes, for instance, from a larger reduction of Customs duties, it would even be inequitable to remove these old taxes. To do so would be simply to make a present of a capital sum to the followers of some particular industry or the owners of some particular property. They have already shared to the full in the general prosperity of the community caused by the lightening of taxation, and now they would obtain in addition the capital value of the tax which they do not really pay, since its burden has been transferred.

I. 
There can be no objection, besides, to special taxes on real property, on the ground of their hindrance to trade. Land-owning is so simple a business, that it is divorced from the very notion of trade, and considered a special occupation for trustees and widows and orphans. So simple a business can hardly be checked by a few plain conditions. The objection of hindrance to trade is also compensated by the consideration that the business itself is in the nature of a monopoly. The abolition of brewers' licences was objected to for this among other reasons, that the business had become practically a monopoly in a few hands; to abolish the licences would have been to put money in the pockets of a few without any real chance of its reaching the public. The passenger duty on railways is defended for a similar reason. The duty, it is said, is only a way by which the State reserves to itself the share of a monopoly. This may be wrong as regards railways, but the principle of the reasoning is obviously sound. Now land-owning is, beyond all other callings, in the nature of a monopoly. The whole quantity in a particular country cannot be increased, and there are besides hundreds of specially favoured spots. As regards land, therefore, that condition exists in the highest degree of force, which makes it probable that any abolition of a tax on profits would not benefit the community:

We are thus a long way from the proposition so confidently assumed, that all property should be taxed alike. There are many questions affecting the regulation of special taxes on property of a very different order. We may look, then, at the particular taxes which form the gravamen of the complaint, and see what portion, if any, offend against the true principle of equality in taxation, by pressing unduly on some classes of income, and which of them, on other grounds, are liable to objection.

The maximum taxation which can form the subject of this inquiry appears to be, from Mr. Goschen's recent report: 


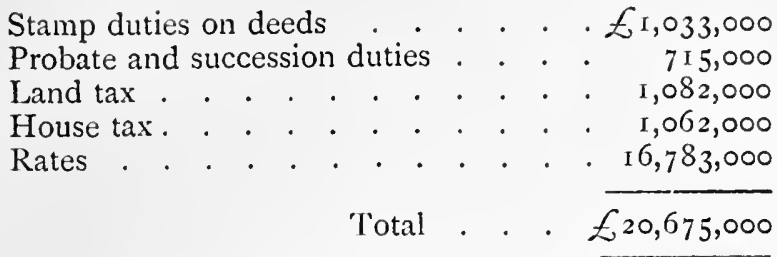

Besides these there is the income-tax, which the owners of real property pay like all others; but this is not an exceptional impost on income, and the only question here is of exceptional burdens.

The total of taxation affecting real property looks very formidable. In fact, it is nearly one-third of the entire taxation of the country, imperial and local, and amounts to a charge of about 3 . per pound on the estimated annual value of the property in the country. ${ }^{1}$ But the moment we examine the items, we find how little reason there is to suppose that the burden is of the nature of an income tax on the owners of real property, or that any part is of such a nature as to raise an overwhelming objection against it.

I. The stamp duties on deeds may very well be left out. The heaviest of them is a half per cent. advalorem charge on the sale of property, a charge which is borne by many kinds of other property as well; and even a half per cent. charge is a hardly perceptible tax. It is sunk in charges of much greater magnitude, which always take place at sales. In any case, the incidence of stamp duties is so peculiar, that it cannot be said to affect a class so much as individuals of a class, and these unevenly amongst each other, in comparison with the amount of the duties. Where they are not defensible as a minute charge on transactions, like the receipt and cheque stamps, as I think they may perhaps be now in the case of real property, though it was not always so, there would be a case for their reduction, so as to make them minute enough for the purpose. In that case they would cease to be taxes which could

$$
1 \text { viz., fir } 43,000,000 \text {. }
$$


be set off against others in a question of comparative taxation. It would be a mistake, however, in the meantime, to make their existence a ground for interfering with some other impost.

2. The probate and succession duties appear to me also to be a tax sui generis, with which no others properly come into comparison. I have to discuss them afterwards; but the distinguishing peculiarity is apparent. They are charges upon a very special extension of the ordinary rights of property, its bequest or descent after death - an extension which necessitates the direct intervention of the State; and as such, the burden which they constitute cannot properly be weighed with burdens of a different nature. If it is discussed as a charge upon a particular description of property, the difficulty at once arises that it is most unequal and severe. Some owners escape with hardly a charge, while others, who own no more, have much to pay. The only plea by which it can be defended, therefore, is that the Acts in respect of which it is levied-the authorizations given by the State to the transmission of property from the dead to the living-furnish occasion for a wholly exceptional charge. In any case, so far as the probate and succession duties are a tax upon real property generally, it will not be denied that they are more moderate than the corresponding imposts upon other property and its owners.

3. The land tax, which is next on the list, should equally cause but little controversy. It is persistently claimed as a burden upon land or landowners; but this will not bear scrutiny when we inquire out of whose income the tax is paid, or what way it causes pressure, so that its reduction or abolition would be a benefit to the community. As a fixed charge upon land for generations, it is now past all controversy a rent-charge. In many instances it has long since been redeemed, the property having subsequently changed hands; in others, inheritors of property have acquired it under the burden, and have calculated their income minus the tax, while 
purchasers, in buying, invariably allow for it. To reduce it now would be to present the landowners of England with a capital sum of nearly $£ 30,000,000$. Their estates, relieved of the burden, would become at once so much more valuable, and if they did not sell, they would pocket an additional income which they never inherited or paid for.

There remain the house duty and the rates-still a formidable amount, if they are considered to fall on the incomes of real property owners, or as forming an objectionable tax on profits, notwithstanding that the burden is shifted to the consumer. We may class them shortly as rates, the only difference being that the house duty is a fixed rate limited to certain descriptions of property, whereas the rates apply more or less to all real property, though in fluctuating proportions. But what is the incidence of these rates? Are they, in the first place, an income tax on the owners of real property? There is one very short answer to this question. If they were an income tax there is none more outrageously unjust. Most properties, we are told, are incumbered, often heavily incumbered, and the residuary owner, as we may call him, the man who would benefit by a reduction of the rates, has often but a barren interest. Measuring the rates with his income from the property, they might be ten or fifteen shillings in the pound. Is it possible to believe that the owners of real property are subjected to any such income tax? The inequality in itself suggests that the incidence of the tax is different-that the burden is on the property and not on the individuals who have incomes from it.

The question remains, however, whether the rates are on other grounds objectionable. And here it should be noticed that it is by no means unanimously admitted that they are burdens on the profits of land-owning at all. A large party maintains that to no inconsiderable extent they really are passed on to the consumers-in the country districts, farmers, who pass it on as a deduction from their farming profits; and in towns, the 
class of occupiers, who both pay it and ultimately bear it. But granting that this transference does not take place to any material extent-a view, I am willing to admit, which I am disposed to agree with-granting that in consequence the whole or most of the charge falls on the profits of owners, are the circumstances such that they have any cause for complaint? The answer is that in the lowest view the business is one which has increased enormously, stimulated by other changes in taxation, and that being a monopoly, as landowning confessedly is, the magnitude of the charge, even if it has been an increasing one, makes nothing against its propriety. Look only for a moment at what the increase of business has been. In i 8 i 5 the annual value of real property-in other words, the annual return of the business - was $£ 53,000,000$; in 1853 it was $£ 85,000,000$; in 1868 it was $£ 143,000,000 .{ }^{1}$ At the same time the rates have barely doubled in the last thirty years, and have not doubled if we take an earlier date for comparison.?

The improvement it may be said has arisen through the investment of capital, but this statement cuts two ways. If it means anything at all, it would mean that the charge upon the profits of the business checks investment, but nothing of the sort is alleged. The fact that investment has continued is thus a proof that the burden, whatever it is, has still left a large enough margin of profit to induce a resort to this species of business. It is certain, however, that a large part of the improvement is due to the increasing value of advantageous sites, an unearned increase of value such as Mr. Mill speaks of, and therefore a kind of profit which the State may restrict with least harm. The increase of the annual value of house property in the country

'In 1884 it was $\mathcal{E} 193,000,000$, and in I90I-2, the latest year before me, $\mathcal{E}_{2} 38,000,000$.

${ }^{2}$ Rates increased from $£_{20,000,000}$ to $\mathcal{E}_{31,000,000}$ between I 868 and r 883 . In the latest year, I900-1, they were (England and Wales only) $f+3,000,000$. 
since I 8 I 5 has been $£ 54,000,000$, or 356 per cent., although the population has barely doubled. If we estimate that only a fifth of this amount is for extra ground rents-that is, rentals in excess of the value of the area occupied for agricultural purposes-we shall probably be far under the mark. And this is not the only unearned increase of value. Against the large amount of rates therefore is to be set an unearned increase of value which altogether will be of equal amount, and double, perhaps treble, what the increase of rates has been.

Nor does the case as to profit end here. The increase of rental value does not measure the actual increase of profit with which the rating-charge should be compared. It is probably the case that as respects the bulk of property in area, the increase of rental measures the whole increase of value; but there is one kind of property, that in the suburbs of large towns not taken up for building, extending in the case of London in all directions but the east over an area of about eighty miles diameter, where the increase of rental is no measure at all of the increased value. The position of the property is in effect discounted, and it is no exaggeration to say that its real selling value is now double what it would have been ten or fifteen years ago upon the same rental. It would be useless to put any figure estimate upon this increase of value, but it must be remembered as a set-off against "increasing" rates.

The question might well be left upon these broad facts, and these general principles stated, but there are other facts about the rates which affect the question of the business profits on which they are a charge. When we look into them we discover that the increase has been far from uniform geographically, or in respect of the class of property affected. The increase has in fact been confined to that class of property in which the investment of capital has taken place to the largest extent, while as respects the remainder of the property, 
there has either been a diminution of the burden or no material increase. The inference is, that while the rates where they have increased have not checked investment, there is an immense mass of property which has augmented in value without any proportionate charge upon its profits. The facts speak for themselves. First of all, of the above sum of $£ 16,783,000$ of rates proper, ${ }^{1}$ there are upwards of $£ 4,000$, 000 of comparatively recent rates which not only form a charge upon the property in which the investment of capital has taken place, but were mainly intended for the improvement of that property. The remainder, $\mathscr{E} \mathrm{I} 2,689,000$, is very little more in amount than similar rates have been during the present century, and the rate per pound is less.

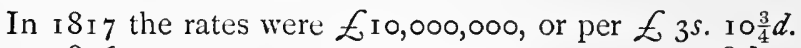

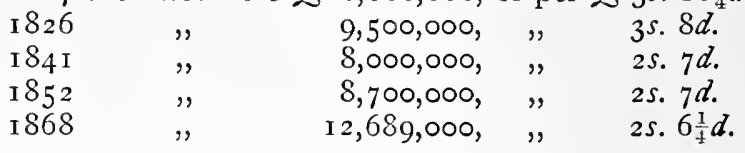

Thus, as respects a large part of the real property in the country, it is incorrect, strictly speaking, to talk of the increase of rates. ${ }^{2}$

The second fact is, that at a time when real property was different in its constituents from what it is now, there was an enormous diminution of the burden, precedent to the subsequent rise in proportion to the value.

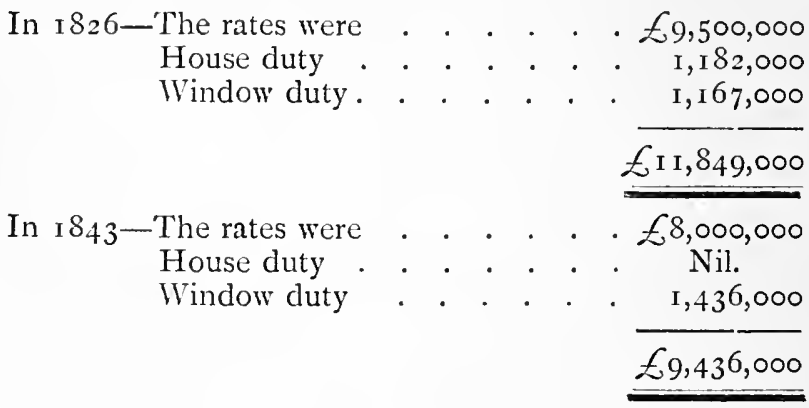

1 This is for England and Wales only.

This is still true, although rates (for England and Wales only) are 
showing an actual diminution of about $£ 2,500,000$, representing a capital sum of about $£ 75,000,000$ in the charges upon the property then existing-a burden which has never since been reimposed, as the rates, including house duty, have only risen in proportion with the augmentation of rent. The relief to the old property has been permanent.

It is thus evident, that while so much has been heard of the increase of rates, the actual fact is entirely different. The increase, such as it was, has been limited in extent, and conceals an actual diminution in the amounts levied upon part of the property which has since never been made good. To complete the statement, we need only ask ourselves what the effect would be of any such reduction of rates as the principles of the anti-rate agitators point to. Consequences are very often a test of principles, the logical result proving the groundlessness of the plea. And this appears to be the case in the present matter. Grant that certain rates ${ }^{1}$ are thrown on the Consolidated Fund, as the most eager reasoners of the party contend, or that they are reduced one half, which would be the effect of throwing them rateably on all the schedules of the income tax, what would be the result? It is not difficult to see that in the former case some people would have $\mathcal{L}_{\mathrm{I}} \mathrm{I}, 000,000$ a-year, and in the latter case $£ 5,500,000$ a-year more than they had before. Possibly it would not all go to the so-called owners of property, for the occupiers would gain where they are dealt with on tenant-right principles; but it may be treated practically as a bonus to owners, and, as such, it is of magnificent dimensions. In the one case, at thirty years' purchase only, it represents a capital of $\{330,000,000$, and in the other of half that amountall to be transferred to a single class by a few lines in

now about $\mathcal{E}_{43}, 000,000$ annually, as above stated (sce note, p. 262). The bulk of the increase has been in improvement rates.

Viz., poor and police rates, amounting to about $\mathcal{E}_{\mathrm{I}} \mathrm{I}, 000,000$. $[£ \mathrm{r} \$, 000,000$ in England and Wales in I900-1.] 
an Act of Parliament! To state such a result is to make the argument absurd. Unless it is to be contended that the State keeps out of the pockets of the class some $£ 300,000,000$ which they ought to have now, there is no call to give the money. And if the State inflicts such a wrong, the sooner it pays back what it has exacted, with interest, the better.

\section{II.}

Having thus examined the case against existing burdens on land, I turn to the second part of my subject-the claims urged by the Land Tenure Reform Association for securing to the State a share of the unearned increase of value. The inquiry, however, should have prepared the way for looking at the question from the Association's point of view. It has been seen that upon the general theory of taxation special burdens on this particular description of property are not unreasonable, that they are not without analogy in taxes upon trade profits, which no one thinks of altering on the ground that "other property" escapes the burden, or that they are a special income tax on the people in the trade. It has also been shown that, if taxes on profits are justifiable in any case, the circumstances of land-owning are such as to reduce the hardship of the owners to a minimum when their profits are taxed. The business is a monopoly, and simple in the highest degree, and nowhere else can be found more favouring conditions for a tax upon profits. We are thus prepared for the inquiry, whether so peculiar a business could not be made to bear a larger burden; and for the theory of the Association, that while it is only on grounds of expediency the State permits individual property in land at all, there is no reason of expediency against its limiting that right of individual property by a large reservation in its own favour. If there is any reason in this theory at all, the facts stated will have suggested the magnitude of the value in which 
the State may claim a share. The augmenting value, on which it is urged the State would have had the first claim under a proper financial system, must have amounted, in the last thirty years, to hundreds of millions sterling.

Now in theory, so far as I can see, there is absolutely nothing to be urged, and nothing has, in fact, been urged, against the principle of the Association. The soil of the nation is primarily the property of the whole nation-the common inheritance of all, regarding which the State, according to its lights, cannot help laying down rules from time to time for the common advantage. There is no other final authority, and if the action of that authority is to be limited by so-called rights, if on cause shown it may not destine the whole land, or any part of it, to any use it pleases, then we have this anomaly - that the most vital necessity of national existence is to be held, not under the direction of the State, but subject to some arbitrary limitations in favour of individuals or classes, based on a superstition of right. In point of fact, as well as theory, no such limitation has ever been admitted by English law. Year after year the national Parliament exercises in innumerable cases the right of diverting some part of the "common inheritance" from one use to another. If it so acts in part and detail, it has clearly a right to take a wider range and exercise its discretion upon the whole or a large part of the soil of the country. The only question would be whether the particular regulations or uses proposed to it are wise.

And whatever regulations may be objected to, it seems to me that, assuming private property in land to be retained as the rule, the imposition of special charges on it, which will be in the nature of mining royalties, or a reserved rent-charge, or like the casualties under feudal tenures, will be about as innocent a way of limiting the privilege, interfering as little as possible with the individual enjoyment as could well be desired. It leaves untouched the right of exclusive possession, 
which is the main thing coveted, and merely keeps to the State a charge, which exactly resembles many other charges by which the privilege of absolute possession is limited. Of course the mode of the reservation will be an important matter; but theoretically there is no reason against reserving something.

It may be added that the more progressive a community, the more likely it is that any proper reservation will be little felt as a burden. By the hypothesis, it is in such communities that competition will cause an immense unearned increase of rent and of capital value. There will be a large margin for ground rents of every description, and the State ground rent will be no more felt than the others. So free from hardship will the charge in fact be, that just as the commuted tithe rentcharge and the land tax are no longer felt as burdens by the present possessors of land, the whole charge of the State, when it is carefully studied, will be acknowledged as equally light.

But what form should the charge of the State assume, and how much in the present condition of things, as respects property, business, and population, should the State endeavour to obtain? Clearly, if the phenomena of the last thirty years are about to be repeated-and there is a reasonable chance that they will be, for there is no sign of check to the growth of population or the increase of machinery and inventions-it is much to be wished that a better system should, if possible, be at work than has hitherto existed for securing to the nation a portion of the augmenting value of its soil. The problem, however, is excessively difficult, and I doubt very much whether Mr. Mill's own suggestion, which must be first considered, will be found, as a general measure, to answer the purpose. It is in effect a proposal to go straight to the end in view-that the State should inquire at prescribed intervals what is the augmenting rental of land, and make a charge upon the owners of some definite portion of that augmentation. If there is no increase of rental due to general causes, 
there will be no increase of tax, and owners who object will have the opportunity of surrendering their estate on what Mr. Mill's enemies must admit will be full compensation. One objection to this proposal is that it is almost wholly novel in European countries, at least where the art of taxation has been most carefully studied, and is least of all fitted for a country in the circumstances of England. Mr. Mill has apparently in view the ideal of the foncior taxes on the Continent, in which the process is for the State at a certain date to impose a lump charge on the whole land of the country in proportion to its estimated value, and then apportion this charge among the various localities and parts of soil in the country, by a carefully arranged cadastre. But there is nothing more tedious in fact than the completion of a cadastre, or unequal when it is completed. Even in France, which has set the example in these foncier taxes, the new cadastre, which was commenced forty years ago, was only completed the other day, and while it was being put into operation the value of the whole land subject to it was changing. It is hardly possible to imagine that even if in England we could give that attention to the nice adjustment of competing qualities of land or property which could alone make the basis of French direct taxes endurable, we should be content to await the slow development of a pretentiously perfect, but really imperfect, cadastre for a period of forty years. It is a still more fatal objection that such taxes do not appear to draw. It is officially estimated in France that the annual value of real property has increased since i 821 from $£ 64,000,000$ to $£ \mathrm{I} 60,000,000$, which is quite comparable with the increase in England. But while the rates have risen in England from about $\delta_{10,000,000}$ to $£_{17}, 000,000$, the special land tax of France has only risen from $£$ I I, 720,000 to $£$ I $2,280,000$, including the additional hundredths imposed for local purposes, as well as the "principal" of the tax. The special tax of England is thus more elastic and effective than the special tax of France, 
which is proposed as a model. Besides, if these objections could be got over, if it could be shown that an improved cadastre is easily possible, and is capable of frequent renewal, there would remain the objection that such a tax, so imposed, might interfere with the enjoyment of private property in an inexpedient manner. It would be very difficult to reassure individuals against the operations of the tax assessors. Every few years they would foresee a demand of an indefinite amount, depending on many points of taste and opinion, and they would only have the alternative of paying or surrendering their property to the State. Careful as Mr. Mill is to suggest safeguards, the essential nature of the transaction would be such as to destroy confidence in the continuity of private right in some particular plot of land. The apprehensions might in the main be unfounded, but their existence would be a public calamity, unless the theory is admitted that the abolition of private property would be beneficial, which in some localities it might be.

Turning from this suggestion, I think there is much to be said in favour of our present special taxes on land, imperfect as we have shown them to be. They have permitted the growth of an immense mass of value in the hands of individuals only, and at a very recent date there was a sudden reduction of the burden, by which a small class received a considerable gain. But with all their imperfections they have the merit of elasticity. They are set apart for the discharge of certain branches of expenditure; and, without fluctuating so widely as to disturb property rights, they may be increased materially, and so reserve for the State some portion, however insignificant it may be, of the augmenting value of property. This is no small merit, especially when compared with the model of the continental land taxes, which have no such capacity of expansion. It is an additional convenience that, as the branches of expenditure which are thrown specially on this property are local, local administration and local 
taxation can be associated. In this view rates are, in fact, a happy English invention, by which different and unconnected advantages are obtained in a rough practical fashion, and as it is a familiar system we have another obvious reason for trying to make the most of it. Could not something more be made of it? It will be of some use perhaps if the discussion of the principles on which the burden is imposed makes it clear that no injustice is now committed-that the support of a certain burden of expenditure is a condition of the enjoyment of the property which the State may properly impose. Every one knows the condition beforehand, and as it is quite a calculable one, notwithstanding the loud talk of the increase of rates, and the addition of new rates, there is no inexpediency in it as a too heavy restriction on the enjoyment of private property in land. But the discussion, I think, may do more, and justify the imposition of new charges which are convenient for local administration. As the tendency of the functions of local government is to increase, and the additional expense has not yet proved commensurate with the increase of the value of property, we have a security in the recognition of this principle, both of the reservation to the State of a part of that value-though, I fear, a most inadequate part-and for the safety of private property against any great disturbance. If I might venture to make a suggestion, there is one new charge which escapes notice, and which might very properly be treated as a branch of local expenditure: the army for home defence ought to be locally maintained. For many reasons it is important that a good deal of local management and self-government should be associated with the organization of our militia and volunteers, and the charges might very properly fall on the rates. This would not only relieve the Imperial army estimates of a heterogeneous charge, but by really associating localities with the work, would contribute much to the strength and vitality of our home system of defence. There is 
another way in which something more could be made of the present system. Under the haphazard methods and want of principle which have hitherto prevailed the local rates have gradually been relieved of a large portion of the burden which properly falls upon them. On one pretext or another, the Imperial Exchequer has been drawn on for "grants," amounting annually in England to a million and a quarter, by which the growth of the local burden has been retarded-or, in other words, the individual landowner has been permitted to retain a larger share than otherwise he would retain of the augmenting value of land. Good reasons, I think, have been furnished for putting a stop to this system, if rates continue to be the form of our especial tax. The proper course would now be to institute a mode of discontinuing the grants by degrees, according to a defined scale, and so reimpose on property a burden which it has escaped. ${ }^{1}$

But while the system of rates is preserved and amended, as the principal agency for securing to the State a share in the national soil, there is another mode in which it seems to me a smaller advantage of the same sort may be gained, equally without disturbing the security of private property in land. I have already referred to the probate and succession duties, pointing out the confusion of thought which leads to the share of them derived from land being added in with taxes of different kinds, so as to present a large total of burdens on land. But the rationale of these taxes is so important a part of the art of taxation that, even apart from the suggestion I intend making, I may be excused from returning to the subject and showing how the special nature of these taxes makes it improper to classify them with the burdens on property.

Their distinguishing feature, as has been already said, is that they are a charge for a special intervention of the State-for the authority it gives to the transmission of property from the dead to the living. It is

${ }^{1}$ The system, alas, has been much extended in recent years. [I g03.] 
common to consider the bequest and descent of property as mere extensions of the right of private property, but they are not so historically or practically. The reasons which make private property expedient during life do not apply with the same force to the transmission of it at death. It would be difficult to conceive of a large society existing without absolute ownership in the fruits of individual industry, but so long as people are secure in what they earn themselves a very severe strain may be put on the rules for disposing of it at death without endangering the existence of society. Instead of the absolute right of bequest and the unincumbered descent of property to individuals when there is no bequest, being an ordinance of nature as of natural right, they are in fact very peculiarly the creations of the State, and have been modified in all civilized countries to suit its varying policy. For these reasons a special tax on successions has an undoubted justification. The State being their author, and having, strictly speaking, the power and right to absorb them altogether, a power which it would be infinitely less inexpedient to exercise than would be its similar power in regard to private property-the special tax becomes virtually a charge for a concession which the State grants, and which it might conceivably withhold, or at least very seriously curtail. Viewed in any other light, it appears to me wholly indefensible, for though it would no doubt fall on the payer at a convenient time for payment, its pressure on individuals would be most unequal, and it would thus offend against a cardinal maxim of taxation.

Regarding it as a charge upon a concession however, we may recognize in the State a capacity for varying it which would not exist in the case of an ordinary tax. It may take into account, in adjusting the so-called tax, the whole policy of the law of succession and bequest, and the nature of the property itself. The principles to guide it seem hardly to admit of discussion. The tax must not be so severe as to check 
accumulation, or be severely felt, so as to cause individual suffering even when accumulation is not checked. Subject to these restrictions the State should simply take by a succession duty what it can. It follows that its charge should be most moderate where the transmission resembles most a continuance of the enjoyment of private property, or is the transmission of property which the deceased person has acquired by his own industry, and in acquiring which he may be supposed to have been influenced by the prospect of regulating the succession; and should be most severe in the contrary case, where the transmission is to strangers, or where the property has been inherited. Unless these points are kept in mind the State will not be able to levy so large an amount as would otherwise be possible for it. To make the charge uniform would simply be to limit it to the minimum possible in those cases where the succession of the dependents of a deceased person, whose income dies with them, gives the tax the appearance of a charge not upon inheritance, but impoverishment. It would be quite consistent with the principle of the tax, however, to look at the composition of the property bequeathed; to say that as the possession of a certain kind of property over which the State had primary rights was keenly competed for, one condition of its enjoyment should be a special liability to taxes on successions. No person could complain, for there are abundant modes of investment besides land, and those who wished to have an unrestricted privilege of bequest could invest in other property. Even a charge of five per cent., however, would probably present no inducement to people to keep away from land. It is very seldom that an entire fortune is thus invested (it would be sheer folly so to invest it), and the total charge on the succession, though it is five percent. on a portion of it, might not be much higher than it is. I need not add that if there is any reason in this view of succession duties, the singular arrangement by which land now pays least 
of all is more than indefensible; it is a gross neglect of the State to secure a due to which it is most fairly entitled. The arrangement is another instance of the perversity of discussions about the incidence of taxes according to the historical method in England. An illogical mode of comparison has not only enabled the owners of land to secure for themselves an augmentin: value in which the State might well have had a larger share, but has enabled a class which enjoys a valuable monopoly to escape payment on its successions of the charges which other classes of the community, enjoying no monopoly, have to bear.

After all, it may well be doubted whether by any process that would not be worse that the disease, anything but a small fraction of the augmenting value of land will ever be secured for the State. At the past rate of increase, the real property of England, which is now worth about $£$ i 50,000,000 a year, will be worth $£ 250,000,000$ in another thirty years. And a large part of this additional $\mathcal{L}_{\mathrm{I} 00,000,000}$, perhaps the half of it or more, will not be owing to any investment of capital in improvements, but to increasing monopoly value. At the past rate of increase, however, our rates

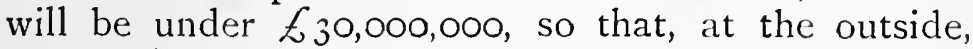
there will not be an additional burden of $f_{1}$, , , oo, , oo to set against an additional value of $f$ I00,000,000, while much of that additional burden will also have fallen, not on the property generally, but on the profits of the improvements. There is little hope of touching this immense augmentation. But this is hardly a result to be rejoiced over by the defenders of private property in land. If they were wise in their generation it should be their aim to show that the present system, besides any indirect advantages to the community it may have, is also directly beneficial to the State, because it provides a large fund for the support of national charges. Looking forward to the great increase of value which is inevitable, they should rather, of all others, be anxious to secure a large appropriation to 
the State, as some compensation to the masses for the privilege of exclusive possession which they enjoy. The divorce of the people of England from the soil would be more, and not less, defensible than it is if it could be shown that private property in it was so regulated as to relieve the general taxpayer of his burdens.-[1 87 I. $]$ 


\section{VIII.}

THE TAXATION AND REPRESENTATION OF IRELAND. ${ }^{1}$

THE House of Commons was occupied on Monday

1 and Tuesday with two subjects which are not at first sight connected, but between which a real connection of some interest may in our opinion be established. We refer to the debate on Monday on the alleged disproportionate taxation of Ireland, and to the debate on Tuesday on Mr. Trevelyan's motion as to the electoral system as far as the question of redistributing seats is concerned. These two debates suggest to us that whatever difficulties there may be about a redistribution of seats within each particular division of the United Kingdom, there can be little question of the expediency of a redistribution of seats between these divisions themselves. The Irish members complain that Ireland is unduly taxed, but England and Scotland may complain that Ireland is unduly represented, and use in support of their complaint the very arguments as to taxation in Ireland which Irish members employ to prove that Ireland should pay less to the Imperial Exchequer. There ought clearly to be some proportion between the representation of different communities in a common Parliament and the wealth and population of these communities; there is an unstable political equilibrium wherever the poorer and weaker communities have a disproportionate share in dictating the general policy, and so voting the burdens which their richer and stronger associates have to bear; and as 1876 .

Written and published as an article of the "Economist" in 
Ireland now has, and has always had, a larger representation in the Imperial Parliament than the proportion of the taxes it paid would give it, the argument that it should pay a still less proportion implies that it should also be less represented. Until lately this argument was partly counterbalanced by the large proportion of the population of Ireland to that of Great Britain, but year by year the claim of Ireland on this ground has become weaker, till now it has no existence.

The facts can be stated very shortly. Ireland sends to the Imperial Parliament 105 members out of 658 , or almost exactly 16 per cent., as compared with 553 members, or 84 per cent., representing Great Britain. As regards taxation, therefore, assuming an exact proportion between it and representation, Ireland would not be unjustly burdened if it contributed 16 per cent. of the Imperial revenue. But its contributions in I 874-5, the last year mentioned in the return obtained by Mr. Mitchell-Henry for the purpose of the debate, were only in the proportion of 10.6 per cent. Of a total of $\measuredangle 74,986,397$, which was the revenue of $1874-5$, Great Britain and Ireland contributed as follows:

\begin{tabular}{|c|c|c|}
\hline & $\mathcal{L}$ & $\begin{array}{l}\text { Per Cont } \\
\text { of Total. }\end{array}$ \\
\hline $\begin{array}{l}\text { Great Britain . } \\
\text { Ireland } . ~\end{array}$ & $\begin{array}{r}67,016,346 \\
7,970,051\end{array}$ & $\begin{array}{l}89.4 \\
10.6\end{array}$ \\
\hline Total & $74,986,397$ & 100.0 \\
\hline
\end{tabular}

The inhabitants of Great Britain may surely ask with some fairness that there shall be no complaints of Irish taxation until Ireland pays taxes in some more exact proportion to the number of representatives it hasthat is, I 6 per cent., instead of I 0.6 per cent., of the total Imperial revenue. If it did so its contribution would have been in $1874-5$, not $£ 7,970,000$, but

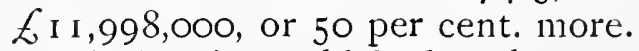

We fear it would be hopeless to tax Ireland in proportion to its present representation, but the inequality 
could be redressed by reducing the representation. In that case Ireland would only elect ro. 6 per cent. of the members of Parliament, instead of 16 per cent., or 70 members instead of 105. And matters would be still worse for Ireland in this respect if the Irish members had their way, and Irish taxation were reduced as they say it should be. Great Britain, we are told, would pay $£ 200,000,000$ if it were taxed as Ireland is. In other words, Great Britain is affirmed to be twenty-five times richer than Ireland. But if representation were to be adjusted accordingly, Ireland would only elect $\mathrm{I}-25^{\text {th }}$ of the members of the Imperial Parliament, or 26 instead of 105. As far as it goes, this argument for diminished taxation is also an argument for enormously diminished representation.

We come then to the facts as to the relative population of Ireland and Great Britain, on which the claim of Ireland to a larger representation than one in proportion to the share of taxes it pays may be based. At the time of the Union, and for many years after, it was certainly intelligible that the magnitude of the population of Ireland should be a set-off to its poverty in a question of representation in a common Parliament with Great Britain. In I82I, which is the first year for which we have good data, the population of Great Britain and Ireland were respectively:

\begin{tabular}{|c|c|c|c|c|c|}
\hline & . & . & & $\begin{array}{l}\text { Numbers. } \\
\text { I } 4,391,63 \text { I }\end{array}$ & $\begin{array}{c}\text { Per Cent } \\
\text { of Total. } \\
67.9\end{array}$ \\
\hline \multirow{2}{*}{ Ireland . . } & . & & & $6,801,827$ & $3^{2.1}$ \\
\hline & Total & & & $2 \mathrm{I}, \mathrm{I} 93,45^{8}$ & 100.0 \\
\hline
\end{tabular}

In other words, Ireland was about a third of the United Kingdom as respects population, and in consequence its claim to have a larger share of representation than the proportion of its wealth and taxation to that of Great Britain would have given it had some foundation. Ireland with such relative numbers, what- 
ever their condition, was a large unit to which much less than a sixth of the representation could not reasonably have been assigned. And this proportion continued during the two following census periods. In I $83 \mathrm{I}$ and $\mathrm{I} 84 \mathrm{I}$ the proportions of Great Britain and Ireland in the total population of the United Kingdom were:

\begin{tabular}{|c|c|c|c|c|c|}
\hline & & - -Great $\mathrm{B}$ & ritain. - & $\sim \mathrm{Ir}$ & nd. $-\longrightarrow$ \\
\hline Yea & $\begin{array}{c}\text { Total } \\
\text { Population. }\end{array}$ & Numbers. & $\begin{array}{l}\text { Per Cent. } \\
\text { of Total. }\end{array}$ & Numb & $\begin{array}{l}\text { Per Cent. } \\
\text { of Total. }\end{array}$ \\
\hline & $24,306,7$ r 9 & I $6,53 \mathrm{I}, 3$ I 8 & 68. I & $7,767,40 \mathrm{I}$ & 31.9 \\
\hline 184 & 26,9 I 6,99 I & I $8,720,394$ & 69.6 & $8,196,597$ & 30.4 \\
\hline
\end{tabular}

But since I 84 I a great change has taken place. The following twenty years were the period of the Irish exodus, and although of late the population of Ireland has remained stationary, or has only diminished very slowly, the stationariness has been coincident with a rapid increase in the population of Great Britain, which is constantly altering the proportion. The effect is seen if we compare the population for the last three census years, and also for 1875 . The figures are:

Population of Ireland and Great Britain compared at various Dates since $185 \mathrm{I}$.

\begin{tabular}{|c|c|c|c|c|c|}
\hline \multirow{4}{*}{$\begin{array}{l}\text { Year. } \\
\text { I } 8_{5} \text { I }^{1}\end{array}$} & \multirow[b]{2}{*}{$\begin{array}{c}\text { Total } \\
\text { Population. }\end{array}$} & \multicolumn{2}{|c|}{-Great Britan.- } & \multicolumn{2}{|l|}{ - Irela } \\
\hline & & & Per Cent. & & $\begin{array}{l}\text { Per Cent. } \\
\text { of Total. }\end{array}$ \\
\hline & $27,435,000$ & $20,88_{3}, 000$ & 76.2 & 2,000 & 23.8 \\
\hline & 28,9 & & So.0 & 4 I 5 & 20.0 \\
\hline & 31,5 I $3,4+42$ & & 82.9 & 36,708 & \\
\hline & $32,737,405$ & $27,439,673$ & 83.9 & $5,297,73^{2}$ & I6. I \\
\hline
\end{tabular}

Thus the proportion of the population of Ireland, which was thirty per cent. of that of the United Kingdom as late as I $84 \mathrm{I}$, had fallen in ${ } 8_{5} \mathrm{I}$ to $23.8 \mathrm{per}$ cent., and in 187 I to 17 . I per cent. only, while since the latter year it has gradually come to be still lower, or I6. I per cent. It is thus quite manifest that Ireland has lost the claim it once had, on the score of its great population, to a larger share of representation than its wealth and taxation would give it. If existing taxation

Part estimated for Scotland. 
were to be the test, the argument for reducing the representation of Ireland in the Imperial Parliament from 105 members to 70 , which is the proportion existing taxation would give it, as we have above seen, and for proportionally raising the representation of Great Britain, would now be irresistible.

We are not using these arguments in a controversial spirit, and as a tu quoque to the Irish members in their demand for lessened taxation. The excessive representation of Ireland in the Imperial Parliament is a substantial mischief to the whole United Kingdom. It gives undue influence to one of the elements in the Union the least in harmony with those which really preponderate, and consequently impedes and thwarts the naturally stronger forces of the nation in their development. On Ireland itself the effect is most pernicious, because the scale of Irish affairs is artificially altered from the natural one. Because I reland has such tremendous power to force its affairs on Imperial notice, the Irish people are encouraged in the belief that their local affairs really compare in importance with those of Great Britain, whereas Ireland is now only a fragment, and relatively a diminishing fragment, of the State in which it is absorbed, and whose fortunes more and more it must inevitably share. Even for obtaining attention to peculiar legislation for Ireland a smaller number of representatives would be better than the present, because their weakness on the one hand would tend to unite them and give them strength for all reasonable ends, while diminishing on the other hand the natural distrust of Ireland and Irish members in Great Britain, which is certainly stimulated at present by the artificial weight of the Irish vote. We are not much in favour of electoral changes so soon after the Reform Act of 1967 , but a reduction of the Irish representation, and an increase of that of Great Britain, constitute a question apart which should be dealt with at no distant date. [1903. Not yet dealt with!] 


\section{IX.}

THE USE OF IMPORT AND EXPORT STATISTICS. ${ }^{1}$

\section{I.-Introductory.}

WE must all agree in this place, I think, that there is cause both for encouragement and discouragement to us as regards the prospects of the study in which we are engaged in the very extensive use of statistics which some recent controversies have occasioned. I refer particularly to the balance of trade controversy, and the controversy between fair trade and free trade which made so much noise last autumn, but which has rather subsided of late, as questions of the kind are apt to do when trade itself is improving. In these controversies, which have run very much into each other, the fair traders having made use of the alleged balance of trade being against this country to support their arguments, the appeal has been very largely to statistics. Literary journals and magazines, which rather dread figures as a rule, have admitted them into their columns on a liberal scale, including even tables in the rough, as we should here consider them. But while this appeal to statistics is cause for satisfaction to us, the actual handling of the subjects of our study has been such, I think, as to prove how little it has really advanced, not merely amongst the multitude only, but amongst the classes who are most carefully and highly cultivated. There has been a great hash of figures, indicating that those who use them

'Read before the Statistical Society, March 2 I, I 882. The Tables in the Appendix referred to in the course of the paper will be found in the "Journal of the Statistical Society" for June, I 882. 
have hardly the rudiments of statistical ideas, whether true or false. In journals of the highest standing there are the wildest blunders of the schoolboy order. Thus in the "Quarterly Review" of July last, a writer states and argues upon the statement: "It is estimated that about a million of acres of land have gone out of cultivation during the last ten years." 1 The fact, of course, is that there is not a year in the last ten in which the cultivated area of the United Kingdom has not increased, the total increase being nearly two million acres. The same writer also makes a great mess of the very figures of imports and exports with which I propose to deal specially to-night. He makes the excess of imports into the United Kingdon in $1879 £$ i $70,595,98_{3}$, and in $1880 £ 187,179,530$, and in the first five months of 188 I $£ 78,782,396$, having obviously omitted in all cases the re-exports of foreign and colonial merchandise, by which these figures would be reduced by 60 million pounds a year or upwards, while he quotes as his authority the quarterly returns of the Board of Trade, which issues no quarterly returns relating to imports and exports, but only monthly and annual returns. Similarly a writer in the "Nineteenth Century" for August last, Sir Edward Sullivan, compares the property assessed to the legacy and succession duties in England with the property assessed to similar duties in France, which has no such duties at all, but which has only probate duties, which are levied like ours on the gross amount of the estates of deceased persons, without deduction for debts, whereas our legacy and succession duties are imposed on the net amounts of property. ${ }^{3}$ Similarly he speaks elsewhere of the "commerce" of the world having increased 36 per cent. in

1 "Quarterly Review," July, r 88 I, p. 282.

${ }^{2}$ Ibid., July, I $88 \mathrm{I}$, p. 288 . It is just possible that the writer may refer to a quarterly account published at intervals in the monthly Board of Trade returns, but his allusion is so vague as to indicate that he has little idea what the publications are.

3 "Nineteenth Century," August, i 88 i, p. I 73. 
ten years, and English commerce so much less, ${ }^{1}$ the actual fact being of course that there is no figure in existence which can be spoken of as representing the commerce of the world; while the writer probably meant the foreign commerce, and yet excluded from his comparison one of the most important parts of English fcreign commerce, viz., the shipping. Our satisfaction therefore at seeing so frequent an appeal to statistics must be considerably qualified by the nature of the appeal. It is evidently still quite possible for essays to find admission to journals of high standing like the "Nineteenth Century" and the "Quarterly Review," in which the writers not only make mistakes, but mistakes of an elementary and substantial character, as if in discussing chemistry a writer were to confound oxygen with hydrogen, or as if in discussing geometry he were to confound an isosceles with a right-angled triangle. Writers who were capable of making such mistakes in chemistry and geometry, however cultivated in other respects, would either not find admission to the pages of the "Nineteenth Century" or the "Quarterly Review," or their mistakes would be corrected by the editors; but the popular standard for statistics is evidently as yet not so strict as it is for other scientific studies. Any man, it seems to be thought, can handle figures, and writers who are otherwise competent are not afraid to touch them as they would be afraid to touch chemistry, or geometry, or botany, or geology, or almost any science one could name. That our special study should be so little advanced, although there is a dim idea in the public mind of the utility of statistics, must surely be a matter for concern to a Society which has been established for nearly fifty years for the express purpose of diffusing right ideas and information. We have still, it is plain, a great work before us to perform. ${ }^{2}$

1 "Nineteenth Century," August, r 88 I, p. I 72.

2 How many fresh illustrations have been furnished by the recent fiscal controversy. 
It is in this view that the present paper, which is mainly directed to the method of statistics, has been written. The object is to show how great may be the errors in using the comparatively well-known figures of imports and exports, unless proper caution is exercised, and how difficult it is to elicit true conclusions on the questions respecting the balance of trade and free trade $v$. protection, which have lately been discussed. Statistics, I need hardly say in this company, are almost always difficult. No table almost can be used without qualification and discretion. The moment we perceive that figures are used without qualifications and without anxiety to appreciate them in their right meaning, and to support no greater conclusion than they can be made to bear, we may be sure there is something wrong. My object will have been gained if the remarks I have to make, and the discussion they elicit, help to popularize what are really truisms within these walls, but which ought also to be truisms outside, if statistics held the place they ought to do among politicians and public men.

\section{II.-General Remarks on Import and Export Figures.}

In dealing with the causes of error in handling import and export statistics, it would of course be superfluous for me to do more than mention such questions of method as are common to them and all other statistics. In using them, as in other statistics, it is of course necessary to see that in comparing different years or different countries the data are substantially of the same nature. I shall have to notice some special difficulties of this sort in regard to imports and exports which I am aware of; but I am only at first noticing the principle as a well-known one. It is also necessary in comparing one period with another, so as to draw out a curve of progress or retrogression, to ascertain whether the figures of single years or of less periods can safely be used, or whether, as is more likely to be 
the case, the mean or average of groups of years ought to be used. For some purposes, as we know from statistics of crime, population, and the like, five, and even ten years' periods are by no means too long to be considered, and common sense will tell us that for many purposes this will also be the case with trade statistics, trade having ups and downs, if nothing else has, whatever regime it may be subject to, and the statistician's first business being to eliminate the errors which may be due to such ups and downs. A large discourse might be written even on these points, which are habitually neglected by popular writers who use statistics, and by persons of more authority. A question, for instance, was put by Mr. McIver last session, ${ }^{1}$ to the President of the Board of Trade, the whole point of which was that our exports to France had diminished from 33 million to 28 million pounds in ten years, while our imports had increased from 30 million to 42 million pounds in the same period, and the explanation being that the apparent decrease in the one case and increase in the other corresponded only to temporary facts of trade, because the year I87I, owing to the FrancoGerman war, was of a wholly exceptional character as regards the trade between France and England. Another elementary difficulty is in the use of percentages, especially those of increase or decrease, nothing being more necessary than a cautious use of such percentages, and, especially when comparisons are made, a use of them only with reference to amounts as well as percentages. In the beginning of things percentages may be large, as we all know, but the real growth may be largest where the percentage is least, in consequence of the greater amount at which the percentage is calculated. We are all familiar here also with M. Quetelet's illustration of the enormous mortality of a particular street, in which nearly all the inhabitants died, and where the area was really too small to yield any good 
average. Some of the arguments of the "Nineteenth Century," already referred to as to the percentages of the growth of the commerce of different countries, are really as illogical. But elementary as this paper is intended to be, I may perhaps be excused from going into such extreme commonplaces, which relate not merely to imports and exports, but to all statistics. When these matters are properly attended to, enough remains to be considered as regards imports and exports which may well demand the utmost caution.

The first point to be considered, as in all statistics, is the degree of accuracy obtained in the original data. The figures of imports and exports are sometimes used, and we are all of us too apt to use them, as if they were figures in accounts, giving rise to no question respecting the nature of the data; as if every particle of commodities and every pound of value sent out or brought into a country, and to and from what countries they were sent or brought, were recorded with perfect accuracy; and as if too the accounts of all countries, and of each country at different times, were made up on the same principles, and could be trusted to the same degree. Those who know anything of statistical compilation, and even those who do not know, if they only consider for a moment the necessary conditions, will perceive at once that no impression could be more unfounded. In all statistical inquiries the nature of the data is a necessary question, and there are great varieties in the possible degree of accuracy, while the same data may be sufficient for one purpose and not for another. Thus a census like that of the United Kingdom, made on the same day for the whole kingdom, by a staff of enumerators collecting individual returns from all householders, yields results which are absolutely trustworthy to a most infinitesimal fraction as regards the numbers of the people, as regards the sexes, as regards the conjugal condition, that is, whether married or not, and-with some exceptions perhapsas regards the numbers at each age. The population 
of small localities on the day of the census may also be considered to be stated as regards all these details with practically complete accuracy. But when we come to such details as the occupations of the people, which involve inherent difficulties of statement by those who have to make the returns, and of classification by those who compile, we are plainly on more treacherous ground. Especially with the smaller occupations, and in comparisons between different localities, it would become necessary for inquirers to use the figures with judgment and discretion, and to bring to their aid a study of the instructions to the enumerators, and information from local or special sources. In using the population figures again for deducing birth, marriage, and death-rates, the fact that the population returned is only the population on a given day, and that there are many localities in which the population on other days of the year would be less or more, has to be considered; while the special birth, marriage, and death-rates themselves, that is the rates as compared with the population at particular ages, would be still more liable to error. There are methods for eliminating errors known to statistical experts by which the data can be used, but the methods must be employed if any good result is to be obtained. To give another illustration from matters within my own department-the emigration statistics. As far as numbers are concerned, these statistics are complete-we have practically a complete record of passengers leaving the country for places out of Europe, and returning to it from places out of Europe. Making the assumption, as I believe we may do, that the balance of the resident population is unaffected by people coming and going from and to European ports, - the excess of "imports" from such places, if I may adapt a well-known expression to this subject, being practically all exported to places out of Europe,- - the emigration and immigration statistics become perfectly trustworthy as to numbers. I think also the distinctions made as to the nationality and sex of the emigrants, and the conjugal condition, 
with the numbers of children, are fairly to be trusted. But when we get to the "occupations" I am not so sure. We have nothing to trust to but the description given by the emigrants themselves, as reported by officers who are busy with other work; and I confess I should not like to found important inferences on minute changes in the numbers from year to year of so-called joiners, or painters, or farmers, or even "labourers." It would be impossible to use the figures for such details to any good purpose without much discretion and a wide knowledge of local facts determining the emigration. To take yet another illustration -again from my own department. While the total entries and clearances of ships at ports in the United Kingdom in the foreign trade may be held to be completely accurate, there is an undoubted defect in the statistics of particular ports, owing to the practice which has been established of only returning a vessel as entered and cleared at one port, though it may really enter and clear at more than one. By the present practice the total of the port accounts agrees with that of the United Kingdom, and I believe the trade of the ports generally is relatively fairly accurate, but the practice nevertheless might obviously lead to difficulty and wrong inferences in special cases. The nature of the data is thus an all-important matter.

Now, as to the nature of the data in import and export statistics, we have the advantage of a paper in our own "Journal," which Mr. Bourne read to us in I $87 \mathrm{I}$, and which will be found the first in his volume, "Trade, Population, and Food." A more useful paper, I think, was never laid before the Society, and I shall do little more than refer to it. Those interested will find a full account in it of how the data are obtained, and the means used to check them, with some critical observations on the main point I am now suggesting-the degree of accuracy of the data. There are many points in the paper and in the whole subject which in my official position I should hardly feel at liberty to discuss,

I. 
but the main points are indisputable. The data, both as to quantities and values, with the countries of origin or destination, are derived from the declarations of importers in the case of imports, and of shippers in the case of exports, subject to a certain check by the customs' officers, and there is a margin of error to be allowed for in these declarations. Mr. Bourne, as regards quantities only, compares the declarations in the case of dutiable goods imported with the actual weights or measurements subsequently made by the customs' officers, and points out a variation between the two ranging from 0.2 I per cent. in the case of cocoa, to 5.70 per cent. in the case of tobacco, and averaging for all the articles 1.50 per cent. According to this, the declarations actually made, and which are the basis of all the statistics, are subject to such variations. They are no doubt checked by the customs' officers and corrected for the annual statement of trade, so that the limit of error is farther reduced, but in the case of non-dutiable goods some limit of error must remain. These are the facts as regards quantities only. As regards values, what Mr. Bourne points out as regards the imports is especially important :

"The present system has great disadvantages, arising from the want of knowledge on the part of the importers, the indifference of many who pass the entries, and the impossibility of the department exercising a valid check. It is well known that a very large proportion of the goods sent to this country are on consignment, and not on purchase, in which case there is no invoice or statement of prices. In these cases the consignee is very much in ignorance of their quality or price, and therefore unable to fix a proper value until they have been examined and sampled. Where, again, as is very frequently done, the entry is made by a mere agent, who may gather the description of the goods from the ship's report, and estimate the weight from the nature of the packages; there is no guide at all to the value. In other instances there is great indisposition to let the true value be known. Supposing, as is constantly the case, wine to be brought from Hamburg in casks, branded with the mark of the best Spanish vintages, it is very improbable that, however vile the stuff may be, it will be valued at less than the price of good sherry. The greatest vigilance, therefore, is necessary to guard against the most erroneous values, but the department can only interfere in extreme cases, for it is unable to 
discover or question any but very extravagant departures from the average. The law has given it the power of calling for invoices or other proof, which is frequently done, and fines are often inflicted for wilful or careless departures from the truth. The only real security, however, is in exciting an interest amongst those who have to declare the value. When once it is understood that these and other particulars are of real importance, there is, in importers generally, too much good feeling and desire to do what is right, to permit of other than the best information it is in their power to give being placed at the disposal of the authorities. There seems, however, no way of providing for the very numerous cases in which the consignee is ignorant of the value, or the agent who puts in the entry is without instructions to guide him."

So far as I can judge, the check on values in the case of exports must be even more difficult of application than it is in the case of imports.

We have thus two facts before us: first, a possibility of error in the original declarations as to quantity, which are found to vary from the actual quantities on a considerable average of articles as much as $\mathrm{I} .50$ per cent., and in extreme cases nearly 6 per cent., and which cannot be completely controlled by the officers compiling the statistics; and next, a farther possibility of error in the declarations of values, owing to the want of interest in the merchants or agents making them. I need hardly say here, that errors arising in this way are not likely to affect the returns as a whole as much as they may affect special articles; that in the absence of special motives for making wrong declarations in one direction, the errors made through indifference or carelessness by thousands of people are likely to compensate each other in so vast a field as that of the imports and exports; and that the comparison between two or three years coming together, in which there is no great change of system, might be fairly trustworthy as to the progress or retrogression shown, even allowing for a larger margin of error than it is necessary to allow for in the original data. But the more detailed the use which is made of the statistics, the more necessary it is to keep in mind that there is a margin of error. Another point has also to be considered. We may 
know pretty well where we are in comparing two or three years at the present time; but the farther we go back the less is our knowledge as to the way the business was done formerly, and as to the increased or diminished accuracy of the data from that time. This last fact we know is especially important as to the imports, for there was a very considerable change of system in 1870 , which Mr. Bourne fully describes in the paper already referred to. One of the principal changes was in the mode of ascertaining the values, which previously to that date, from i 854 downwards, had been computed according to a plan introduced by Mr. James Wilson, but which have since been declared by the merchants as already explained. We cannot be quite sure, I think, that the computed values before I 870 are on all fours with the declared values since; the presumption would be that they are not. On this head I can most heartily re-echo the complaint made by Mr. Bourne in the paper already cited, that the old plan was not maintained in conjunction with the new for several years. His assertion that the change of system produced in many articles of import an apparently great divergence between the values of $187 \mathrm{I}$ and former years, is a most serious one, and should warn us all to use a great deal of caution in carrying our comparisons of import values farther back than I 870 .

Farther, whatever dependence may be placed on the returns of the total imports and exports of particular articles, and of the aggregate imports and exports, a fresh difficulty arises in making the data complete as regards particular countries traded with. Formerly it was a very general practice to consider imports as coming from the country they had last left, although they might only have been in transit through that country; and exports as being despatched to the country they would first arrive at, although they might only be going there in transit. The attempt has been made in recent years to show the countries of ultimate origin and destination, but it is impossible to suppose 
that this attempt has been completely successful. Where there is a through bill of lading, merchants can easily declare the country of origin or destination as appearing in that document, but such documents themselves do not always disclose the exact facts on this head. I have again to refer to Mr. Bourne's statements in the paper already referred to, but I may add one or two obvious facts, which you can all test. It is beyond question that there is an appreciable amount of trade between this country and Switzerland. We import Swiss clocks and watches, and we send there cotton and other yarns to be made up, besides other articles. But Switzerland does not even figure as a separate country in our returns. Our trade therewith figures as part of the trade with France, Belgium, Holland, and perhaps Italy. Another of these facts is, that in recent years a great deal of the raw sugar we imported was of Austrian origin, but the bulk of it figured in our returns as an import from Germany. Apart then from the above question as to the data themselves, there is a special source of error in the accounts of the trade with particular countries. It must not be supposed that all the so-called trade with France, or Belgium, or Holland, or the United States, is really our trade with those countries. Large deductions or additions may have to be made in a thorough study of the subject.

I have spoken mainly of the import and export statistics of the United Kingdom, but mutatis mutandis the same remarks apply to the data of imports and exports in every country. Governments which have a voluminous tariff are probably more careful about the imports than we are, verifying values and quantities in a way we do not attempt; such Governments are probably also very careful in verifying the quantities and values of articles exported on which there is a drawback; but they are none of them likely to be more careful than we are about exports where there is no drawback, and none, we believe, are in fact more careful, while their extra care as to imports is no doubt 
balanced in most cases, in countries like the United States for instance, by the ingenuity and resource of the smuggler. No foreign country, therefore, any more than England, has import and export statistics which can be used as absolutely accurate in the sense commonly assumed. The remarks already made as to the possibility of useful comparisons, the nearer the years compared are together, and the danger of not allowing for changes of system, also apply to foreign countries as well as our own. On this latter head it happens to be possible to give one or two good illustrations from the experience of foreign countries. My first illustration is from the experience of the United States. Mr. Wells, the special commissioner of revenue of the United States in I867-69, in one of his well-known reports, that for 1869 , after stating at one place that he assumes the sums chargeable to smuggling and undervaluation of imports to be counterbalanced by the undervaluation of exports, goes on to say in a footnote: "If we confine ourselves to the comparison of the values given to imports and exports respectively, in previous years, this may be considered a reasonable estimate; but for the last fiscal year it is certainly not the case. Under the present organization of the bureau of statistics, the values given to the exports of the country have been scrutinized and verified to such an extent as to leave but little doubt that the statement for last year is substantially accurate and complete. The fraudulent undervaluation of imports, however, it is not within the power of such an agency to prevent." 1

A statement like this discloses the existence of a very serious pitfall for us, when we carry our comparisons of United States trade farther back than I 869. It may throw some light perhaps on such questions as the excess of exports from the United States in recent years, which may after all be largely due to the insufficient record of the imports. As regards compari-

Report of Mr. Wells for 1869, pp. xxix to xxxi. 
sons before 1869 , it is immediately suggested that the apparently slow increase of United States trade between I 860 and I 870 may in part be apparent only, being due to the imperfection of records, and especially to a check on the record of imports through the introduction of the war tariff between the two dates.

The second illustration I shall give is from the last number of the foreign statistical abstract, in which it is noticed that the Austrian Statistical Bureau has lately begun to substitute real for official values, and tables are given showing side by side for four years these official and real values. The subject is of so much interest that I propose, for the sake of reference in our "Journal," to extract the tables. They will be found in the Appendix (Table I.). The following is a summary of the totals:

[Values in $£ \mathrm{I}, 000$ sterling- $-\infty$ 's $^{\prime}$ omitted.]

\begin{tabular}{|c|c|c|c|c|}
\hline & \multicolumn{2}{|c|}{ IMPORTS. } & \multicolumn{2}{|c|}{ EXPORTS. } \\
\hline & Official Values. & Real Values. & Official Values. & Real Values. \\
\hline I 875 & $\underset{55,255}{f}$ & $\underset{54,9^{27}}{\underset{E}{E}}$ & $\underset{5^{\circ}, 447}{f}$ & $\underset{55,086}{\mathcal{E}}$ \\
\hline${ }^{\prime} 76$ & 51,807 & 53,428 & $5^{\circ}, 8_{57}$ & $59,5^{2} 3$ \\
\hline$' 77$ & 54,666 & 55,526 & $55,06 \circ$ & 66,660 \\
\hline$' 78$ & 59,672 & 55,210 & 59,970 & 65,469 \\
\hline
\end{tabular}

The discrepancies in the two values are perhaps not very serious in the case of the imports, except for the year 1878 , but in the case of the exports they are serious all through, the "real" being 5 millions to I I millions more than the "official," and the proportion of the discrepancy being from io to 20 per cent. In the case of special articles, it will be observed, on referring to the tables, that the discrepancies are still more serious, and 
that the very first article on the list-animals (except horses)-is a good instance of extreme differences. In the imports of this article the "real" are in almost all cases about twice the "official" values, and in the exports they are about four times the "official" values.

I have a third illustration to give you, derived from French experience. In i 870 the French statistical authorities began to give the countries of origin and destination. It is impossible, therefore, in France to continue from the French accounts any real comparison of French trade with certain foreign countries from a period before i 870 . The change of practice throws out all comparisons, and throws out especially any comparison of French trade with England, England being a country of transit to and from France.

The conclusion surely is that in regard to imports and exports, as with most other statistics, comparison with distant periods is not the easy matter it seems. The changes in the data from time to time interpose certain difficulties in the way of comparisons, which must be recognized and met. Besides these foreign instances, I have already given a recent illustration from the change in our own statistics so late as i870, but the instances might be increased indefinitely. As regards our own statistics especially, the imports were affected by a change from official to computed values in 1854 , already referred to, involving quite as serious consequences as those just mentioned in the case of Austria. At a still earlier date also there was a change from official to declared values in the case of the exports, involving large discrepancies.

There is yet another question as regards these data which I must notice before passing on to the next point. The "values" so called when ascertained, whether official, computed, or declared, or in whatever way yet devised they are ascertained, are not identical with the values realized by merchants. They do not profess to be so when they are official or computed values, but even when they are declared by the merchants them- 
selves, they are still different things from the values which the merchant realizes. A merchant who declares a particular quantity and value at the time of import may be himself misled. A cargo of wool or grain when it comes to be delivered may turn out less or more than invoiced or estimated by a slight percentage, and the cargo when sold may realize less or more per $\mathrm{lb}$. or cwt.; consequently may realize less or more in the aggregate than the value in the merchant's declaration. Errors in the estimate of quantities may possibly tend to compensate each other in accounts on a large scale, and such errors are also liable to check by the customs authorities, but the difference between the declared and realized values must remain and will not be so surely compensated. We must always consider, then, when we deal with these declared or other values, that they are not necessarily the same as the realized values, but are only the best substitute we can obtain for them, and we must not use them as if they were accurate to a fraction. When an argument is used in which that accuracy must be assumed in order to make it of any value, we may be sure that the argument is bad, and the person who uses it does not know the necessary limitations of statistics.

A second cause of difficulty in the data-operating more especially when comparisons are made between the imports and exports of different countries-is to be found in the difference of methods by which the data are obtained. I am referring now especially to the values. The nature of the difficulty has already been glanced at in reference to the changes of system in a particular country itself, but the systems used are still so various in different countries, that the fact requires to be incessantly remembered in any comparisons. The most important foreign countries have none of them adopted our practice of declaring values, which, as regards imports even here, is comparatively recent. In France the values of both imports and exports are computed according to tables of prices established by 
a commission of values; in Austria values are partly computed and partly official; in other countries there are still official values, modified in part as to imports, where there are ad valorem duties, by the declarations of the importers. There is the greatest variety of system. Not only then do the statistics of imports and exports in all countries vary from the values actually realized by the merchants, to which they ought to approximate, but they probably vary in different ways and degrees from the true standard, so that a comparison of the figures of two different countries ought to be made with great caution. ${ }^{1}$ One fact alone will show what is meant. The tendency of our own method is at least to indicate very quickly any great change in the level of prices which may occur. The statistics being made from declarations of value, checked by the daily use of price lists, changes in price act instantaneously, even in the returns as they are issued month by month. But it is not so in France. The monthly returns of quantities are there valued according to the last table established by the commission of values. They do not show quickly, therefore, any change in the level of price. In years when prices are falling they do not fall off as the English monthly returns do, and in years when prices are rising they do not increase so quickly. Again, in countries where official values are used, the variations will depend on quantities far more than on values, and the changes from year to year will consequently be different from those of a country which has declared or computed values. In comparing two countries together, or several colintries with each other, or one country with all others or with a group, the

1 How great the difference is, any one who chooses may find out by comparing the exports from England to France, say, as they appear in the English official returns of exports, with the imports into France from England as they appear in the French official returns of imports. See also return of the trade between England and France, according to the official statistics of the respective countries (No. 405, Sess. I88I), in which other difficulties in the comparison of the returns of the two countries are pointed out. 
differences arising from the original differences of data must be remembered. We must always beware of pushing any conclusions too far.

I need hardly say how much this conclusion strikes at a good deal of reasoning lately about the comparative growth of English foreign trade, and the foreign trade of other countries. A country with official values in a time of falling prices would show steady progress, where a country with declared values, as in the United Kingdom, would show a falling off, although in both countries the real movement might be much the same.

A third point to be considered, in using import and export statistics, is the periodical variations in price to which commodities are liable. As regards particular articles variations in price do not matter so much if quantities are also given. In showing the progress of wheat exports from the United States, for instance, it would be expedient to use the record of quantities and not of values. But when articles come to be grouped, values must be used, as they must also be used in showing aggregate trade, and here variations in prices are most important. A low range of values in a particular year will make the aggregate smaller than it would otherwise be, and a high range of values would increase it; and clearly this cause of variation must be allowed for. How it is to be allowed for may be a difficult problem, but the difficulty cannot safely be ignored. When it is considered that the range of difference in the aggregate values of the exports of the United Kingdom, owing to difference of price only, amounted to 30 per cent. between 1873 and 1879 , we can easily perceive that no comparison between the two years which omits to take note of the different levels of price, can be of any value. This consideration, by the way, disposes altogether of the fair trade argument, which assumes a decline of the English export trade between 1873 and 1879 , corresponding to the decline of value only.

This difference of price may also be most material 
in comparing the relative progress of the foreign trade of two different countries. The articles of one country may be affected more by a change in the level of values than the articles of another. If the exports of cotton manufactures, for instance, constitute a larger part of the export trade of the United Kingdom than they do of the export trade of France, and the price of cotton manufactures has declined greatly, it would be reasonable, other things being equal, to look for a greater apparent reduction in English than in French exports, although perhaps, as the decline may have been mainly due to a decline in the price of the raw material contained in the exports, the falling off in the real exports of France, i.e., the exports of what is strictly the production of the country, may be greater than the falling off in the real exports of England. In other words, not only is the comparison of the trade of the same country in different years not simple but difficult, owing to this question of price, but a comparison of the progress of two foreign countries may be still more complicated by the same cause of variation.

A fourth difficulty in using the statistics of imports and exports, so as to show normal progress or retrogression, arises from the disturbing influence of great economic events. A great war, for instance, between two countries, may destroy the foreign trade of one or the other, or both-stimulate certain parts of the foreign trades of third countries, necessitate large loans, which may in turn stimulate the foreign exports of the third countries trading, and in general act as a cause of great disturbance to the foreign trade of their neighbours as well as themselves. Such an event, again, as the gold discoveries of California and Australia, disturbs the normal course of trade by causing an immense migration and colonization. The Lancashire cotton famine, itself one of the secondary consequences of the American civil war, disturbed the trade of the civilized world for probably fifteen years. It stimulated the growth of cotton in countries like India, Egypt, and Brazil; led 
to a great export of capital to those countries for their farther development; induced a great movement of the precious metals, which in turn stimulated trade in various ways; and finally, as the stimulant was withdrawn, and the cotton trade returned nearly to the old channels in which it ran before 1860 , contributed to such incidents as the failure of Alexander Collie in I 875 and the City of Glasgow Bank in 1878 , the rottenness disclosed by these failures having been largely due to the excessive investment of capital in the eastern trade in the times of the cotton famine. The abnormal swelling of trade at one time, in consequence of the disturbance of this great event, and its abnormal diminution at another time, when the stimulus is withdrawn, have all to be allowed for of course in extracting the real lessons as to trade progress or the reverse from import and export statistics. The payment of the German indemnity in 187 I-73 may be noted as another disturbing event, tending to swell for a time the export trade of France and the countries which lent to France. But it would be needless to enumerate all such causes. Suffice it to note that the history of the last forty years alone comprises the Irish famine, and the exodus to America which followed, the gold discoveries, the Crimean war, the Franco-Austrian war, the American civil war, the Lancashire cotton famine, the AustroGerman war of i 866, the Franco-German war of i $870-1$, the Franco-German indemnity, the introduction of gold and demonetization of silver in Germany, the resumption of specie payments in gold in the United States, and last of all, an unusual run of bad seasons for agriculture in England between 1875 and 1879 inclusive. What a complicated business it must really be to extract from the records of imports and exports of the period any conclusion as to their normal progress, or as to the effect of differences in the economic regime of different countries in promoting their foreign trade or general welfare, especially when differences in the volume of imports and exports due to differences of 
price and changes in the mode of obtaining the returns may also have to be allowed for.

A fifth cause of difficulty in appreciating the figures of imports and exports, especially for comparative purposes, arises from the different character intrinsically of the foreign trade of different countries. Admitting that quantities and values are stated in precisely the same way, the figures do not mean the same thing to each country. There are at least two important differences possible, which I shall notice, viz., the differing degrees in which the trade may be one of transit only, and the different amounts of the carrying trade of different countries, as to which there is no precise record of values, yet the outlay on which, by a shipping country, may be as much an "export" as the export of grain from a grain-growing country like the United States, which happens to be exactly recorded.

As regards the degrees in which the foreign trade of different countries may be one of transit only, I think the differences are really most signal. Some of these differences are on the surface. England has on the face of the account a large transit trade, the re-exports, as they are called, being a very large item. Belgium affords a still more striking illustration of a large transit trade. But there may be further differences of a vital character which are not on the surface. Any foreign articles once admitted into consumption in a country, and re-made up in any way, and sometimes with little or nothing done to them, are treated, when exported, as exports of native produce and manufactures. You will actually find tea, coffee, and raw cotton among the exports of domestic produce from France. The result is that the exports, so-called, of domestic produce and manufactures from a country which manufactures largely, are, in part, in the strictest sense of the word, re-exports. The raw material previously imported goes out in a different guise, but it is still the same raw material. To compare the exports of native produce of such a country with those of a country which does 
not import raw material to be re-exported in a manufactured form, we ought clearly to deduct from the exports the value of the previously imported raw material which they contain. The explanation specially applies to a country like England, which is a manufacturing country more than any other, as compared with countries like the United States, which re-export in a manufactured form very little of what they import. If a correction were made, probably it would appear that our exports of domestic produce, exclusive of our carrying trade, though nominally larger than those of any other country, are not really much larger than some, and are perhaps, in some cases, exceeded. The United States, for instance, exported in I 879-80 about I 70 million pounds' worth of domestic produce and manufactures, hardly any raw material previously imported being included, for the manufactures altogether are only a few million pounds. The United Kingdom, on the other hand, exported nominally, in I 880, 223 million pounds; but from this sum a large deduction must be made for the value of the previously imported raw material contained in it, perhaps about 60 million pounds; deducting this, the real export of British produce would be only $16_{3}$ million pounds, as compared with I 70 million pounds from the United States. Our exports per head would still be larger than those of the latter country, and a special difference is made by the shipping, which again brings up our total, but the figures may serve to illustrate how different the real may be from the apparent facts. When the real magnitude of the export trade of different countries is compared so as to show their dependence on foreign countries for markets, the point of view here referred to is not to be lost sight of.

A similar rectification is also necessary as regards the imports, in any comparison at least of what is imported for final consumption with the exports of native produce. In some countries the whole imports, less the re-exports, may be treated as imports for final con- 
sumption; in the United Kingdom, to arrive at a comparable figure, we must deduct the value of the previously imported raw material contained in the manufactures exported, this raw material being merely the block to which British capital and labour are applied. Applying these considerations to the case of England and other countries, we find that our imports for final consumption are still by far the largest, but the interval between us and other countries is considerably reduced. Our gross imports last year in round figures were 4 I 0 million pounds, but deducting

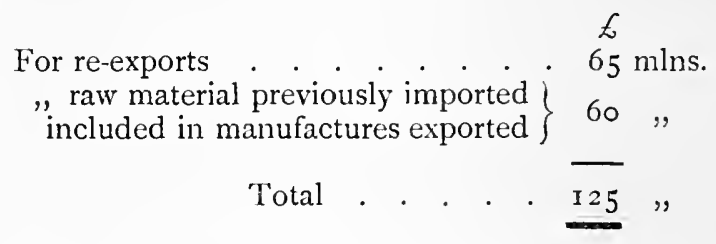

we arrive at a sum of 285 million pounds only as the net imports for final consumption in the country. This is a very different figure, though large, from the gross total of 4 ro million pounds. ${ }^{1}$ It shows that our dependency on foreign countries for supplies, or for a market for our own produce, is really much less than is sometimes supposed. We are no doubt dependent on them for the "blocks" with which we work in making for export, and this is an important fact by itself, while the fact of so much foreign produce going through our hands, though we do not ourselves consume it, has its value in the proper place; but our dependency in these respects is a different thing from our requiring foreign markets where we may sell what we produce, in order to buy what we finally consume. In this respect foreign countries are more nearly on an equality with us than is sometimes supposed.

${ }^{2}$ This last figure, it may be explained, is itself, strictly speaking, too small, not including the transhipment trade and bullion, which ought, I think, to be included, and which would bring the total up to 450 million pounds; the imports for final consumption being, however, as stated in the text, only about 285 million pounds. 
Another important conclusion is to be drawn from this consideration. The exports of a manufacturing country may be nominally affected by a change in the value of the previously imported raw material, although there is no real change in the native produce exported, or when the real change may be the opposite of the nominal one. Say that a fourth of the exports consists of previously imported raw material, then a decline of 50 per cent. in the value of the raw material would produce a decline of $12 \frac{1}{2}$ per cent. in the aggregate exports, which would be entirely nominal. If at such a time the exports were apparently stationary, the real fact would be that they had increased i $2 \frac{1}{2}$ per cent., or rather about I 7 per cent., allowing that the increase really takes place on three-fourths only of the nominal total. The influence of changes of price has already been referred to generally, but the special influence of this factor on the exports of manufacturing countries appears also worthy of attention. It is by no means an immaterial point. The apparent falling off in the exports of British produce and manufactures between 1873 and $\mathrm{I} 879$ is to be accounted for largely by a reduction merely in the price of the raw cotton-the block to which our industry was applied-contained in the manufactures. ${ }^{1}$ To talk of the decline between 1873 and I 879 without taking note of such facts would clearly be to mistake show for substance. No wonder figures are so often said to be capable of proving anything, when pitfalls like these, which have seldom even been referred to in past discussions, are in the way.

With regard to shipping, the facts may be more simply stated. A country with a large carrying trade may export little in the shape of commodities, and yet be to all intents and purposes a considerable exporter. Its outlay in wages and provisions for ships' crews, in equipping and repairing ships, in insurance and renewals, and the profits it earns, are all parts of its exI 88 I.

1 See Report on Prices of Imports and Exports, C-3079, Sess. 
port as much as if the export were embodied and stored up in a commodity. In any complete account of the foreign trade, therefore, the carrying done by carrying countries, with analogous charges, ought to be included; otherwise no proper comparison is possible with countries which have a small shipowning business. The so-called foreign trade in the one case is the whole foreign trade, in the other it is only part of the whole.

I shall have to make use of this principle afterwards in dealing with the question of the balance of trade; but it is enough to state it, I hope, to prove its reasonableness. To put the point in a concrete shape, the import and export statistics of a shipowning country like England do not show its foreign trade, as the imports and exports show the foreign trade of the United States, which has only a very small shipowning business.

That all these questions are substantial and not formal may be shown by a single example of how much our view of the foreign trade of the United States as compared with that of England would be altered by taking account of them. See, it is said, how much of American goods the United Kingdom imports, and how little of British goods America imports. This difference, I confess, would not, in my opinion, be at all material if the real facts were the same as the apparent ones. Trade is well known to be very often triangular; we may buy from America, and send goods elsewhere on American account, though not directly to America. But the statement is itself untrue if we examine the facts carefully. No doubt we record an import of 107 million pounds from the United States, and only record a return of 38 million pounds, showing an excess of imports over our exports amounting to 69 million pounds, which it is supposed the Americans prevent us by their tariff from sending to them. But people forget first that our trade is largely one of transit both directly and indirectly through our manufactures. Among the articles we import from the United States there was $£_{31,784,000}$ worth of raw 
cotton alone in 1880 , of which directly as a re-export, and indirectly through our manufactures, we would send away at least four-fifths or 26 million pounds. Why should we expect the United States to take goods directly from us for this amount? Surely the countries which ultimately get the raw cotton directly or indirectly are the countries which should pay, and they may do so in part directly as well as through our agency, our only share being a commission on the whole transaction. The second fact is that we export to America in the form of carrying goods on American account, and this item probably amounts at the present time to 16 million pounds a year. These two sums together-what we send away elsewhere of raw cotton alone among articles we have imported from America, and what we export to America in the shape of doingcarrying work for her-go a long way towards extinguishing the apparent balance against us on the import and export account. They amount together to 42 million pounds, thus reducing the apparent balance from 69 million pounds to 27 million pounds. This is a much smaller sum than might at first be expected from the bare record of so-called imports and exports, and shows how short a way the latter figures carry us by themselves. As already stated, it is of no consequence whether there is an exact balance or not, but the actual facts should be well understood, and they cannot be understood without appreciating the totally different character of the foreign trade of the two countries.

The above, let me add, are not the only points of difficulty in the study and use of import and export statistics which ought to be considered. I have not attempted to make an exhaustive catalogue. I have simply noticed a few points which have lately been brought under my notice as material or which recent controversies have suggested. They are enough to slow, however, that there is no royal road to this branch of learning any more than to other branches. There is a great deal in the study, and patience and 
labour are required of all who would enter into the field. That there are yet more difficulties will be apparent when we come to the special applications of these statistics which I have thought it would be useful to investigate, viz., their bearing on the question of the balance of trade or balance of indebtedness between countries, and their bearing on the points in dispute in the fair-trade controversy. We can show not only by a statement of principles, but by the actual steps necessary in applying the statistics, how much consideration is required in the application of figures which appear very simple, and how difficult it is to arrive at correct views. To prevent misunderstanding let me only add that, while pointing out the difficulties of the study, I am saying nothing to imply any doubt of conclusions which are arrived at after a sufficient study of all the facts. There are conclusions in all studies which it is hard for the unlearned to follow, but they are none the less certain to those who care to learn.

\section{III.-Balance of Trade and Balance of Indebtedness. The Generality of the Excess of Imports.}

The first special question I propose to discuss is the application of the import and export statistics to the problem of the balance of trade, and the connected problem of the balance of indebtedness of a country; the case I propose more particularly to investigate being that of the United Kingdom. Importance has come to be attached to the question in this way. The imports into the United Kingdom, as recorded, have in late years shown a great excess over the exports from the United Kingdom, as recorded. By many this excess is treated as a trade balance against this country, and without much ado there is also an assumption that the country is running into debt. We are buying, it is thought, more than we can pay for, and we can only pay by an export of securities. The conclusion itself seems so extravagant to any one who watches 
the constant issues of foreign securities on the London Stock Exchange, or the constant lending by private capitalists to foreign countries, which hardly ever ceases, that for one I have never thought it worth while to discuss it. A statement was actually brought me on one occasion showing that the country had become indebted to foreigners in twenty years to the extent of I,000 million pounds, which had never been paid, and which was all represented by bills the nonpayment of which would bring about, some day, a financial collapse. The writer was plainly unaware that the whole amount of bills current at one time in the country, in both home and foreign trade, was under I,000 million pounds, that the amount has not been increasing lately, and that the foreign bills are only about a third or fourth part; and I think also he was unaware that in the foreign trade it is English capitalists who give credit to foreign nations, and not foreign capitalists who give credit to England. Still the statements as to the excess of imports have acquired a certain amount of currency, and we may see how far they are really countenanced by import and export statistics.

'The general statement of the difficulties of the inquiry already made has somewhat cleared the ground. IVe are prepared to see at the very threshold that the imports and exports themselves are not exact to a fraction. There may be an error in the data of 1 or 2 per cent., and the values may also differ from the values realized by merchants. Suppose there is a difference of 2 per cent. only, and that it acts on imports and exports in opposite directions, increasing the former and diminishing the latter, we have a difference at once of about 5 million pounds in the so-called excess of impcrts. Our imports, bullion and transhipment included, amounting to nearly 450 million pounds; our exports, bullion and transhipment also included, to over 300 million pounds, on all of which 2 per cent. comes to the sum of i 5 million pounds, as stated. The balance of probabilities is perhaps against 
any variation of such great magnitude from the amounts actually realized by merchants, while the variation may be in the opposite direction, tending to swell the excess of imports; but the great effect of what is really a slight percentage should warn us against reasoning too finely. Even the apparent amount by which the recorded imports exceed the recorded exports may be subject to great reduction.

The variations in the level of prices from year to year are also most material in such a question. A sudden rise or fall of 5 per cent. in the average price of the exports beyond the corresponding rise or fall in the average price of the imports, would alter momentarily the excess of imports to a most material extent, without implying any real changes in the general conditions of our trade. Similarly, any of the great disturbing economic events referred to, two of which have at least affected business during the last few years, viz., the resumption of specie payments in America, and the bad harvests in western Europe, might largely alter for a moment the balance of trade. Last, and more important, the fact of our being a shipowning country, and doing other duties in connection with the foreign trade of the world, causes what is really a large export of the produce of our capital and labour in an unrecorded form, and there can be no commencement even of a discussion of the facts without a proper allowance for this export; while the trade balance itself, when properly ascertained, is no more than one item in the general account of international transactions, especially when the country concerned is a country like the United Kingdom, having investments abroad in endless number and variety. We see at once from these considerations that even to ascertain the exact excess of apparent imports over apparent exports is no easy matter; that this excess is different from the real excess in the case of a country like the United Kingdom, which has a large ship-owning business; and that the excess when ascertained is only one 
item in an international account. We are far enough already from the rough-and-ready handling which the excess of imports receives from writers in the "Quarterly Review" and the like authorities.

Grappling now with the subject more directly, what I have first to suggest, in accordance with a sound maxim of statistical investigation, is an inquiry how far the excess of imports is a new or not a general fact. There is little use in discussing it at all until we look about us. The question of the generality of the fact is very soon settled. An excess of imports is a very common thing indeed. I have only to refer you to the Appendix No. II. on the point. In this I have had taken out for a late year in each case, usually 1878 or I 879 , the imports and exports of every country in the world: there is hardly an exception, I think. The result is that in forty-five instances there is an excess of imports, and in forty-two instances an excess of exports. I say nothing at present of amounts in each case: it is possible that the United Kingdom is specially unfortunate on account of the magnitude of the case. It is clear, however, that the mere fact of excess of imports is a very general one in the experience of nations. We do not stand alone.

Another general fact which appears is that, taken altogether, the column of imports is in excess of the column of exports. The totals are :

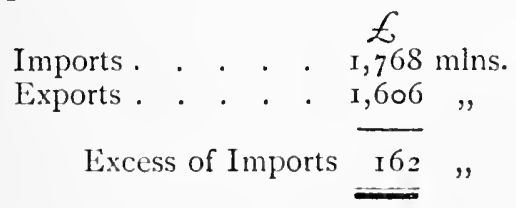

This fact is surely very significant. It is the same goods substantially which are dealt with in both cases, the fact that it is not the same year which is dealt with in all cases making no sensible difference when so many countries are dealt with and the years are selected without any bias. But although it is the same goods that are dealt with, they are represented in the one column as 162 million pounds more than in the other 
column. This of itself suggests, I think, a natural reason for an excess of imports. A difference like this can only be due to a common cause, and that cause obviously is the cost of conveyance; the imports, being mostly or often valued at the place of arrival, include the cost of conveyance; the exports, being valued at the place of departure, do not include that cost. Hence the difference between the two columns. In so general an account, putting all the countries of the world together, I can suggest no other cause of difference. Of course, after what I have already said, you will not expect me to put forward the figure as absolutely exact. We know too little of the methods followed in more than eighty countries to be sure that the values are comparable one with another. Still the resulting difference, being in accordance with reasonable expectation, is evidently to be relied upon as a fact, though we cannot state a figure which pretends to any exactness.

It follows also that, as there is and must be an excess of imports in the aggregate, some particular countries are entitled to the excess. These must also be the carrying countries. Freight must be the chief matter; but the difference cannot be wholly freight, as the figures include goods which have passed from country to country by land, though not a large amount in proportion, as well as goods which have passed by sea. There are also other charges on the conveyance of goods besides the freight paid to ship-owners, and all must be included in the difference here stated, or the true figure which it approximately represents. Still, whoever carries, in proportion to what he does carry, or rather in proportion to the outlay he contributes for the carrying and the profit he thereby earns, must be entitled to a corresponding amount of imports. If the account were exact, and there were no other cause for an excess of imports or exports in particular cases, the table would show not only what the excess of imports was in the aggregate, but what were the carrying nations and how much each received. The table, how- 
ever, does not show this. No doubt the countries with an excess of imports are largely carrying nations: the United Kingdom, Norway, Denmark, Germany, Holland, France, Italy; but there are other countries with an excess of imports, while in some cases, perhaps, the excess is not so large as that to which the share of the country concerned in the carrying trade would apparently entitle it. This suggests obviously that besides the cause which produces an excess of imports in the aggregate, the excess varies in the case of particular countries, or becomes even an excess of exports, owing to another cause. That cause I have to suggest is that countries are either borrowing or lending in their international transactions, or that some are receiving while others are paying interest. The result is that if we add the excesses of imports on the one side and put against them the excesses of the exports on the other, the aggregate excesses of imports are found to be $286 \mathrm{mil}$ lions, and the aggregate excesses of exports 124 millions, the difference being the net excess of imports already stated. The excesses of exports in certain cases, amounting to 124 millions, would also imply that in the international transactions of the world, unless the figure should be modified by including the bullion, as we ought to do for this purpose, but which I have found it impossible to do in all cases, a sum of that amount was passed as the balance of the various loan and interest transactions of the world. The total amounts lent and the total amounts paid for interest may both have been larger, and there is nothing to indicate the amounts; but of the fact of a balance having to be passed there can be no question. While we conclude then, from the general fact of an excess of imports, that it corresponds to the cost of conveyance in international trade, it is quite possible that the countries entitled to share in it may show a smaller excess than they would otherwise do through their lending to foreign countries, or may show a larger excess through their receiving interest or borrowing on balance; while, on 
the contrary, non-carrying nations may show a small excess of exports, or even an excess of imports, in consequence of the balance of their other transactions. The figures in the case of each country are no guide to the state of its general account with other nations.

It is to be observed, however, that there is a geographical distribution to some extent of the countries having an excess of imports or of exports respectively. The nations in the tables are classified geographically, with a cross division for the British empire and for the rest of the world; and the result is, that while Europe shows an enormous excess of imports, viz.:

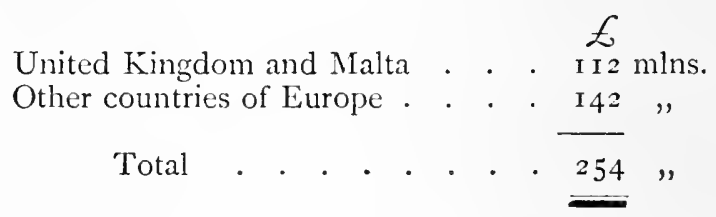

the other quarters of the world show on the whole an excess of exports, viz.:

Africa-

British empire

Other countries Asia-

British empire

Other countries

Australasia-

British empire

Other countries

America and West Indies-

British empire

Other countries .

Excess of

\begin{tabular}{|c|c|}
\hline \multicolumn{2}{|c|}{ Excess of } \\
\hline Imports. & Exports. \\
\hline Milns. & Mlns. \\
\hline $\mathcal{L}$ & $E$ \\
\hline 4 & - \\
\hline- & 4 \\
\hline- & I 9 \\
\hline 一 & 2 \\
\hline 6 & - \\
\hline - & - \\
\hline I & - \\
\hline - & 78 \\
\hline I I & 103 \\
\hline- & I I \\
\hline- & 92 \\
\hline
\end{tabular}


The figures at least suggest, I think, that it is the old countries - the homes of capital - which have to receive interest, and the new countries-principally the United States-which have to pay it. Certainly no inference can be drawn to the effect that it is the countries with an excess of exports which are the most prosperous, the list comprising Peru and other South American States, which have lately been passing through the most serious calamities. The most singular fact disclosed by the table is perhaps the excess of imports in the case of the Australian colonies; but this is partly to be accounted for, I believe, by the fact of the continuous lending of this country to Australasia, which has been going on for many years past. Its natural place would have been with America and the new countries generally. The facts as to the Cape Colony give rise to a similar remark.

I shall have to return to the figures shortly in reference to the question of the charges for conveyance to which the United Kingdom is entitled; but I pass on to remark that as the fact of an excess of imports is general, it is also by no means new, either in the case of the United Kingdom or of the world generally. With regard to the United Kingdom, the fact is tolerably well known; but to make this paper complete, I have included in the Appendix (Table III.) a statement of what the excess has been since i 854 . The annexed (see p. 316) is a summary of this table in three years' periods: 
Excess of Imports, and Proportion to Total Imports and Exports, including Bullion and Specie, $1854-80$.

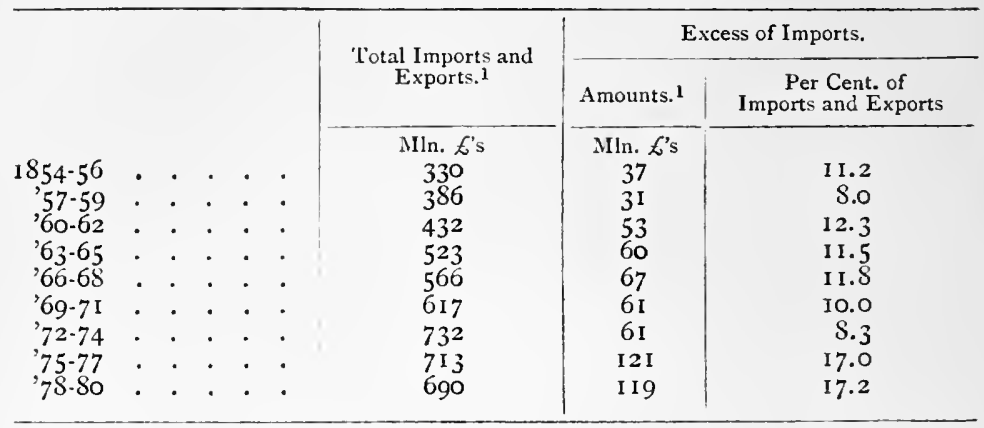

Thus we have always had an excess of imports into this country. Of late years it has been larger in amount and in proportion to the imports and exports recorded than formerly, but the only novelty to be inquired into is clearly the increase of the excess: (I) whether it is apparent or real-a most important inquiry, as the mode of valuing the imports, we have seen, was changed in 1870 , and in 187 I there is a sudden and remarkable increase in the imports, and a still more remarkable increase in the re-exports; and (2) whether there are any circumstances to account for a real increase of the excess of imports, such as an unusual diminution of our current lending to foreign countries, or an unusual increase of ship-owning business making our unrecorded exports unusually large. At present I do no more than suggest these answers, the main point to be considered being that the excess of imports, and that on a very large scale in proportion to our whole foreign trade, is itself no novelty.

The excess of imports, as I have stated, is also no novelty in the aggregate trade of the world. On this head I have to quote the figures given by Dr. von Neumann-Spallart, ${ }^{2}$ to whom I am indebted for some of the figures in the second table of the Appendix, viz. :

1 Averages of three years.

${ }^{2}$ Uebersichten der Weltwirthschaft, von Dr. F. X. von NeumannSpallart. Jahrgang i 880. Stuttgart. I88 I. P. 360. 
Imports and Exports of the World.

[In millions sterling, converting the mark at 20 per $\mathcal{L}$.]

\begin{tabular}{|c|c|c|c|c|c|}
\hline & & & Imports. & Exports. & Excess of Imports. \\
\hline I $867-68$ & . & . & $\underset{1, \stackrel{£}{1} 6_{5}}{£}$ & $\underset{1, \stackrel{£}{0}}{£}$ & $\underset{120}{6}$ \\
\hline '69-70 & . & . & 1,266 & 1,100 & 166 \\
\hline $72-73$ & . & . & $\mathrm{I}, 554$ & 1,334 & 220 \\
\hline ' $74-75$ & . & . & $I, 45^{\circ}$ & $\mathrm{I}, 289$ & 161 \\
\hline '76. & . & . & I,493 & $I, 296$ & 197 \\
\hline$' 78$ & . & . & 1,508 & $\mathrm{I}, 359$ & 149 \\
\hline '79 & . & . & $\mathrm{I}, 57 \mathrm{I}$ & $\mathrm{I}, 355$ & 216 \\
\hline
\end{tabular}

Thus an excess of imports in the aggregate trade of the world is a permanent fact. There is nothing new in it. There is also some proportion between the aggregate trade and the excess of imports. The more trade there is the more charges for conveyance, though the progression is of course not quite constant, and the figures themselves are of course somewhat incomplete, which makes it difficult to exhibit a regular progress from year to year. ${ }^{1}$

\section{$I V$.-Subject continued: how the Excess of Imports into the United Kingdom is to be accounted for.}

Having thus brought out the facts of the generality and want of novelty in the excess of imports, and having suggested as a necessary cause of it the cost of conveyance between countries which must always exist, and as a contributing cause the settlements of international accounts through the remittance of loans or interest on money previously borrowed, I propose now to inquire more particularly with reference to the

${ }^{1}$ It will be observed that the annual amounts here are in no case so large as the annual amount in 'Table II. of the Appendix. Some of the figures in the latter table, however, are for a year later than 1879 , and the figures I have used also include the bullion and specie as much as possible, which are not included, apparently, in Dr. Spallart's figures. 
United Kingdom how the excess is to be accounted for.

How much, to begin with, is annually due to us as a ship-owning and carrying nation? As we have seen, there is no reason why the actual excess of imports, in the case of a ship-owning nation, should correspond to the sum it earns in the carrying trade; the actual excess may be less or more than that sum; but the sum is nevertheless an item in the account just as much as the so-called exports on the one side or the imports on the other. I have to call attention to the words ship-owning and carrying. According to the definition already given, the question is, what is the amount of our contribution to the carrying of the world's goods? and though it is mainly a ship-owner's question, it is not wholly so. ${ }^{1}$

Replying to this question, I propose to take the facts as to ship-owning first, and to use first in a general view of the subject the excess of imports already shown in the aggregate trade of the world. Assuming this excess of 162 million pounds to represent approximately the cost of conveyance, how much of it should fall to the share of the United Kingdom? I have to suggest first of all, for reasons to be given afterwards, that about 32 million pounds of the amount, or rather less than 2 per cent. on the aggregate trade, represent

1 The following propositions appear to cover the various cases of an excess of imports or exports arising in connection with carrying operations :

I. A non-carrying nation, in the absence of borrowing or lending, ought to show in its accounts an equality between inports at the place of arrival, and exports at the place of departure.

2. A nation carrying half its foreign trade ought to have an excess of imports equal to the cost of carrying the goods one way; and so in proportion for whatever its contribution to carrying may be.

3. A nation carrying its whole foreign trade will have an excess of imports equal to the cost of carrying the goods both ways.

4. A nation carrying for others is entitled, in addition, to an excess of imports equal to the freight earned, less any expenses incurred abroad. Any nation contributing to carriage will also have something to receive. 
miscellaneous charges and commissions, which all form part of the cost of conveyance, and of which the English share may be put at one-half, or I 6 million pounds. Deducting this 32 million pounds, the sum of $1_{3} 0$ million pounds is left as the amount due for freight. How much should fall to the share of England? It would also be natural in reply to compare the mercantile tonnage of England with the tonnage of the rest of the world, and divide the I 30 million pounds between them in proportion. For all practical purposes England's proportion may be put at something like 55 per cent., ${ }^{1}$ and assuming this proportion, the division would be as follows:

\begin{tabular}{|c|c|c|c|c|c|c|c|c|c|}
\hline & & & & & & & & Per Cent. & Proportion. \\
\hline United Kingdom & - & . & . & - & . & · & . & 55 & $\stackrel{\text { Mlns. }}{\underset{71 \frac{1}{2}}{f}}$ \\
\hline Other countries. & - & - & . & - & . & . & . & 45 & $5^{\delta \frac{1}{2}}$ \\
\hline Total & - & - & . & - & . & . & . & $一$ & 130 \\
\hline
\end{tabular}

This is a rough deduction from the tables in the return, "Progress of British Merchant Shipping," No. I 25, Sess. I88I. The calculation (for 1879 ) in millions of tons is:

Tonnage of-

United Kingdom

Foreign countries

Total
Rest of Pritish empire

\begin{tabular}{|c|c|c|c|c} 
Sailing. & \multicolumn{2}{|c|}{ Steam. } & Total. & $\begin{array}{c}\text { Per Cent. } \\
\text { of } \\
\text { Total. }\end{array}$ \\
\cline { 2 - 5 } & Amount. & $\begin{array}{c}\text { Equivalent in } \\
\text { Sailing tons. }\end{array}$ & & \\
\hline 4.0 & 2.5 & 10.0 & 14.0 & 50 \\
2.0 & 0.2 & 0.8 & 2.8 & 9 \\
\hline 6.0 & 2.7 & 10.8 & 16.8 & 59 \\
7.2 & 1.1 & 4.4 & 11.6 & 41 \\
\hline 13.2 & 3.8 & 15.2 & $2 S .4$ & 100 \\
\hline
\end{tabular}

Thus the proportion of ships belonging to the United Kingdom alone is 50 per cent., and allowing a certain proportion of colonial ships to be owned in the United Kingdom, the figure of 55 per cent. in the text seems near the mark. Since 1879 our proportion has largely increased. 
The sum of 71 millions sterling is certainly enormous. Still, the figures, whatever they may be worth, are not cooked in any way I have simply taken the excess of imports as I have found it, and made a proper deduction as I think, so as to leave only what is due to freight, and I have then merely divided this freight between England and other countries in proportion to their tonnage. As regards the actual amount of this freight, it cannot be called extravagant. On the total imports of the world, as shown in Table II. of the Appendix, it amounts to a charge of $7 \frac{1}{2}$ per cent. only, and on the total tonnage of the world, sailing and steam together, it would show a gross earning of no more than $£ 8$ per ton.

As regards the division between England and other countries, it would perhaps be necessary to make a correction for the amount of outlay by English ships in foreign ports, in excess of the outlay by foreign ships in English ports; but the outlay of this sort, I believe, from a consideration of the other outlays in earning freight, cannot exceed about a sixth part of the total earnings. Deducting a sixth from the above sum of $7 \times \frac{1}{2}$ millions would leave about 60 millions as the sum due to the United Kingdom for freight. This would be our share of the 130 millions.

Adding together the 60 millions for freight and the I 6 millions for miscellaneous charges and commissions, we arrive at a total of 76 millions, as the share of the above 162 millions, for cost of international conveyance annually due to the United Kingdom at the present time.

These figures are, of course, too uncertain to be relied upon by themselves, but they are not without corroboration. I have first to refer to various authorities who have dealt especially with the amounts of freight earned in the direct trade of the United Kingdom. Mr. Bourne, in a paper read before the Society, and printed No. 3 of the volume already referred to, was one of the first to grapple with the problem. His 
method, I believe, was incomplete, but some of his statements were most interesting. One of them (p. 63) is to the effect that I I per cent. on the value of our imports would be a fair average allowance for freight. The imports are now, roughly speaking, over $4 \mathrm{co}$ millions a year, on which I I per cent. would be 44 millions, and of this 44 millions the English share, dividing the sum in the proportion of the entries of English and foreign ships-70 per cent. to 30 per cent. -would be very nearly $3^{\mathrm{I}}$ millions. Similarly Mr. Bourne gives the freight on exports as 20s. per ton for sailing vessels, and jos. per ton for steamers, at which rates in $\mathrm{I} 880$, the clearances of British sailing vessels being 3, i 82,000 tons, and of steamers I 5,685,000 tons, the freight on exports in British bottoms would be nearly 27 millions. The total for imports and exports is $5^{8}$ millions. Adding a sum for freights earned by British ships in the indirect trade, which must be enormous, and again making a deduction for outlays in foreign ports, we should still, on this showing, get well on to the figure of 60 millions, if not beyond it.

I must, of course, allow that Mr. Bourne was writing several years ago, and freights are a variable item; but I do not believe that one year with another they have fallen permanently below the level of price he quoted. Some freights have fallen, but not the run of freights to any material extent. There has been, in truth, no large margin for a fall in freights, the cost of working being itself from 70 to 90 per cent. of the income, and the absolute outlay per ton, though it tends to diminish with the increasing size of vessels, not having diminished very greatly from the time Mr. Bourne wrote.

Mr. Newmarch again, in a paper read to this Society in $1878,{ }^{1}$ proposes to deduct 5 per cent. from the imports and add 10 per cent. to the exports for all charges of conveyance. These amounts on our present trade would come to about 50 millions. Mr. Newmarch does

${ }^{1}$ Statistical Society's “Journal," vol. xli., pp. 2 I 8-220.

I. 
not indicate what he thinks the other charges as distinguished from freight would be, and does not enter into the question of outlays in foreign ports or of work done by British vessels for foreign countries. The sum of 50 millions, which he actually arrives at for the direct trade of the United Kingdom alone, appears to corroborate the notion that the sum of 60 millions for the whole earnings of our mercantile fleet, less all outlays abroad, is not wide of the mark.

In the same paper Mr. Newmarch quotes a letter of Mr. McKay, of Liverpool, who estimates the freights earned in British bottoms at 30 s. per ton for imports and $20 \mathrm{~s}$. per ton for exports. ${ }^{1}$ These rates on the tonnage of $\mathrm{r} 880$, converting the net registered tons into gross tons in the proportion of two-thirds to $\mathrm{I}$, would give:

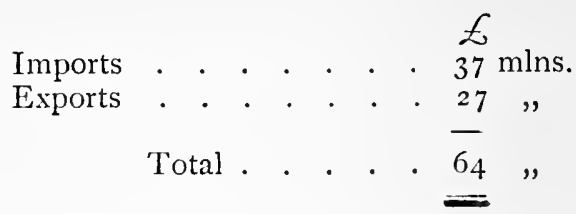

Again, there is no mention of any outlays abroad, but the figures amply support those already stated. The sum these authorities deal with, it must always be remembered, is for the direct trade of the United Kingdom alone; and the figure of 60 millions already given represents our whole earnings from freight, less actual outlays abroad in earning it.

Quite lately I have obtained a calculation from a ship-owning friend (whom I shall call $\mathrm{A}$, as I have many other facts from ship-owners, whose names I am not at liberty to mention, and to whom I shall assign the letters of the alphabet) with reference to average freights at the present time. His calculation is that on the weights of goods actually imported and exported in the American trade, freights come to about $27 \mathrm{~s} .6 \mathrm{~d}$.

I am unable to identify the tomnage actually quoted by $\mathrm{Mr}$. Mckay. 
and 20s. respectively. It is not quite clear what these weights are, or whether they would be represented by the tonnages entered and cleared; but assuming the latter to be the case, and converting the net registered tons into gross tons, as is done above, and assuming also that the American trade is a good average of the whole foreign trade, as I believe we may do, we get the following figures:

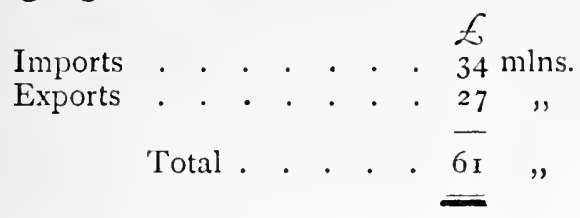

This is substantially the same figure as that arrived at on Mr. McKay's calculation. ${ }^{1}$ It manifestly supports the conclusion that 60 millions at least is earned by our shipping, after deducting all outlays abroad, in the direct and indirect trades.

I propose now, however, to deal more directly with the matter. The tonnage of the British mercantile fleet being known, how much per ton, according to direct evidence, does the sailing ship and the steamer earn on the average, and how much ought to be the deduction for outlay abroad? I have many figures on this head to submit to you, and I must crave your patience on account of the very great importance of the subject.

I have first to call your attention to Appendix No. IV., in which there are certain tables extracted from the "Statist" newspaper of 26 th November last [I 88 I] These tables summarize the accounts of our principal joint-stock shipping companies in a form which was partly of my own suggestion, with a view to the present paper, though the tables themselves are not my own

${ }^{1}$ It is hardly worth while cumbering the paper with the details, but I have made a calculation of the actual weights of goods imported and exported, and these charges for freights would bring out a sum on such weights of 50 million pounds. I have also to call attention, on this head, to Appendix X., showing the amount of weights carrice in our direct foreign trade, as far as weights can be stated. 
work, but the work of a gentleman already well known to many of you, Mr. Wynnard Hooper, whose analysis, I think, does him great credit. The points in this statement to which I desire to call attention are these:

$a$. The capital value of the fleets of eight companies, including some of the largest and best, but also including one or two of a second class, comes out on the average at $\mathcal{L}_{\mathrm{I} 6} 6 \mathrm{I} 3 \mathrm{~s}$. per ton gross, which is not less than about $\mathscr{f}_{25} 5$ per ton net, taking the net as two-thirds of the gross, and the real proportion being less. The range of value is from $£^{\mathrm{I}} 32 s$. to $\ell_{\mathrm{I}} 8$ i $2 s$. per ton gross, or from $£ 19$ i $3 s$. to $£ 27$ i $6 s$. per net registered ton. These are much lower values in all cases, I believe, than the ships could be built for. They are not extreme values.

b. The gross income of six of the above companies, representing fairly well the average of the nine, works out at $£$ I4 I $2 s$. per ton gross, or about $£ 22$ per net registered ton. This is a percentage on the value of about 88 per cent. The percentage on the value in each case is:

\begin{tabular}{|c|c|}
\hline & \multirow{2}{*}{$\begin{array}{l}\text { Per Cen } \\
. \quad 9 \mathrm{I}\end{array}$} \\
\hline & \\
\hline \multirow{2}{*}{\multicolumn{2}{|c|}{ am . }} \\
\hline & \\
\hline \\
\hline \\
\hline
\end{tabular}

Thus the lowest value per net registered ton is about $£ 20$ and the lowest proportion of gross earnings about 60 per cent.

c. The proportion of expenditure to gross income works out as follows :

Per Cent.

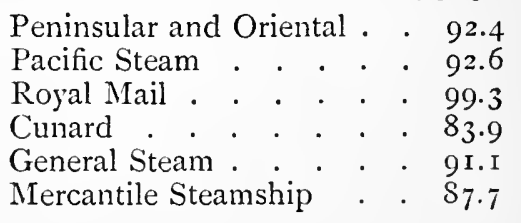


The average of the six is about 9 I per cent., and the lowest is about 84 per cent. As the gross earnings are a large percentage of the value, so the gross outlay is also a large percentage of the gross earnings.

The outlay per ton gross amounts to $\delta_{1} 37 \mathrm{~s}$. on the average of the six companies, equal to about $£ 20$ per net registered ton. The value being $£_{25}$, this shows an average outlay in proportion to the value of 80 per cent.

$d$. In the case of three of the principal companies practically little more than half the gross earnings are from freights, but they earn from freights alone $£ 2$, i 16,000 , or about $£ 8$ per gross ton, equal to about $£$ I 2 per net registered ton. In any case a part of their income from passengers, probably the larger part, being for the conveyance of foreigners, or of persons travelling on foreign account, has the same effect on the international account as a charge for conveyance of goods. It is a debit to foreign nations, and a credit to the ship-owner in this country.

$e$. The average expenditure per ton is stated under several heads for each of the three principal companies, and is in all very nearly alike, the mean being as follows:

\section{Pay of Crews .}

Coal.

Provisions

Repairs and Renewals

Insurance and depreciation

Other expenses

Per Ton Gross.

Per Ton Register.

\begin{tabular}{|c|c|c|c|}
\hline $\mathcal{E}$ & $s$ & - $t$ & s. \\
\hline 2 & I 2 & 3 & I 8 \\
\hline I & Io & 2 & 5 \\
\hline I & 8 & 2 & 2 \\
\hline I & 12 & 2 & 8 \\
\hline 2 & 2 & 3 & 3 \\
\hline 4 & 8 & 6 & I 2 \\
\hline I 3 & 12 & 20 & S \\
\hline
\end{tabular}

I postpone drawing any deductions from the figures, as I have other figures to give, but I may note before 
passing that the figures as to the eight companies comprise 442,000 tons gross of shipping; the figures as to six, 400,000 tons; and the figures as to three, 278,000 tons. A considerable part of the steam mercantile fleet is thus represented.

I have next to direct attention to the series of statements respecting different classes of ships in Appendix No. V. The statement B is exactly parallel, it will be observed, to the statements above quoted, relating to the leading companies which publish their accounts, with the differences that only the outlay is stated, and that the outlay abroad is distinguished from the outlay at home. The general result is that on a somewhat higher valuation, the steamers being valued at $£ 20$ per ton gross, or $£ 3$ I per ton net register, the outlay is also about 65 to 70 per cent. of the value, or $£^{21.88}$ per registered ton in the one case and $£ 20.34$ in the other case. The amount spent per ton on wages, coal, and other items is less than in the case of the companies which publish their accounts, but the total outlay is swollen by a large charge for depreciation.

With regard to the distribution of the expenses between this country and abroad, the point to note seems to be that the total abroad in the one case is $£ 7.70$ per ton and in the other $£ 7.60$ per ton, or about 35 per cent. of the total outlay. The amount is chiefly for port expenses and Suez Canal expenses.

The next statement, $C$, also relates to a steamer, but of a different class from the above, the value being $£$ ig only per net registered ton, and the gross outlay $L_{1} 43$ s. per ton. The wages are again much lower than in the case of the first-class steamers, but the outlay for coal is as much as $£ 5$ per ton.

The next statement, $\mathrm{D}$, is also a steamer-a cargo boat - the actual value not being stated, but apparently belonging to a class which is valued at $£ 25$ per ton. Here the outlay is $\mathcal{L}_{\mathrm{I}} 4 \mathrm{I} 3 s .7 d$. per ton, and the wages are as much as $£^{2}$ i $7 s .6 d$. per ton. 
E. Is another steamer, a plain cargo boat, valued at $£ 25$ per ton, with an annual outlay of $£$ I I $2 s$. per ton, including only $\mathscr{E} \mathrm{I}$ IOS. per ton for wages.

F. Is another cargo boat, value about $£ 22$ per ton. Here the gross earnings are stated, and amount to about $£$ I 7 per ton, nearly 80 per cent. of the value. Of the $£$ I 7 per ton earned, the outlay abroad is $£ 7$ per ton, or between a half and a third.

G. Contains an account of four steamers in the Mediterranean trade valued at $£$ i 5 per gross ton, or $£ 22$ net, whose average outlay amounts to about $\measuredangle$ IO I $6 s$. per ton gross, equal to about $£$ I 6 per ton net. The results are in fact much the same as for $F$, though the payments abroad do not appear so large.

$\mathrm{H}$. Is a record of four steamers engaged in the coasting trade or short voyages. Their average value is also about $\ell^{1} 5$ per gross ton, or $£^{22}$ per ton net, and the average outlay is about $f \mathrm{IO} \mathrm{IOS}$. per gross ton, or $£ \mathrm{I} 5 \mathrm{I} 5 \mathrm{~s}$. per net ton.

The next records, I, K, and $\mathrm{L}$, all relate to sailing ships: I shows an outlay of $£ 5$ i $7 s$. per net registered ton; $\mathrm{K}$ an outlay of $\delta 6 \mathrm{Is}$. 8d.; and $\mathrm{L}$, which gives an average of no fewer than fifty vessels engaged in miscellaneous trades, an average outlay of about $£_{5} 6 \mathrm{~s}$. per net registered ton. The values in $I$ and $K$ are $\ell_{15}$ and $\delta 14$ respectively, and in $L$ about $\delta 9$ ios. per ton. In the case of $\mathrm{L}$ the statement is accompanied by a private note, indicating that the profit is about $£ \mathrm{I} \mathrm{I} 6 s$. per ton, that is, about one-third of the outlay. This would make the gross earnings over $£ 7$ per ton; and as" the outlay abroad is $\mathscr{L}_{\mathrm{I}}$ Ios. per ton, the gross earnings receivable at home would be about $£ 5$ ios. per ton.

Combining all the information from the variolis sources, what it seems to point to in the case of steamers is first a gross outlay, ranging from about $£$ I I or $£$ I 2 up to $\ell_{20}$ and even more per net registered ton, this gross outlay being also about 80 or 90 per cent. of the income, which would thus range from about $£$ I 5 to 
$£ 22$ per ton. In no case, apparently, not even that of the lowest collier, can the gross income be put at less than about $£$ I 5 per ton. The subjoined table brings out this clearly:

\begin{tabular}{|c|c|c|c|}
\hline Six Steamers in "Statist" & $\underset{22}{\ell}$ & $\begin{array}{lll}\mathcal{E} & s . & d . \\
20 & 0 & 0\end{array}$ & 88 \\
\hline Statement B . . & - & $2 I 00$ & - \\
\hline,$\quad \mathrm{C}$ & - & 143 & - \\
\hline D & - & I 4 I 3 & - \\
\hline $\mathrm{E}$ & - & I I 2 & - \\
\hline $\mathrm{F}$ & 17 & 120 & 70 \\
\hline G & - & 160 & - \\
\hline $\mathrm{H}$ & - & I5 I5 & - \\
\hline
\end{tabular}

Thus, in any case where the income is mentioned at all, even in the case of an ordinary steamer spending no more than $\mathscr{L}_{\mathrm{I} 2}$ per ton, there is no lower sum mentioned than $f_{\mathrm{I}} \mathrm{f}$ per ton. Assuming that in all the other cases the percentage of expenses is also high, and not less than 80 per cent. of the income, we should have an income in all, except the lowest class, amounting to about $£$ i 6 to $£ 18$ per ton and upwards.

I shall propose then to place the earnings of our steam fleet on home account, inclusive of the earnings from passengers, at not less than $£$ I 5 per ton, which would allow for expenditure in foreign ports. This on the tonnage registered at the end of 1880 , viz., 2,723,000 tons, would come to about $4 \mathrm{I}$ million pounds.

With regard to the sailing vessels, the problem seems more simple. The average earnings may be put at not less than $£ 7$ per ton, the outlay being $£ 56$ s. per ton. The sum of $£ 7$ per ton on a fleet of 3,85 I, 000 tons comes to about 27 million pounds, from which about EI Ios. per ton, or say 6 million pounds, would fall to be deducted for outlay in foreign ports, leaving about 
2 I million pounds as earned on home account. The two sums together amount to 62 million pounds, which is not far from the sum of 60 million pounds already arrived at. A certain deduction would of course have to be made from this calculation for the earnings of the fleet engaged purely in coasting, but not sufficient, I think, to alter the round figure of 60 million pounds.

As a rough calculation, I would suggest that $£ 5$ per ton from sailing ships, and $£ \mathrm{I} 5$ per ton from steamers, will give us an approximate figure for the foreign earnings of our mercantile fleet, making all corrections for outlays abroad. If there is any over-estimate, there would be a set-off to some extent in the outlay on foreign vessels in our own ports.

My own impression is that the figure is under and not over the mark. The above account deals only with vessels on the register of the United Kingdom, and known to be employed in the foreign trade. There are many vessels, as already hinted, on colonial registers, or which have been lost sight of, which are really British owned, and which bring an income to British owners. We may be sure that there are considerable sums beyond what has been stated to be brought to account.

It will serve to make clear to us what all this trade means, besides confirming the conclusion as to the income derived from it to the United Kingdom, if we further inquire what the share of the gross earnings which comes to us is composed of. What are the principal items? The information in the Appendices IV. and $V$. bears a good deal on this point, and may be connirmed in various ways.

The principal items are clearly-wages, victualling, insurance, repairs, renewals and depreciation, and profit. I have to submit the following table, deduced from the accounts annexed, always premising that the figures show only what is earned for the United Kingdom : 


\begin{tabular}{|c|c|c|}
\hline Sailing Vessels- & & Mins. \\
\hline Wages. & $\begin{array}{ccc}t & s . & a \\
\mathrm{I} & \mathrm{I} & 0\end{array}$ & $\underbrace{2}_{4}$ \\
\hline Victualling. . . . . . . . . . . . & O II & 2 \\
\hline $\begin{array}{l}\text { Insurance, } 7 \frac{1}{2} \text { per cent. on mean } \\
\text { value of } f \text { Io per ton }\end{array}$ & $\circ 150$ & 3 \\
\hline $\begin{array}{l}\text { Repairs, renewal, and deprecia- } \\
\text { tion, i } 2 \frac{1}{2} \text { per cent. on mean } \\
\text { value of } £ \text { io per ton }\end{array}$ & I 50 & 5 \\
\hline Profit, I $2 \frac{1}{2}$ per cent. . . . . & I 50 & 5 \\
\hline Total & -' & 19 \\
\hline Steamers- & & \\
\hline Wages . & 200 & $5 \frac{1}{2}$ \\
\hline Provisions . . . . . . . . . . . & I IO & $4 \frac{1}{2}$ \\
\hline $\left.\begin{array}{c}\text { Insurance, } 7 \frac{1}{\tilde{E}} \text { per cent. on mean } \\
\text { value of } \hat{\mathcal{E}} 25 \text { per ton }\end{array}\right\}$ & I 176 & 5 \\
\hline $\begin{array}{l}\text { Repairs, renewals, and deprecia- } \\
\text { tion, is per cent. on mean } \\
\text { value of } f 25 \text { per ton }\end{array}$ & & Io \\
\hline Profit, $\mathbf{2} 2 \frac{1}{2}$ per cent. . . . . . & 326 & $8 \frac{1}{2}$ \\
\hline Total . & - & $33 \frac{1}{2}$ \\
\hline
\end{tabular}

\section{Summary.}

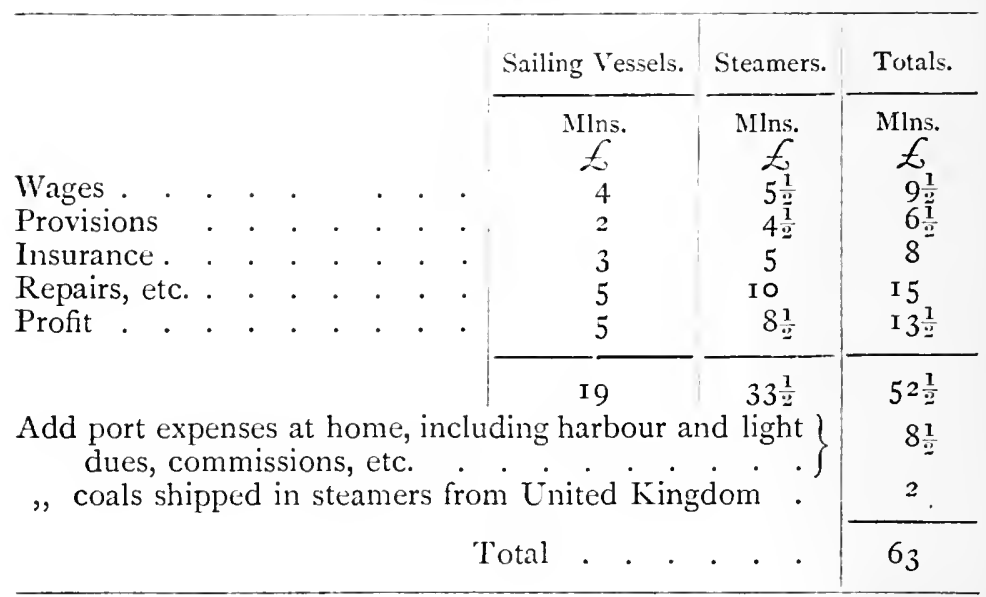


Here again little is included for the outlay on foreign vessels in English ports, while no deduction is made for the earnings of our fleet engaged in the coasting trade. Making all allowances, the figure of 60 million pounds as our foreign earnings in connection with shipping is submitted as near the mark.

The question arises whether the figures are vraisemblable, and it is immediately suggested as regards wages that we have a check. The number of persons employed in our mercantile fleet in 880 , not including masters, was 193,000 . Dividing $9 \frac{1}{2}$ million pounds by this sum we get at an average money wage of $£ 5$ o per per man. I do not consider this a very high average, allowing for the fact that it includes the pay of masters, and officers of every grade, engineers, stokers, and others, all receiving more than the ordinary A.B. wages, which are not less than $\ell_{2}$ Ios. or $£_{3}$ per month. ${ }^{1}$ The averages for sailing vessels and steamers would work out at about $£ 40$ per man for sailing vessels, and rather less than $£ 70$ per man for steamers, which of course include a much larger proportion of highly skilled labour. ${ }^{2}$

With regard to victualling, I think I need do no more than refer you to the paper of Mr. Bourne, already cited, in which he gives the estimate of 6 million pounds for victualling and stores for the year 1879 -that is, victualling and stores put on board ships from the United Kingdom. As I understand Mr. Bourne's mode of doing the sum, this would include victuals and stores put on board foreign ships also, whereas this item in the above account only includes British ships; but the item in any case is not a large one.

See return, "Progress of Merchant Shipping for I SSo."

2 It will obviously be suggested that two deductions should be made, one for the wages of the fleet engaged in coasting, the other for wages paid abroad; but the deductions on these heads would, I believe, be immaterial, while I have sought to allow for minor corrections like these by the moderation of the estimates. In I 88 I, wages generally advanced above the figures here dealt with about $\_6$ per head, or nearly $f \mathrm{r}, 500,000$ in all. 
The other items of insurance, repairs, renewals and depreciation, and profit require less remark. They amount altogether to 35 per cent. on the value of our shipping, which I assume to be about 40 million pounds for sailing vessels, and about 70 million pounds for steamers, in the year I880. With regard to insurance, however, it may be pointed out that the annual replacements required by wrecks to vessels of the United Kingdom-I speak of total losses onlyamount to about

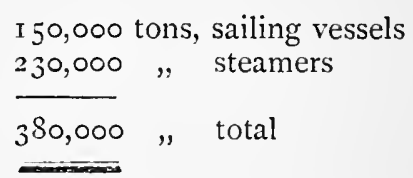

annually. The cost of building these vessels, at $£$ i 5

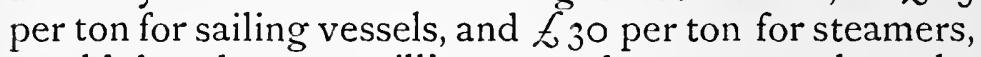
would be about 9 million pounds, or more than the 8 millions put down for insurance. I am inclined to think that this estimate in particular is under the mark, but I leave the figure as it stands, in case it should be thought by some that there is an over-estimate for repairs and depreciation. This last is a high estimate, though I consider it fully justified by the figures before me, shipping property ageing rapidly. With regard to the profit, in putting it at $12 \frac{1}{2}$ per cent., I have kept a good deal below what more than one ship-owner owns to, but the rate is undoubtedly a good deal more than that paid by the high-class steam shipping companies whose accounts are published. There is reason to believe, however, that the latter are among the least remunerative of vessels. With regard to port expenses at home, the broad facts are that harbour, pilotage, and light dues alone would account for nearly three-fourths of the amount here stated, and only a small part would fall on the coasting fleet. The final item of coal put on board steamers at home is rendered necessary in this calculation by the exclusion from the other items of 
any payments abroad, which are included in the general accounts above dealt with. ${ }^{1}$

There is a concurrence of testimony, therefore, to the effect that an enormous sum accrues annually to the United Kingdom in connection with its shipping business, and that the sum of 60 million pouuds is not far from the mark. First, in examining the imports and exports of the whole world, we find a difference between them which must represent the cost of conveyance, and analyzing and dividing this amount among the principal ship-owning nations, we get a figure of about 60 million pounds as due annually to the United Kingdom for freight alone. Second, according to various testimonies - Mr. Bourne, Mr. Newmarch, Mr. McKay and others-there is known to be a large sum annually accruing in connection with the direct trade of the United Kingdom alone, a sum of 40 to 50 millions sterling, and this sum, making due allowance for what comes to us from the shipping in the indirect trade, again points to the probability of a large sum being due to us which cannot be less than about 60 million pounds. Third, the direct evidence of the accounts of numerous steamers and sailing ships points to a gross earning of this amount, if not more, deducting all outlays abroad. Last of all, there is additional confirmation in the analysis of the different items of the expenses of our fleet, and the comparison of these items with other sources of information, such as, for wages - the number of men employed, for victualling and stores-the independent inquiry of Mr. Bourne, for insurance-the sums actually spent in replacing wrecks, for profit - the actual admissions of ship-owners themselves, and the accounts of leading companies, and

There ought to be some further correction, perhaps, as regards the latter figures in respect of the earnings of our mercantile fleet engaged in the coasting trade, already referred to, but that portion, as already stated, is comparatively small, while these last calculations do not include anything for the carnings or profit of British-owned ships not on the register of the United Kingdom. 
or such items as port expenses-the amounts actually paid for harbour and light dues. I must again repeat, however, my impression that probably a much larger sum is really due to us, in consequence both of the moderation of the estimates and the circumstance of a large number of vessels not on the register of the United Kingdom being in fact owned in the United Kingdom. It is not necessary, however, for the special purpose of this paper to name an exact figure. I shall be content if I have made clear that the business of ship-owning is really enormous, and that if we would make any use at all of the import and export figures in the question of the balance of trade, we must dwell on the invisible export which takes place by means of our shipping. The discussion on the subject ought to include a formal treatment of the question of how much our shipping earns.

The inquiry does not end here. I have already drawn attention to the point that the ship-owner is not the only person concerned in the cost of conveyance, of which the aggregate excess of imports in the imports and exports of the world is composed. There are other commissions and charges, of which I have suggested that the English share amounts at least to 16 million pounds--perhaps 20 million pounds would be nearer the mark. The latter sum is only $2 \frac{1}{2}$ per cent. on the total of our imports and exports-about 800 million pounds; and when I point out that insurance cannot be estimated at less than I5s. per cent., and bankers' commission, bill stamps, and minor charges 5 s. per cent., leaving only $\mathrm{I} \frac{1}{2}$ per cent. for all other charges, the estimate must be held to be moderate. Mr. McKay, in the letter already referred to, makes the commission and charges amount to more than double this sum, and quotes the case of a Manchester shipment, in which the insurance and other charges came to 4 per cent. I confess I am afraid of too big figures, and have tried to keep well within the mark. The sum of 20 million pounds, added to the 60 million 
pounds due to us for freight, make a total of 80 million pounds, which is really, to use a phrase which I have tried to make familiar, an invisible export. In using the import and export statistics for the question of the balance of trade, we have to credit ourselves, in addition to our recorded exports, with a sum of at least this amount.

Such figures, if accepted, without any further correction for interest receivable for investments abroad, would serve of themselves to revolutionize the conception of the international balance between this country and other nations, which would be suggested by the bare consideration of the import and export figures. In the last few years the excess of imports, as we have seen, has been about I 20 million pounds (see supra, p. 3 I5), but a deduction from this sum of 80 million pounds would reduce the amount to 40 million pounds, without any correction whatever for other international transactions, such as the receipt of interest upon our foreign investments. Even apart from such a correction, then, the excess of imports is almost accounted for. A nominal difference of about 40 million pounds, subject to the qualifications already stated, is practically much the same thing as no difference at all. As we have seen, we cannot be sure to within 15 or 20 million pounds of the totals of our imports and exports and the balance shown by them, while there is also a very great probability that the sum of 80 million pounds, which I have assumed to be annually earned by the country in connection with its shipping, and other charges in connection with the conveyance of goods from country to country, is a good deal under the mark. When we establish, therefore, that 40 million pounds is a maximum sum for the apparent excess of imports, we establish that there is nothing in such a figure by itself to give us any concern about the nation living on its capital. An excess of that amount might easily be balanced by an excess in the opposite direction in other years; we must expect so great a trade as 
that of the United Kingdom to exhibit oscillations of this magnitude. If it is to be proved that the nation is living on its capital to any extent at all, it must be shown aliunde, from the operations of the stock exchanges and otherwise, that the nation is borrowing abroad, or is bringing home its capital.

The figures suggest another correction of the first impression of the import and export figures. The excess of imports being itself no novelty, and the only thing new being the sudden increase in recent years, the question is naturally suggested whether there is any change in the invisible items of our export which would help to account for such an increase. On this head I need hardly say that nothing has been more remarkable during the last twenty years than the wonderful progress of our shipping, both in absolute amount and in relation to the rest of the world. The figures as to the United Kingdom are:

Tonnage of Sailing and Steam Vessels belonging to the United Kingdom.

[In thousands of tons.]

\begin{tabular}{|c|c|c|c|c|c|}
\hline & \multirow{2}{*}{ Sailing. } & \multicolumn{2}{|c|}{ Steam. } & \multirow{2}{*}{$\begin{array}{c}\text { Total in } \\
\text { Sailing Tons. }\end{array}$} & \multirow{2}{*}{$\begin{array}{l}\text { Increase Per } \\
\text { Cent. in Five } \\
\text { Periods. }\end{array}$} \\
\hline & & Amount. & $\begin{array}{l}\text { Equivalent in } \\
\text { Sailing Tons. }\end{array}$ & & \\
\hline I 840 & 2,637 & 87 & 348 & $\begin{array}{l}\text { Tons. } \\
2,985\end{array}$ & - \\
\hline '50 & 3,336 & 168 & 672 & 4,008 & 30 \\
\hline '6o & 4, I 34 & $45^{2}$ & I, 808 & 5,942 & 50 \\
\hline '70 & 4,506 & I, I I I & 4,444 & 8,950 & 50 \\
\hline '80 & 3,799 & 2,720 & I 0,880 & 14,679 & 64 \\
\hline
\end{tabular}

The business is thus a rapidly increasing one. Twenty years ago the mercantile fleet of the United Kingdom was capable of performing the work of about two-fifths only of the present mercantile fleet. Assuming the earnings to be in much the same proportion, the sum accruing to the United Kingdom in connection with its shipping would be about 27 million pounds 
only twenty years ago, as compared with 60 million pounds now. Even as compared with a period ten years ago, since which our mercantile fleet has increased 65 per cent., such an increase would imply that the earnings ten years ago were only about 35 million pounds, as compared with 60 million pounds now, a difference of 25 million pounds, by which our invisible exports, in connection with the shipping alone, have increased in the ten years. Not only then is the excess of imports no new fact, but the increase of it in recent years is obviously to be largely accounted for by the increase of our shipping business. ${ }^{1}$

The increase of our shipping has been going on quite steadily all through the recent years of depression. You had the figures before you at your last meeting in Mr. Glover's very able paper; but for convenience of reference I have included in the Appendix (No. VI.) a statement of the progress of our mercantile fleet in each year since 1854 , from which date we are able to compare it with the excess of imports, adding a note of the estimated earnings for the United Kingdom on the basis already established. This shows a progressive increase from about 24 million pounds in i 854 to over 60 million pounds at the present time. It will be said perhaps that rates of freight have been diminishing, which is perhaps true to a certain extent; but such a reduction is allowed for in the mode of calculation adopted, the earning power of steamers being stated at three times only that of sailing ships, whereas their effeçtiveness is as 4 to 1 . The reduction of freights cannot have been very great all round, though it may be large on some descriptions of cargo. The expenses, owing to the rise of wages, notwithstanding the great economy of iron as compared with wood, and the economy of labour by means of large vessels and the

1 See also on this head Appendix X., already referred to, showing the great increase in recent years of weights carried in the direct foreign trade of the United Kingdom, where weights are stated or can be calculated.

I. 
substitution of steam for sailing, still remain very large, both per ton per annum and per voyage.

The other charges for conveyance accruing to a country like the United Kingdom must also have increased greatly during the last twenty years. The charge of $2 \frac{1}{2}$ per cent. on the foreign trade of twenty years ago would have been under Io million pounds, as compared with 20 million pounds now.

These corrections will best be shown in a short table, for which I have made use of the figures in Table III., already summarized (see supra, p. 3 I 5):

Excess of Imports as shown in Appendix III., and Summarized above (supra, p. I69), Corrected by Deducting (I) the Charges for Gross Earnings of Shipping as shown in Appendix VI.; and (2) the charge of $2 \frac{1}{2}$ per Cent. for Commissions, Insurance, etc., on the Total Amount of the Direct Trade of the United Kingdom.

[In millions of pounds.]

\begin{tabular}{|c|c|c|c|c|c|c|}
\hline & \multirow{2}{*}{$\begin{array}{l}\text { Total Im- } \\
\text { ports and } \\
\text { Exports. }\end{array}$} & \multirow{2}{*}{$\begin{array}{l}\text { Apparent } \\
\text { Excess of } \\
\text { Imports. }\end{array}$} & \multicolumn{3}{|c|}{ Charges to be Deducted. } & \multirow{2}{*}{$\begin{array}{c}\text { Corrected } \\
\text { Excess. }\end{array}$} \\
\hline & & & $\begin{array}{l}\text { Freight, } \\
\text { etc. }\end{array}$ & $\begin{array}{c}\text { Commission, } \\
\text { Insurance, } \\
\text { etc. }\end{array}$ & Total. & \\
\hline & $f$ & f & $E$ & E & $E$ & $E$ \\
\hline $1854-56$ & 330 & 37 & 24 & 8 & $3^{2}$ & 5 \\
\hline '57-59 & 386 & $3^{I}$ & 27 & Io & 37 & $(-) 6$ \\
\hline $60-62$ & $43^{2}$ & 53 & 28 & I I & 39 & $\mathrm{I} 4$ \\
\hline$' 63-65$ & 523 & 60 & 34 & I3 & 47 & I 3 \\
\hline '66-68 & 566 & 67 & 37 & $I_{4}$ & $5 \mathrm{I}$ & I 6 \\
\hline$' 69-71$ & 6 I 7 & $6 I$ & 39 & I 5 & 54 & 7 \\
\hline $72-74$ & $73^{2}$ & $6 r$ & 46 & I 8 & 64 & $(-) 3$ \\
\hline $75-77$ & $7 \times 3$ & I 2 I & $5^{I}$ & I 8 & 69 & $5^{2}$ \\
\hline $78-80$ & 690 & I I9 & $5^{8}$ & I 7 & 75 & 44 \\
\hline
\end{tabular}

This table needs no comment. The figures are not presented as exact, but they show approximately the difference between the real and the apparent excess, and one of the reasons for the apparent excess increasing in recent years. There remains, of course, the more 
general question of the balance of indebtedness between nations, all the points yet dealt with, the imports and exports themselves, and the sum accruing to the United Kingdom for the gross earnings of its mercantile fleet and for other charges of conveyance being only items in a more general account. On this head, however, I may be permitted not to enlarge. It is notorious that a large sum is due to this country annually for its investments abroad; we belong, as has been seen, to a geographical group which has probably such interest to receive. The usual estimate has been about 50 million pounds to 60 million pounds a year; but since these estimates were made our investments abroad have increased enormously, the public issues on foreign account of the last six years alone, i.e., since the foreign loan collapse of 1875 on the London Stock Exchange, having been about 210 million pounds, this figure not including, moreover, some very large issues, in which the London Stock Exchange was interested, but where the issue was abroad. (See Appendix VII.) I am disposed to think also, from a consideration of the enormous investment of capital in the movement of goods in our ships, and in the conduct of our trade in foreign countries themselves, that this private capital has never been sufficiently estimated, and that our investments of capital abroad at the present time are not less than $\mathrm{I}, 500$ million pounds sterling, on which interest at only 5 per cent. would be 75 million pounds per annum, at 6 per cent. 90 million pounds per annum, and at 7 per cent. I05 million pounds per annum. Whatever sum we take, looking at the small magnitude of the excess of imports which remains after proper corrections for the charges of the cost of conveyance, there can be no question that in recent years, large as the apparent excess of imports has been, this country has been continuing to invest capital abroad-from 40 million pounds to 60 million pounds per annum, if not more. But for this lending, the excess of imports would have been still greater than it has been. 
I do not propose to go farther into this question of the balance of indebtedness in its international transactions for the United Kingdom. To complete it would require an elaborate investigation of the magnitude of private investments, while such points as the expenditure of British citizens abroad, and the expenditure by foreigners in this country, and the minor movements of international capital in connection with exchange operations, would all require to be considered. To treat this subject properly would require a paper by itself almost as long as the one now before you, which is already of ample dimensions. I shall be quite content if I have established to your satisfaction (I) that the question to be investigated is not that of the diminution, but of the increase, of our investments abroad-that there is really no question at all of the nation bringing home capital or living on its capital in recent years; and (2) that, whatever may be our conclusion on this point, the import and export figures themselves are only a small part of the question, and that the use of these figures by some writers as if they were the whole is only to be excused, if it is excusable, on the score of ignorance of the nature of statistics and the necessary conditions of dealing with them.

V.-Subject continued: the Excess of Imports or Exports in France and the United States. Conchusion.

Mutatis mutandis, all these points have to be considered of course in dealing with foreign nations. I shall only consider two, the United States and France. The United States is the country which has perhaps the largest excess of exports. In the last six years, including bullion, that excess has been 37 million pounds annually. (See Appendix VIII.) The United States is practically a country whose exports, apart from the question of interest on borrowed money, ought to balance its imports, its foreign shipping being quite insignificant, earning 
for it probably, according to the above calculation of $£ 5$ per ton for sailing ships, about 6 million pounds a year only. How then is the excess of exports to be accounted for? What economic circumstances or conditions does it imply? I have to suggest two things: (I) the expenditure by United States citizens travelling abroad less the expenditure of foreigners travelling in the United States; (2) the interest payable to foreigners on account of foreign capital invested in the United States. The former cannot be less, I believe, than Io million to 15 million pounds, the annual migration of Americans to Europe being 20,000 to 30,000 in addition to an American colony of several thousands almost constantly resident in Europe, and the latter cannot be less than 30 million pounds; total 40 million pounds. Even if the latter ought to be a smaller figure, we should still have to consider the margin of error in the United States figures, especially those for the imports, on account of the undervaluations and smuggling, so that the apparent excess of exports would be more than the real excess, because of the imports being undervalued. There is certainly nothing in the excess of exports to indicate unusual prosperity, whether present or prospective. The recent increase of the exports, and of the excess of exports, is also to be accounted for by the fact that in the last twenty years American foreign shipping has been diminishing in proportion to its total trade. That trade twenty years ago was $\mathrm{I} \hat{3} 5$ million pounds only, the tonnage of American shipping in the foreign trade being over $2 \frac{1}{2}$ million tons, which, at the rate of $£ 5$ per ton, would entitle it to a gross income of $12 \frac{1}{2}$ million pounds a year. Now the trade is 347 million pounds, and the earnings from the shipping must be about 6 million pounds only. There is ample reason, therefore, for the excess of imports in the American trade ceasing, and an excess of exports beginning, apart from the farther obvious explanation that America borrowed large sums abroad during the civil war and afterwards, the interest of which has now 
to be paid. It seems a nice question whether America of late years has been reducing its indebtedness abroad, but there is nothing, at least in the import and export figures, corrected as they ought to be, to indicate such a reduction. I am only concerned, however, at present, with pointing out the nature of the inquiry which must be made. ${ }^{1}$

As regards France, the account stands as follows for the last twenty years (see Appendix IX.):

[In thousands of pounds.]

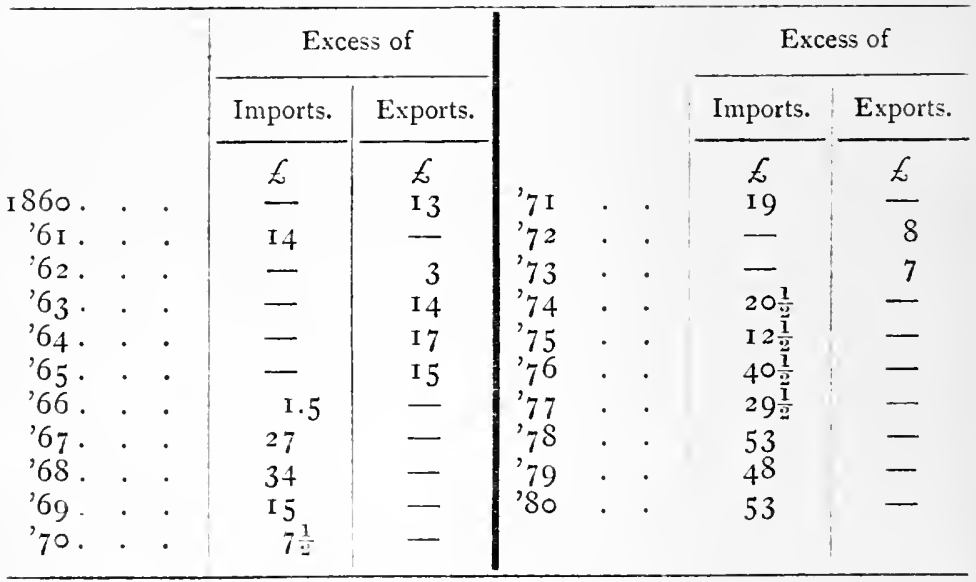

Here the excess of imports is less marked than it is in the case of the United Kingdom, and there has been a smaller increase in the excess in recent years compared with six or seven years ago. The explanation, no doubt, is that French shipping is comparatively

1 See also an Essay on the Foreign Trade of the United States ("Essays in Finance," and Series, ed. I 886). I may add too a fact, of which I was not aware when I wrote this paper, that the system in America is to value the imports not at the port of arrival, but as at the place from which the goods were sent. The value in America therefore does not include the cost of conveyance, and the proportion of the exports is accordingly higher than it would otherwise be as compared with a country like England, where the value of the imports does include the cost of conveyance. 
small, being 932,000 tons, and has increased very little in recent years, the only change being that since 1860 about 200,000 tons of steam shipping have been substituted for as many tons sailing, the total rather diminishing. The total gross earnings for France, at the same rate as for England, can only be about 6 million pounds, and the increase in twenty years little over 2 million pounds. At the same time, leaving out our shipping, the excess is as great in proportion for France as for the United Kingdom. There can be little question that France has increased its investments abroad, notwithstanding the payment of the indemnity, while it must derive a large income annually from the expenditure of foreigners travelling or residing in France, French citizens by comparison going very little abroad. It would be interesting for France as for England to trace the growth of its foreign investments in recent years, but the problem of stating its balance is neither so large as that for England nor so complicated in various ways. The figures, however, when rightly considered, are in apparent accordance with the economic circumstances of the country, while they teach nothing as to comparative prosperity or the reverse.

The broad conclusion is that the importance attached in some of the recent discussions to the excess of imports in any country, and to the increase of that excess in this country in recent years, and contrariwise to the excess of exports in the case of other countries, and to the increase of that excess, is wholly mistaken. There is nothing in the facts either way to indicate special circumstances of prosperity or adversity, or that one nation is living on its foreign capital, and another increasing its foreign capital or diminishing its indebtedness abroad. The facts when investigated throw a great deal of light on the industrial circumstances of different countries, but until investigated and compared with other facts they are entirely without meaning. In other words, import and export figures require delicate and careful handling for any such inquiry as the ac- 
count of indebtedness between nations. Quod erat demonstrandum.

\section{VI.-Import and Export Statistics and the Protectionist Controversy.}

The second special inquiry I have proposed is the way to use import and export figures in the controversy between free traders and protectionists. How do the statistics assist?

In answering this question, we must be struck by the fact that there can hardly be any statistics available to settle directly the cardinal question between free trade and protection, viz., which regime favours most the general prosperity of a people, morally as well as materially. No such question can be treated practically from a material point of view alone; political and moral considerations must come in. I could quite understand a free trader admitting a protectionist system to be the best materially, and a protectionist admitting the free trade system to be the best materially, and yet each on moral and political grounds preferring the less advantageous system in a material view. But how difficult to trace out all the effects of an economic régime in the moral and political sphere! Even materially, however, there can hardly be adequate statistics. To make any statistical comparison at all possible between different régimes, it would be necessary either to find two countries practically alike in their economic and industrial circumstances, and in the character of their people, subject them to the opposite regimes, and then ascertain and compare their relative material progress; or to find a particular country subjected at different periods to the two opposite régimes without any other differences, and then compare the different results, if any such are appreciable. Experience does not supply us with such cases. No two communities are sufficiently alike to be comparable in strict logic. The slightest differences in the race or moral condition of the two 
communities which are to outward appearance much the same, might make a great deal of difference in their material progress. If the two are subjected to different economic regimes, how are we to tell whether the inferior progress of the one materially-even when we are sure about the inferiority-is due to the regime, and not to other differences in the character of the communities, which we cannot so well appreciate? The same with a community at different periods of its own history. How can we tell that there is no moral difference of a serious kind to affect the economic progress of the community between one period and another? External economic circumstances are, besides, incessantly changing, and may affect two communities apparently of much the same character and position quite differently. If it were possible to institute many pairs of comparisons and exhibit a uniform result in all, it might be safe to infer that it was the regime which did make the difference, no other uniform cause of difference being assignable; but this condition of course it is impossible to fulfil.

Quite lately an interesting attempt has been made by Mr. Baden-Powell ${ }^{1}$ to show that the regime does make all the difference in the case of two communities which he compares-New South Wales and Victoria, the former free-trading and the latter protectionist; but directly, I fear, the comparison proves nothing. In strict logic one comparison is not enough. There must be many comparisons. It may be doubted, moreover, as regards this particular case, whether the two communities compared were really in sufficiently like circumstances at starting to make the comparison really valuable; while it is not shown that no other circumstances besides the economic ones may have helped to make the difference since; nor is it shown that the difference of the régime itself was so great as to justify us in calling the one colony free-trading and the other

1 "Fortnightly Review," March, I $S S_{2}$. 
protectionist. But granting the apparent likeness of the two cases in all except the one point, what I have to urge is that one comparison proves nothing in strict logic, and at best does no more than raise a presumption to be confirmed or set aside by farther inquiry.

There would be a farther difficulty in making such an inquiry statistically, in the facility with which the visible consequences of an inferior régime may be masked by an increase of industry on the part of the suffering community to make up the loss. The community, rather than lose in the return to its labour, might labour more energetically, and so the outward result would be as before-the production, consumption, and saving might remain what they were. It is even conceivable that the community suffering most might apparently gain, in consequence of a greater development of industry and energy than what is absolutely necessary to supply the loss. In any case, I am quite ready to believe that the visible difference, as between free trade and protection, if the protection is not extreme, may often not be so great as to be traceable by statistics. Suppose the protected industries in a country giving protection to be one-tenth of the whole, or the industries which might be protected in a free-trading community, but which are left free, to be also one-tenth, which is a large proportion, and that the loss arising to the community by the diversion of capital and labour from more profitable to less profitable employments is io per cent. on the production of this one-tenth of the people; then the loss to the whole community-the difference it makes -is only I per cent. of the total production. Even if the diversion should cause a waste of 25 per cent. in the protected industries in the one case, and the unprotected industries in the other case, the difference to the whole community would still be only $2 \frac{1}{2}$ per cent. Such small margins, it is obvious, may be lost sight of among other things, and easily made up by a little more industry on the part of those who suffer. They may also affect still less the growth of wealth, 
through the community bearing what loss there may be out of its income and accumulating wealth as rapidly: as before. There is an inherent difficulty, then, of a very formidable kind, in showing by statistics that any given economic régime is more favourable to the material welfare of a community than another. Unless the differences are extreme and marked, it seems hardly possible that there can be much difference in the results, of which statistics can take note, whether a community is freetrading or protectionist.

Such being the case as regards statistics generally, it is hardly necessary to add that import and export statistics alone cannot give much help. They are even irrelevant to the question to be answered. It is quite conceivable that a country may be very prosperous without foreign trade at all, or with very little foreign trade, or that for special reasons the foreign trade of the least progressing country as a whole may be making greater progress than the foreign trade of a more progressing country. Were the British Empire, for instance, to form one customs union, the foreign trade of that union would probably be less than the foreign trade of the United Kingdom alone is now, and its growth or decline would be less important in proportion to the whole business of the empire than the growth or decline of the foreign trade of the mother country is now to the mother country itself. The progress of the foreign trade of different countries is thus no index at all of their relative progress materially. Even therefore if you could reduce the so-called imports and exports of different countries to common denominators, and make all proper allowances for changes of prices and the like disturbing influences, which I have already shown to be most difficult, you would be no nearer than you were before to proving that the country whose foreign trade increases fastest is the most prosperous materially: There is a more serious difficulty still. Foreign trade is trade between nations, and the foreign trade of a country which has an inferior régime may consequently 
increase as much in amount, and perhaps infinitely more in proportion, than the foreign trade of a country with a superior rigime. The trade of the inferior may. be with the superior, and the two will increase pari passu, though the impetus may be given by the superior and not by the inferior. We may see this very clearly if we put the hypothetical case of two countries, the one free-trading and the other protectionist, trading exclusively with each other, that is, having no other foreign trade, with a third country doing no trade itself but carrying for the two others. Clearly, the foreign trade of the free-trading and protectionist countries must exactly balance. Their imports and exports will be exactly alike. Whether, to give a practical illustration, the foreign trade of the United States with the United Kingdom has been the result of the impetus of the former or the latter will, I think, hardly be open to question. It is the United Kingdom which by its purchases has stimulated the foreign trade of the United States, small as that trade is compared with our own. In any case, these considerations show sufficiently that the increase of foreign trade proves nothing by itself as regards the relative material prosperity of different countries. The circumstances affecting foreign trade, besides the differences of regime, are innumerable; and above all, it is a necessity that countries with different régimes should trade with each other, so that the greater prosperity of free trade countries may cause the foreign trade of protectionist countries to advance more rapidly than that of their own.

But while statistics are thus not available in giving a distinct yes or no to the cardinal question between free trade and protection, it does not follow that they are of no use at all. Rightly used and handled they may contribute materially to the solution of the points at issue. I have to suggest various ways in which they may be so used.

First. The proposition, if accepted, that statistics are not available to prove directly the superiority of 
one régime to another in promoting material prosperity, appears to be entirely on the free trade side of the argument. It is the protectionist on whom the onus of proof lies. He affirms that if the State interferes with trade and does certain things, the greater material prosperity of a country will ensue. He is bound therefore to furnish proof that the State ought to interfere, and interfere in the way indicated. The free trader, on the other hand, need not prove anything at all. $\mathrm{He}$ simply wishes to let things alone unless it can be shown that something should be done; the whole onus of proof is on his opponent. When it appears, therefore, that statistics cannot be appealed to in the direct issue between free trade and protection; that statistics can hardly be got to indicate in any way the superiority of one regime to another; this is as much as to say that the protectionist is not helped by statistics. One great branch of argument is cut away from him. Logically then the unsuitability of statistics, owing to their necessary imperfections, for solving the direct issue between free trade and protection, is a material fact. In pointing out that they are unsuitable we do a great deal to destroy the protectionist case.

It may be asked, then, how it is that the protectionist appeals so much to statistics-that he talks of the greater increase of prosperity in protectionist countries, of the greater increase relatively of the foreign trade of protectionist countries, of special industries promoted by protection, and so forth? The reply is that very often the facts appealed to are themselves misunderstood, being, as we have seen, very difficult to read, while their logical treatment is a difficult matter. I notice in all these discussions that the statement of the major premiss is aroided. The protectionists do not make clear to themselves what they wish to prove. They show, for instance, that the United States is prosperous; but that is not what they have to prove. What they have to prove is that it is more prosperous than it would have been under a free trade régime, a 
statement in which statistics cannot help them. They assert, again, that the foreign trade of protectionist countries increases faster than that of free-trading countries; but what they have really got to prove is not only that it increases faster than that of other countries, but that it increases faster than it would have done under free trade, and that this more rapid increase is itself an index of greater growth of material prosperity generally than would have otherwise taken place. The proof again that special industries have been ostered by protection is nihil ad rem. What has to be proved is that the industry of the country as a whole has prospered, which is a very different thing. Without discussing, then, the whole case between free trade and protection, we are entitled, as a scientific body, to point out that the call which protection makes on statistics is one which cannot be answered. The protectionist seeks an affirmative answer to a question which statistics cannot answer affirmatively or negatively.

We may perhaps go farther, and say that as the protectionist relies so much on statistics, and has nothing else to rely on,--his argument is always an appeal from theory to facts-then there can be no argument for protection. This appears, in fact, to be the logical position of the controversy.

\section{VII.-Subject continued: the negative use of Import and Export Statistics.}

Second. While statistics can be of no use to the protectionist, they may be of use to the free trader, negatively, by affording presumptive conclusions that the anticipations of the protectionist are unfounded. The protectionist, in arguing that a country will be better off under protection than under free trade, implies and assumes that the condition under free trade will not be satisfactory, that this is the reason for not letting things alone. If, then, it can be shown that, taking countries as they stand, the condition of things is 
tolerably satisfactory under free trade, the difficulty of the protectionist would be enormously increased. The reverse, as we have seen, would prove nothing against free trade logically, but if free trade, on the average, appears to do as well, or better than protection, the protectionist is clearly out of court. His only appeal is to statistics, which could not by any possibility help him; but if the answer they give, as far as it goes, makes against him, he is hopelessly in the wrong.

Looking at economic statistics generally in this way, it is plain that free trade nations, and especially the United Kingdom, have nothing to complain of. The fact of the United Kingdom having made great strides in material prosperity since the free trade period is undeniable, and is not really denied by protectionists. Of late, they say, owing to foreign tariffs and other causes, the results are less satisfactory, and they shake their heads ominously about the future, but the advance in the past, I apprehend, is not denied. If it is desired, I think there are ample materials in our "Journal" to prove the contrary, so that a mere passing reference may be sufficient for me to-night. The satisfactory result may not be wholly due to free trade, and no free trader ever said that it was; Mr. Newmarch's repudiation of any such idea, in his paper read in 1878 , was most emphatic; but it has been consistent with free trade, and it is upon protectionists to prove that the result with protection would have been better.

We are concerned to-night, however, with import and export statistics specially, and on this narrower fieid I may perhaps be allowed to refer to one or two facts which appear to raise an insuperable presumption against protection. I should not think of going into the history of our foreign trade exhaustively, the subject having been treated so fully by Mr. Newmarch in 1878 , and our special business to-night being with the method of statistics; but without exhaustive treatment a few broad facts can be made to stand out clearly enough. Before pointing them out, however, I must again call 
attention to the remark already made, to the effect that the progress of foreign trade is not necessarily an index of the progress of material prosperity in a country generally. It may or may not be so. But conceding it to be an index, the facts of our experience are not such as to encourage a protectionist to appeal to them. Our progress has been astonishing. The protectionist may imagine, or say he imagines, that under protection we would have done better, but surely he cannot deny that under free trade we have done well.

The first facts to be mentioned are those relating to the movements of shipping. Of these you had a very full account at the last meeting, and I have said a good deal to-night about the growth of our shipping business as a separate business; but I wish now to speak of those movements as an indication of the growth of imports and exports. To some extent they are a better indication than the figures of imports and exports themselves. The latter may fluctuate, as we have seen, owing to changes of price; but if increased quantities of goods are carried, whatever nominal sums they may be entered at, you must have more ships. It is quite true, of course, that shipping may increase disproportionately to the trade through the articles handled being more largely of a bulky and less valuable nature than before; but this is a point which can easily be inquired into. The entries and clearances of shipping, then, in the foreign trade of the United Kingdom during the last forty years have progressed as follows:

\begin{tabular}{|c|c|c|c|c|c|c|}
\hline \multirow[b]{3}{*}{$\begin{array}{r}840 \\
\text { '50 } \\
\text { '60 } \\
\text { '70 } \\
\text { '80 }\end{array}$} & \multirow[b]{3}{*}{. } & \multirow{3}{*}{\multicolumn{2}{|c|}{\begin{tabular}{ll|}
$\cdot$ & $\cdot$ \\
$\cdot$ & $\cdot$ \\
$\cdot$ & $\cdot$ \\
$\cdot$ & $\cdot$ \\
$\cdot$ & $\cdot$
\end{tabular}}} & \multirow{2}{*}{$\begin{array}{l}\text { Tons: } \\
9,440,000\end{array}$} & \multicolumn{2}{|c|}{ Increase on Previous Ten Years. } \\
\hline & & & & & Amount. & Per Cent. \\
\hline & & & & $\begin{array}{r}9,440,000 \\
14,505,000 \\
24,689,000 \\
36,640,000 \\
58,736,000\end{array}$ & $\begin{array}{l}\overline{5,065,000} \\
\text { I 0, I } 84,000 \\
\text { I I,95 I,000 } \\
22,096,000\end{array}$ & $\begin{array}{l}- \\
53.4 \\
70.2 \\
48.6 \\
60.4\end{array}$ \\
\hline
\end{tabular}


And the increase from first to last, between i 840 and 1880 , covering the whole free trade period, is no less than $49,296,000$ tons, and 525 per cent. To be quite fair, even in dealing with protectionists, it may be admitted that the increased use of steamers which do a calling trade may have caused some increase of entries and clearances without an increase of goods carried to correspond; but the self-interest of ship-owners may of course be trusted to fill up their vessels as much as possible. Comparing the figures with the increase of population in the interval, it appears that while the entries and clearances in 1840 were 0.36 ton for each unit of the population, in 1880 they were 1.73 tons for each unit of the population, an increase of $38 \mathrm{I}$ per cent.

We may give some idea of these figures in another way. The entries and clearances of shipping in the foreign trade of almost all foreign countries put together, excluding British colonies, may be taken as I 40 million tons. ${ }^{1}$ The increase of our entries and clearances, therefore, since 1840 is equal to one-third of the whole existing business of all foreign countries put together. Assuming imports and exports, therefore, to have increased in the same proportion, we may say broadly that the increase of the foreign trade of the United Kingdom since 1840 is equal to one-third of the whole foreign trade of the world, not comprised within the British Empire. The increase, moreover, is equal to about $1 \frac{2}{3}$ tons for each individual of the United Kingdom, or five-sixths of a ton of goods conveyed each way. If a growth of foreign trade like this does not please protectionists, what sort of trade is it which will satisfy them?

We come then to the suggestion that the goods have changed in character. They are said to be more bulky than they were. This is especially the case, we may be told, with the exports, where the increase is chiefly in coal and pig iron, in raw materials. But this does not prove that the real values involved have not risen in

I See Statistical Abstract for Foreign Countries.

I.

$A \Lambda$ 
proportion. On the contrary, it is probable that, value for value, an export of so much coal or pig iron implies a much larger employment for labour and capital within the country than an export of so much cotton manufactures. The whole value in these cases is an export of the produce of British capital and labour; whereas, in the case of cotton manufactures, four-fifths or twothirds of the value may be a re-export. In other words, Io million pounds worth of coal exported may mean an export of as much produce of British capital and labour as 50 million pounds worth of cotton manufactures. Not only so: the fact that equal values of coal or pig iron exported means more employment for shipping than values of cotton manufactures implies, as the shipping is mostly British, that there is an immense indirect employment for capital and labour in connection with the shipments. We may assume then that the increase in the movements of shipping is a very good index of the increase in the imports and exports themselves.

We may look, however, at the actual facts of a few chief articles, always remembering the circumstances pointed out by Mr. Newmarch in the paper already referred to, that the part of our foreign trade which has most conspicuously increased is the miscellaneous trade. Take first the exports of cotton yarn and piece goods. The progress we find is shown as follows:

\begin{tabular}{|c|c|c|c|c|c|c|}
\hline & & Cotton Varr & & Cott & n Piece G & ods. \\
\hline & Totol & $\begin{array}{c}\text { Increase } \\
\text { Ten }\end{array}$ & $\begin{array}{l}\text { Previous } \\
\text { ears. }\end{array}$ & Total & $\begin{array}{c}\text { Increase } \\
\text { Ten }\end{array}$ & $\begin{array}{l}\text { Previous } \\
\text { ears. }\end{array}$ \\
\hline & & Amount. & Per Cent & & Amount. & Per Cent. \\
\hline I 840. & $\begin{array}{l}\text { Min. Ibs. } \\
\text { I I } 8.5\end{array}$ & - & - & $\begin{array}{c}\text { Miln. yds. } \\
79^{\circ}\end{array}$ & - & - \\
\hline '50. & I 3 I. 4 & I 2.9 & I I & $1,35^{8}$ & $5^{67}$ & 72 \\
\hline 60. & I 97.3 & 65.9 & 50 & $2,77^{6}$ & $\mathrm{I}, 4 \mathrm{I} 8$ & 104 \\
\hline 70. & I 86.0 & (-) I I.3 & $(-) 6$ & 3,267 & $49 \mathrm{I}$ & I $7 \frac{1}{2}$ \\
\hline 'So. & 2 I $5 \cdot 5$ & 29.5 & I 6 & $4,+96$ & $x, 229$ & $3^{8}$ \\
\hline
\end{tabular}

Note.-Percentage increase between $8_{40}$ and i 880 : cotton yarn, $\$_{4}$ per cent., and cotton piece goods, 468 per cent. 
THE USE OF IMPORT AND EXPORT STATISTICS 355 On the same plan I make up the following short tables:

Exports of Iron and Steel.

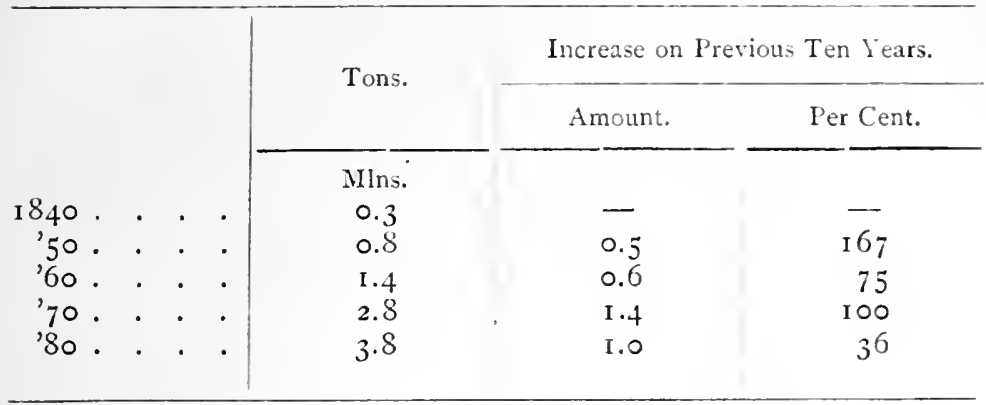

Note.-Percentage increase between I 840 and I 880 equal to I, I 67 per cent.

Exports of Hardware and Cutlery.

\begin{tabular}{|c|c|c|c|c|c|c|}
\hline \multirow[b]{3}{*}{$\begin{array}{r}840 . \\
\text { '50. } \\
\text { '60. } \\
\text { '70. } \\
\text { '80. }\end{array}$} & \multirow[b]{3}{*}{$\begin{array}{l}\cdot \\
\dot{\cdot} \\
\dot{\cdot} \\
\dot{\cdot}\end{array}$} & \multirow{3}{*}{\multicolumn{2}{|c|}{$\begin{array}{ll}\cdot & \cdot \\
\cdot & \cdot \\
\cdot & \cdot \\
\cdot & \cdot \\
\cdot & \cdot\end{array}$}} & \multirow{2}{*}{$\begin{array}{l}\text { Value. } \\
\begin{array}{c}\text { Min. } \mathscr{L}^{\prime} \text { 's. } \\
\text { I. }\end{array}\end{array}$} & \multicolumn{2}{|c|}{ Increase on Previous Ten Years. } \\
\hline & & & & & Amount. & Per Cent. \\
\hline & & & & $\begin{array}{c}\text { Min. E's. } \\
\text { I.3 } \\
2.6 \\
3.8 \\
3.8 \\
3.5\end{array}$ & $\begin{array}{c}- \\
\text { I.3 } \\
\text { I.2 } \\
-\overline{(-) 3}\end{array}$ & $\begin{array}{r}- \\
100 \\
46 \\
-\overline{-} 8\end{array}$ \\
\hline
\end{tabular}

Note.-Percentage increase between i 840 and i 880 equal to I 69 per cent.

Exports of Machinery.

\begin{tabular}{|c|c|c|c|c|c|c|}
\hline \multirow[b]{2}{*}{ 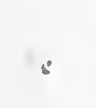 } & & & & \multirow{2}{*}{ Values. } & \multicolumn{2}{|c|}{ Increase on Previous Ten Years. } \\
\hline & & & & & Amount. & Per Cent. \\
\hline I 840 . & - & - & . & $\begin{array}{c}\text { Mln. } \mathcal{L}^{\prime} \mathrm{s} . \\
0.6\end{array}$ & - & - \\
\hline '5o. & . & . & . & I.O & 0.4 & 67 \\
\hline '6o. & . & - & . & 3.8 & 2.8 & 280 \\
\hline 70 . & • & - & - & $5 \cdot 3$ & I. 5 & 40 \\
\hline '8o. & . & . & . & $9 \cdot 3$ & 4.0 & 75 \\
\hline
\end{tabular}

Note.-Percentage increase between i $S_{4} 0$ and i 880 equal to $r_{4} 8_{3}$ per cent. 
Exports of Coal.

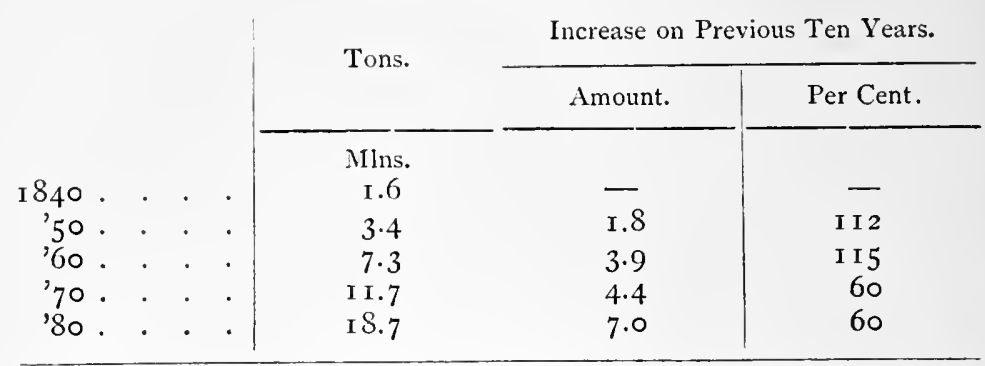

Note.-Percentage increase between I 840 and I 880 equal to I,०70 per cent.

These tables of course are not, and do not pretend to be, exhaustive as regards foreign trade, while if they were exhaustive, many questions would be suggested as to the precise character of the increase, the countries with which it takes place, and other particulars. Comparing these exports, however, with the above stated facts as to shipping, they serve to show what a gigantic growth we are dealing with. It is difficult to imagine what foreign trade there can be which increases more rapidly. I have omitted giving any quantities for the imports, for the practical reason that the quantities of our importations are less in dispute, but they are easily enough accessible to all concerned.

The facts as to quantities being thus clear, we are able to use the facts as to values. The whole exports of British and Irish produce between I 840 and I 880, according to the declared values, have been:

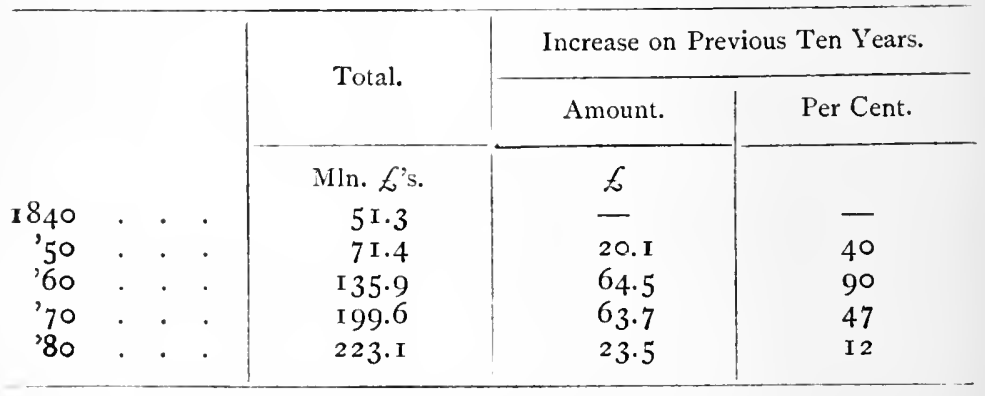


and the increase between 1840 and I 880 is 335 per cent. There are some points in detail to be observed upon, but the progress generally is evidently as remarkable as that of entries and clearances of shipping and the quantities of the principal articles of export, and, taken in conjunction with these facts, gives fair ground for supposing that the whole foreign export trade in quantities, as well as values, has increased in about the same degree.

Dealing with values alone, as regards the imports, we get the following comparison:

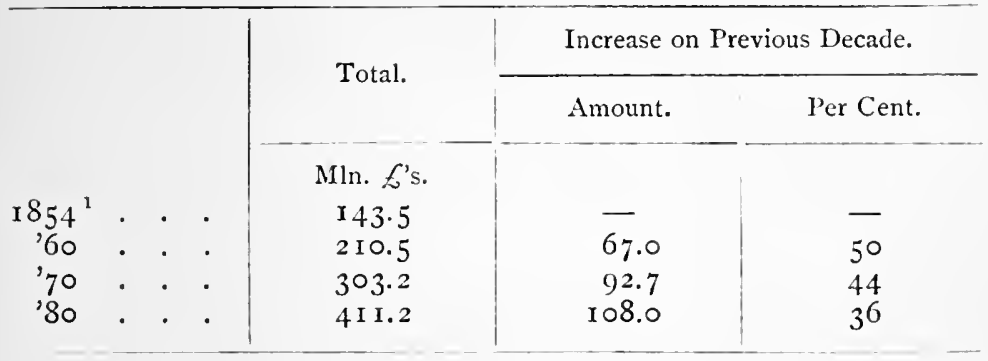

and the increase since 1855 is 186 per cent. Thus both in imports and exports there has been an enormous increase for the United Kingdom during the free trade period-an increase which has been demonstrated to be as great in quantities as in values in the case of the exports, and which is presumably so in the case of the imports, though it would encumber this paper too much to go into detail. As regards imports at least, there can be no question of its having continued to the latest date. There is no apparent falling off in the last few years to account for.

Clearly, then, in these figures the protectionist has a very difficult argument. If our foreign trade had progressed less, the onus of proof would still have been on the protectionist to show that under another regime

1 In the case of the imports, there are no computed or declared values before 1854 . 
it would have progressed more; logically, figures showing a less progress would not have helped his argument a bit. But the figures being what they are, he has to prove that protection would have had a better result, and promises better in future. He must

"Gild refined gold, and paint the lily."

Thus, negatively, the statistics of foreign trade are useful. The prosperity of the last forty years may not be owing to free trade, but it has been consistent with free trade, and protectionists must look elsewhere than in our import and export statistics for any argument against free trade policy.

There are one or two points, however, which are likely to be cavilled at, though the figures themselves will help to supply an explanation. There is apparently a little support given by some of the figures to the contention that in recent years foreign trade has ceased to progress quite as rapidly as it did at an earlier period. The increase in the export values is only I 2 per cent. in the last decade, as compared with 47 per cent. in the previous decade, 90 per cent. between I 850 and I 860 , and 40 per cent. between I 840 and 1850. There is a similar diminution in the quantities of the principal articles exported, though not in all; while in one decade at least, viz., between 1850 and 1360, the proportionate growth of the movements of shipping was a little greater than it has been since. A little consideration will show, however, I believe, that while there were probably real causes between I 850 and I860 for a greater proportionate increase of our foreign trade than there has been since-such causes as the great growth of railways between 1840 and 1850 , which came really into use between $185^{\circ}$ and I 860 , the gold discoveries, and the great colonization which went on in the latter decade-yet the diminution in the rate of increase lately is much less than it appears to be. The period between 1850 and I 860 was the one in which the first effect of the gold 
discoveries, which beyond question raised prices considerably, was experienced. In the period since 1870 there has been a general decline in prices, aggravated, specially as regards our own exports, by a special decline in cotton. Keeping in mind then the important element of price, we see reason at once for looking more to the quantities and to the movements of shipping than to the values only. The figures, in fact, corroborate what has already been stated in the first part of this paper as to the importance of price. Unless we allow for this element, we shall be bewildered by the figures.

The point is perhaps worth even more minute consideration. Comparing the percentages of increase of the values of the exports and of the movements of shipping, we get the following results:

\begin{tabular}{|c|c|c|c|c|c|c|c|}
\hline & & & & & & $\begin{array}{c}\text { Increase of Shipping } \\
\text { Movements. }\end{array}$ & $\begin{array}{c}\text { Increase of Export } \\
\text { Values. }\end{array}$ \\
\hline & & & & & & Per cent. & Per cent. \\
\hline I $840-50$ & . & . & . & . & . & $53 \cdot 4$ & 40 \\
\hline '50-6o & . & - & . & . & . & 70.2 & 90 \\
\hline '60.70 & . & . & . & . & . & 48.6 & 47 \\
\hline '70-8o & . & . & . & . & . & 60.4 & I 2 \\
\hline $1840-80$ & . & . & . & . & . & 525.0 & 335 \\
\hline
\end{tabular}

Thus between I 840 and 1850 , before the gold discoveries had caused prices to rise, and when they were probably tending to decline, the increase of shipping was rather more than the increase of export values; in the following decade, when prices were undoubtedly rising, the increase of export values is more than the increase of shipping movements; in the third decade, 
viz., between 1860 and I 870 , when prices were probably stationary, the rate of growth is about even in the two cases; in the last decade, when the level of price has probably declined considerably, the rate of growth of shipping remains much the same as in the previous decades, but the rate of growth of the export values shows a diminution. To my mind the suggestion of this table as to a fall of prices between 1870 and $\mathrm{I} 880$ is most direct, and such questions of price, I am satisfied, will require to be more and more considered. We have not had import and export figures on a tolerably satisfactory basis for many years to deal with, and we are only beginning to find out the diffculties of using them when long periods are compared. Meanwhile the practical conclusion appears beyond question.

I have to suggest, moreover, what has already been stated in the previous part of the paper as to the increase of our shipping business as a means of accounting for the non-increase of our apparent exports. It is because our invisible exports have been increasing so enormously, that there is less increase of the visible. But it is the same thing of course whether we export the produce of our capital and labour stored up in goods, or in the shape of repairs to ships, or new ships built to replace old ones, which carry the foreign goods of the world. In any way that we take the figures, there has obviously been an enormous growth of our foreign trade since the free trade period, continued to the most recent date. What the protectionist has to prove is that protection would probably have done better or so well.

It would be impossible to go through the imports and exports of foreign countries in detail, to show how they also raise a presumption against the protectionist. Looking at the difficulties of analyzing the data themselves, and allowing for special circumstances which may have affected the foreign trade of different countries, the difficulty of inquiring what the facts are as 
regards foreign countries, and of finding suitable pairs of free trading and protectionist countries for comparison, would in truth be insuperable. To mention only some of the difficulties which occurred to me in endeavouring to form a group of protected European countries, I may state that the fact already mentioned as to the recent change from official to real values in Austria throws out all comparisons as regards that country; and that for Russia comparisons are equally thrown out by the recent clepreciation of the rouble and rise in nominal prices, which unduly swell the figures of the foreign trade, while a reduction of the rouble to specie value in each year would be open to some exceptions. For Germany, again, we have statistics for ten years only, too short to be of any value. This leaves no other country than France among the great European States as to which a special inquiry would seem worth while, and even as regards France we have also to remember that the separation of Alsace and Lorraine ten years ago was a special cause of increase in the foreign trade, what was home trade in France becoming in fact foreign.

In the absence of any general grouping, then, I shall refer specially to two foreign countries only-the United States and France-the former a protectionist country, which became in the period under review more protectionist than at the beginning, and the latter a protectionist country, which became less protectionist. Is there anything on the face of the figures of either country to suggest such a progress in their foreign trade, assuming that trade to be a good index of material prosperity, as to imply that protection is a specially advantageous régime?

With regard to the United States, making a table in much the same form as that for the United Kingdom, but including specie, the general figures are: ${ }^{1}$

I make use here of the figures in the Essay already referred to on the Foreign Trade of the United States. 
Foreign Trade of the United States.

[In millions of pounds.]

\begin{tabular}{|c|c|c|c|c|c|c|}
\hline & & Imports. & & & Exports. & \\
\hline & Amount. & $\begin{array}{r}\text { Increase } \\
P\end{array}$ & $\begin{array}{l}\text { previous } \\
\text { od. }\end{array}$ & Amount & $\begin{array}{r}\text { Increase } \\
\mathrm{P}\end{array}$ & $\begin{array}{l}\text { previous } \\
\text { od. }\end{array}$ \\
\hline & & Increase. & Per Cent. & & Increase. & Per Cent. \\
\hline & $£$ & & & $E$ & & \\
\hline 18.40 . & $2 \mathrm{I}$ & 一 & - & 26 & - & - \\
\hline '50. & $3^{6}$ & I 5 & 72 & 30 & 4 & I 6 \\
\hline '60. & 72 & $3^{6}$ & 100 & 80 & 50 & 165 \\
\hline '70. & $9^{2}$ & 20 & 28 & 90 & 10 & I $2 \frac{1}{2}$ \\
\hline '80. & $5^{2}$ & 60 & $6_{5}$ & 170 & 80 & 89 \\
\hline
\end{tabular}

And the increase in the imports for the whole period is nearly 700 per cent., and in the exports between 500 and 600 per cent. In proportion, therefore, there is a greater rate of progress in protectionist America than in free trade England, though, if we take the whole period, not so much greater an increase as to raise any presumption in favour of protection as being more likely to develop the foreign trade. I need hardly say, however, that in such a question the mere proportion of increase is not the proper test. The amounts are also material, and it cannot fail to be observed that the United States being a larger unit than the United Kingdom, had at the beginning, and still has, a smaller foreign trade. The whole imports are, in fact, $1_{50}$ million pounds only at present, as compared with 400 million pounds and upwards into the United Kingdom; and the whole exports are 170 million pounds, as compared with 223 million pounds of domestic produce exported from the United Kingdom; the latter 
figure, besides, as already explained, not including the invisible export in the shape of outlay for earning freight. The increase in imports again between 1840 and 1880 is 130 million pounds, as compared with an increase of 268 million pounds into the United Kingdom since 1854 only; while the increase of the exports between 1840 and 1880 is 144 million pounds, as compared with 17 I million pounds in the case of the United Kingdom, again remembering in the latter case that our invisible exports have increased so much, and are not reckoned in this calculation.

These figures, then, rather suggest, if anything, the superiority of a free trading to a protectionist régime. They are something for the protectionist to get over if he appeals to progress in imports and exports as a proof of the superiority of protection. No doubt in any complete discussion we should have to analyze minutely what the foreign trade in each case is composed of; while it would be fair to allow, I think, that the United States, from its geographical extent and the ancient development of its manufactures-for the eastern States are as much an old country as England-may have a smaller foreign trade in proportion than another country of less extent with large manufactures, or another country of large extent without manufactures. It is an empire within a ring fence, and the foreign trade of the British Empire, if that empire were made a customs union, would, as already stated, be less than the foreign trade of the United Kingdom now is, and certainly much less in proportion to the home trade. Sirll all these nice considerations are out of place in the mouths of protectionists, who have dwelt lately on the wonderful progress of the American foreign trade. The figures, in the way they use them, turn against themselves.

Coming to the French figures, I have to submit a similar table, beginning, however, in I 850 only, as there are only official values in 1840 : 
General Imports into France, and Exports of Domestic Produce.

[In millions.]

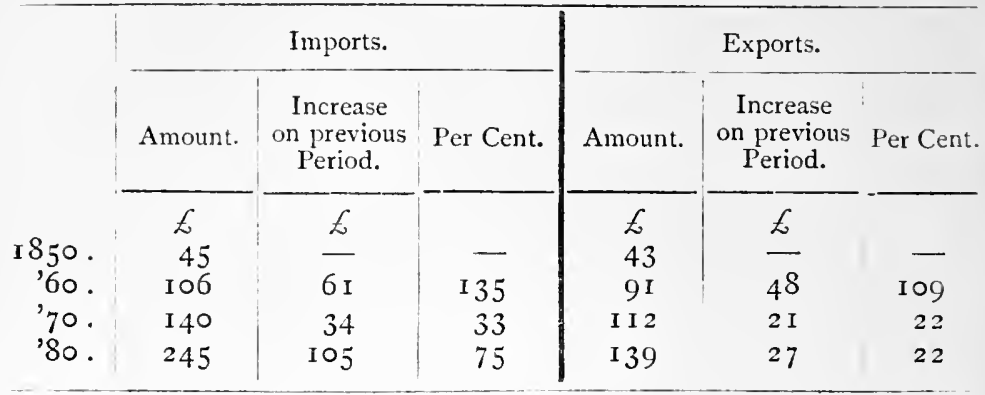

Here again the rate of growth is apparently as great as that of the United Kingdom, though an exact comparison is impossible, as we cannot go back to I 840 . The amount of trade and amount of growth, however, are, like those of the United States, much smaller than the amount and growth of our own trade, although France, like the United States, is a larger unit. In the imports the growth is 200 million pounds between I 850 and I 880 , as compared with 286 million pounds in the United Kingdom, between 1854 and I880, and in the exports it is 96 million pounds between 1850 and 1880 , as compared with I 5 I million pounds in the same period in the United Kingdom. There is nothing then in the French figures to make a case for the protectionist, while there is ground for claiming that between 1860 and 1880 France had made considerable steps in the direction of free trade, so that whatever progress had been made might be ascribed to free trade, and not to protection. There is no need, however, to press this point. France may be taken as a protectionist country. There is surely nothing in the figures to raise any doubt of our free trade regimc, always remembering, besides, our own invisible exports.

It is interesting to note, in passing, the great augmentation of French trade between 1850 and 1860 , a sign of the rise of prices I have already suggested in 
connection with the English figures for the same period. In France, however, the augmentation may partly be due to the more intimate connection which then took place between France and its neighbours on the different land frontiers, which must have been a powerful special cause, I believe, for the development of foreign trade among inter-continental countries.

To bring these figures to a point, it may be useful to look at a calculation per head of the population in each case:

Imports and Exports per Head of the Population in England, Franie, and the United States compared.

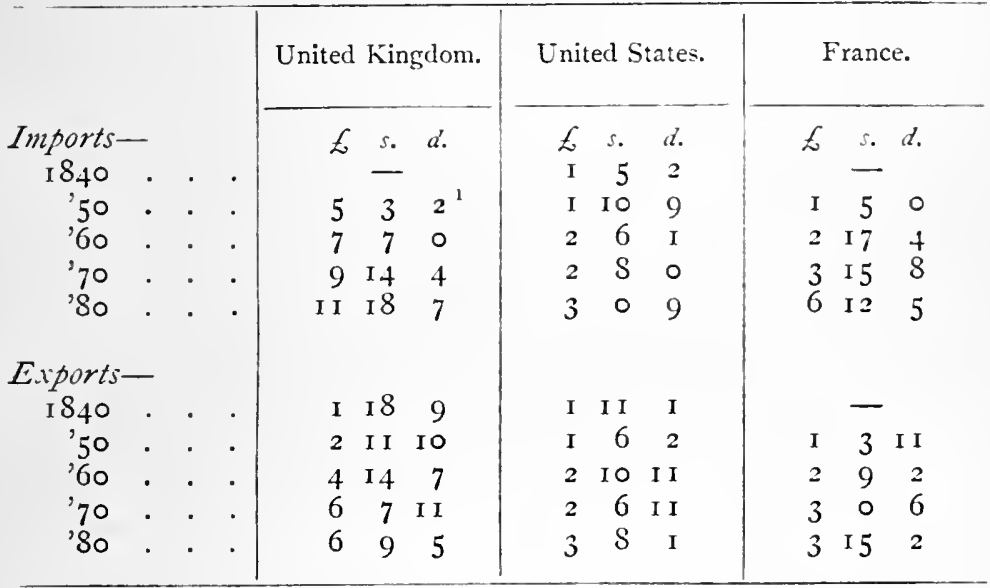

Thus our imports are still about four times per head those of the United States, and twice per head those of "France, and our exports are about twice those of either country, not counting, what I must always insist on, our invisible exports. The increase of our imports per head since i 850 is also double the whole of the present imports per head into the United States, and about equal to the present imports per head into France, and the increase of our exports since the same 
date is between 25 and 50 per cent. more than the total exports per head in either case. ${ }^{1}$

We may conclude, then, that not only has England made satisfactory progress in its foreign business under free trade, but the most prominent foreign countries have advanced less under protection. The onus of proof thus laid on the protectionist to show that we would have done better than we have done under protection, or that we shall do better in future with protection, appears to me overwhelming. There is no bearing up against it. Thus statistics, though they cannot logically prove the affirmative in the direct issue between free trade and protection, from the difficulty of finding exactly parallel cases and eliminating other causes, may be used to prove negatively that there is nothing in the apparent facts to help the protectionist. The presumptions are altogether against the latter.

\section{VIII.-Subject continucd: other uses of Import and Export Statistics. Conclusion.}

A third way in which statistics may be used in the argument is to show that protection does certain particular things which are obviously of an injurious tendency, while there is and can be no proof that the advantages of protection counterbalance these evils; and on the other hand that free trade effects certain ends which are obviously beneficial, which are additive to the welfare of a community, without any drawbacks. Facts of this nature corroborate the general theory of free trade, though they do not demonstrate completely and logically by themselves that the one regime is better than the other.

We may examine what a few of these facts are.

${ }^{1}$ For later figures as to English, French, and American foreign trade, I may refer to the Tables I laid before the Royal Commission on Trade Depression, and to the recent Board of Trade Blue-book Cd i 76i, Sess. i 903. 
Peoples adapt themselves quickly to any régime, and when a particular régime has been long established, it is difficult to see what its permanent effects are; but when changes are made, the nature of the influence may be perceived, and it is from such transition periods we get evidence for or against the one régime or the other.

To go back a long way, let me refer you to a comparatively old book, Sir Henry Parnell's "Financial Reform," published in I $83^{2}$. At pages 37-39 et seq. of the book, this author gives numerous instances of the effect of high duties in checking consumption - that is, in diverting trade and imposing various hardships on the community. He refers to tea, tobacco, wine, spirits, and other articles, in which an increase of taxes produced no more or little more revenue; and I shall quote as a specimen what he says of flint and plate glass :

"In I 8I 3 the duties on flint and plate glass were doubled. In four years to $18{ }_{13}$, the average annual quantity made for home consumption was 66,500 cwts. In the four years following I 8 I 3 , the annual average quantity was only $30,000 \mathrm{cw}$ ts. The duties on all other kinds of glass were doubled in the same year. The revenue received in the four years preceding I 8 I 3 was, on an average, $£ 340,000$; that received in the three years following i 8 I 3 was, on an average, $£ 395$, 000 , so that the doubling of the duties, instead of producing $£ 340,000$, produced only $£ 55$,000."

In the opposite sense Sir Henry Parnell then refers to aumerous remissions of high duties which produced increase of revenue, and I shall again only mention the case of flint glass, in which a reduction of duty, in 1825, from $98 s$. to $56 s$. per cwt., was followed by an increase of consumption from 30,000 to 47,000 cwts. annually. Sir Henry Parnell adds:

"The Committee of Finance state, in their fourth report on the revenue and expenditure, that if the revenue had fallen off in the five years from ${ }_{1} \$ 25$ to 
I 828 [sic] in the same proportion that taxes had been reduced, the diminution of it would have been 9 million pounds; but that, owing to increased consumption, it had only fallen off about one-third of that sum."

No doubt Sir Henry Parnell is speaking of high taxes generally, but the greater includes the less, and high tariffs of a protective character must have exactly the same or a worse effect in diverting industry and diminishing consumption as high taxes of a non-protective character. It is the tendency of the system which is exhibited in such instances as those given by Sir Henry Parnell. The book I refer to is comparatively forgotten nowadays, but it was famous once, and those who look into it will find it to deserve its reputation.

Another case of the effect of the large remission of duties at the period of transition is supplied by the experience of what occurred in this country in the first two years after the introduction of the free trade tariff of I 842 . Historically this experience had a great deal to do with the practically unanimous conversion of the country to free trade principles, but the striking nature of the facts statistically is still worth repeating. They are recorded for us in a little book of Mr. Gladstone's, not, I fear, very well known, entitled "Remarks upon Recent Commercial Legislation," published in $1845 .^{1}$ It would be hopeless for me to attempt to give a condensed account of this book, to which I can but refer you; but among the principal points I note, (I) that the calculated money loss of the reductions of the tariff in $I_{422-44}$ was $£ 5,142,000$, and that other duties were repealed or reduced, involving a money loss of $£ \mathrm{I}, \mathrm{r} 62,000$, making together a sum of $£ 6,304,000$, and that the free surplus of the income tax over and above what was required to supply actual deficiency was only $£ 2,62 \mathrm{I}, 000$. This was all that was really required, as the event proved, to balance remissions of taxation amounting to $£ 6,304,000$ (pp. 12 and $\mathrm{r} 3$ ). (2) The

'London: John Murray, I 845. Third edition. 
mean estimated loss from remissions of duties on raw material mainly was $£ \mathrm{I}, 452,000$, and the actual loss in the first year after the tariff Act was about this sum; but this first year was a year of great depression, and the actual loss in the second year was $£ \mathrm{I}, \mathrm{I} 33,000$ only, showing a recovery in that year of $£ 325$,000 on a total of about 3 millions only (pp. 27 and 28). (3) The net loss of revenue from a great remission of the timber duties, while it was greater in the first year by f I I 4,000 than Sir Robert Peel had estimated, was less in the second year than he had estimated by no less a sum than $£ \mathrm{I} 93,000$, showing a great recovery in the trade (pp. 36 and 37 ); and (4) the predictions of injury to our manufactures and other industries by exposing them to foreign competition-there was quite as much talk of foreign competition then as there is now-were ludicrously falsified in the case of cork-cutting, candlemaking, vinegar-making, and other industries (pp. 49 et seq.). In all these matters a free trade tariff had apparently done what it was expected to do, and had contributed to swell the volume of national trade. As I have said, I am by no means condensing the volume, which is itself in a highly condensed form, but only pointing it out as a mine of information on the proposition that the change from a protective to a free trade régine appears to stimulate trade, from which we infer that the stimulus continues to operate afterwards, though it becomes impossible, from change of circumstances, to compare in a strictly logical manner a freetrading and a protectionist régime.

A third source of information to which reference cannot be too often made is Mr. Wells's valuable reports as commissioner of internal revenue in the United States. These are so well known that I may refer to them very briefly only. We hear a great deal of the growth of certain manufactures in the United States which have been protected, but these reports show clearly the reverse of the medal-the injury to other industries incidental to these changes. 'Thus the first 
report for I 866 dwells largely on the injury to the woollen manufacture by the protective tariff on wool designed to protect the growth of raw wool. Then in the report for I 869 we have many such statements as this about boots and shoes, viz., that the export value declined from $1,329,000$ dollars in 1863 to 682,000 in I 867 , and 475,000 dollars in I 869. Lastly, there is the well-known story of the decline in the American shipping trade, and the great increase in the amount of the foreign trade of the United States itself, carried on in foreign ships. Mr. Wells gives a table at p. 30 of the report for $\mathrm{i} 867$, showing even then the preponderance of foreign vessels in the carrying trade of the United States, and calculating the amount which the United States has to pay to foreigners in consequence, the opposite of the calculations I have submitted to you to-night as to what this country has to receive. These are all instances of loss arising through protectionist measures, and they should be remembered, as being undoubtedly in operation as a check to industry, though we cannot well see the effects from day to day, when a country has adapted itself to a protectionist régime. What they prove is, that protection does not add to the industry of a country, but that it only diverts the industry at a great expense at the time and presumably at a continuous expense. The loss is certain and the gain entirely problematical, however much it may be proved that certain special industries have been fostered by protection.

As there are many later figures about American shipping since the date of Mr. Wells's report in I 869, and there is still a vague impression that it was the "Alabama" which diverted shipping business from the United States, I may be allowed to notice briefly these later figures, and see how far the impression as to the "Alabama" is confirmed. The first set of figures shows the increasing preponderance of foreign vessels in the American carrying trade. For the years ended 30 th June, r87 I-80, we get the following figures: 
Table showing American Imports and Exports Carried in American and Foreign Vessels respectively.

[In millions of dollars.]

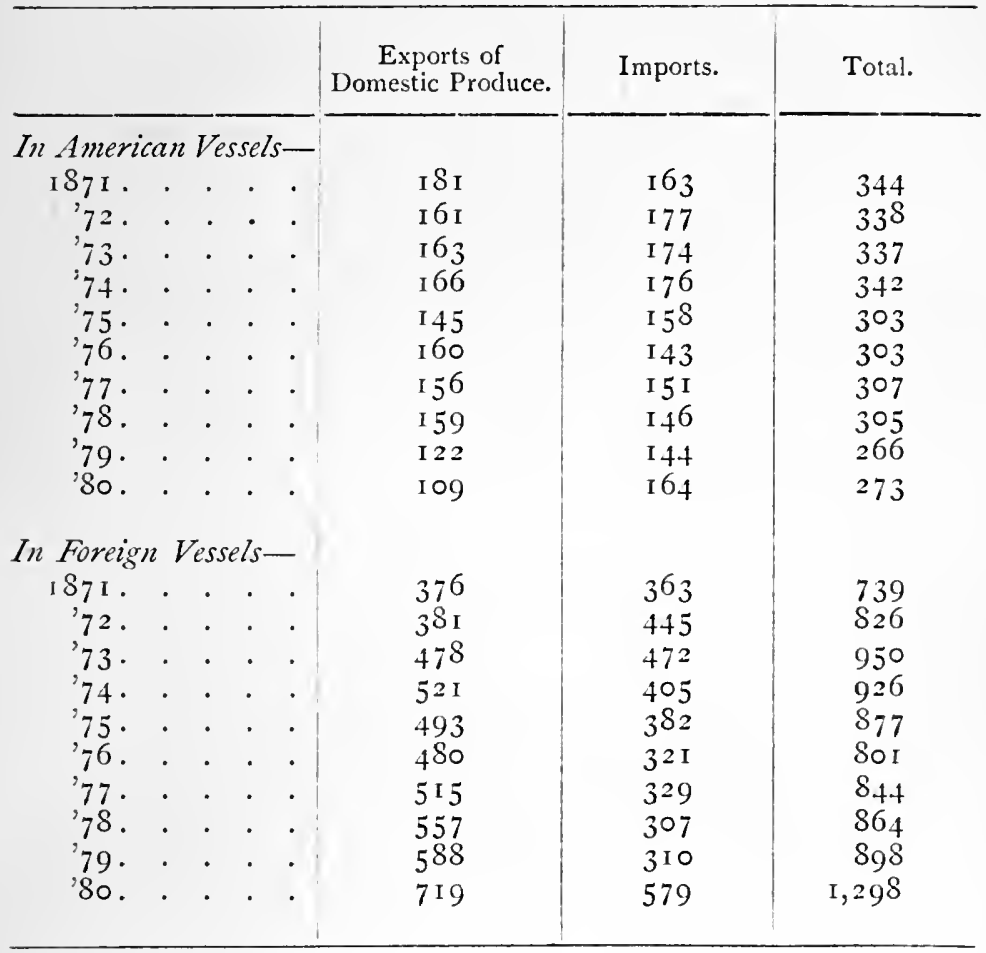

A table like this speaks for itself. While the amount of American trade carried in foreign vessels increases in ten years from 739 million to 1,298 million dollars, or more than 70 per cent., the amount carried in American diminishes from 344 to 273 million dollars. The American share, which is nearly half the foreign at the beginning of the period, is at the close just about a fifth of the foreign.

The second set of figures relates to American shipbuilding. I give the figures for twenty years, covering the whole of the "Alabama" period. They are as follows: 
Tonnage of Vessels Annually Built in the United States in the Years i 860-80.

\begin{tabular}{|c|c|c|c|c|c|c|c|}
\hline & & & [In thousa & of tons.] & & & \\
\hline Year. & & & $\begin{array}{l}\text { Thousand } \\
\text { Tons. }\end{array}$ & Year. & & & $\begin{array}{c}\text { Thousand } \\
\text { Tons. }\end{array}$ \\
\hline I 860 & . & & . $\quad 213$ & $187 \mathrm{I}$ & . & . & . $\quad 273$ \\
\hline '6I & • & • & 233 & '72 & . & . & 209 \\
\hline '62 & • & • & 175 & 73 & . & . & 359 \\
\hline '63 & . & . & 310 & '74 & . & . & $43^{2}$ \\
\hline 64 & • & . & 415 & 75 & - & - & 297 \\
\hline$' 65$ & - & . & $3^{8} 3$ & 76 & . & . & 203 \\
\hline ' 66 & . & . & $33^{6}$ & '77 & . & . & 176 \\
\hline '67 & . & . & $3 \circ 3$ & 78 & - & . & 235 \\
\hline '68 & . & . & . 285 & '79 & . & . & 193 \\
\hline '69 & . & . & 275 & '80 & . & . & I 57 \\
\hline '70 & $\cdot$ & & . 276 & & & & \\
\hline
\end{tabular}

What this table shows, I think, is, that American ship-building did not fall off till after the war. From I $86_{3}$, the third year of the war, down to and inclusive of 1871 , the ship-building is larger than in 1860 and I 86 I, and not much short, I may state, of the figures in the previous decade, which was one of great prosperity in American shipping. As late again as 1873 and 1874 the building is considerable. I think we may infer from this that down to a very recent period even American ship-building and ship-owning had a sufficient basis for its development, if that development had not been checked by external causes. The effects of the "Alabama" would in fact have been very speedily recovered from but for other causes. Probably, indeed, the operation of the civil war was not so unfavourable as it seemed. If ship-building for private individuals was checked, there was a great demand for Government ships, and miscellaneous vessels of all kinds, and at the close of the war there was nothing to prevent American ship-builders and ship-owners from recovering some of the ground they had lost. It may perhaps be doubted whether even with a free trade tariff in America the results would not have been the same as they have been. There were natural causes, I believe, 
operating in favour of the extension of the industry in British hands. But that the American tariff made impossible the extension of American ship-building, which would otherwise have been difficult only, is beyond doubt.

Last of all, coming to more recent times, the experience of the high tariff in Germany may be referred to as proving that those particular evils happen which free traders predict from such a tariff as Germany has established, viz., a high price of food, the deterioration of the position of the labourer, and a general malaise. On this head I need do no more than mention the well-known paper containing extracts from reports of the German Chambers of Commerce respecting the new tariff and its effects, lately presented to Parliament by the Board of Trade. ${ }^{1}$ The reports summarized in that paper do not contain many figures, but the statements are distinctly quantitative, and when a sufficient time has elapsed we shall no doubt have the statistics.

Thus in many ways statistics can be used to show that the tendencies of free trade and protection are what they are said by free traders to be-the former additive to the material prosperity of a country, the latter subtractive, in some of their effects at least, so that no proof can be given of their being on balance beneficial. The quantity of evidence of this sort is overwhelming-I have only given a few instances. If we keep in mind the exact logical value of this evidence, it is destructive, I believe, of the protectionist case, as far as the appeal to statistics is concerned. In the absence of direct comparisons between free trade and protectionist regimes, which is a circumstance entirely against the protectionist, all the indirect evidence of tendencies exhibited at transition periods is in favour of the free trader.

A fourth way in which statistics may help in this controversy is by demonstrating the confusion of ideas 
which one always finds to be of the essence of a fair trade argument. The difficulty in dealing with these arguments is the difficulty of understanding them only, of trying to form a conception of what is in the mind of your opponent. We are told at one time that our foreign trade is falling off enormously, the alleged proof being that the exports of domestic produce have declined in value; while the obvious fact, apart from statistics, is the preponderance of English foreign trade in the business of the world, so that if the figures apparently showed the contrary, that would be no reason for arriving at a conclusion with which other facts would not fit in, but a reason only for studying and inquiring into the figures themselves, and seeing what they really meant, when properly rectified. We are told at another time that imports of manufactured articles into the United Kingdom are increasing, leading to the decay of manufacturing at home; the fact being, as distinguished from what some statistics may show or appear to show, that there never was more manufacturing than there is in England at the present time, of which the obvious proof is the rapid increase of the population in recent years, and the fact that pauperism has been stationary or declining. If any statistics therefore appear to show the contrary, that is only a reason for studying the statistics with all the collateral aids possible, not for blindly rushing at a conclusion with which nothing else will agree. Similarly we have had the excess of imports in a country dealt with as a proof that the country is running into debt; the excess of exports of other countries used as a proof that they are prosperous, these countries being also assumed not only to be protectionist, but to owe their great exports to protection, and so forth; the real facts as to whether one country is running into debt and another gaining not being otherwise inquired into. The peculiarity of most such ideas is, that even if true they do not help the protectionist argument, which is of such a kind, as we have seen, that it cannot be 
helped by statistics; but the so-called arguments and statements are themselves misleading and unintelligible. Now one supreme use of the study of statistics, including import and export statistics, which is our special subject to-night, is to clear up all this confusion; to introduce true ideas where there are strictly no ideas at all-no picture of what is really going on in the world; and in this way to purge the mind of any tendencies to protectionist heresy. The mind capable of thinking about economic questions from a statistical point of view, and forming a true picture of the facts of the business world, would not, I maintain, be liable to the influence of protectionist ideas. It is not amongleading business men in the City, or men conversant with great business affairs anywhere, with the single exception perhaps of Prince Bismarck, that you find these confused notions, which are the congenial soil of protectionist heresy.

How statistics help in these matters has already been set forth, I hope, to some extent, by the discussion of the excess of imports controversy, and by reference to many special points. But a few more remarks may be permitted to illustrate the extreme confusion of ideas which require to be cleared up. To come back to the excess of imports controversy; even if the excess of imports meant what it is assumed to mean, it would not help the protectionist, but the real facts are wholly different from the apparent ones, and any true study of the subject gives quite a different idea of the business activity of England from the careless one. Our exports of British produce being nominally 223 million pounds, of which about 60 million pounds is raw material previously imported, the real export of the produce of British capital and labour shown in the so-called exports is thus about 160 million pounds only. We have found, however, on investigating the facts, that our unrecorded exports, in the shape of freights carried and other charges on the conveyance of goods, apart altogether from interest on investments abroad, amount to 
about 80 million pounds-about half the real amount of our recorded exports of British produce-so that without having some view of these unrecorded exports, we have no true idea of English trade. Without taking the unrecorded figures into account, we should err in our appreciation of the actual fact of England's business activity by 30 per cent. or more. It is not that the statistics-the figures themselves-are wrong. They merely require study and careful interpretation to get at the facts which underlie the statistics.

Another illustration of how the true study of statistics clears up false conceptions is supplied by the confutation of many historical arguments which have recently been used by fair traders. Not long ago an evening journal of the very highest literary reputation admitted into its columns a series of letters comparing the relative progress of English trade at different dates during the last two centuries, in which not the slightest reference was made to the fact that we have no good statistics of aggregate imports before 1854 , and no declared values of exports before 1820 , so that all comparisons before these dates, or between facts before and facts after these dates, are most difficult. The true study of statistics of course shows the necessary limitations of any such comparisons. I do not say it would be quite impossible to go back farther to some good purpose. It is quite likely that a careful student, with a good record of prices in his hand, willing to take the trouble to compare this record with the official valuations from time to time, and to attend to the relative magnitude of the chief articles of trade, might arrive at results which would throw a great deal of light on the economic history of the last two centuries. But for the present the confused notion that our recent progress under free trade has been less than in former periods before free trade, which was the conclusion or apparent conclusion of the remarkable letters I have referred to, must be dismissed as a mere wild notion which cannot be known to have any relation to actual facts. The range of our 
genuine knowledge in these matters is much more limited than such discussions assume.

Another illustration of how true ideas may be substituted for false is supplied by the discussion in Sir T. Farrer's recent pamphlet issued by the Cobden Club, on "Free Trade $\approx$. Fair Trade." A great deal of this pamphlet is taken up with the refutation of the idea that our trade with the colonies is specially beneficial, or tends to increase more than our trade with foreign countries. For myself, I cannot see how the idea which Sir T. Farrer refutes tends to support the protectionist argument. It rather seems to prove that as the colonies are less protectionist than foreign countries, their relative free trade is only a sign that if they were more free trading the better for us. But Sir T. Farrer's demonstration that there are "colonies " and "colonies," and that there have been great fluctuations in the amount of trade and its proportion to our whole trade which we have done with them in different periods, is conclusive as to there being nothing in the protectionist notion of the special value of colonial trade. Perhaps I may add that a reference to one of the tables which I have given to you to-night, viz., that showing the issues of public loans and companies on the London Stock Exchange on foreign account in the last six years, throws some light on the momentarily greater development of our trade with the colonies as compared with our trade with foreign countries. This list comprises a very large proportion of colonial issues, a much larger proportion than the previous six years, before the foreign loans collapse, would have shown. The truth is, I should say, our exports to the colonies lately have kept on increasing because their credit was never impaired, while our exports to many foreign countries fell off because we ceased to lend to them. At any rate the point seems worth investigating before drawing absolute conclusions.

Yet one more remark on this head. Sir T. Farrer shows conclusively enough that colonies are of different 
sorts, and they are not to be grouped together, nor are all foreign countries to be grouped together. This reminds me of a different grouping of countries, which some of you may remember, by a gentleman, Mr. Ernest Seyd, who was one of us, and for whom we all had the highest respect, though few of us agreed with his conclusions or methods. Mr. Seyd grouped countries into those having the gold standard, and those having the silver standard, and found, or believed he had found, that it was with countries having the gold standard our trade had progressed most, while with countries having the silver standard it had tended to decline. I do not know whether if Mr. Seyd had lived and observed the very last advance in the trade with India he would have adhered to his view, but his division was at least quite as logical as the division into colonies and foreign countries which has lately. been made.

The conclusion is that such rough groupings and the facts apparently shown are not to be relied upon, and do not yield true ideas in a statistical view. The inquirer in this as in other matters must try many methods, and must not conclude that the apparent look of the figures corresponds to facts. A true history of the recent course of the foreign trade of the principal nations of the world would lay stress upon many things besides the division of nations into British colonies and foreign countries, or into gold standard and silver standard countries. The progress of invention; the growth of shipping in one country, and its decline in another; the settlement of new countries, and the like facts, would all have a place, and perhaps a larger place, than the points which protectionists and fair traders, or enthusiasts like Mr. Seyd, who concentrate their attention on one subject only, take up. I need not, however, multiply illustrations, especially as the whole course of the argument to-night has been to substitute, as I hope, true ideas for false ones, on many points. 
In various ways, then, we conclude that a use can be made of statistics of imports and exports in the discussion between free traders and protectionists. The fact that such statistics cannot be used in the direct argument as to which régime is most favourable to material progress is against the protectionist, who calls for Government interference, and must thus prove his case, while the free trader is passive. The statistics at the same time supply ample proof prima facie that there is nothing in the apparent figures of imports and exports to supply a case against free trade. Next, they can also be used to prove that at the period of transition from one régime to another, the tendency of free trade measures is to add to the prosperity of a country, while no such tendency can be proved of protectionist measures. Finally, they help to prove the utter confusion of ideas which is found to be the most fitting soil for the growth of the protectionist idea itself. Without then making more of statistics than can really be made of them, we can affirm that they are most useful in these controversies. They are, however, useful in proportion only as we observe their necessary limitations. If the example of protectionists is imitated by free traders, and the first figures that come to hand are shied at opponents on the principle that any stick is good enough to beat a dog with, I am not sure that figures will help the free trader much. The public will simply be puzzled, and induced more than ever to believe that there is nothing at all in statistics.

\section{IX.-Conchusion.}

I have now to return to the point from which I started. My complaint at the beginning was of the wrong use of statistics, and the neglect of the conditions upon which alone they can be rightly used. If I have made out a case at all, it is that even import and export figures, which are so familiar to many, cannot be handled with facility; that there is a world of 
knowledge to be learnt concerning them; and that in all directions sound and diligent study must precede any good use of them; but that if there is such a study of statistics, useful and valuable conclusions can be arrived at with certainty. My suggestion, then, would be that there is need, not only for the members of this Society to redouble their exertions in the way of diffusing a knowledge of statistical methods, but for some improvements in our system of education, in which there is hardly any visible place given to statistics. There are many chairs of political economy in this country, but no chair of statistics that I know of, and very few, if any, of the political economy chairs, where the teaching of statistics forms part of the course. Some remedy surely ought to be applied to this defect. As regards political economy, it is quite certain that any study of that science in its applications is impossible without statistics. A theoretical teacher may trace out tendencies or forces on paper, but in the real world quantities must be dealt with; and in the measurement of tendencies or forces statistics are absolutely needed. It is easy to prove theoretically, for instance, that a protectionist tariff does harm, but it is a different thing in the real world to give any notion of how much harm is done, and when the protection is slight in proportion to the whole business of a country to measure the effect at all. How to deal with such questions is the problem for the economist who is also a statistician, and they are much more difficult and complex than those belonging to theoretical or deductive political economy. The time has come then, it seems to me, when the public have a right to expect that in our universities statistics should have some recognized place as well as political economy. If the facts of the business world, as it is constituted at present, were taught statistically, and some notion given of the sources of information and of how they could be rightly used, much of the recent discussion between free traders and protectionists would probably have been saved: 
most educated men would have seen at once when propositions were stated which were incapable of statistical proof, and when figures were used without any study or appreciation of the facts underlying them. The protectionist or fair trader would have been summarily laughed out of court, instead of being supposed for a time to have had so much of a case that party politicians on one side thought fit to give him some encouragement, and party politicians on the other side were a little apprehensive of the result. The study of statistics should undoubtedly form a necessary part of liberal education, especially of those who aspire to be politicians or public men.

NoTE.-In 1899 I read a paper at the Statistical Society on "The Excess of Imports," in which the figures on that part of the subject are continued and a new estimate is made of the earnings of our shipping fleet. The paper will be found in the "Journal " of the Statistical Society for March, 1899 . See also the recent Board of Trade Blucbook in connection with the fiscal controversy, $\mathrm{Cd}$ I $76 \mathrm{r}$. 
THE PROGRESS OF THE WORKING CLASSES IN THE LAST HALF CENTURY. ${ }^{1}$

I $\mathrm{N}$ assembling for the labours of another session, our first duty, as it was a year ago, is to commemorate the heavy loss which the Society has sustained by death. On the last occasion the names before us were those of Mr. Newmarch and Mr. Jevons, identified for many years with our work, and intimately known to many of us. On the present occasion the loss to be recorded is of another co-worker equally distinguished, though in a different way, and perhaps possessing a more exclusively statistical reputation-Dr. Farr. The "Journal" of the Society already contains a record of our sense of loss, but a few words more may surely be permitted here-in memory of one who was present year after year, not only at our inaugural meetings, but at almost all the ordinary meetings as well: who, throughout a long career, contributed numerous and valuable papers to our discussions, the interval between his first and last paper read at our meetings being over thirty years; who in the fulness of time, and certainly not before he deserved the distinction, presided over us for the usual period; and who, in fact, deserves credit as one of the makers and promoters of this Society, and of the study which we cultivate, in the most literal sense of the words. It is a very great loss we have sustained. Happily in Dr. Farr's case we have not to lament the premature shortening of days which we had to lament in referring to the loss of Mr. Newmarch and Mr. Jevons. Dr. Farr had reached

1 Inaugural address as President of the Statistical Society. Delivered 20 th Norember, 1883. 
the limit of a tolerably long life, and, till within a very few years of the close, had been able to take an active part in the studies to which he was devoted. There are at least two remarkable monuments of his later labours, the special report to the Registrar-General on the mortality of the I86I-7 I decade, which was completed only seven or eight years ago, and his paper on the mode of estimating the value of stocks having a deferred dividend, read at one of our meetings in King's College in the year 1876 , after Dr. Farr had served his term as President of the Society. We can only lament Dr. Farr's loss, therefore, as the common lot of humanity, and though we could have wished a longer life and greater service, we may rejoice that the life was not incomplete, and that Dr. Farr had time to perfect his best work. What he has left is a noble monument of industry and ingenuity, full of example to all of us who have devoted time and strength to statistics, and he is certain to be honoured, we may be sure, by future generations even more than he has been by the present. To have organized, as he did, the official records of vital statistics on a model which has been widely followed not only here but abroad, and which has done much even already to promote the health and welfare of mankind, by revealing and making evident to all some main causes of disease and mortality, is a great work for one man to have done. Politicians and members of Parliament, who are ready enough to use whatever figures come to hand as implements of political warfare, but who seldom study them, may not have been able to recognize the work as the public did; but the work remains, and we, at any rate, as members of the Statistical Society, are all proud of it.

I am sorry to have to add that after this address was prepared, the announcement appeared in the newspapers of the death of Lord Overstone, who was also one of the founders of this Society, and one of its most active promoters in its earlier years, and who was President in the years $1851-53$. Lord Overstone has long 
survived the limit of the active period of life, and as we have been reminded within the last day or two, the public have very largely forgotten the services which he rendered; but in this Society there is enough knowledge and enough interest in the economic pursuits to which Lord Overstone devoted himself, for many of us here really to possess some acquaintance with what he accomplished.

There can be no doubt that in the evidence which he gave before several Committees of the House of Commons, and in the opinions which he expressed privately to Cabinet ministers and public men on economic and more especially financial matters, upon which he was frequently consulted, Lord Overstone was able to render eminent services to the country. As a preacher of the doctrine of "hard money" he did much to settle the basis of the national currency in a difficult time, and that in a way which has left no room for change, and which has thus done not a little to steady the business of the country. There is no doubt also that it was in his capacity as a statistician very largely that he was able to render these services. He was pre-eminently one of those men who were extremely practical and careful about the facts upon which they gave their opinions. We may thus claim Lord Overstone as one of our distinguished members. I may add that of the original members of the Society there are now very few surviving. We have others surviving, as I shall notice presently, who were members almost from the beginning, but I am speaking now literally of our formal beginning. Amongst those who will be known to you, I think, Mr. Heywood and Mr. Edwin Chadwick are to be mentioned as among the very distinguished members who were at the foundation of the Society, and who still survive to take an interest in our labours.

The mention of the names of Lord Overstone and Dr. Farr carries us back naturally enough to the origin 
of the Society. IVe are carried back to the same date by an impending event which now casts its shadow before-our approaching jubilee, which we may hope will be worthily celebrated. It is of good augury, I trust, that we commence our fiftieth session with the election of no fewer than fifty-eight new members. It seems fairly probable now that when we complete our fiftieth year we shall have the round number of one thousand members-a wonderful improvement upon the small number of fifty years ago. On such an occasion I believe the subject on which I propose to address you to-night will be not unsuitable - a review of the official statistics bearing on the progress of the working classes-the masses of the nation-in the last half century. If you go back to the early records of the Society, you will find that one of the leading objects of its founders was to obtain means by which to study the very question I have selected. Happily we have still with us, in addition to those I have named as original members, one or two honoured members associated with the early history of the Society-Dr. Guy and Sir Rawson Rawson-who will bear me out in what I have stated. I may remind you, moreover, that one of the founders of the Society was Mr. Porter, of the Board of Trade, whose special study for years was much the same, as his well-known book, "The Progress of the Nation," bears witness; and that in one of the earliest publications of the Society, a volume preceding the regular issue of the "Journal," he has left a most interesting account of what he hoped might be effected by means of statistics in studying the subject I have put before you, or the more general subject of the "Progress of the Nation." In asking you, therefore, to look for a little at what statistics tell us of the progress of the great masses of the nation, I feel that I an selecting a subject which is connected with the special history of the Society. That it happens for the moment to be attracting a considerable amount of popular attention in connection with sensational politics

I.

$\mathrm{C} \mathrm{C}$ 
and sociology, with agitations for land nationalization and collectivism among pretended representatives of the working classes, is an additional reason for our not neglecting this question; but it is a question to which the Society has a primary claim, and which the authors of the agitations I have referred to would have done well to study from the statistical point of view.

There are two or three ways in which statistics may throw light on such a question as I have put forward. The first and most direct is to see what records there are of the money earnings of the masses now and fifty years ago, ascertain whether they have increased or diminished, and then compare them with the rise or fall in the prices of the chief articles which the masses consume. Even such records would not give a complete answer. It is conceivable, for instance, that while earning more money, and being able to spend it to more advantage, the working classes might be no better off than formerly. There may be masses, as there are individuals, who do not know how to spend. The question of means, however, will carry us some distance on the road to our object. We shall know that the masses must be better off, unless they have deteriorated in the art of spending, a subject of separate inquiry.

In investigating such records, however, we have to recognize that the ideal mode of answering the question is not yet possible. That mode would be to draw up an account of the aggregate annual earnings of the working classes for a period about fifty years ago, and a similar account of the aggregate annual earnings of the same classes at the present time, and then compare the average per head and per family at the different dates. Having thus ascertained the increase or diminution in the amount per head at the different dates, it would be comparatively easy, though not in itself quite so easy a matter as it seems, to ascertain how much less or how much more the increased or diminished sum would buy of the chief articles of the workman's 
consumption. But no such account that I know of has been drawn up, except for a date about fifteen or sixteen years ago, when Mr. Dudley Baxter and Professor Leone Levi both drew up statements of enormous value as to aggregate earnings, statements which it would now be most desirable to compare with similar statements for the present time, if we could have them, and which will be simply invaluable to future generations. In the absence of such statements, all that can be done is to compare what appear to be the average wages of large groups of the working classes. If it is found that the changes in the money wages of such groups are in the same direction, or almost all in the same direction, then there would be sufficient reason for believing that similar changes had occurred throughout the entire mass. It would be in the highest degree improbable that precisely those changes which could not be traced were in the opposite direction. The difficulty in the way is that in a period of fifty years in a country like England the character of the work itself changes. The people who have the same names at different times are not necessarily doing the same work. Some forms of work pass wholly away and wholly new forms come into existence. Making all allowances, however, and selecting the best comparative cases possible, some useful conclusion seems obtainable.

What I propose to do first and mainly, as regards this point, is to make use of an independent official record which we have to thank Mr. Porter for commencing. I mean the record of wages, which has been maintained for many years in the miscellaneous statistics of the United Kingdom, and which was previously commenced and carried on in the volumes of Revenue and Population Tables which Mr. Porter introduced at the Board of Trade about fifty years ago. It is curious on looking back through these volumes to find how difficult it is to get a continuous record. The wages in one volume are for certain districts and trades; in a subsequent volume for different districts and trades; 
the descriptive classifications of the workers are also constantly changing. Picking my way through the figures, however, I have to submit the following particulars of changes in money wages, between a period forty to fifty years ago-it is not possible to get the same year in all cases to start from-and a period about two years ago, which may be taken as the present time. This comparison leaves out of account the length of hours of work, which is a material point I shall notice presently.

Comparison of Wages Fifty Years ago and at Present Time.

[From "Miscellaneous Statistics of the United Kingdom," and Porter's "Progress of the Nation."]

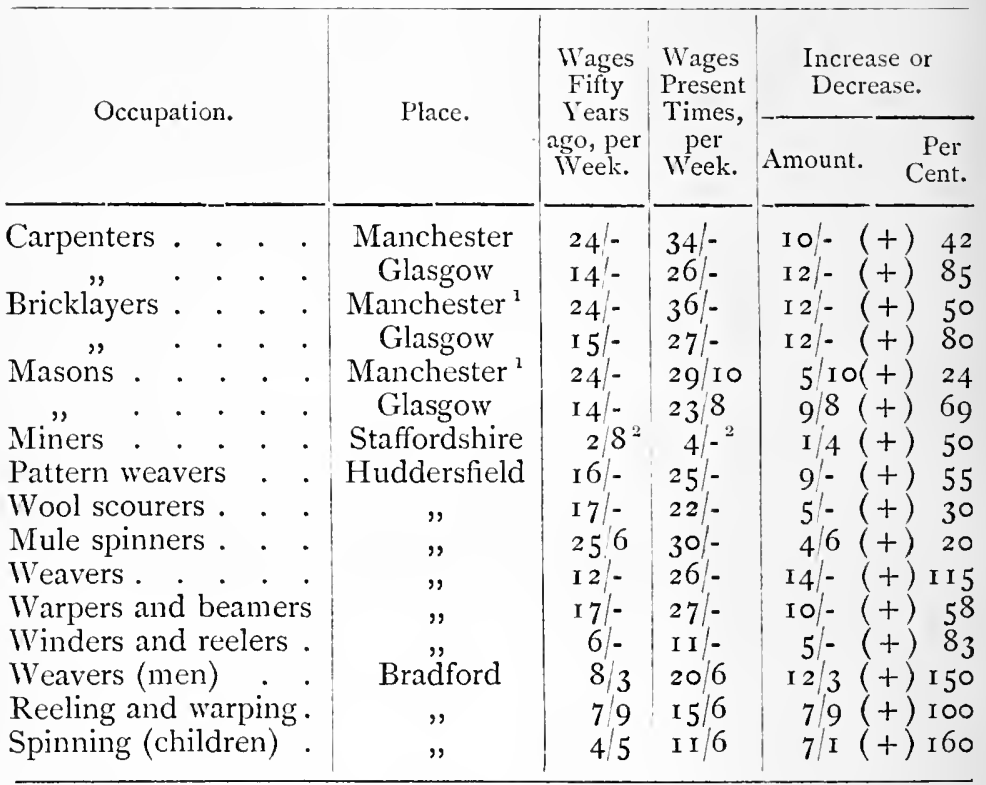

Thus in all cases where I have found it possible from the apparent similarity of the work to make a comparison there is an enormous apparent rise in money wages ranging from 20 and in most cases from 50 to IOO per cent., and in one or two instances more than Ioo per cent. ${ }^{3}$ This understates, I believe, the real
${ }^{1} 1825$.
${ }^{2}$ Wages per day.
${ }^{3}$ The mean of the percentages of increase is over 70 . 
extent of the change. Thus, builders' wages are given at the earlier date as so much weekly, whereas in the later returns a distinction is made between summer and winter wages, the hours of labour being less in winter, and as the wages are so much per hour, the week's wages being also less, so that it has been possible to strike a mean for the later period, while it does not appear that anything more is meant at the early period than the usual weekly wage, which would be the summer wage. Without making this point, however, it is obvious that in all cases there is a very great rise.

Before passing from this point, there is another and continuous official record I would refer to. Unfortunately it does not go back for much more than thirty years. Still, as far as it goes, the evidence is in the same direction. I refer to the return of merchant seamen's wages annually issued by the Board of Trade, in what is known as the Progress of Merchant Shipping Return. From this Return may be derived the following comparison of seamen's wages:

\section{Comparison of Seamen's Money Wages per Month at $\mathrm{I} 850$ and the Present Time.}

[From the "Progress of Merchant Shipping Return."]

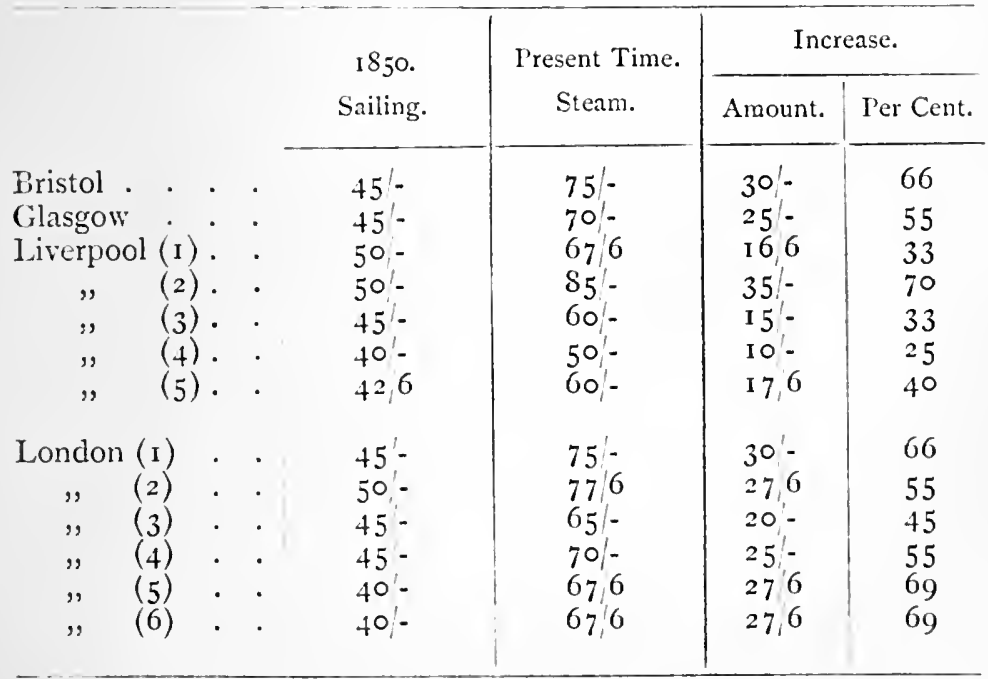


Here again there is an enormous rise in money wages. This return is specially subject to the observation that money wages are only part of the wages of seamen, but I assume it is not open to dispute, that with the improvement in our shipping there has been an improvement in the food and lodging of the sailor, quite equal to the improvement in his money wage.

This question of seamen's wages, however, well illustrates the difficulty of the whole subject. Ships are not now navigated by able seamen so much as by engineers and stokers. It would seem that as a class the new men all round are paid better than the able seamen, but I should not press this point; it might well be the case that steam ships as a whole could be worked by an inferior class of labourers as compared with sailing-ships, and yet the fact that inferior labour is sufficient for this special trade would be quite consistent with the fact that the whole conditions of modern labour require more skill than the conditions fifty years ago, so that there is more labour relatively at the higher rates than used to be the case.

The comparison, except for seamen's wages, where it has only been possible to go back for about thirty years, is made between a period about fifty years ago and the present time only. It would have complicated the figures too much to introduce intermediate dates. I may state, however, that I have not been inattentive to this point, and that if we had commenced about twenty to twenty-five years ago, we should also have been able to show a very great improvement since that time, while at that date also, as compared with an earlier period, a great improvement would have been apparent. A careful and exhaustive investigation of the records of wages I have referred to, in comparison with the numbers employed in different occupations, as shown by the census reports, would in fact repay the student who has time to make it; and I trust the investigation will yet be made.

The records do not include anything relating to the 
agricultural labourer, but from independent sourcesI would refer especially to the Reports of the recent Royal Agricultural Commission-we may perceive how universal the rise in the wages of agricultural labourers has been, and how universal at any rate is the complaint that more money is paid for less work. Sir James Caird, in his "Landed Interest" (p. 65), put the rise at 60 per cent. as compared with the period just before the Repeal of the Corn Laws, and there is much other evidence to the same effect. The rise in the remuneration of labour in Ireland in the last forty years is also one of the facts which have been conspicuously brought before the public of late. In no other way is it possible to account for the stationariness of rents in Ireland for a long period, notwithstanding the great rise in the prices of the cattle and dairy products which Ireland produces, and which, it has been contended, would have justified a rise of rents. The farmer and the labourer together have in fact had all the benefit of the rise in agricultural prices.

The next point to which attention must be drawn is the shortening of the hours of labour which has taken place. While the money wages have increased, as we have seen, the hours of labour have diminished. It is difficult to estimate what the extent of this diminution has been, but collecting one or two scattered notices I should be inclined to say very nearly 20 per cent. There has been at least this reduction in the textile, engineering, and house-building trades. The workman gets from 50 to 100 per cent more money, for 20 per cent. less work; in round figures, he has gained from 70 to 20 per cent. in fifty years in money return. It is just possible of course that the workman may do as much or nearly as much in the shorter period as he did in his longer hours. Still there is the positive gain in his being less time at his task, which many of the classes still tugging lengthily day by day at the oar would appreciate. The workman may have been wise or unwise in setting much store by shorter hours in 
bettering himself, but the shortening of the hours of labour is undoubtedly to be counted to the good as well as the larger money return he obtains.

We come then to the question of what the changes have been in the prices of the chief articles of the workman's consumption. It is important, to begin with, that, as regards prices of commodities generally, there seems to be little doubt things are much the same as they were forty or fifty years ago. This is the general effect of the inquiries which have been made first as to the depreciation of gold consequent on the Australian and Californian gold discoveries, and next as to the appreciation of gold which has taken place within the last twenty years, consequent on the new demands for gold which have arisen, and the falling off in the supply as compared with the period between 1850 and 1860. It would burden us too much to go into these inquiries on an occasion like the present, and therefore I only take the broad result. This is that while there was a moderate rise of prices all round between the years i $847-50$, just before the new gold came on the market, and the year I 862, when Mr. Jevons published his celebrated essay, a rise not exceeding about 20 per cent., yet within the last twenty years this rise has disappeared, and prices are back to the level, or nearly to the level, of i $847-50$. The conclusion is that, taking things in the mass, the sovereign goes as far as it did forty or fifty years ago, while there are many new things in existence at a low price which could not then have been bought at all. If, in the interval, the average money earnings of the working classes have risen between 50 and Ioo per cent., there must have been an enormous change for the better in the means of the working man, unless by some wonderful accident it has happened that his special articles have changed in a different way from the general run of prices.

But looking to special articles, we find that on balance prices are lower and not higher. Take wheat. 
It is notorious that wheat, the staff of life, has been lower on the average of late years than it was before the free trade era. Even our fair trade friends, who find it so difficult to see very plain things, were forced to allow, in that wonderful manifesto which was published in the "Times" some weeks back, that wheat is about 5 s. a quarter cheaper on the average than it was. The facts, however, deserve still more careful statement to enable us to realize the state of things fifty years ago and at the present time. The fair trade statement, if I remember rightly, showed an average fall of $5^{s}$. in the price of wheat, comparing the whole period since the Repeal of the Corn Laws with a long period before. This may have been right or wrong for the purpose in hand, but for our present purpose, which is to compare the present period with that of half a century ago, it is important to note that it is mainly within the last ten years the steadily low price of wheat has been established. Comparing the ten years before 1846 with the last ten years, what we find is that while the average price of wheat in $1837-46$ was $58 s$. $7 d$., it was $48 s .9 d$. only in the last ten years-a reduction not of $5 s$. merely, but ios. The truth is, the Repeal of the Corn Laws was not followed by an immediate decline of wheat on the average. The failure of the potato crop, the Crimean War, and the depreciation of gold, all contributed to maintain the price, notwithstanding free trade, down to I862. Since then steadily lower prices have ruled; and when we compare the present time with a half century ago, or any earlier part of the century, these facts should be remembered.

There is a still more important consideration. Averages are very good for certain purposes, but we all know in this place that a good deal sometimes turns upon the composition of the average,- - upon whether it is made up of great extremes, or whether the individual elements depart very little from the average. This is specially an important matter in a question of the price of food. The average of a neces- 
sary of life over a long period of years may be moderate, but if in some years the actual price is double what it is in other years, the fact of the average will in no way save from starvation at certain periods the workman who may have a difficulty in making both ends meet in the best of times. What we find then is that fifty years ago the extremes were disastrous compared with what they are at the present time. In 1836 we find wheat touching $36 s . ;$ in 1838,1839 , I 840 , and in 1841 , we find it touching $78 s .4 d ., 8 \mathrm{r} s .6 d ., 72 s$. 1od., and $76 s$. $1 d$. ; in all cases double the price of the lowest year, and nearly double the "average" of the decade; and in 1847 the price of IO2s. 5 ., or three times the price of the lowest period, is touched. If we go back earlier we find still more startling extremes. We have such figures as 106s. $5 d$. in $1810 ; 126 s .6 d$. in 1812 ; Iogs. $9 d$. in $18 \mathrm{I} 3$, and $96 s$. I $d d$. in 1817 ; these figures being not merely the extremes touched, but the actual averages for the whole year. No doubt in the early part of the century the over-issue of inconvertible paper accounts for part of the nominal prices, but it accounts for a very small part. What we have to consider then is, that fifty years ago the working man with wages, on the average, about half, or not much more than half what they are now, had at times to contend with a fluctuation in the price of bread which implied sheer starvation. Periodic starvation was, in fact, the condition of the masses of working men throughout the kingdom fifty years ago, and the references to the subject in the economic literature of the time are most instructive. M. Quetelet, in his well-known great book, points to the obvious connection between the high price of bread following the bad harvest of 1816 , and the excessive rate of mortality which followed. To this day you will find tables in the Registrar-General's returns which descend from a time when a distinct connection between these high prices of bread and excessive rates of mortality was traced. But within the last twenty years what do we find? Wheat has not been, 
on the average, for a whole year so high as $70 s$, the highest averages for any year being $64 s .5 d$. in i 867 , and $63 \mathrm{~s} .9 \mathrm{~d}$. in 1868 ; while the highest average of the last ten years alone is $58 s .8 d$. in 1873 ; that is, only about ios. above the average of the whole period. In the twenty years, moreover, the highest price touched at any period was just over $70 s .$, viz., $70 s .5 \%$., in 1867 , and $74 s .7 d$. in 1868 ; while in the last ten years the figure of $70 s$. was not even touched, the nearest approach to it being $68 s .9 d$. in 1877 . Thus of late years there has been a steadily low price, which must have been an immense boon to the masses, and especially to the poorest. The rise of money wages has been such, I believe, that working men for the most part could have contended with extreme fluctuations in the price of bread better than they did fifty years ago. But they have not had the fluctuations to contend with.

It would be useless to go through other articles with the same detail. Wheat had quite a special importance fifty years ago, and the fact that it no longer has the same importance-that we have ceased to think of it as people did fifty years ago-is itself significant. Still, taking one or two other articles, we find, on the whole, a decline:

\section{Prices of Various Articles about Fiffy Years ago and at Present Time.}

\begin{tabular}{|c|c|c|c|}
\hline & & IS $39-40$ & Present Time. \\
\hline $\begin{array}{l}\text { Sugar } \\
\text { Cotton cloth exported }\end{array}$ & $\begin{array}{l}\text {. per cwt. } \\
\text {. . per yard }\end{array}$ & $\begin{array}{rl}\text { s. } & d . \\
68 & 8^{1} \\
0 & 5 \frac{3}{8}\end{array}$ & $\begin{array}{rl}s . & d . \\
2 \mathrm{I} & 9^{2} \\
0 & 3 \frac{1}{\ddagger}\end{array}$ \\
\hline
\end{tabular}

"Porter's "Progress of the Nation," p. 543. In the paper as read to the Society I gave the price without the duty, but including the duty the price was what is now given here. The average price with the duty of the ten years ending I $S_{40}$ was $58 s .4 d$.

2 Average price of raw sugar imported. 


\section{Prices of Various Articles-continued.}

\begin{tabular}{|c|c|c|c|}
\hline & & 1840. & 1882. \\
\hline Inferior beasts & per 8 lbs. & $\begin{array}{cc}s . & d . \\
3 & \mathbf{I}\end{array}$ & $\begin{array}{cc}s . & d . \\
4 & 3 \frac{3}{4}\end{array}$ \\
\hline Second class . & & & $\begin{array}{ll}4 & 9 \frac{3}{4} \\
4\end{array}$ \\
\hline Third " . & $"$ & 3 II $\frac{3}{4}$ & $57 \frac{1}{2}$ \\
\hline Inferior sheep & $"$ & $\begin{array}{ll}3 & 5\end{array}$ & 57 \\
\hline Second class & $"$ & $310 \frac{1}{4}$ & \\
\hline Large hogs & $"$ & $4 \quad 3 \frac{1}{2}$ & $46^{6}$ \\
\hline
\end{tabular}

I should have liked a longer list of articles, but the difficulty of comparison is very serious. It may be stated broadly, however, that while sugar and such articles have declined largely in price, and while clothing is also cheaper, the only article interesting the workman much which has increased in price is meat, the increase here being considerable. The "only" it may be supposed covers a great deal. The truth is, however, that meat fifty years ago was not an article of the workman's diet as it has since become. He had little more concern with its price than with the price of diamonds. The kind of meat which was mainly accessible to the workman fifty years ago, viz., bacon, has not, it will be seen, increased sensibly in price.

Only one question remains. Various commodities, it may be admitted, have fallen in price, but house rent, it is said, has gone up. We have heard a good deal lately of the high prices of rooms in the slums. When we take things in the mass, however, we find that however much some workmen may suffer, house rent in the aggregate cannot have gone up in a way to neutralize to any serious extent the great rise in the money wages of the workman. It appears that in 1834 , when the house duty, which had existed up to that date, was abolished, the annual value of dwelling houses charged to duty was $£ 12,603,000$, the duty being levied on all houses above $£$ io rental in Great Britain. In I $881-82$ the annual value of dwelling houses charged 
to duty, the duty being levied on houses above $£ 20$ only, was $£ 39,845$,000, while the value of the houses between $£_{10}$ and $£_{20}$ was $£$ i $7,040,000$, making a

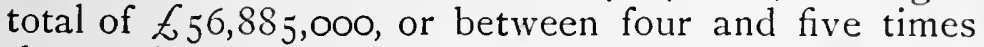
the total of fifty years ago. Population, however, in Great Britain has increased from about i $6 \frac{1}{2}$ millions in $183 \mathrm{I}$, to nearly 30 millions in $188 \mathrm{I}$, or nearly 100 per cent. Allowing for this, the increase in value would be about 32 million pounds, on a total of about 25 million pounds, which may be considered the increased rent which householders above $£$ ro have to pay-the increase being about I 30 per cent. Assuming that houses under $f$ Io have increased in proportion, it may be considered that house rents are now $1 \frac{1}{2}$ times more than they were fifty years ago. In other words, a workman who paid $£ 3$ a year fifty years ago, would now pay $£ 7$ Ios. Even, however, if rent were a fourth part of the workman's earnings fifty years ago, he would still be much better off at the present time than he was. His whole wages have doubled, while the prices of no part of his necessary consumption, except rent, as we have seen, have increased-on the contrary, they have rather diminished. Say then that the rent, which was a fourth part of his expenditure, has increased $1 \frac{1}{2}$ times, while his whole wage has doubled, the account, on a wage of 20 . fifty years ago, and 40 s. now, would stand:

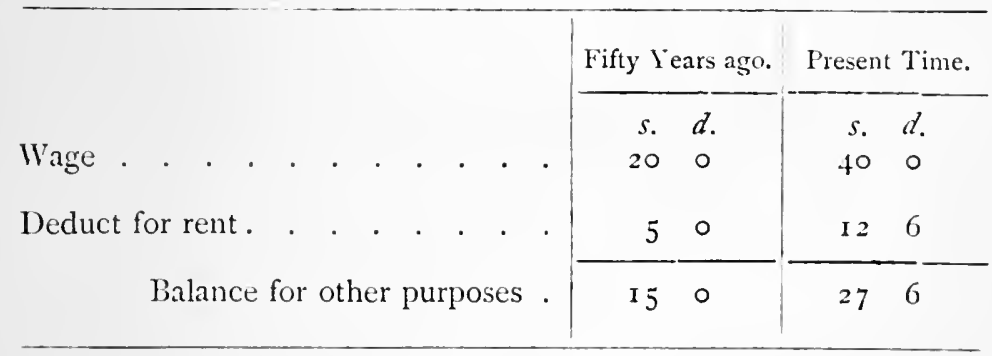

- showing still an enormous improvement in the workman's condition. 
It may be pointed out, however, that houses are undoubtedly of the better value all round than they were fifty years ago. More rent is paid because more capital is in the houses, and they are better houses. It appears also that fifty years ago there were far more exemptions than there are now, rural dwellings particularly being favoured as regards exemption. The increase of rent for the same accommodation, there is consequently reason to believe, has not been nearly so great as these figures would appear to show. It has further to be considered that the whole annual value of the dwelling houses under $£_{\mathrm{I}} \mathrm{o}$ even now is $£_{\mathrm{I}} 7,88_{5}, 000$ only, the number of houses being 3.I 24,000. This must be a very small proportion of the aggregate earnings of those portions of the working classes who live in houses under $£$ Io rent, and even adding to it the value of all the houses up to $£ 20$, which would bring up the total to $\delta 34,925$, ooo, the proportion would still be very small. On the five million families at least of the working classes in Great Britain, the sum would come to about $£ 7$ per family, which is not the main portion of an average working man's expenditure. ${ }^{1}$

We return then to the conclusion that the increase of the money wages of the working man in the last fifty years corresponds to a real gain. While his wages have advanced, most articles he consumes have rather diminished in price, the change in wheat being especially remarkable, and significant of a complete revolution in the condition of the masses. The increased price in the case of one or two articles-particularly

${ }^{1}$ It may be convenient to note here that the figures as to dwelling houses which I have made use of are those relating to the Inhabited House Duty. The figures as to houses in the income tax returns include shops and factories as well as dwelling houses, and are not available in a question of house rent. I have also omitted the question of rates. The rates per pound, however, have not increased as compared with what they were formerly, and it would make no material difference if they were to be included. The workman's payment for rates and rent together cannot have increased more than is here stated for rent. 
meat and house rent-is insufficient to neutralize the general advantages which the workman has gained. Meat formerly was a very small part of his consumption, and allowing to house rent a much larger share of his expenditure than it actually bore, the increase in amount would still leave the workman out of his increased wage a larger margin than he had before for miscellaneous expenditure. There is reason to believe also that the houses are better, and that the increased house rent is merely the higher price for a superior article which the workman can afford.

It has to be added to all this that while the cost of government has been greatly diminished to the working man, he gets more from the government expenditure than he formerly did. It would not do to count things twice over, and as the benefit to the working man of diminished taxes has already been allowed for in the lower prices of wheat and sugar, we need say nothing more on this head. But few people seem to be aware how, simultaneously with this reduction of the cost of government, there has been an increase of the expenditure of the government for miscellaneous civil purposes, of all of which the workman gets the benefit. It may be stated broadly that nearly 15 million pounds of the expenditure of the central government for education, for the post office, for inspection of factories, and for the miscellaneous purposes of civil government, is entirely new as compared with fifty jears ago. So far as the expenditure is beneficial, the masses get something they did not get before at all. It is the same even more markedly with local government. In Great Britain, the annual outlay is now about 60 million pounds, as compared with 20 million pounds fifty years ago. This 20 million pounds was mainly for poor relief and other old burdens. Now the poor relief and other old burdens are much the same, but the total is swollen by a vast expenditure for sanitary, educational, and similar purposes, of all of which the masses of the population get the benefit. To a great deal of this 
expenditure we may attach the highest value. It does not give bread or clothing to the working man, but it all helps to make life sweeter and better, and to open out careers even to the poorest. The value of the free library. for instance, in a large city, is simply incalculable. All this outlay the workman has now the benefit of as he had not fifty years ago. To repeat the words I have already used, he pays less taxes, and he gets more-much more-from the Government. ${ }^{1}$

1 With regard to this question of prices, I have been favoured since the delivery of this address with the copy of a letter, dated i ith June, I88I, addressed by Mr. Charles Hawkins, of 27 , Savile Row, to the editor of the "Daily News" on the cost per fatient of the expenditure of St. George's Hospital in 1830 and i 880 . The facts stated confirm in an interesting way what is here said as to the cost of articles of the workman's consumption fifty years ago and at the present time. Mr. Hawkins, who was at one time one of the treasurers of the hospital, and therefore speaks with authority, gives the following table and notes :

"Although each patient costs now is. i $d$. less than in i 830 , there have been great alterations in the different items of expenditure, viz. :

\begin{tabular}{|c|c|c|c|c|c|c|}
\hline \multirow[b]{3}{*}{ Meat . . . } & \multirow[b]{3}{*}{. } & & \multirow{3}{*}{\multicolumn{2}{|c|}{. . }} & \multicolumn{2}{|c|}{ Cost per Patient. } \\
\hline & & & & & 1830. & 188o. \\
\hline & & & & & $\begin{array}{ll}\text { s. } & d . \\
\text { I8 } & 4\end{array}$ & $\begin{array}{cc}s . & d . \\
22 & 2\end{array}$ \\
\hline Bread and flour. & . & . & . . . . & . & I0 7 & $4 \mathrm{I}$ \\
\hline Wine and spirits & . & . & . . & . & 010 & 3 \\
\hline Malt liquor . . & . & . & . & . & 55 & \\
\hline Milk . . . . & . & . & . & . & 62 & 5 II \\
\hline Tea and grocery & . & . & . . . & . & 310 & 35 \\
\hline Drugs . . . & . & . & . & . & I6 5 & 7 I I \\
\hline Coals and wood & . & . & . & . & I0 6 & 310 \\
\hline Laundry . . & . & . & . . . & . & 210 & 4 ro \\
\hline Instruments and & urg & cal & appliance & es & I 9 & 52 \\
\hline Staff;一officers, se & rva & ats & , nurses & . & 20 & 343 \\
\hline
\end{tabular}

"Had wheat cost in I 880 what it did in $1830, \mathcal{E}_{1}, 88_{4}$ must have been spent in bread and flour instead of $\delta_{73} 8$. The cost of port wine in 1830 was $£_{72}$ per pipe; in I $880 £ 45$. In 1830 many of the patients provided themselves with tea and sugar. Under the head 'Drugs' is included the cost of leeches; in I $846,14,800$ leeches were used, at a cost of $\mathcal{E}^{\mathrm{I}} 43$; in I 880 only 425 , costing $\mathcal{E} \mathrm{I}$ I 6 s. In I 833 another hospital, treating double the number of patients, used 48,900 leeches, but in 1880 only 250 .

"These items show the great advantage of the reduction of price in 
As already anticipated, however, the conclusion thus arrived at only carries us part of the way. Assuming it to have been shown that the masses have more money than they had fifty years ago, and that the prices of the chief articles they consume are cheaper rather than dearer, the question remains whether the condition of the masses has in fact been improved. This can only be shown indirectly by statistics of different kinds, which justify conclusions as to the condition of the people to whom they apply. To such statistics I propose now to draw your attention for a moment. I need hardly say that any evidence they contain as to the condition of the people having actually improved corroborates what has been already said as to their having had the means of improvement in their hands. The evidence is cumulative, a point of material importance in all such inquiries.

The first and the most important statistics on this head are those relating to the length of life among the masses of the nation. Do the people live longer than they did? Here I need not detain you. A very effective answer was supplied last session by Mr. Humphreys, in his able paper on "The Recent Decline in the English Death Rate." ${ }^{\prime}$ Mr. Humphreys there showed conclusively that the decline in the death-rate in the last five years, $1876-80$, as compared with the rates on which Dr. Farr's English Life 'Table was based-rates obtained in the years $1838-54$-amounted to from 28 to 32 per cent. in males at each quinquennium of the twenty years 5-25, and in females at each quinquennium from 5-35 to between 24 and 35 per cent.; and that the effect of this decline in the death-rate is to raise the mean duration of life among males from 39.9 to 41.9

some articles of diet, and the great extra expenditure now necessary for the treatment of hospital patients, depending on the greater call for additional 'staff,' more especially for nursing, and an altered mode of treatment of accidents and operations, as also the greater amount of stimulants now exhibited, etc."

'See Statistical Society's "Journal," vol. xtri., p. I95, etc.

I.

D D 
years, a gain of 2 years in the average duration of life, and among females from $4 \mathrm{I} .9$ to 45.3 years, a gain of nearly $3 \frac{1}{2}$ years in the average duration of life. Mr. Humphreys also showed that by far the larger proportion of the increased duration of human life in England is lived at useful ages, and not at the dependent ages of either childhood or old age. This little statement is absolutely conclusive on the subject; but we are apt to overlook how much the figures mean. No such change could take place without a great increase in the vitality of the people. Not only have fewer died, but the masses who have lived must have been healthier, and have suffered less from sickness than they did. Though no statistics are available on this point, we must assume that like causes produce like effects; and if the weaker, who would otherwise have died, have been able to survive, the strong must also have been better than they would otherwise have been. From the nature of the figures, also, the improvement must have been among the masses, and not among a select class whose figures throw up the average. The figures to be affected relate to such large masses of population, that so great a change in the average could not have occurred if only a small percentage of the population had improved in health.

I should like also to point out that the improvement in health actually recorded obviously relates to a transition stage. Many of the improvements in the condition of the working classes have only taken place quite recently. 'They have not, therefore, affected all through their existence any but the youngest lives. When the improvements have been in existence for a longer period, so that the lives of all who are living must have been affected from birth by the changed conditions, we may infer that even a greater gain in the mean duration of life will be shown. As it is, the gain is enormous. Whether it is due to better and more abundant food and clothing, to better sanitation, to better knowledge of medicine, or to these and other 
causes combined, the improvement has beyond all question taken place.

The next figures I shall refer to are those well-known ones relating to the consumption of the articles which the masses consume. I copy merely the figures in the Statistical Abstract for the years I 840 and I 88 I :

Quantities of the Principal Imported and Excisable Articles retained for Home Consumption, per Head of the Total Population of the United Kingdom.

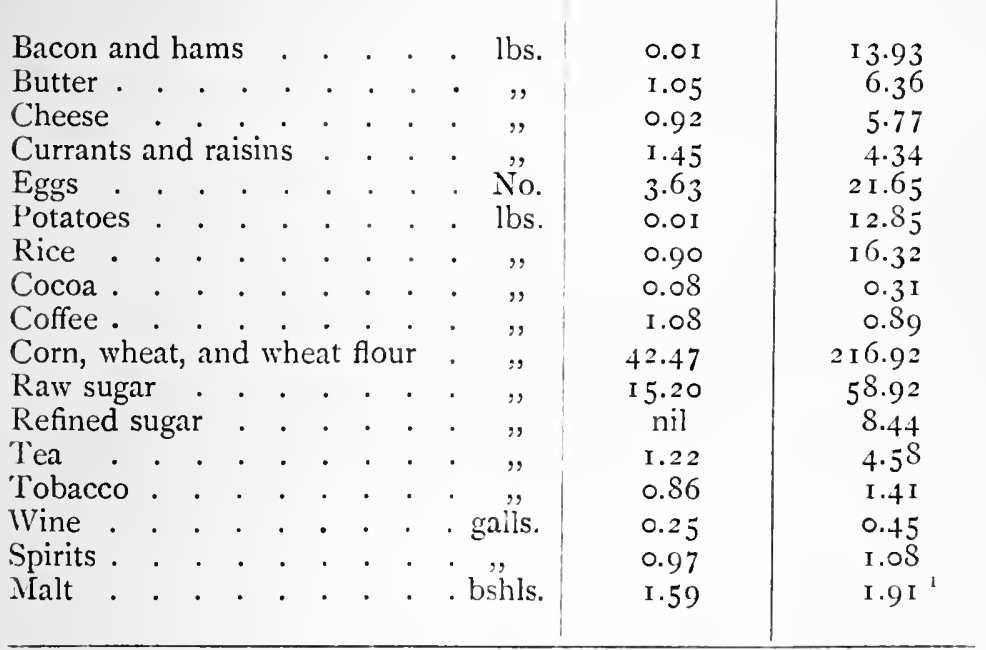

This wonderful table may speak for itself. It is an obvious criticism that many of the articles are also articles of home production, so that the increase does not show the real increase of the consumption of the whole population per head. Assuming a stationary production at home, the increased consumption per head cannot be so much as is here stated for the imported article only. There are other articles, however, such as rice, tea, sugar, coffee, tobacco, spirits, wine

$$
1 \text { Year }{ }^{1} S_{7} 8 \text {. }
$$


and malt, which are either wholly imported, or where we have the excisable figures as well, and they allwith the one exception of coffee-tell a clear tale. The increase in tea and sugar appears especially significant, the consumption per head now being four times in round figures what it was forty years ago. There could be no better evidence of diffused material well-being among the masses. The articles are not such that the increased consumption by the rich could have made much difference. It is the consumption emphatically of the mass which is here in question.

As regards the articles imported, which are also articles of home production, it has, moreover, to be noted that in several of them, bacon and hams, cheese and butter, the increase is practically from nothing to a very respectable figure. The import of bacon and hams alone is itself nearly equal to the estimated consumption among the working classes fifty years ago, who consumed no other meat.

The only other figures I shall mention are those relating to education, pauperism, crime, and savings banks. But I need not detain you here. The figures are so well known that I must almost apologize for repeating them. I only insert them to round off the statement.

As to education, we have practically only figures going back thirty years. In $185 \mathrm{I}$, in England, the children in average attendance at schools aided by parliamentary grants numbered 239,000 , and in Scotland 32,000 ; in I 88 I the figures were 2,863,000 and 410,000 . If anything is to be allowed at all in favour of parliamentary grants as raising the character of education, such a change of numbers is most significant. The children of the masses are, in fact, now obtaining a good education all round, while fifty years ago the masses had either no education at all or a comparatively poor one. Dropping statistics for the moment, I should like to give my own testimony to an observed fact of social life-that there is nothing so striking or so satis- 
factory to those who can carry their memories back nearly forty years, as to observe the superiority of the education of the masses at the present time to what it was then. I suppose the most advanced common education forty or fifty years ago was in Scotland, but the superiority of the common school system there at the present day to what it was forty years ago is immense. If Scotland has gained so much, what must it have been in England, where there was no national system fifty years ago at all? Thus at the present day not only do we get all children into schools, or nearly all, but the education for the increased numbers is better than that which the fortunate few alone obtained before.

Next as to crime, the facts to note are that rather more than forty years ago, with a population little more than half what it is now, the number of criminal offenders committed for trial (1 839) was 54,000: in England alone 24,000. Now the corresponding figures are, United Kingdom 22,000, and England I 5,000; fewer criminals by a great deal in a much larger population. Of course the figures are open to the observation that changes in legislation providing for the summary trial of offences that formerly went to the assizes may have had some effect. But the figures show so great and gradual a change, that there is ample margin for the results of legislative changes, without altering the inference that there is less serious crime now in the population than there was fifty years ago. Thus an improvement as regards crime corresponds to the better education and well-being of the masses.

Next as regards pauperism; here again the figures are so imperfect that we cannot go back quite fifty years. It is matter of history, however, that pauperism was nearly breaking down the country half a century ago. The expenditure on poor relief early in the century and down to $1830-3$ I was nearly as great at times as it is now. With half the population in the country that there now is, the burden of the poor was the same. Since I 849 , however, we have continuous figures, 
and from these we know that, with a constantly increasing population, there is an absolute decline in the amount of pauperism. The earliest and latest figures are:

\section{Paupers in Receipt of Relief in the undermentioned Years at given Dates.}

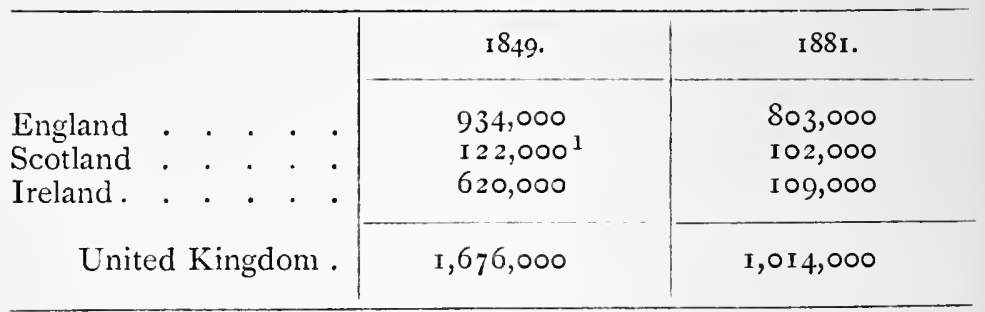

Thus in each of the three divisions of the United Kingdom there is a material decline, and most of all in Ireland, the magnitude of the decline there being no doubt due to the fact that the figures are for a period just after the great famine. But how remote we seem to be from those days of famine!

Last of all we come to the figures of savings banks. A fifty years' comparison gives the following results for the whole kingdom:

\begin{tabular}{|c|c|c|}
\hline & $\mathrm{I}_{3} \mathrm{I}$. & I $88 \mathrm{I}$. \\
\hline $\begin{array}{c}\text { Number of depositors. } \\
\text { Amount of deposits } \\
\text { " per depositor. }\end{array}$ & $\begin{array}{c}429,000 \\
\mathcal{E}^{13} 37^{2} 9,000 \\
3^{2}\end{array}$ & $\begin{array}{c}4,140,000 \\
£ 80,334,000 \\
\text { E1 } 9\end{array}$ \\
\hline
\end{tabular}

An increase of tenfold in the number of depositors, and of fivefold and more in the amounts of deposits! It seems obvious from these figures that the habit and means of saving have become widely diffused in these fifty years. The change is of course in part due to a mere change in the facilities offered for obtaining de- 
posits; but allowing ample margin for the effect of increased facilities, we have still before us evidence of more saving among the masses.

There is yet one other set of statistics I should like to notice in this connection, those relating to the progress of industrial and provident co-operative societies in England and Wales. These I abstract from the special appendix to the "Co-operative Wholesale Society's Annual Almanac and Diary" for the present year (pp. $8 \mathrm{I}$ and 82). Unfortunately the figures only go back to 1862 , but the growth up to i 862 appears to have been very small. Now, however, most material advance is shown:

I 862.

1881 .

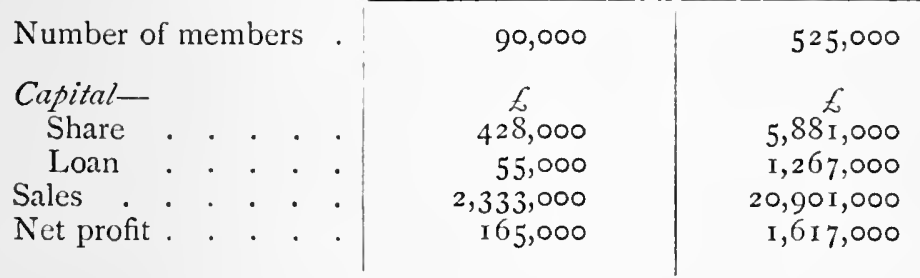

Such figures are still small compared with what we should like to see them, but they at least indicate progress among the working classes, and not retrogression or standing still.

To conclude this part of the evidence, we find undoubtedly that in longer life, in increased consumption of the chief commodities they use, in better education, in greater freedom from crime and pauperism, and in increased savings, the masses of the people are better, immensely better, than they were fifty years ago. This is quite consistent with the fact, which we all lament, that there is a residuum still unimproved, but apparently a smaller residuum both in proportion to the population and absolutely, than was the case fifty years ago; and with the fact that the improvement, measured even by a low ideal, is far too small. No one can contemplate 
the condition of the masses of the people without desiring something like a revolution for the better. Still, the fact of progress in the last fifty years-progress which is really enormous when a comparison is made with the former state of things-must be recognized. Discontent with the present must not make us forget that things have been so much worse.

But the question is raised: Have the working classes gained in proportion with others by the development of material wealth during the last fifty years? The question is not one which would natually excite much interest among those who would answer the primary question as to whether the working classes have gained or not, as I have done, in the affirmative. Where all are getting on, it does not seem very practical in those who are getting on slowly to grudge the quicker advance of others. Usually those who put the question have some vague idea that the capitalist classes, as they are called, secure for themselves all the benefits of the modern advance in wealth; the rich, it is said, are becoming richer, and the poor are becoming poorer. It will be convenient then to examine the additional question specifically. If the answer agrees with what has already been advanced, then, as nobody doubts that material wealth has increased, all will be forced to admit that the working classes have had a fair share.

At first sight it would appear that the enormous figures of the increase of capital, which belong, it is assumed, to the capitalist classes, are inconsistent with the notion of the non-capitalist classes having had a fair share. In the paper which I read to the Society four years ago, on "The Recent Accumulations of Capital in the United Kingdom," the conclusion at which I arrived was that in the ten years, I865-75, there had been an increase of 40 per cent. in the capital of the nation, and 27 per cent. in the amount of capital per head, that is, allowing for the increase of population. 
Going back to 1843 , which is as far as we can go back with the income tax returns, we also find that since then the gross assessment, allowing for the income from Ireland not then included in the returns, has increased from 280 million pounds to 577 million pounds, or more than roo per cent. in less than fifty years. Assuming capital to have increased in proportion, it is not to be wondered at that the impression of a group of people called the capitalist classes getting richer and richer, while the mass remain poor or become poorer, should be entertained. Allowing for the increase of population, the growth of capital and income-tax income is really much smaller than the growth of the money income of the working classes, which we have found to be something like 50 to roo per cent. and more per head in fifty years, but the impression to the contrary undoubtedly exists, and is very natural.

The error is partly in supposing that the capitalist classes remain the same in number. This is not the case; and I have two pieces of statistics to refer to which seem to show that the capitalist classes are far from stationary, and that they receive recruits from period to period -in other words, that wealth, in certain directions, is becoming more diffused, although it may not be diffusing itself as we should wish.

The first evidence I refer to is that of the Probate Duty returns. Through the kindness of the Commissioners of Inland Revenue, I am able to put before you a statement of the number of probates granted in I 88 I, and of the amounts of property "proved," with which we may compare similar figures published by Mr. Porter in his "Progress of the Nation" for $1 \delta_{3} \delta$. I am sorry to say Mr. Porter's figures for i $\delta_{3} 8$ are far more detailed than those $\mathrm{I}$ am able to give; a more minute comparison would be most instructive; but I was unfortunately too late in applying to the Commissioners of Inland Revenue for the details, which I found they were most willing to give. However, the statement they supplied to me, and the comparison 
which can thus be made, seem most instructive. They are as follows:

Statement of Number of Probates granted in 1882, with Amounts of Property Proved, and Average per Prolate [from figures supplied by the Commissioners of Inland Revenue]; and Comparison with a similar Statement for 1838 [from Porter's "Progress of the Nation," pp. 600 et seq.].

\begin{tabular}{|c|c|c|c|c|c|c|c|c|}
\hline \multirow[b]{3}{*}{ England } & \multirow{3}{*}{\multicolumn{2}{|c|}{. . . }} & \multicolumn{2}{|c|}{ Number of Probates. } & \multicolumn{2}{|c|}{ Amount of Property. } & \multicolumn{2}{|c|}{$\begin{array}{l}\text { Amount of } \\
\text { Property } \\
\text { per Estate. }\end{array}$} \\
\hline & & & 1882. & $183^{8}$. & 1882. & 1838. & 1882. & 1838 \\
\hline & & & 45,555 & 21,900 & $\underset{1}{£} 18,120,961$ & $\underset{47,604,755}{£}$ & $\underset{2,600}{E}$ & $\begin{array}{c}£ \\
2,170\end{array}$ \\
\hline Scotland & - & . . & 5,221 & 1,272 & I $3,695,314$ & $2,817,260$ & 2,600 & 2,200 \\
\hline Ireland. & . & . . & $4,5^{8} 3$ & 2,196 & $8,544,579$ & $4,465,240$ & 1,900 & 2,000 \\
\hline \multicolumn{3}{|c|}{ United Kingdom } & 55,359 & 25,368 & I $40,360,854$ & $54,887,255$ & 2,500 & 2,160 \\
\hline
\end{tabular}

Thus, in spite of the enormous increase of property passing at death, amounting to over I 50 per cent., which is more than the increase in the income-tax income, the amount of property per estate has not sensibly increased. The increase of the number of estates is more than double, and greater therefore than the increase of population, but the increase of capital per head of the capitalist classes in England only 19 per cent., and in the United Kingdom only i 5 per cent. Curiously enough, I may state, it is hardly correct to speak of the capitalist classes as holding this property, as the figures include a small percentage of insolvent estates: but allowing all the property to belong to the capitalist classes, still we have the fact that those classes are themselves increasing. They may be only a minority of the nation, though I think a considerable minority, as 55,000 estates passing in a year represent from $\mathrm{I}, 500,000$ to $2,000,000$ persons as possessing property subject to probate duty; and these figures, it must be 
remembered, do not include real property at all. Still, small or large as the minority may be, the fact we have before us is that in the last fifty years it has been an increasing minority, and a minority increasing at a greater rate than the increase of general population. Wealth, to a certain extent, is more diffused than it was.

If I had been able to obtain more details, it would have been possible to specify the different sizes of estates and the different percentages of increase, from which it would not only have appeared whether the owners of personal property were increasing in number, but whether the very rich were adding to their wealth more than the moderately rich, or vice vers $\hat{a}$. But it is something to know at least that there are more owners. I trust the Commissioners of Inland Revenue will see their way in their next report to give more details on this very interesting point. ${ }^{1}$

Before passing on I should like to add a caution which may not be necessary in this room, but which may be needed outside. All such figures must be taken with a good deal of qualification, owing to variations of detail in the method of levying the duty at different times, variations in the character of the administration, and the like causes. I notice, for instance, an unusually remarkable increase both in the number of owners and amount of property passing in Scotland; this last fact, I believe, having already given rise to the statement that there has been something unexampled in the increase of personal property in Scotland. The explanation appears to be, however, that the increase of property in Scotland is, to some extent, only apparent, being due partly, for instance, to the fact that by Scotch

1 It appears that the increase in the number of probates for less than $\oint_{1,000}$ is from $1 S, 490$ to $41,27 S$, or about i 20 per cent., the average value per probate being much the same; while the increase of the number of probates for more than $£_{\mathrm{r}}, 000$ is from $6, S 7 S$ to 12,629 , or over 80 per cent., and the average value per probate has increased from $\mathcal{E}_{7,1}$ 5 to $£, 9,200$. 
law mortgages are real property, whereas in England they are personal property, so that it was necessary, in the course of administering the tax, to pass a special law enabling the Commissioners of Inland Revenue to bring Scotch mortgages into the category of personal property. ${ }^{1}$ This is only one illustration of the caution with which such figures must be used. Taking them in the lump, and not pressing comparisons between the three divisions of the United Kingdom, or any other points of detail which might be dangerous, we appear to be safe in the main conclusion that the number of owners of personal property liable to probate duty has increased in the last fifty years more than the increase of population, and that on the average these owners are only about I 5 per cent. richer than they were, while the individual income of the working classes has increased from 50 to roo per cent.

The next piece of statistics I have to refer to is the number of separate assessments in that part of Schedule D known as Part I., viz., Trades and Professions, which excludes public companies and their sources of income, where there is no reason to believe that the number of separate assessments corresponds in any way to the number of individual incomes. Even in Part I. there can be no exact correspondence, as partnerships make only one return; but in comparing distant periods, it seems not unfair to assume that the increase or decrease of assessments would correspond to the increase or decrease of individual incomes. This must be the case, unless we assume that in the interval material differences were likely to arise from the changes in the number of partnerships to which individuals belonged, or from partnerships as a rule comprising a greater or less number of individuals. Using the figures with all these qualifications, we get the following comparison:

1 See "Special Report of Commissioners of Inland Revenue," I 870, vol. i., p. 99. 'The law on this and other points was altered by $23 \& 24$ Vict. cap. 80. 
Number of Persons at different Amounts of Income charged under Schedule D in 1843 and $1879-80$ compared [in England]. ${ }^{1}$

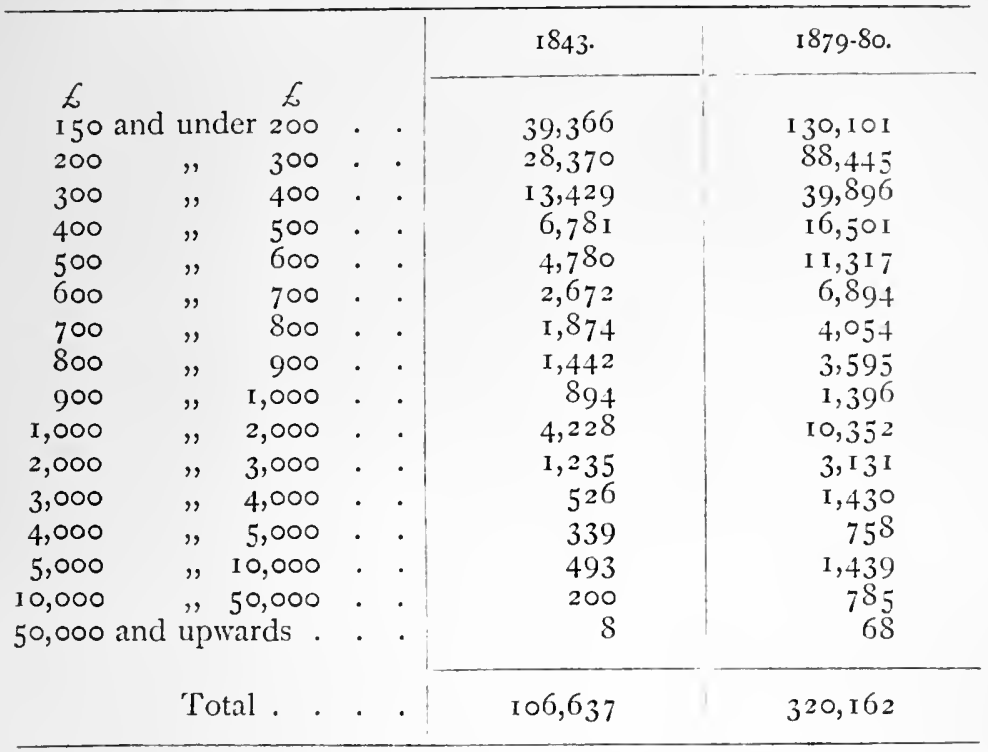

Here the increase in all classes, from the lowest to the highest, is between two and three times, or rather more than three times, with the exception of the highest class of all, where the numbers, however, are quite inconsiderable. Again a proof, I think, of the greater diffusion of wealth so far as the assessment of income to income tax under Schedule D may be taken as a sign of the person assessed having wealth of some kind, which I fear is not always the case. If the owners of this income, at least of the smaller incomes, are to be considered as not among the capitalists, but among the working classes-a very arguable proposition-then the increase of the number of incomes from $£$ i 50 up to say $\ell_{\mathrm{I}, \mathrm{o}}$ a year is a sign of the increased earnings of working classes, which are not usually thought of by that name. The increase in this instance is out of all proportion to the increase of population.

' The figures for $18+3$ cannot be given for either Scotland or Ireland. 
In giving these figures I have omitted the incomes under $\delta 150$. There is quite a want of satisfactory data for any comparison, I think, except as regards incomes actually subject to assessment, and the data at the beginning of the period are specially incomplete.

Whichever way we look at the figures, therefore, we have this result, that while the increase of personal property per head of the capitalist class, according to the probate returns, is comparatively small, being only about 15 per cent., yet there is an increase of the number of people receiving good incomes from trades and professions out of all proportion to the increase of population. IVe cannot but infer from this that the number of the moderately rich is increasing, and that there is little foundation for the assertion that the rich are becoming richer. All the facts agree. The working classes have had large additions to their means; capital has increased in about equal ratio; but the increase of capital per head of the capitalist classes is by no means so great as the increase of working-class incomes.

I should wish further to point out, however, that it is a mistake to speak of the income in the various schedules to the income tax as the income of a few, or exclusively of classes which can be called capitalist or rich. A suspicion of this has already been raised by the facts as to trades and professions. Let me just mention this one little fact in addition. Out of $£ 190,000,000$ assessed under Schedule $A$ in $1881-82$, the sum of $\mathcal{L}_{\text {I I }} 359,000$ was exempted from duty as being the income of people whose whole income from all sources was under $\delta$ I 50 a year. If we could get at the fact as to how the shares of public companies are held, and as to the immense variety of interests in lands and houses, we should have ample confirmation of what has already appeared from the probate duty figures, that there is a huge minority interested in property in the United Kingdom, great numbers of whom would not be spoken of as the capitalist classes.

To test the question as to whether there has been 
any disproportionate increase of capital, and of the income from it, in yet another way, I have endeavoured to make an analysis of the income tax returns themselves, distinguishing in them what appears to be the income of idle capital from income which is derived not so much from the capital itself as from the labour bestowed in using the capital. Only the roughest estimate can be made, and the data, when we go back to I 843, are even more incomplete than they are now; but I have endeavoured as faras possible to give everything to capital that ought to be given, and not to err on the side of assigning it too small a share. The whole of Schedule $A$ is thus assigned to capital, although it is well known that not even in Schedule $A$ is the income obtained without exertion and care, and some risk of loss, which are entitled to remuneration. In Schedule $\mathrm{D}$ also I have allowed that all the income from public companies and foreign investments is from idle capital, although here the vigilance necessary, and the risk attendant on the business, are really most serious, and part of the so-called profit is not really interest on idle capital at all, but strictly the remuneration of labour. I have also rather exaggerated than depreciated the estimate for capital employed in trades and professions, my estimate being rather more than that of Mr. Dudley Baxter in his famous paper on the National Income. With these explanations I submit the accompanying estimate of the share of capital in the income-tax income at different dates (see p. 4i 6).

This estimate may be summarized as follows:

Summary of Analysis of Income-Tax Income in undermentioned Vears.

[In millions of pounds.]

\begin{tabular}{|c|c|c|c|c|c|}
\hline & Vear. & & From Capital. & From Salaries, & Total. \\
\hline $\begin{array}{l}\text { I } 843 \\
\text { I } 862 \\
\text { I } 88 \text { I }\end{array}$ & $\begin{array}{llll}\cdot & \cdot & \cdot \\
\cdot & \cdot & \cdot \\
\cdot & \cdot & \cdot\end{array}$ & $\begin{array}{l}\cdot \\
\cdot \\
.\end{array}$ & $\begin{array}{l}E_{1} \\
1 S 8 \frac{1}{\tilde{i}} \\
252 \frac{i}{:-1} \\
407\end{array}$ & $\begin{array}{c}\mathcal{L} \\
93 \frac{1}{2} \\
107 \% \\
177\end{array}$ & $\begin{array}{c}\mathcal{E}_{2} \\
282 \\
360 \\
5^{84}\end{array}$ \\
\hline
\end{tabular}


Analysis of the Income Tax Returns for the undermentioned Years, showing the Estimated Income from Capital on the one side, and the Estimated Income from IVages of Superintendence and Salaries on the other side.

[In millions of pounds, $, 00,000$ 's omitted, i.e., $10=£ 10, \infty \infty 0, \infty 00$.]

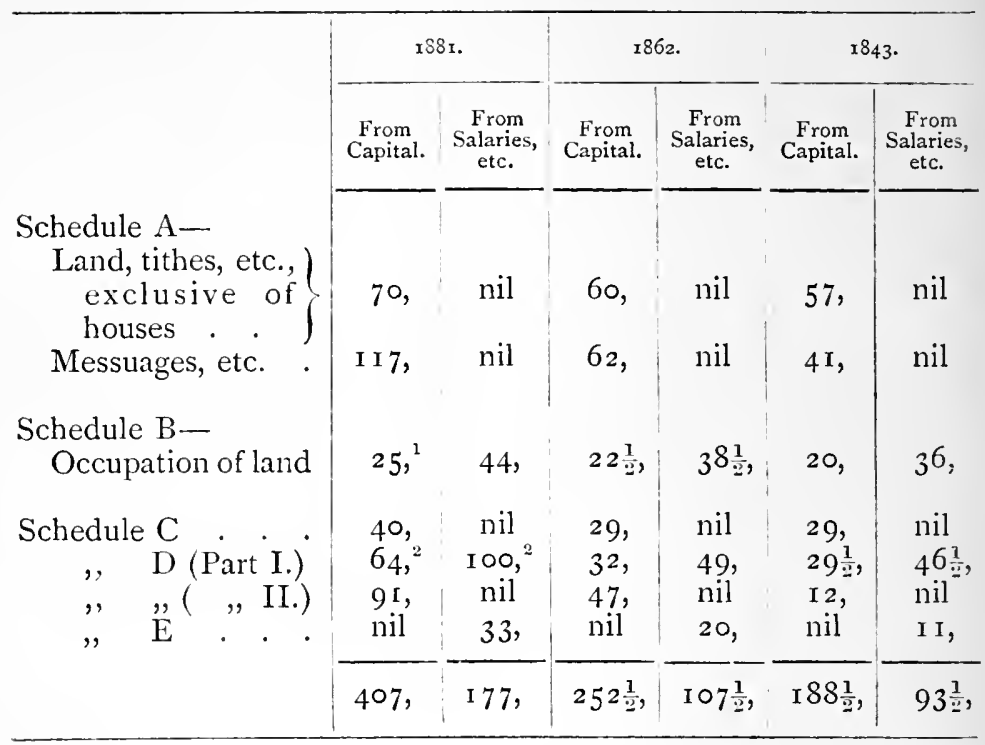

Note.-In the estimate for I 843 the figures assigned to Schedule A are only those of lands and tithes and houses to correspond with the existing Schedule A: and the figures of Schedule D include mines, quarries, railways, etc., now in Schedule D. An estimate is also made of the totals for Ireland, based on the returns of 1834 , the total gross income under all the schedules thus estimated being about 30 million pounds.

1 Interest on 500 millions of capital in $\mathrm{I} 88 \mathrm{I}$ at 5 per cent. In my paper on accumulations of capital, I estimated agricultural capital at a larger sum than this; but since then there has been some loss of agricultural capital, and if a larger sum were taken, the rate of interest used in the calculation for the present purpose should be less.

${ }^{2}$ Estimating that the income here is worth four years' purchase, and that it may be capitalized at that rate; and then allowing that this capital earns ro per cent., the rest being wages of superintendence or salaries. 
Thus a very large part of the increase of the incometax income in the last forty years is not an increase of the income from capital at all in any proper sense of the word. On the contrary, the increase in the income from capital is only about two-thirds of the total increase. This increase is, moreover, at a less rate than the increase of the capital itself, as appearing from the Probate Duty returns, ${ }^{1}$ a point which deserves special notice. The conclusion therefore is, that the working classes have not been losing in the last fifty years through the fruits of their labour being increasingly appropriated to capital. On the contrary, the income from capital has at least no more than kept pace with the increase of capital itself, while the increase of capital per head, as we have seen, is very little; so that it may be doubted whether the income of the individual capitalist from capital has on the average increased at all. If the return to capital had doubled, as the wages of the working classes appear to have doubled, the aggregate income of the capitalist classes returned to the income tax would now be 800 instead of 400 millions. In other words, it would not be far short of the mark to say that almost the whole of the great material improvement of the last fifty years has gone to the masses. The share of capital is a very small one. And what has not gone to the workmen, so called, has gone to remunerate people who are really workmen also, the persons whose incomes are returned under Schedule $\mathrm{D}$ as from "Trades and Professions." The capitalist as such gets a low interest for his money, and the aggregate return to capital is not a third part of the aggregate income of the country, which may be put at not less than I,200 millions, and is, I should estimate. not much more than a fourth part.

It will be interesting, I think, to present these conclusions in the form of an account. We have not, as I have already said, an exact statement of aggregate

' These returns, however, it should always be remembered, do not include real property.

I.

E E 
earnings, either at the beginning or at the end of the period; but assuming the aggregate income of the people as about I, 200 millions now, and that the wages of working men are, per head, twice what they were, the aggregates in $S_{4} 3$ and at the present time would compare as follows:

\section{Progress of National Income.}

[In millions of pounds.]

\begin{tabular}{|c|c|c|c|c|}
\hline & \multirow{2}{*}{$\begin{array}{l}\text { Income } \\
\text { in } 1843 .\end{array}$} & \multirow{2}{*}{$\begin{array}{l}\text { Income } \\
\text { at Present } \\
\text { Time. }\end{array}$} & \multicolumn{2}{|c|}{ Increase. } \\
\hline & & & Amount. & Per Cent. \\
\hline 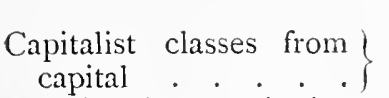 & $\underset{190}{£}$ & $\underset{t}{E}$ & $\underset{210}{f}$ & I IO \\
\hline $\left.\begin{array}{l}\text { Working income in in- } \\
\text { come-tax returns . }\end{array}\right\}$ & 90 & I 80 & 90 & I OO \\
\hline \multirow{2}{*}{$\left.\begin{array}{l}\text { Working income not in } \\
\text { income-tax returns }\end{array}\right\}$} & 235 & 620 & 385 & I 60 \\
\hline & $5^{\text {I } 5}$ & I, 200 & 685 & I 30 \\
\hline
\end{tabular}

Progress of National Capital Paying Probate Duty.

\begin{tabular}{|c|c|c|c|c|}
\hline & \multirow{2}{*}{${ }_{1} \mathrm{~S}_{3} \mathrm{~S}$. } & \multirow{2}{*}{$\begin{array}{c}\text { Present } \\
\text { Time. }\end{array}$} & \multicolumn{2}{|c|}{ Increase. } \\
\hline & & & Amount. & Per Cent. \\
\hline Amount of capital & $\begin{array}{c}£ \\
55 \text { mlns. }\end{array}$ & $\begin{array}{c}\qquad \\
\text { I } 40 \mathrm{mlns} .\end{array}$ & $\begin{array}{c}6 \\
85 \text { mlns. }\end{array}$ & I 55 \\
\hline " per estate. & 2,200 & 2,500 & 300 & I4 \\
\hline
\end{tabular}

Note.--Increase of working income per head roo per cent.

From this it appears that the increase of what is known as working-class income in the aggregate is greater than that of any other class, being i 60 per cent., while the return to capital and the return to what are called the capitalist classes, whether it is from capital proper or, as I maintain, a return only in the nature of wages, has only increased about 100 per cent., although 
capital itself has increased over 150 per cent. At the same time the capitalist classes themselves have greatly increased in number, so that the amount of capital possessed among them per head has only increased i 5 per cent., notwithstanding the great increase in capital itself, and the average income per head can have hardly increased at all. On the other hand, as the masses of the nation, taking the United Kingdom altogether, have only increased about 30 per cent. since 1843 , when these income tax figures begin, while their aggregate incomes have increased 160 per cent., it is explained how these incomes have gained, individually, about too per cent. as against hardly any increase at all in the incomes of what are called the capitalist classes, on the average. Thus the rich have become more numerous, but not richer individually; the "poor" are, to some smaller extent, fewer; and those who remain "poor" are, individually, twice as well off on the average as they were fifty years ago. The "poor" have thus had almost all the benefit of the great material advance of the last fifty years.

We may now conclude this long inquiry. It has been shown directly, I believe, that, while the individual incomes of the working classes have largely increased, the prices of the main articles of their consumption have rather declined; and the inference as to their being much better off which would be drawn from these facts is fully supported by statistics showing a decline in the rate of mortality, an increase of the consumption of articles in general use, an improvement in general education, a diminution of crime and pauperism, a vast increase of the number of depositors in savings banks, and other evidences of general well-being.

Finally, the increase of the return to capital has not been in any way in proportion, the yield on the same amount of capital being less than it was, and the capital itself being more diffused, while the remuneration of labour has enormously increased. The facts are what 
we should have expected from the conditions of production in recent years. Inventions having been multiplied, and production having been increasingly efficient, while capital has been accumulated rapidly, it is the wage receivers who must have the benefit. The competition of capital keeps profits down to the lowest point, and workmen consequently get for themselves nearly the whole product of the aggregate industry of the country. It is interesting, nevertheless, to find that the facts correspond with what theory should lead us to anticipate.

The moral is a very obvious one. Whatever may be said as to the ideal perfection or imperfection of the present economic regime, the fact of so great an advance having been possible for the masses of the people in the last half-century is encouraging. It is something to know that whether a better regime is conceivable or not, human nature being what it is now (and I am one of those who think that the regime is the best, the general result of a vast community living as the British nation does, with all the means of healthy life and civilization at command, being little short of a marvel if we only consider for a moment what vices of anarchy and misrule in society have had to be rooted out to make this marvel); still, whether best or not, it is something to know that vast improvement has been possible with this regime. Surely the lesson is that the nation ought to go on improving on the same lines, relaxing none of the efforts which have been so successful. Steady progress in the direction maintained for the last fifty years must soon make the English people vastly superior to what they are now.

I should like to add just one or two remarks bearing on questions of the moment, and as to the desirability or possibility of a change of régime now so much discussed, which the figures I have brought before you suggest. One is, that apart from all objections of principle to schemes of confiscating capital,-land nationalization, or collectivism, or whatever they may be called, 
- the masses could not hope to have much to divide by any such schemes. Taking the income from capital at 400 million pounds, we must not suppose that the whole of that would be divisible among the masses if capital were confiscated. IVhat the capitalist classes spend is a very different thing from what they make. The annual savings of the country now exceed 200 million pounds, being made as a rule, though not exclusively, by the capitalist classes. If then the 400 million pounds were to be confiscated, one of two things would happen: either the savings would not be made, in which case the condition of the working classes would soon deteriorate, for everything depends upon the steady increase of capital; or the savings would be made, in which case the spending power of the masses would not be so very much increased. The difference would be that they would be owners of the capital, but the income would itself remain untouched. The system under which large capitals are in a few hands may, in fact, have its good side in this, that the Jay Goulds, Vanderbilts, and Rothschilds cannot spend their income. The consequent accumulation of capital is, in fact, one of the reasons why the reward for labour is so high, and the masses get nearly all the benefit of the great increase of production. The other remark I have to make is that if the object really aimed at by those who talk of land nationalization and the like is carried out, the people who will suffer are those who receive large wages. To effect what they intend, the agitators must not merely seize on the property of a few, they must confiscate what are as much earnings as those of a mechanic or a labourer, and the wages of the most skilled mechanics and artisans themselves. The agitation is, in fact, to level down, to diminish the reward of labourers who receive a large wage because they can do the work the community requires, the proof being that in a market without favour they get the wage, and to increase the reward of other labourers beyond what in the same free market the community 
would freely give them. Whether the production would be continued at all if there were any success in these attempts, common sense will tell us. Those who have done some hard work in the world will, I am sure, agree with me that it is only done by virtue of the most powerful stimulants. Take away the rewards, and even the best would probably not give themselves up to doing what the community wants and now pays them for doing, but they would give themselves up either to idleness or to doing something else. The war of the land nationalizer and Socialist is then not so much with the capitalist as with the workman, and the importance of this fact should not be lost sight of.

[Note.-This essay is reprinted as it stood originally, for the general reasons stated in the preface to the present volumes, though it is specially tempting to give later figures in this case, prices having become lower and wages having risen in the last twenty years. I would refer all interested to the recent Board of Trade Blue-book (C. d. 1 761) mentioned in notes to previous essays, and to the Report on Wholesale and Retail Prices, No. 32 I, Sess. 1903.] 


\section{$\mathrm{XI}$.}

FOREIGN COMPETITION. ${ }^{1}$

A PHENOMENON is being repeated at the pre$A$ sent time which is often witnessed in times of depression of trade. The cry is raised that trade is being destroyed by foreign competition. Every bale of goods or ton of ironwork which comes from a foreign country into England "at a lower price than the same articles could be produced at home" is made the text of a discourse on the decline of English manufacturing. The multiplication abroad of manufactories of those articles which we produce for export is made the text of similar discourses. "See," it is said, "how some nations which were formerly our customers are manufacturing for themselves, and how other nations are going to the shops of rivals like the United States, France, and Germany, who are gaining upon us every day in the race." There is an essential fallacy in the whole argument, for the alleged facts, even if they were true, would not prove that foreign competition causes our manufacturing industry to decline, although it may be coincident with that decline. It is notorious, indeed, that everywhere abroad, and not least in Germany and the United States, manufacturing industry is depressed as much as it is here, so that our agitators really mean that English manufacturing causes that of Germany to fall off and German manufacturing that of England, whereas the natural inference would be that a common effect must have a common cause, and that it is something else than competition which makes foreign and

1 Written in 1877. 
English manufacturing be simultaneously depressed. But, apart from direct arguments as to the causes of the present depression in trade, we think it may be useful to inquire into the meaning of the words so freely employed. What would happen if English manufacturing were "declining" to any material extent and foreign manufacturing beginning to take its place? What would be the loss of income or transfer of labour and capital involved? If people were accustomed to measure their words in such discussions, or realize to themselves what they mean, a good deal of loose talk would be prevented, and a juster and more practical view formed of the economic incidents of the hour.

To take first the question of our foreign export trade. How much of the national income is really derived from that trade? To judge by the common language of the agitators we refer to, England would be nothing without its exports to foreign nations. Almost our whole trade and industry, it seems to be thought, would be at an end; an extensive emigration would be necessary; we should be a ruined nation. But, apart from questions as to the mutual conveniences of our exchanges with foreign nations, from whom we get much we cannot produce at home, and to whom we also send much they cannot produce at all, and much they cannot produce so easily as what they send usconveniences which are such that the total extinction of our foreign export trade is inconceivable-we believe it may be affirmed that the possible loss of income from the entire loss of our foreign trade would be a most measurable and by no means a fatal injury. It may be calculated that the earnings of the people of the United Kingdom approximate at the present moment $£_{\mathrm{I}, 200,000,000}$ sterling a year, if they do not exceed that amount. Mr. Dudley Baxter, in his wellknown book on the "National Income," published in I 868, computed that in the previous year the aggregate income of the people was $\oint^{8}$ I $_{4}, 000,000$, and there is ample reason to believe both that he was fairly accurate 
and careful in his calculations, into which the element of conjecture enters comparatively little, and that since he wrote the numbers, wealth, and resources of the people have increased at a wonderful rate. In these estimates there is one central fact about which there is no dispute-the amount of income assessed to income tax; and we know that income has increased over 40 per cent. in the last ten years of which we have an account. In the year ended the 5 th of April, I 865 , the gross amount of annual value assessed to income tax was $£ 396,000,000$ sterling, and in 1875 the corresponding amount was $£ 57 \mathrm{I}, 000$,000. This is an increase of very nearly 44 per cent. in ten years, and shows with what rapid strides the country has progressed. In i 865, again, the amount charged to income tax, as distinguished from the gross annual value, was $\mathcal{E} 349,000,000$ sterling, while in 1875 the corresponding figure is $£ 498,000,000$ sterling, the increase being at the rate of 43 per cent. Taking into account the increase of exemptions and abatements from the income tax, which has been a characteristic of our recent finance, we can well believe that the real increase of net income must have been more, and must have exceeded the proportionate increase of gross income. That the net incomes chargeable to income tax, if the exemptions were the same now as in 1865 , would considerably exceed $£ 500,000,000$ there can be no doubt; and altogether, allowing as well for the incomes under Schedule D which escape assessment through incomplete returns, we can hardly err in placing the net incomes of the incometax-paying classes at somewhere about $£ 600,000,000$ sterling. But the income thus arrived at does not include the large incomes in the aggregate of the wagesreceiving classes, or the incomes of many in the upper and middle classes which are under the income-tax limits; and this remainder can hardly be taken as less than another $£ 600,000,000$. What with the increase of population and the great rise of wages which has occurred since i 867 , there is no reason to believe that 
the proportion of the aggregate income of the country to what pays income tax is less now than it was when Mr. Dudley Baxter wrote, and this proportion would give about $£^{1,200,000,000 ~ s t e r l i n g ~ a s ~ t h e ~ a g g r e g a t e . ~}$ There is thus some sanction beyond mere conjecture for putting the aggregate income of the country at the latter figure.

Now, to come to our present question-How much of this income is derived from our foreign exports? We perceive at once that instead of these exports being our main business, it may be doubted if they contribute more than an eighth or so much to the total. Last year, which we take to be a more normal year for prices than such years as 1872 and 1873 , when our exports seemed so much augmented, we exported goods of British and Irish produce to the value of $f^{200,000,000}$ sterling. But this amount was not in reality exclusively British and Irish produce. It included the value of an immense amount of raw material imported from abroad which we had worked up-where we had added to, but had not created the whole value. It included, for instance, in cotton yarn and piece goods, about $970,000,000$ lbs. of raw material, worth, say, $\mathcal{E}_{25,000,000}$ at the average price of the cotton imported in the same year. It included, again, in woollen yarn and manufactures, about $140,000,000 \mathrm{lbs}$. or more of raw material, worth, say, $\mathcal{E}_{\mathrm{I}} 0,000,000$ at the average price of the wool imported in the same year. Altogether, deducting for the value of raw material in these exports which had previously been obtained from abroad, we doubt if we can estimate the probable maximum amount of the net income directly derived from our exports as more than $£$ I 40,000,000. In addition, there are, no doubt, indirect benefits in the connection between our trade and shipping interests which are difficult to estimate, but no large sum important for such an inquiry as the present would fall to be added in that way to the amount. Comparing, then, $\oint_{14} 0,000,000$ with $£ \mathrm{I}, 200,000,000$, it is at once 
seen that the labour and capital engaged in foreign manufacturing is only a fraction of our whole industry. England might still be a great and prosperous country - not so great and prosperous as it is now, but still great and prosperous-even if the whole of that fraction were to be at once swept away. But even if we were to lose our entire foreign custom, the whole of the income from what we send to foreigners would not be lost. The machines and tools used in manufacturing and the labourers would remain, and some use could be made of them. Only the difference between what would be earned in that use and what we now get from abroad in return would be lost. The precise net loss would be difficult to state; but it would be something much less than $£ \mathbf{I} 40,000,000$, and perhaps not a tenth or a twelfth of the aggregate income of $£ \mathrm{I}, 200,000,000$. It is evident that no such loss would be fatal to a great country. It would make us no worse, probably, than the reimposition of the taxes which have been remitted cluring the last twenty years, and would be a less calamity, in proportion, than the economic losses of the Franco-German War to France, which was much less fitted beforehand than we are to stand such a calamity. Probably it could all be made up by the community sacrificing only a portion of that additional leisure which it has acquired during the last thirty years, in addition to the increase of money wages and profits.

But there is, of course, no question of losing our whole foreign custom at one fell swoop. What people have in their minds is that we are threatened with the loss of a considerable part of our export trade. They should be asked, then, to define what they mean by a considerable part. Is it a half, a fourth, a fifth, or what? Of course, as we reduce the amount, the ridiculous smallness of it, compared with our whole industry, becomes apparent. The loss of a fifth of our foreign export trade would only be the loss at most of a fortieth or fiftieth part of our whole income, which a very little 
additional industry would make good. Looking at the matter in this way, besides, there is one conspicuous illustration that a considerable breach in the foreign trade is not fatal to our whole industry. In I $863-65$ England suffered from the cotton famine, which came upon us quite suddenly. But, saddening and distressing as the results of that famine were, the distress was merely local; the country, as a whole, prospered, and probably the distress in Lancashire would have been less but for the common expectation of a more rapid turning of the tide than what actually occurred. The diversion of labour and capital to other pursuits was retarded by the belief that the loss of trade was only to be temporary.

On the other hand, while our foreign export trade is small in proportion to our gigantic industry as a whole, it is large enough to make it a very difficult matter for any foreign competitors to displace us materially. The capital sunk in producing annually $£ \mathbf{1 4 0 , 0 0 0 , 0 0 0}$ of value must be immense-at least several hundred millions. But even $£$ 100,000,000 would not be easily found in the whole civilized world outside of England for the erection of new works to compete with our manufactories. The annual accumulations of France are computed at $£ 60,000,000$ a year, and of Germany at $£ 40,000,000$; and the accumulations of the United States must also be very large. But the accumulations are not free savings, to be directed into any enterprise. They are largely used in building houses, in furniture, in improving land under the direction of its owners, and in other ways, so that it is only a small surplus which is annually available for new enterprise. We see, therefore, what an effort of imagination is required when the displacement of England as a manufacturer for export is talked of. Even if she could be displaced at once from her whole export trade, the loss would be much less than is sometimes thought; but the amount of capital required to displace us even partially is so great that it must take 
many years for our competitors to accumulate any such amount. The displacement of labour, we believe, would be an equally serious matter; for workmen are not made in a day, and many more skilled workmen must be trained abroad if they are to undertake any serious part of the labour which is now performed in England. There is even a more serious difficulty, we believe, in the way of quickly-increased foreign competition. It is the complexity, variety, and minute subdivision necessary in great manufacturing enterprise which make displacement almost inconceivable. No workshop is complete in itself; we doubt if any manufacturing town is complete; England is one vast workshop, fitted with complete appliances of every sort, with a capability of turning on great force in any given direction, unexampled and not even approached elsewhere. But, apart from this complexity, we are content to call attention to the mere amount of the capital involved in any question of a material transfer of our foreign export trade.

We come, then, to the question of our home trade. Foreign nations, we are told, are not only going to do without us and cease altogether to be our customers; they are to send goods here and cut up our home manufactures. But our remarks in the last paragraph apply with tenfold force to the question of such a foreign invasion. If foreign nations are likely to find it difficult to procure capital which would enable them to take away a material part of our foreign export tracle, how are they to find capital to make any impression on our vast manufacturing industry for home consumers? Here it is a question, not of hundreds, but of thousands of millions of capital, and of a transfer of labour which fairly takes one's breath away. In this respect foreign nations would have to begin at the beginning. Of our whole imports in 1876 , amounting to $£_{375}, 000,000$, little more than $\mathcal{E}_{40,000,000}$ were of manufactured goods, and these included a great deal which we could hardly make for ourselves at home, 
even if our workmen were not otherwise employed; while the manufacturing in them, representing wages and profits-i.e., exclusive of the value of raw material, which we should have to buy in any case-would only be a part of the total. ${ }^{1}$ How are foreign nations to add seriously to this relatively insignificant sum, at least within any reasonable limit of time to which we can look forward? If they are to displace any considerable part of our home trade, the work must be one of generations, and it is not to be lightly associated with a few isolated augmentations of imports of Belgian iron or American cotton goods.

We trust we shall not be misunderstood. IVe have not a word to say against efforts to keep the public informed of the prices of foreign manufactures and the nature of their competition with our own manufactures at points where there is competition. There is enough indolence and routine and mismanagement even in English manufacturing to make it desirable in every way to have the stimulus of foreign competition applied. But when the decline and ruin of our whole manufacturing, or even any material part of it, are talked of, people should know what they mean. If they did know, they would not, as sensible men, confuse their minds with notions which are just as sensible and relevant, and no more, as the familiar illustration of Tenterden Steeple being the cause of Goodwin Sands. Harm is done in the end by all such confusion of ideas, including the harm in the present case of distracting attention from the obvious causes of the depression of our foreign trade. $-[1877$.

There are larger figures now ( 1903 ), but the so-called manufactures imported from abroad are still for the most part raw materials of our own industries, which have increased enormously since 1877 , and are still increasing. 


\section{XII.}

THE ECONOMIC VALUE OF IRELAND TO GREAT BRITAIN. ${ }^{1}$

THAT one of the roots of mischief in Ireland is 1 economic everybody agrees. The curse of Ireland is its poverty. The hunger for land which is so unintelligible to English feeling is at the bottom of outrages of every kind, and is played upon by political agitators. It is not, however, generally understood how the weakness of Ireland affects the whole aspect of the Irish political difficulty.

I have thought it worth while, therefore, when the notion of splitting partnership is in the air, to bring together some notes as to the economic position of Ireland, relatively to Great Britain, from the point of view of a statesman in Great Britain looking at the suggested proposal to part company as a mere matter of business-as he would look, in fact, at the analogous suggestion of union with a State which was seeking partnership with us. The statesman, of course, must weigh moral and political considerations as well as economic, and the various questions involved are necessarily intermixed; but it is expedient nevertheless to separate the economic from the other elements. We shall know better what we are doing or going to do in Ireland if the business loss or gain is clear.

The first point to notice in such a question is population. The people of Ireland are rather less than five millions, as compared with nearly thirty-one and a half millions in Great Britain. If Great Britain were to be

1 From the "Nineteenth Century" of March, 1886. 
offered a partnership of about five millions of people of equal character and resources to those of Great Britain themselves, the addition to the strength of the empire would be as five to thirty-one and a half. The population thus to be added would constitute in the new State somewhat less than a seventh of the whole. Equally the deduction of a people of this magnitude from the existing Union would be the deduction of rather less than a seventh.

A change of this description would be a very considerable one. But, apart from what it might lead to, it cannot be described as in itself formidable. With the loss of a seventh, the United Kingdom would be as great a Power as it was in 1870 , and in fact a much greater Power, because the remaining six-sevenths are richer and stronger individually than the population of I 870 . Their condition in the interval has enormously improved.

Of course, if by any arrangement the splitting of partnership were only to be partial-if we retained Ulster, while permitting to the rest of Ireland more or less complete separation-the deduction from the United Kingdom would be materially less. The disaffected parts of Ireland are not more than three-fifths of the whole, or three millions. In losing the three millions we should only lose one-twelfth of our numbers, or less than the growth of our population every decade.

Looking at the matter historically, we must come to the conclusion that the problem of disaffection in Ireland is mitigated in its intensity by the changes of population which have occurred. Down to about I 845 , from the beginning of the century, the people of Ireland were about half those of Great Britain-about a third of the whole population of the United Kingdom. The population of the disaffected parts of Ireland was also nearly three-fourths of the whole of that country, and consequently about a fourth of that of the United Kingdom. The change from such proportions to those 
of about one-seventh for the proportion of Ireland itself to the United Kingdom, and one-twelfth for the proportion of the disaffected parts of Ireland, requires no comment. Disaffection in Ireland is obviously not what it was in relation to the United Kingdom as a whole.

I have called attention to this point for some years past as necessarily altering our entire conception of the Irish difficulty. It is dealt with in "Essays in Finance" (first series), in an essay on the "Taxation and Representation of Ireland," which was first published in I $876,{ }^{1}$ and I have introduced the same topic in two essays in the second series of "Essays in Finance"viz., an essay on the Utility of Common Statistics, ${ }^{2}$ and another on Some General Uses of Statistical Knowledge. I doubt if the full force of this consideration is properly appreciated even yet. Relatively I reland is still losing ground most rapidly, not so much because Irish population diminishes, as because that of Great Britain increases. We grow a new people in Great Britain equal to the whole disaffected part of Ireland at the present time every ten years. In a few generations, at this rate, Ireland must become relatively to Great Britain very little more than a somewhat larger Isle of Man or Channel Islands. To let Ireland split partnership would differ in no way in kind, and comparatively little in degree, as far as business is concerned, from letting the Isle of Man remain a separate State.

The second point is even more important. The people of Ireland are not equal in industrial character and resources to those of the United Kingdom. They are very far from being equal. Great Britain, in adding to itself an Ireland, would add a community having only a twentieth part of the income of the United Kingdom; the United Kingdom, in losing an I reland, would only lose a small percentage of its strength.

It is very difficult, of course, dealing with questions of the aggregate income of different communities; but,

See supra, p. 277.

I.

${ }^{2}$ See postea, vol. ii., p. I. 
practically, we need have little doubt of the proportions stated.

In the assessments to the income tax the proportion of Ireland is as I to I 7-viz., United Kingdom (including Ireland), $£ 629,000,000$ sterling; Ireland, $£ 37,000,000$ sterling. This is more than five per cent., but not very much more. And there is reason to believe that Ireland is more strictly valued than Great Britain, and that it is over-valued.

At any rate, when it comes to be a question of the whole aggregate income of the different communities, there can be little doubt that other sources of income, outside of the income tax, are larger relatively in Great Britain than in Ireland. In dealing with the subject lately in "Further Notes on the Progress of the Working Classes," I put down the whole income of Great Britain as about $f_{1}, 200,000,000$, and that of Ireland alone as just over $£ 70,000,000$. But I have a strong feeling that in these figures, which were based very. much on what Mr. Dudley Baxter and Mr. Leone Levi had done, I gave too little to Great Britain, if not too much to Ireland.

With regard to Ireland specially, it is easy to see that the income cannot be very large. The chief industry is agriculture, which employs in round figures about sixty per cent. of the population. Out of I, 290,000 males of twenty years and upwards, with specified occupations, according to the census of I $88 \mathrm{I}$, no fewer than 757,000 were engaged in agriculture, which is just under sixty per cent. Among the remainder, there were no fewer than I I 5,000 called "mechanics or labourers," among whom, I suspect, would be many partly or largely engaged in agriculture. The proportion of sixty per cent. may, however, be taken. In other words, three millions of people in Ireland depend on agriculture directlythe breadwinners of the family are engaged in that occupation. And this means that, all told, the average income of these three millions, including those who receive rent, as well as farmers and labourers, is not 
more than about $£ \mathrm{I} 3$ or $£ \mathrm{I} 4$ per head. The gross produce of the crops of Ireland, according to the latest returns, is about $£ 33,000,000$ only, from five million acres, of which about $£ \mathrm{I} 0,000,000$ are from cereal crops, $f_{10,000,000}$ from potatoes, and the remainder mainly; from hay and green crops, which latter, of course, along with a large part of the cereal crops themselves, are not in their final form when thus valued. Making a deduction from the $£ 33,000,000$ on this account, and making an estimate for the value of cattle, sheep, and pigs sold, and for dairy produce, the gross produce of pastureland being, of course, much less than that of cereal or other crops, it seems impossible to arrive at a larger figure than about forty to forty-five millions as the value of the agricultural produce of Ireland, deducting seed, manures, and expenses of that nature. On this forty to forty-five millions, three millions of people have to live, which gives about $£$ i 4 per head; or less than $£ 60$ for a family of four persons.

Deducting the total rent of just under $£$ I0,000,000 according to the income-tax returns, with practically. no deduction from the numbers of people on the other side, we should leave about $£$ I I per head only for farmers and labourers and their families. And if we take the rent at a less figure, as I believe we ought to do-say at about eight millions sterling only-we should still make the income of the Irish agricultural classes, farmers and labourers together, vily $\mathcal{L}^{2} 2$ per head; or under $£_{50}$ for a family of four persons. Comparing this with England, it would appear that the tenantfarmers and labourers of Ireland are not so well off as the average of the English agricultural labourers, which implies that very many must be far below that level.

On this basis, also, we may calculate the aggregate income of Ireland. Assuming the income per head of the rest of the people of Ireland to be one-half equal to the income per head of those engaged in agriculture. and the other half fifty per cent. more, we should still arrive at a figure of less than eighty millions only as 
the total aggregate income of the whole people of Ireland.

In this way, according to estimates of income generally, the proportion of Ireland to the United Kingdom also comes out as one to seventeen, the same as from income-tax assessments only.

Another test of resources would be the relative capital of Great Britain and Ireland. I have to refer to Irish capital later on, and estimate it at $£ 400,000,000$, or thereabouts. There can be no exact estimates in such matters; but the total capital of the United Kingdom ten years ago I ventured to estimate at not less than $f 8,500,000,000$, and, calculating on a similar basis now, it cannot be less, I think, than $£ 9,600,000,000$. In other words, Irish capital is only a twenty-fourth part of that of the United Kingdom. And, whatever doubt there may be about the figures, which are necessarily very wide, and which assume that a nation can be valued as a going business concern, it is at least certain that no emendation would sensibly alter the proportions. An addition to Irish capital and a deduction from English capital that would both be large would leave the proportions much the same.

It is easy to see, then, how little the gain of an Ireland would add to the resources of Great Britain, or the loss of it would deduct from those resources. The taxable income of Ireland must bear a still smaller proportion to the taxable income of Great Britain than does its gross income or capital to the gross income or capital of Great Britain. The taxable income is the income remaining after allowance for the minimum necessary to maintain a population upon a given standard of living. In this sense, giving the people of Great Britain an average of $\delta$ I 2 per head as the minimum, they have a taxable income of about $£ 800,000,000$ sterling annually. ${ }^{1}$ On the same scale, five millions of people in Ireland would absorb sixty out of, say,

${ }_{1}^{1}$ Thirty-two millions, multiplied by 12 , is 384 millions, deducting which from $\mathrm{I}, 200$ millions leaves rather more than 800 millions. 
seventy-five millions gross income, leaving a taxable income of $£_{15}, 000,000$ sterling only. Even allowing that the standard in Ireland is necessarily lower, the taxable income would not be much increased. As a partner with so rich a State as Great Britain, Ireland must therefore be considered strictly as entirely insignificant. It hardly counts one way or the other.

Of course the practical taxable income of Great Britain is not so much as $£ 800,000,000$. The State could not levy $£ 800,000,000$, or anything like that sum, without reducing many classes in the scale of living. There would be a revolution if any such levy were attempted. But, limiting the $£ 800,000,000$ as we may, there would still be a vast amount to compare with the taxable income of Ireland, where the practical taxable income must be very small indeed.

Here again, as with regard to population itself, it is quite true that Ireland is becoming less and less important to Great Britain. At the beginning of the century there was some excuse for an expectation that was never fulfilled-that Ireland would participate in the burdens of the United Kingdom to the extent of two-seventeenths. With a third of the population of the United Kingdom, Ireland, it was calculated, might contribute rather less than one-eighth to joint objects. This was allowing that even then Ireland, man for man, was nothalf as rich as Great Britain, which seemed an extreme calculation, as both countries were then mainly agricultural, and Ireland had quite a third of the cultivated area. Now there is no question that Ireland's resources in proportion, instead of being two to seventeen, are less than one to seventeen. Its numbers are relatively to Great Britain not half what they were, and the distance between the average incomes per head of the two communities continues very great. The taxable income and capital of Great Britain have increased enormously, and those of Ireland hardly at all.

To put the matter shortly, and in the roundest 
figures-there can, of course, be no exact figures of income and capital - Ireland in population has sunk from one-third to less than one-seventh; in gross income, from two-seventeenths to less than one-seventeenth; in capital, from a proportion that was material to about one-twenty-fourth only; in taxable resources, from a proportion that was also material, being perhaps about one-tenth, to a proportion that is almost inappreciable -the proportion of only one to fifty. In resources, Ireland has no doubt increased absolutely. The Irish people are much better off individually, partly because there are fewer people than there were fifty years ago, but with much the same resources; but as a community in relation to Great Britain there is an immense decline.

The relative decrease of the disaffected part of Ireland only is quite as remarkable. From being about one-tenth of the United Kingdom in resources, it has become about one-fortieth or less. As regards taxable income, the proportion of the whole of Ireland to the United Kingdom being only about one to fifty, that of the disaffected part of Ireland only must be about one to a hundred!

How small the proportion of Ireland is will also be impressed on us more if we consider for a moment the economic relations of Great Britain with other British dependencies. Compared with Ireland, our interests in India, where we have invested over $f, 200,000,000$, and

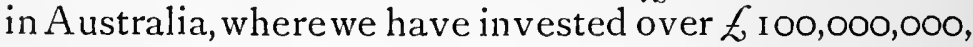
are enormous. And our trade with India figures up as $£ 66,000,000$ annually, and with Australia as $£ 55,000,000$ annually, as compared with a trade of about $£ 40,000,000$ with I reland, imports and exports together. The Indian and Australian trades also give more employment to our shipping in proportion than that of Ireland does. And neither India nor Australia imposes on us any direct charge for government, such as we shall find Ireland does, to constitute a deduction from the profit we derive, as a community, from the connection. 
As regards this question of resources, it will be interesting to go farther and to look at the matter a little more closely. Great Britain and Ireland have been in close partnership for over eighty years. How does the account stand as regards government and people? Has Ireland been a help or the reverse?

It is obvious, to begin with, that Ireland has not helped as the framers of the Union expected. According to the Act of Union, Ireland was expected to contribute to the joint expenditure of Great Britain and Ireland in the proportion of two-seventeenths. In point of fact, Ireland could not do so under the strain of the enormous outlay at the beginning of the century. Under that arrangement between 1800 and 18 I 5 Irish debt increased rapidly-viz., from $£ 24,000,000$ to $£$ I 28,000,000-although I rish taxation was enormously increased, viz., from three and a half to nearly seven millions. In i 8 I 6 , the amalgamation of the exchequers and indiscriminate taxation were recommended, because it was quite impossible for Ireland to bear two-seventeenths of the joint burdens.

Actually at the present moment Ireland is no gain to the exchequer of Great Britain. The facts are as follows: Ireland's gross contributions from Customs, Excise, and Inland Revenue generally are put down in Thom's Almanac as about $£ 7,700,000$; but of course no such account shows exactly what Ireland's proper contribution is. Duties are paid in Ireland on spirits consumed in England, and duties are paid in England on tobacco and tea consumed in Ireland. An exact account is impossible. It seems to be believed, however, according to the return No. 36 , session $188_{4}$, that, after corrections are made on this head, about $f^{6,700,000}$ represents the contributions of Ireland to imperial purposes, exclusive of Post Office, etc., the contributions of Great Britain being nearly ten times that amount. In other words, Ireland, while constituting only about a twentieth part of the United Kingdom in resources, nevertheless pays a tenth or 
eleventh of the taxes. Ireland ought to pay about $£ 3,500,000$ and it pays nearly $£ 7,000,000$. To the extent of the difference Great Britain is better off in the partnership than could have been expected beforehand.

This is only a part of the account. When we look at the other side-viz., the disposal of the taxes-we shall see that Great Britain does not gain so much as would appear from the revenue side only. But I ought to explain in passing that it is not surprising, considering the nature of our imperial taxes, that Ireland should contribute more than its proper share, although the taxes are not merely indiscrimate, but Ireland is really exempted from some of them. The reason is that imperial taxes fall so much on the common luxuries of the poor-on spirits, tobacco, and tea. Nearly the whole cost of the first two articles to the consumer is a tax, and the ad valorem tax on tea is also very high. The poor, if they are to have these common luxuries at all, must contribute disproportionately to the exchequer. Ireland as a poor country is disproportionately taxed, although the taxes of the United Kingdom are technically indiscriminate.

Turning to the other side of the account, what we find is that the Imperial Government has, first, to garrison Ireland to a degree unnecessary in Great Britain; and, second, to pay disproportionately for the local government of Ireland. If the home troops were to be stationed in Ireland in proportion to the population, the troops in Ireland would be about 12,000 only; if in proportion to resources, about 5,000 only. Actually Ireland has at least 24,000 troops, sometimes more, ${ }^{1}$ an excess on the first basis of 12,000 troops, and on the second basis of nearly 20,000. At $£ 150$ per man, which is the cost of the British standing army, we thus spend in Ireland on the first basis $£_{\mathrm{I}} \mathrm{I}, 800,000$ which we might save; and on the second basis nearly

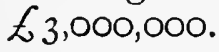
home.

${ }^{1}$ In 1884 the numbers were 24,400 , out of a total of 90,000 at 
Next, the Imperial Government spends a certain amount of money on the internal administration of different parts of the United Kingdom-the Civil Service expenditure. Altogether it spends in this way the sums shown in the following table (the particulars being extracted from the last finance and revenue accounts):

Statement of Charges on Imperial Revenues for Local Administration in Great Britain and Ireland compared. From the Finance and Revenue Accounts, 1884-85.

[In thousands of pounds-ooo's omitted.]

Pensions for judicial services. pp. 52-60.

\begin{tabular}{|c|c|c|}
\hline Total. & $\begin{array}{l}\text { Great } \\
\text { Britain. }\end{array}$ & Ireland. \\
\hline$£$ & $£$ & $£$ \\
\hline 127 & 103 & 24 \\
\hline $84^{1}$ & 42 & 42 \\
\hline 506 & 392 & $\mathrm{II}_{4}$ \\
\hline $\mathrm{I}, 662$ & $\mathrm{I}, 457$. & 205 \\
\hline 2,397 & $2,109^{2}$ & 288 \\
\hline $6,34 \mathrm{I}$ & $4,10 \mathrm{I}$ & 2,239 \\
\hline 5,135 & 4,368 & 767 \\
\hline I, I 93 & $\mathrm{I}, 078$ & I I 5 \\
\hline I 7,445 & 13,650 & 3,794 \\
\hline
\end{tabular}

In addition there have been numerous grants of loans to Ireland in the last forty years which have never been repaid.

It is easy to see that, on any hypothesis, the Imperial Government spends on Ireland more than its proper share, whether measured by its resources, its population, or its actual contributions to imperial revenues. Out of a sum of $£$ I 7,500,000 spent out of imperial revenues for the internal administration of Great

'Including salary of Lord-Lieutenant and Queen's Colleges. I have only included salaries and allowances special to Great Britain and Ireland.

${ }^{2}$ Ireland gets the benefit of part of this sum. 
Britain and Ireland, it obtains very nearly a fourth. The following compares what Ireland would be entitled to on these different hypotheses with what it actually receives out of this sum of $£ I 7,500,000$ :

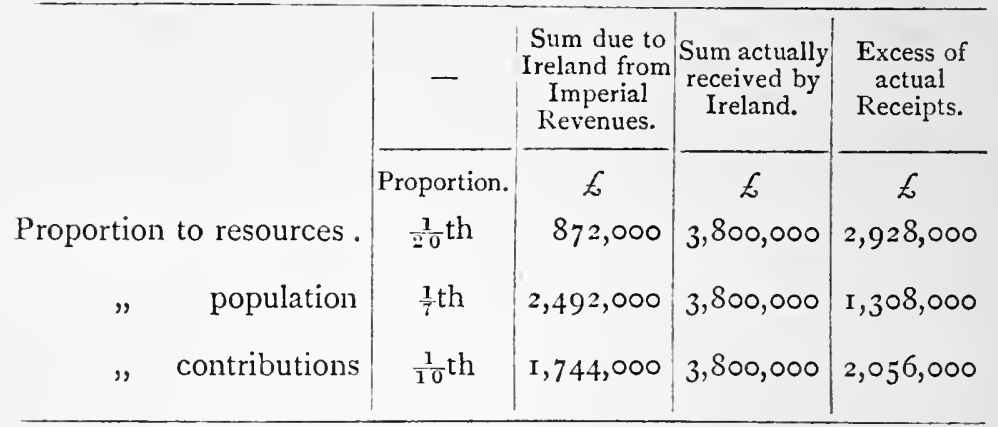

In any case Ireland gets more than is due to it, assuming in the last two cases that a contribution according to population or on the present scale is just. In these two ways, then, partly through excessive military expenditure, and partly through excessive civil expenditure, Great Britain spends upon Ireland a disproportionate sum. Taking the resources as a measure, the account would balance as follows:

Overspent for British troops in Ireland.

" local administration . . $\quad 3,000,0000$

Deduct excess of receipts from Ireland in proportion to its resources .

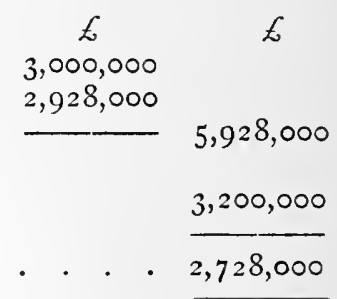

Deficit . . . . . 2,728,000

The English Government is thus a loser by Ireland to the extent of about $£ 2,750,000$ per annum, although it receives from Ireland over $£ 3,000,000$ more revenue than Ireland, on any fair computation, ought to pay. If Ireland only paid a fair contribution for imperial purposes, we should be out of pocket by this $£ 3,200,000$ more, or nearly $£ 6,000,000$. Actually, it is beyond 
question, we lose as a government nearly $£_{3}, 000,000$, while taxing Ireland over $£_{3}, 000,000$ more than it ought to be taxed.

Of course it may be said that we do not lose by the army expenditure; that the troops being in Ireland are available, to a certain extent, for the miscellaneous purposes of the United Kingdom. Unfortunately, it is beyond question that the troops are not available. The extra 12,000 or 20,000 troops that are in Ireland, beyond what is necessary to garrison it in proportion to Great Britain, are lost to us for imperial purposes. The expenditure is pure waste.

So much for the balance of the account as far as the Government is concerned. The question remains as to the account of the community as a whole.

English capital, it may be said, is invested in Ireland, and there is a large profit to the community, if not to the Government. I am sorry to say I can find little foundation for this impression. There is some profit, but not a large profit.

The whole capital of Ireland must be inconsiderable -probably not over $£ 400,000,000$ - the principal items being:

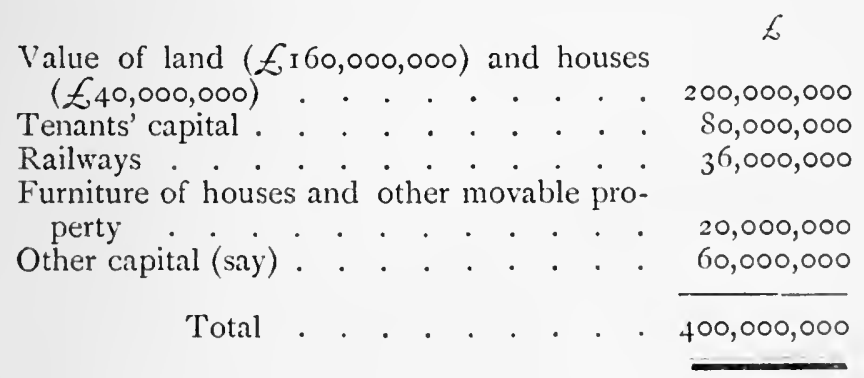

What banking capital there is I include in other capital, as part of it at least is no doubt invested by loan or otherwise in agriculture, railways, etc., and it ought not to be counted twice over. The $£ 400,000,000$ is probably over the mark. 
And most of this capital must be held locally. The trading and farming capital is so held. The banking capital is so held; out of the $£ 400,000,000$ of resources of the Irish banks, capital and deposits together, the share owned by English people must be very small, for the deposits are necessarily those of the locality, and Irish bank shares, I know, are held locally. Part of these resources finds its way to London, and is invested in London. Irish railway shares are also, for the most part, held in Ireland. There remains only the real property, which is said to be mortgaged largely to English insurance companies, and so on. But English insurance companies only hold a little over $£ 70,000,000$ of mortgages altogether, and I should doubt if a fifth part of these mortgages are in I reland. The mortgages there, all told, can hardly exceed $£ 50,000,000$, of which only a part would be held in England. There are, of course, the landlords who reside in England. Per contra, however, residents in Ireland hold English securities, not inconsiderably, I believe, in proportion to the resources of Ireland, and this holding, putting the two communities against each other, is a set-off to Irish securities held in England.

Ireland, as a field for English capital, does not seem, therefore, to count for much. But, if we allow that even a sum equal to a fourth part of the nominal agricultural rent of Ireland, which appears to be under $£ \mathrm{I} 0,000,000$, finds its way to England on balance in the shape of mortgage interest, etc., deducting what is received in Ireland on similar account from Great Britain, the English community as a whole, Government and people together, would still have very little out of Ireland. The gain to the community, whatever it is, would be balanced, pro tanto, by the deficit on Government account. If Ireland were only to be taxed according to its resources, there would be a very large deficit.

It is quite clear, it may be added, that, as compared with the enormous capital and income from capital 
which the community of Great Britain enjoys, the share due to the Irish connection, even if the whole nominal rental of Ireland were to be remitted to Great Britain, would be inconsiderable. Our income from capital is over $£ 400,000,000$ annually, to which a contribution of $£$ I0,000,000 would not be very material. What has been said above as to the superior importance to us of India and Australia has a bearing on this point. There are many parts of the world which are more important, economically, to Great Britain than Ireland is.

Next, it may be said, we gain by the trade of Ireland. Ireland is a good customer of Great Britain, and we get conveniently from Ireland much of what we require. It will follow, however, from what has been said, that, as the income of Ireland altogether is about

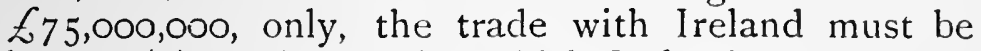
limited (I) by the surplus which Ireland can afford to export out of that sum, and (2) by the proportion of that surplus which Ireland can afford to spend on the produce and manufactures of Great Britain.

The total exportable surplus of Ireland cannot be very large. The exports and export value of cattle, sheep, and pigs, valuing them at about the average given by "Thom" for Irish live stock in general in ${ }^{I} 8 S_{4}{ }^{1}$ are as follows (average of three years $I S S_{I}-\delta_{3}$ ):

\begin{tabular}{|c|c|c|c|c|c|}
\hline \multirow[b]{2}{*}{ Cattle } & & & \multicolumn{3}{|c|}{ Value per head. } \\
\hline & & & 630,000 & $E_{12}$ & $\mathcal{L}_{7,560,000}$ \\
\hline Sheep & . & & 530,000 & $E^{2} 3$ s. & $\mathcal{E}_{1}, 220,000$ \\
\hline Pigs & . & . & 450,000 & $E_{3}$ & $\mathcal{L}_{1}, 350,000$ \\
\hline & Tota & & . & . & \\
\hline
\end{tabular}

And the export of butter and cheese, allowing that the produce available for export from each milch cow is about $£ 4$ per head, would not be more than about $£ 6,000,000$.

Adding these two sums together, the total agricultural exports of Ireland would be about $f_{1}, 16,000,000$

1 Thom's Almanac for 1885 , pp. 692-694. 
only; of course at lower prices the exports would be less.

In addition, there are the exports of the linen manufacture, the Belfast shipbuilding trade, the spirits and porter of Dublin and Belfast, the produce of Irish fisheries, and other miscellaneous productions, amounting in all, I should say, to about other $£ 5$,000,000total $£ 21,000,000$. The calculation is necessarily very rough.

The imports on the other side would more than balance, I think, but they are largely of articles which are not the produce and manufactures of England. Grain of different kinds is a principal item. There are no returns of imports now, but in 1874 they amounted from foreign countries only, principally grain and flour, to $£ \mathrm{I} 0,000,000$. At recent prices the same quantity of imports would of course be of less value.

Ireland in addition takes sugar, tea, and other articles of tropical produce, principally imported from Great Britain, probably to the amount of $£ 5,000,000$, giving a much smaller quantity of tea and sugar per head than is consumed in the United Kingdom generally.

Adding these two amounts together, the total is $£$ I $5,000,000$, and the difference between this sum and the total required to balance the estimated exports only amounts to $£ 6,000,000$. Ireland probably imports somewhat more; the particulars I cannot give, except for coal, of which Ireland imports $3,000,000$ tons, worth, say, including freight, rather more than $£ 2,000,000$. The other articles which Ireland must import, including textiles, would necessarily contain a large amount of raw materiai. Altogether, it may be doubted whether Ireland is a customer for British labour to the extent of more than a few millions per annum.

When it is considered that even complete separation need not involve loss of trade, and partial separation, by which I mean any tolerably comprehensive scheme of local self-government, would not involve loss of trade 
at all, except through Ireland falling into anarchy, it cannot be said that the risk to our trade is a very serious element in the question of the loss or gain which the separation of Ireland, and $\grave{a}$ fortiori a mere alteration of the form of the political connection, would involve.

I have been looking at the question exclusively from the British point of view. The view presented, when looked at from an Irish standpoint, is somewhat different. The precise interest of Ireland in the connection requires a little explanation.

I. On the direct Government account, Ireland would probably gain by separation or by a revisal of present arrangements. It would have about $£ 7,000,000$ of revenue to dispose of, which it now contributes to the Imperial exchequer, and out of the difference between this sum and the sum of $f 3,800,000$ it gets back from the Imperial Treasury for internal administration, it would have to defray its army and navy, if any, its share of the Imperial debt, and any expenses of that sort. Assuming economy in spending for the purposes on which the $£ 3,800,000$ is now spent, Ireland might get on very well, the scale of expenditure all round being lower than in Great Britain. For less than a million a year I reland could have a very tolerable force to maintain internal order; its share of the imperial debt, proportioning that share to its resources, would not cost more than $£ \mathrm{I}, 500,000$ per annum; there would remain over $£ 4,000,000$ for all the miscellaneous purposes of internal administration, which is more than what is now spent. Ireland would thus gain by the severance; while Great Britain, which loses now, although extracting over three millions more from I reland than its proper share of taxation, would decidedly gain. Both sides would gain, assuming no political danger to arise, because the present government of Ireland by England involves very serious waste.

2. Ireland would lose indirectly by the withdrawal of English troops. English army expenditure in Ire- 
land now recoups a part of the loss inflicted on Ireland by disproportionate taxation.

3. Separation, if it should bring about an interruption of trade between Ireland and Great Britain, would be disastrous to Ireland. The $£ 20,000,000$ which Ireland exports find almost their sole market in Great Britain. If more capital is to be invested in Ireland, the capital must come from England. In this respect Great Britain is indispensable to Ireland.

On balance the direct advantages to Ireland from complete or partial separation are apparently so little that they cannot compensate the danger involved in anything like complete separation. Of course in isolation and hostility to Great Britain, Ireland would be lost. It is utterly without resources to maintain such an attitude. On the other hand, the advantage to Ireland of a partial separation, involving a settlement of the direct accounts, and leaving to it all the advantage of forming part of the United Kingdom, would be enormous.

I have thus answered the question with which I started, or nearly so. The conclusion is that Great Britain has not much to lose in dissolving partnership, while Ireland has.

The only point I have left untouched is the question of the indirect political danger in separation and the loss it may involve. This is almost too remote a speculation for such an inquiry as I have been making. It is obvious, however, still keeping strictly to the economic question, that the sum of $£ 2,750$,000, the amount of the deficit we now incur on account of Ireland, would go some way towards the expense of extra military and naval preparation which the presence of a hostile Ireland near us might involve. I should like further to ask the question why a State like Ireland beside us, if completely separate, should add sensibly to the dangers we incur from States like Belgium and Holland, which are just about as populous and much 
richer, and almost equally near. The question is one of military strategy; but, without being dogmatic, I would suggest that the experience of past times, when France tried to use Ireland against us, does not wholly apply. In past times Ireland was useful positively to Great Britain, because of the relative magnitude of its resources in both men and wealth. The loss of it would have been a great loss to Great Britain in the life-anddeath struggles in which it was engaged. Further, Ireland hostile might in former times have been a real danger to England for two reasons - the first, its relative magnitude, already referred to; and next, the necessity or convenience, in the days of sailing-ships, of using as the basis of hostile operations against a State which was to be reached by sea a place near to that State, so that a Power like France might have gained something by "enveloping" Great Britain. Now all the circumstances have changed. Ireland is so poor in resources that the loss of it positively would hardly count. Even as a recruiting ground it is no longer required, because a State like Great Britain with $31 \frac{1}{2}$ millions of men, not to speak of its colonial reserves, can have as many men for soldiering as its finances can afford out of its own numbers. Negatively also we can keep military possession of Ireland much more easily than was formerly the case; it is an easier task than it was in proportion to our resources: and just because it is easier, it is less worth the while of an opponent to seek to overcome us through Ireland. In these days of steam also a great Power meaning to attack us could do so as easily, or nearly as easily, from Antwerp or Hamburg or Havre, or even Cadiz, as from Dublin or Belfast; to attempt to reach us through I reland would not be worth while. To guard against accidents, it is prudent and best for both countries that we should keep military hold of Ireland; but it would seem to be conceivable that Ireland, cven if clisposed to be hostile, would not "count" when separate, if we were only to put forth our strength. If we lose command of the sea,

I. G G 
we shall be liable to be assailed directly by a military Power; if we keep the command, Ireland will not count.

There is less need, however, to discuss a point like the last, because there is no question, under any scheme of local self-government or Home Rule that I have seen, of permitting to Irish local authorities an army or a navy. Many of those who are in favour of Home Rule appear to admit as a possibility that the Irish local authorities may attempt illegally and covertly to raise a military force. But the cost of guarding against such a risk, which is the economic aspect of the question, ought not to be very material. Would it conceivably be necessary to keep more troops in Ireland than we now do? I consider myself precluded from fully discussing the latter question. It involves those moral and political considerations from which I have endeavoured to disentangle the economic problem. But it would seem just at least to notice, economically, that Ireland, even if separate, would have overwhelming motives to be on good terms with Great Britain.

I propose to leave the question of the economic value of Ireland to Great Britain at this point. As I have stated at the beginning, and as I have just been repeating, there are moral and political considerations to be taken into account after the economic aspect of the question has been studied. For historical reasons, for the sake of the connection between Ulster specially and Great Britain, for the sake of a minority who have been encouraged to trust to English law administered by an English Parliament, neither separation nor any form of Home Rule for Ireland may be desirable or possible. To discuss all these matters would take me into regions which, for many reasons, even if I desired to do so, I must avoid. I may venture to express the hope, however, that the facts I have stated are of a tendency to mitigate apprehensions which are generally entertained. If Ireland in a business view hardly counts in a question of force against Great Britain, we 
can afford to arrange its destinies and its relations to Great Britain in any way that may be politically found expedient. Having practically omnipotent power, we should discuss with reasonable coolness how Ireland is to be governed.

I shall only, then, permit myself one or two remarks appearing to verge on politics, because they arise directly out of a consideration of the economic and business aspects of the Irish problem.

The first of these remarks is that all claim of Ireland to be represented in Parliament, if it really contributes nothing material to the strength of the empire when properly taxed, is taken away. At present it is unprofitable to us, because, though it is overtaxed, the circumstances are such that it absorbs the surplus taxation. If it were to be taxed properly, and the present system of government were to continue, it would be still more unprofitable. It appears, then, to be an intolerable anomaly that such a State should be represented in the Imperial Parliament, helping to vote the taxes which another community pays, and meddling in all the affairs of that community. The anomaly might be endurable if the representatives returned happened to be friendly or to be sensible of deriving advantage from the imperial connection. But to admit into the Imperial Parliament representatives of a State which can be no contributory to imperial needs; which could not bear the strain of an imperial emergency; which requires for its own internal administration all the taxable income it can spare, and which, moreover, sends representatives avowedly hostile, with no other mission than to make imperial government impossible, is nothing less than the reductio ad absurdum of Parliamentary government. The affairs of an empire like that of England cannot possibly go on upon such conditions. The enormous reduction or absolute extinction of the Irish representation in the Imperial Parliament, with or without terms of Home Rule for I reland, is a measure on which both parties in Great Britain might justifiably unite. 
Another remark I have to make is with reference to a certain scheme which appeared in the "Statist" newspaper, and which became known as "Economist's" plan of settling the Land and Home Rule questions in Ireland. There is no reason why I should not assume responsibility for a suggestion which I was encouraged to ventilate, when I first put it forward in conversation, by official and political friends, although for obvious reasons I am most anxious to keep out of political controversy, and could take no part, either in my own name or anonymously, in the incessant discussions of the last few months. What I should like to point out is that the idea of buying out Irish landlords at the expense of the imperial exchequer, and of handing over a rent-charge to Irish local authoritics in lieu of the present imperial payments for the internal administration of Ireland, is closely related to the view of Ireland's economic position which I have set forth in this paper. It is all based on the notion that Ireland is a comparatively small State which has gained a footing in the imperial system of Great Britain to which it is not entitled, and for which, therefore, another system, excluding Irish representatives wholly, or nearly so, from the Imperial Parliament, must be devised. If Irish local authorities can be set up amicably, and with the consent of Ireland's representatives, so much the better; if no such authorities can be set up, then it will be necessary still to exclude hostile Irish representatives from the Imperial Parliament, and set up local authorities of a non-popular kind. As far as I can see, there is no getting out from between the horns of this dilemma. In either case a settlement of the land question seems expedient, in order to give the new authorities a chance, and in order to disentangle the imperial and Irish exchequers. No merely Irish authorities could buy out the landlords, because they would not have credit enough. If the exchequers are not disentangled, the Irish people would have the apparent grievance of being taxed without representation, whereas 
in some form or other they could be represented in local councils. It is, therefore, expedient at the same time at once to buy out Irish landlords effectively, which can be done by the imperial exchequer, and to give the new local authorities a revenue which they could collect and administer themselves, and which would be the equivalent of the contributions to the imperial exchequer they would continue to make under existing taxes, deducting a certain fixed proportion as due from them for the imperial protection. Subject to the condition that the Imperial Parliament imposed no new taxes on Ireland, which it is not worth while doing, there would be no injustice in such an arrangement, and the Irish people could not then say they were taxed without representation. But the existing intolerable anomaly would be got rid of, and Great Britain would cease to be governed in a large degree by a hostile faction coming from a country which contributes nothing to imperial strength.

I desire, likewise, to call special attention to the fact which has come out incidentally that Ireland is overtaxed in comparison with Great Britain. It contributes twice its proper share, if not more, to the imperial exchequer. The taxation in one view is not reprehensible; it is levied in the shape of indirect taxes, mainly on spirits and tobacco. 'The Irish masses could untax themselves by the simple expedient of consuming less spirits and tobacco. This is the easy view which has often been acted upon when the subject has come up in the Imperial Parliament. Long ago, in I864, when there was a Committee on Irish Taxation, Mr. Lowe embarrassed an able witness, Mr. E. Senior, a Poor-law Inspector in Ireland and well acquainted with Irish poverty, by putting this very point (sce No. $5^{1} 3$, Session I 864). But it is not the right view. How much of the expenditure of the Irish people on spirits and tobacco is really wasteful is not certainly known. People who have so little taxable income have at any rate a claim to have the money thus taken from them 
by the Government applied for their special benefit. At present, nearly the whole taxable income of the Irish people is, in fact, absorbed by the State. The taxable income being about $£_{15,000,000}$ only, the Imperial Government, as we have seen, takes nearly $£ 7,000,000$, and the local taxes are over $£ 3,000,000$ more, or about $£ \mathrm{I} 0,000,000$ in all. So large a proportion of taxation to taxable income would be a serious fact for any country, and there can be little accumulation in Ireland under such conditions. Considerations like these, which are so material, have, however, made no impression in the Imperial Parliament hitherto, and that this has been the case is one reason, among many others, why on this side of St. George's Channel we should speak with some modesty of the Imperial Parliament being capable of dealing with Irish affairs. Here is certainly a matter on which, with no intention to be unjust, with an apparent willingness to be more than fair to Ireland, as is shown by the exemption of Ireland specially from certain taxes, we have nevertheless acted unjustly and to the injury of Ireland. I may commend Mr. Senior's evidence on this head, in the Blue Book of i 864 already referred to, to those who care to study the subject. Surely the whole blunder clearly suggests the expediency of devising some form of government for Ireland, under which the special needs and circumstances of the country and people would receive more and better attention than they do under present arrangements, although the attention which they do get disturbs and disorganizes the management of Imperial affairs themselves.

[This essay was originally prepared for a discussion at the Political Economy Club early in I886, when the agitation about Home Rule was at its height. At this distance of time I may be allowed to explain, what I could hardly have said at the time, owing to my position in the Civil Service, that I was not, and have never been, a Home Ruler in the sense of favouring a separate Parliament and executive for Ireland. The question of the relative overtaxation of Ireland has since been much discussed, and formed the subject of inquiry by a Royal Commission presided over by Mr. Childers, before which I 
gave evidence as to the resources of Ireland, though not as to taxation, which was officially done by Treasury experts. The subject of late years has lost its practical interest, in consecjuence of Government grants to compensate for Irish overtaxation, which have been accepted by Irish representatives as such compensation. This arrangement for meeting the grievance does not commend itself to me, and I opposed it in my evidence to Mr. Childers's Commission; but the matter is obviously in a different position from what it was when this paper was written.]

END OF VOL. I. 




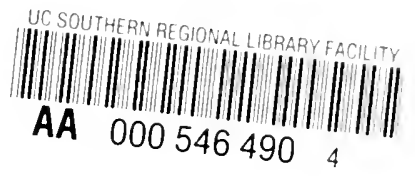


